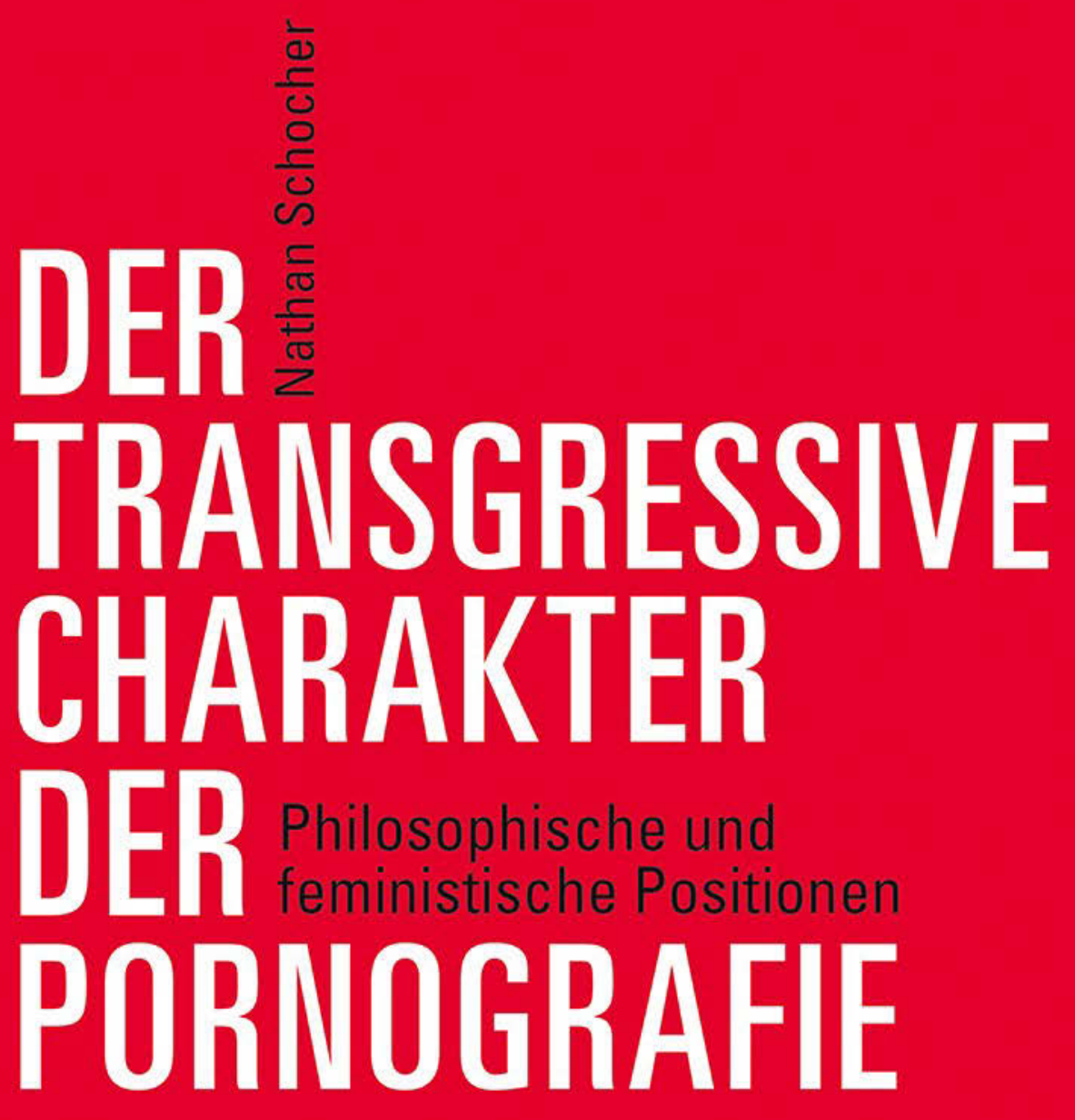

[transcript] Edition Moderne Postmoderne 
Nathan Schocher

Der transgressive Charakter der Pornografie 
Nathan Schocher, geb. 1978, hat an der Universität Zürich Philosophie, Deutsche Literatur- sowie Politikwissenschaft studiert und war Mitglied des Graduiertenkollegs am Zentrum Gender Studies der Universität Basel. Er lebt in Zürich und arbeitet als Programmleiter bei der Aids-Hilfe Schweiz. 
Nathan Schocher

\section{Der transgressive Charakter der Pornografie}

Philosophische und feministische Positionen

[transcript] 
Die vorliegende Arbeit wurde von der Philosophischen Fakultät der Universität Zürich im Herbstsemester 2017 auf Antrag von Prof. Dr. Georg Kohler und Prof. Dr. Andrea Maihofer als Dissertation angenommen.

Publiziert mit Unterstützung des Schweizerischen Nationalfonds (SNF) zur Förderung der wissenschaftlichen Forschung.

\section{Bibliografische Information der Deutschen Nationalbibliothek}

Die Deutsche Nationalbibliothek verzeichnet diese Publikation in der Deutschen Nationalbibliografie; detaillierte bibliografische Daten sind im Internet über http://dnb.d-nb.de abrufbar.

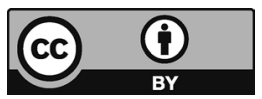

Dieses Werk ist lizenziert unter der Creative Commons Attribution 4.0 Lizenz (BY). Diese Lizenz erlaubt unter Voraussetzung der Namensnennung des Urhebers die Bearbeitung, Vervielfältigung und Verbreitung des Materials in jedem Format oder Medium für beliebige Zwecke, auch kommerziell. (Lizenztext:

https://creativecommons.org/licenses/by/4.o/deed.de)

Die Bedingungen der Creative-Commons-Lizenz gelten nur für Originalmaterial. Die Wiederverwendung von Material aus anderen Quellen (gekennzeichnet mit Quellenangabe) wie z.B. Schaubilder, Abbildungen, Fotos und Textauszüge erfordert ggf. weitere Nutzungsgenehmigungen durch den jeweiligen Rechteinhaber.

\section{Erschienen 2021 im transcript Verlag, Bielefeld () Nathan Schocher}

Umschlaggestaltung: Kordula Röckenhaus, Bielefeld Korrektorat: Die Orthografen GmbH, Zürich

Druck: Majuskel Medienproduktion $\mathrm{GmbH}$, Wetzlar

Print-ISBN 978-3-8376-5467-7

PDF-ISBN 978-3-8394-5467-1

EPUB-ISBN 978-3-7328-5467-7

https://doi.org/10.14361/9783839454671

Gedruckt auf alterungsbeständigem Papier mit chlorfrei gebleichtem Zellstoff. Besuchen Sie uns im Internet: https://www.transcript-verlag.de Unsere aktuelle Vorschau finden Sie unter www.transcript-verlag.de/vorschau-download 


\section{Inhalt}

1. Einleitung: Die Ambivalenz der Pornografie $\ldots \ldots \ldots \ldots \ldots \ldots \ldots \ldots \ldots . \ldots$

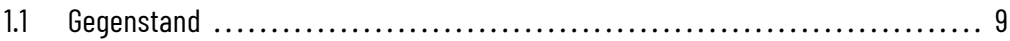

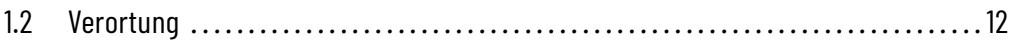

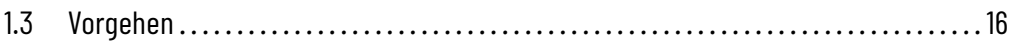

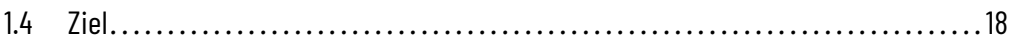

2. Das Verhältnis von Pornografie und Transgression .................... 19

2.1 Überblick........................................................... 19

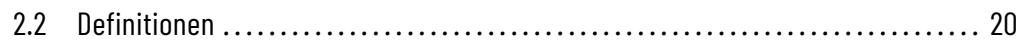

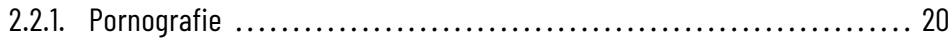

2.2.2. Transgression ....................................... 21

2.3 Normative Aspekte der Sexualität .................................. 23

2.3.1. Das Subjekt und die Wahrheit des Sex ........................ 23

2.3.2. Die Regulierung sexueller Beziehungen zwischen Männern ........... 27

2.3.3. Zweigeschlechtlichkeit und die Objektivierung der Frau .............. 30

2.3.4. Intimität und die Ablehnung des Obszönen .................... 33

2.4 Transgressive Aspekte der Sexualität ............................ 37

2.4.1. Erotismus und Transgression .............................. 37

2.4.2. Sexualität an der Grenze des Diskursiven...................... 42

2.4.3. Triebunterdrückung durch Kulturanforderungen ................. 47

2.4.4. Subjektivierung und Geschlechtsidentität ................... 52

2.4.5. Subversive Handlungsspielräume .......................... 57

2.5 Pornografie zwischen Normierung und Transgression.................... 63

2.5.1. Das Problem der Masturbation ............................... 63

2.5.2. Die Pornografie der Viktorianer ............................ 69

2.5.3. Organisierte Transgression und utopisches Begehren .............. 74

2.5.4. Die Relationalität des Begehrens .......................... 78

2.5.5. Das Verlangen nach Überschreitung ...................... 82 
2.5.6. Die Interaktion zwischen Medium und Subjekt ................ 85

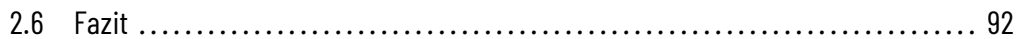

3. Transgression in der feministischen Pornografiekritik ................ 101

3.1 Überblick........................................................ 101

3.2 Die feministische Kritik an der Pornografisierung ................... 102

3.2.1. Der Begriff Pornografisierung ............................. 102

3.2.2. Bedingungen für Pornografisierung ........................ 108

3.2.3. Der pornografische Blick.................................... 110

3.2.4. Objektivierung, Selbstobjektivierung und Empowerment .............. 112

3.3 Die feministische Kritik an der Pornografie ......................... 121

3.3.1. Das Recht auf sexuelle Selbstbestimmung..................... 121

3.3.2. Der Schutz der Redefreiheit................................. 130

3.3.3. Verortungen und Bezugnahmen ............................. 135

3.3.4. Parallelen in der Argumentation ............................ 144

3.3.5. Parallelen in Methodik und Rhetorik ........................... 150

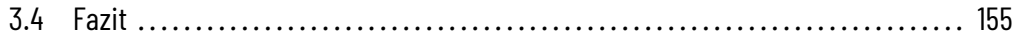

4. Transgression in alternativen Pornografien ........................ 161

4.1 Überblick...................................................... 161

4.2 Strategien alternativer Pornografien .............................. 162

4.2.1. Eine weiblichere Pornografie............................. 162

4.2.2. Die identitätsstiftende Funktion schwuler Pornografie ............... 172

4.2.3. Camp als politisch-ästhetische Strategie ......................179

4.2.4. Transgender-Körper in der Pornografie....................... 184

4.3 Post-Pornografie ......................................... 187

4.3.1. Ein subversives Potenzial .................................. 187

4.3.2. Kontra-Sexualität ........................................ 192

4.3.3. Die Pornotopie....................................... 196

4.3.4. Alternative Körper, Gonzo und Post-Pornografie .................. 200

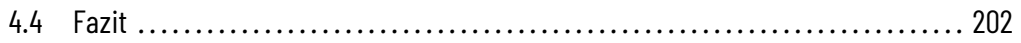

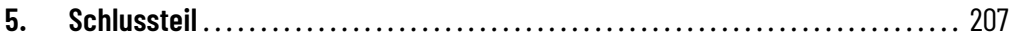

5.1 Résumé ................................................... 207

5.2 Transgressive Aspekte der Pornografisierung .......................... 214

5.3 Irreguläre Identifizierungen ................................. 220

5.4 Für eine neue Ethik der Lüste ............................... 225 
6. Dank

229

7. Literaturverzeichnis

231 



\section{Einleitung: Die Ambivalenz der Pornografie}

\subsection{Gegenstand}

Unsere Gesellschaft hat ein ambivalentes Verhältnis zu Pornografie. Auf der einen Seite finden viele Menschen Pornografie problematisch; deren zum Teil gewaltförmige, rassistische und frauenfeindliche Inhalte stoßen auf Kritik. Auf der anderen Seite wird Pornografie täglich von einer großen Anzahl Menschen genutzt; Angehörige sexueller Minderheiten empfinden sie zum Teil gar als ermutigend und bestärkend. Wie kommt es zu diesem ambivalenten Verhältnis der Gesellschaft zu Pornografie?

Die vorliegende Arbeit geht dieser Frage in der Analyse zweier aktueller gesellschaftlicher Phänomene nach: Das eine ist die sogenannte Pornografisierung der Gesellschaft, das andere ist das Aufkommen von zur Mainstream-Pornografie alternativen Konzepten wie etwa der PostPornografie. Beide Phänomene verweisen auf ein der Pornografie inhärentes Spannungsfeld zwischen Normierung und Transgression. Dieses soll in dieser Arbeit näher beleuchtet werden. Beginnen wir mit einem kurzen Überblick über die erwähnten Phänomene.

Was ist Pornografisierung? Hier ein Beispiel: Der Bachelor heißt eine aktuelle Fernsehshow im Privatfernsehen. Zwanzig leicht bekleidete Damen buhlen um einen begehrten Junggesellen, den Bachelor. Die Sendung, ein international erfolgreiches Format, oszilliert zwischen Märchen und Pornografie. Dem Märchen entsprungen ist die cinderellahafte Anlage der Sendung, in der Frauen auf nichts anderes warten, als von ihrem Traumprinzen erwählt zu werden. Pornografisch sind dagegen das Setting, die Posen, die Outfits, die Gespräche. Mehrere Kandidatinnen haben eine Karriere als Nacktmodell oder gar als Pornodarstellerin vorzuweisen. Ist eine solche Sendung ein Beleg für eine Pornografisierung der Gesellschaft? Ein Großteil der feministischen Kritik an der Pornografisierung ist dieser Ansicht, wobei unter dem Begriff 
nicht immer dasselbe verstanden wird. Teils wird der Begriff für Phänomene verwendet wie Der Bachelor, in denen Pornografie über Werbung, Reality-TVShows, Musikvideos etc. unsere Pop- und Alltagskultur unterwandert; teils beschreibt er ganz generell den erleichterten Zugang zu Pornografie über Internet und Smartphones, der zu einer größeren Verbreitung von Pornografie in der Öffentlichkeit geführt hat. Uneinigkeit besteht auch in der Bewertung der Pornografisierung. In der öffentlichen Debatte dominant sind kritische Stimmen wie die der feministischen Autorin und Aktivistin Gail Dines. Ihr letztes Buch hieß Pornland: How porn has hijacked our sexuality - die Metapher im Titel gibt einen deutlichen Hinweis darauf, worum es Dines geht. Sie behauptet, Pornografie raube insbesondere Jugendlichen ihre Sexualität, indem sie sie schon in einem frühen Entwicklungsstadium mit pornografischen Bildern überflute. Sie beeinflusse so Sexualverhalten wie auch Körperbild der Jugendlichen negativ. Sie propagiere gewalttätige und Frauen herabwürdigende Sexualpraktiken, und die perfekten und sexuell hyperleistungsfähigen Körper der Sexindustrie führten zu einem objektivierenden, sozusagen pornografischen Blick auf den eigenen und andere Körper.

Was ist dagegen unter alternativer Pornografie zu verstehen? Dieser relativ breite Begriff umfasst alle Formen von Pornografie, die nicht Mainstream sind, also nicht industriell für ein männliches, heterosexuelles Publikum hergestellt werden. Darunter fallen Amateurpornos, aber auch speziell für Frauen, Schwule oder Transmenschen produzierte Pornografie oder die in den letzten Jahren wachsende Szene der Post-Pornografie. Letztere verfolgt den Anspruch einer nicht sexistischen, nicht heteronormativen, nicht rassistischen Pornografie. Sie sollte im besten Fall subversiv, revolutionär sein und versuchen, die herrschende Geschlechter- und Gesellschaftsordnung zu verändern. Damit wendet sie sich direkt gegen Aspekte der Mainstream-Pornografie, die auch von feministischer Seite kritisiert werden: Frauenfeindlichkeit, Rassismus etc. Sie antwortet darauf jedoch nicht mit Zensurbestrebungen, sondern mit einer alternativen Form von Pornografie.

In dieser Einleitung möchte ich zunächst auf die Ambivalenz der Pornografie eingehen. Anschließend werde ich aufzeigen, wo sich meine Arbeit innerhalb der Pornografiedebatten verortet. Dann werde ich mein Vorgehen skizzieren, Methode und Material vorstellen. Zuletzt umreiße ich, welches Ziel ich mit dieser Arbeit verfolge.

Angenommen, Pornografie ist einfach eine Art und Weise, wie Wissen über Sexualität in der Gesellschaft zirkuliert: Was unterscheidet sie dann von anderen Arten der Wissensvermittlung zu Sexualität? Im Gegensatz etwa zu 
einer Aufklärungsbroschüre oder der Sexualerziehung in der Schule gibt die Pornografie eine erste Antwort auf eine Frage, die für das Leben der eigenen Sexualität wichtig ist: Was erregt mich? Die Antwort auf diese Frage dürfen offizielle Informationen über Sexualität nicht geben, da sie sonst in Verdacht kommen, Pornografie zu verbreiten. Sexualerziehung an Schulen sieht sich beispielsweise oft mit diesem Vorwurf konfrontiert. Auch wird immer wieder öffentlich diskutiert, wie explizit zum Beispiel HIV/Aids-Prävention zu erfolgen hat.

Woher kommt nun diese Frage, und weshalb ist sie so zentral? Der wichtigste Auslöser sind wahrscheinlich die körperlichen Veränderungen, die die Pubertät mit sich bringt. Veränderungen in intimen Bereichen des eigenen Körpers festzustellen, stellt die Jugendlichen vor Fragen, deren Antworten unmittelbar mit der Sexualität zusammenhängen. Diese Veränderungen geschehen zudem zeitgleich bei einer ganzen Gruppe von Gleichaltrigen, was die Diskussion zu sexuellen Themen zusätzlich anfacht. Zusammen mit in den Medien aufgeschnappten Informationen entsteht so bereits ein vages Wissen über eigene sexuelle Präferenzen, entstehen Fantasien und sexuelle Bilder, die in den allermeisten Fällen einem sexuellen Erstkontakt vorausgehen. Sexueller Kontakt erfolgt also in der Regel nicht, ohne dass vage Bilder davon, was ein solcher Kontakt bedeuten könnte, schon vorhanden sind. Diese ersten Bilder und Fantasien lösen Neugier auf sexuelle Praxis aus, haben jedoch auch Unsicherheiten und Ängste zur Folge. Das beste Mittel gegen diese Ängste ist Wissen, das über Sexualaufklärung, aber auch über Pornografie beschafft werden kann. Dieses Wissen liefern natürlich auch die ersten sexuellen Kontakte selbst. Nur sind solche Kontakte nicht für alle an diesem Wissen Interessierten unmittelbar verfügbar. Wenn Menschen zumindest ein Grundwissen darüber haben wollen, was sie erregt, bevor sie effektiv sexuellen Kontakt haben, sind sie auf Pornografie angewiesen.

Doch stellt Pornografie nicht gerade Bilder und Fantasien als erregend dar, die für die sexuelle Praxis sogar schädlich sind? Dies behauptet zumindest ein Teil der feministischen Pornografiekritik. Um diese Behauptung zu überprüfen, müssen wir uns detailliert mit den Inhalten, die Pornografie transportiert, auseinandersetzen. Vorläufig gehe ich davon aus, dass Pornografie die Macht hat, unterschiedlichste Reaktionen auszulösen in einer Spannbreite von Verlangen über Indifferenz bis zu Ekel und Widerwillen. Des Weiteren treffe ich die Annahme, dass Pornografie zwar sehr wohl sexuelle Fantasien erzeugen, formen und steuern kann, aber in der Regel bereits auf einen Nährboden von vagen Präferenzen und Bildern auftrifft. Die Inhalte 
der Pornografie und deren Manipulationsmacht treffen also immer schon auf einen gewissen Bestand an Wissen, den Jugendliche über sich, ihre Körper und sexuellen Präferenzen haben, so klein dieser Wissensbestand auch sein mag. Dies ist wichtig, da - falls diese These zutrifft - dieser Grundbestand an Wissen über Sexualität durch pornografische Inhalte zwar überformt, gelenkt und erweitert würde, aber nicht grundlegend gelöscht und ersetzt werden könnte.

In dieser Arbeit werde ich mich detailliert mit den Argumenten der feministischen Pornografiekritik befassen und ihr in vielen Punkten zustimmen. Es gibt jedoch einen zentralen Punkt, der mich in vielen Texten, die Kritik an Pornografie und Pornografisierung üben, befremdet und der in Dines' eingangs genanntem Buchtitel explizit wird. Wenn Pornografie uns unserer Sexualität berauben kann, ist Sexualität etwas, was wir unabhängig von Pornografie bereits besitzen. Hier kommt eine essenzialisierende Vorstellung von Sexualität zum Vorschein: Sexualität ist etwas, was wie ein Pflänzchen möglichst unbeeinflusst von äußeren Eindrücken im Inneren des Individuums heranwachsen soll, bis es stark und kräftig genug ist, um dann dem verzerrenden Einfluss der Pornografie zu widerstehen. Ich halte es für sinnvoller, davon auszugehen, dass sich sexuelle Identität und sexuelles Begehren gerade im Austausch mit der Umwelt und so auch mit pornografischen Bildern, die sich da befinden, herausbilden. Eine ursprünglich reine, harmonische, nicht gewaltförmige Sexualität, die von der Pornografie geraubt werden kann, gibt es nicht.

\subsection{Verortung}

Die Kritik an der Pornografie ist nicht neu. Sie existiert mindestens, seit Pornografie eine gewisse Verbreitung hat. Doch seit wann ist das der Fall? Die Historikerin Lynn Hunt begreift Pornografie als Phänomen der westlichen Moderne, das im 18. Jahrhundert zusammen mit der Verbreitung des Buchdrucks auftritt. Sie stehe in engem Zusammenhang mit typischen Merkmalen der Moderne: »Pornographie hängt mit Freidenkertum und Häresie, mit Wissenschaft und Naturphilosophie und mit Angriffen auf absolutistische politische Autoritäten zusammen.«(Hunt 1996, S. 9) Ihr Zweck lag Hunt zufolge nicht vorrangig im Stimulieren von Lust, sondern darin, Kritik gegen Autoritäten zu äußern. Erst im 19. Jahrhundert habe sich diese Gewichtung verschoben. Lange wurde Kritik an der Pornografie von staatlicher oder kirchli- 
cher Seite geäußert und stellte insbesondere deren sittenwidrigen Charakter in den Vordergrund. Dies änderte sich durch die Frauenbefreiungsbewegung der 1960er- und 1970er-Jahre. Sie thematisierte sexuelle Gewalt und deren einschränkende Wirkung auf die Bewegungs- und sexuelle Freiheit von Frauen. Eine Reihe von feministischen Theoretikerinnen - die wichtigsten waren Andrea Dworkin und Catharine MacKinnon - machten in der Pornografie einen zentralen Auslöser für sexuelle Gewalt aus.

Wie die Pornografie selbst bewegt sich auch die Forschung über sie in einem stark moralisch und politisch aufgeladenen Feld. Der Queertheoretiker Paul B. Preciado schreibt dazu:

Porn is not yet considered a worthy subject for either cinematographic or philosophical study. Coupled with the academic scorn poured onto pornography - seen as mere cultural garbage - there is the persistence of what we might term the hypothesis of the brainless masturbator: pornography is seen as the zero degree of representation, a closed and repetitive code whose only function is and should be that of uncritical masturbation - with criticism understood as an obstacle to masturbatory success. In any case, as we are told, pornography does not deserve a hermeneutics. (Preciado 2009 , S. 25)

So existiert erst seit ein paar Jahrzehnten eine nennenswerte akademische Forschung zu Pornografie, sei es aus kultur- oder medienwissenschaftlicher Perspektive, sei es aus philosophischer Perspektive. Einen großen Anteil daran haben feministische Autorinnen. Politischer Aktivismus gegen Pornografie hat im Lauf der Zeit zahlreiche Debatten angestoßen, die helfen, das Phänomen Pornografie in all seinen Facetten besser zu verstehen. Besonders virulent wurden in den letzten Jahren einerseits Fragen rund um die sogenannte Pornografisierung der Gesellschaft diskutiert, andererseits die Frage nach der Möglichkeit und dem Status von zum Mainstream alternativen Pornografien. Beide Fragen stehen deshalb im Fokus dieser Arbeit. Allerdings ist es mein Anspruch, auch über diese aktuellen Debatten hinaus Grundlagen sowie Grundbegriffe zu klären. Angelehnt an einen Aufsatz der Philosophin Alisa L. Carse (2000) möchte ich im Folgenden eine Auslegeordnung philosophischer Positionen in der Pornografiedebatte vornehmen. Auf dieser Grundlage verorte ich dann meine Arbeit.

Geht es um Pornografie, dreht sich die philosophische Debatte in der Regel um eine Frage: Soll man Pornos verbieten? Etwas philosophischer formuliert: Steht Pornografie unter dem Schutz der Rede- und Meinungsfreiheit, 
oder darf diese im Falle der Pornografie eingeschränkt werden? Ein protektionistisches Lager steht also einem restriktionistischen gegenüber.

Carse unterscheidet innerhalb des protektionistischen Lagers noch zwischen absolutem und gemäßigtem Protektionismus. Der absolute Protektionismus sieht in jedem Versuch, Pornografie staatlich zu regulieren, eine Bedrohung der Redefreiheit - eine Tyrannei des Moralismus. Der gemäßigte Protektionismus lässt Einschränkungen der Redefreiheit zu, wenn der aus der Redefreiheit entstehende Schaden größer ist als der durch die Einschränkung verursachte. Dies ist gemäß dieser Position aber bei Pornografie nicht der Fall.

Das restriktionistische Lager teilt Carse in Anstößigkeits- und Schadensrestriktionismus. Der Anstößigkeitsrestriktionismus erachtet Pornografie per definitionem als obszön und deshalb nicht von der Redefreiheit geschützt. Den Schadensrestriktionismus stört an Pornografie nicht der obszöne Gehalt. Er kritisiert die Schäden, die diese sowohl bei den an Entstehung und Konsum beteiligten Personen als auch in der Gesellschaft allgemein verursacht. Dieser Schaden sei groß genug, um die Regulierung der Pornografie zu rechtfertigen.

Carse befasst sich nicht eingehend mit der Position des Anstößigkeitsrestriktionismus, da sie die juristische Definition von Obszönität für so vage und problematisch hält, dass sie eine eigene Untersuchung verdient hätte. Sie hält jedoch fest, dass für den Anstößigkeitsrestriktionismus die sexuelle Explizitheit des Materials das Hauptkriterium für die Entscheidung darstellt, ob das Material pornografisch ist oder nicht. Sexuelle Explizitheit ist für diesen nur dann unproblematisch, wenn sie künstlerischen oder wissenschaftlichen Wert besitzt. Der Schadensrestriktionismus hingegen definiert Pornografie als Darstellung von Frauenhass, der die Erniedrigung des weiblichen Körpers bezweckt. Wenn eine sexuell explizite Darstellung Gewalt an Frauen nicht erotisiert, handelt es sich aus Sicht des Schadensrestriktionismus streng genommen nicht um Pornografie.

Carse selbst nimmt eine Position ein, die Argumente des gemäßigten Protektionismus mit solchen des Schadensrestriktionismus kombiniert. Gegen den absoluten Protektionismus führt sie an, dass Redefreiheit nicht als negative Freiheit auszulegen sei, also als Freiheit, uneingeschränkt alles zu sagen, was man wolle. Für Carse ist Redefreiheit ein Teilaspekt der positiven Freiheit, worunter sie in Anlehnung an Hannah Arendt Autonomie und Selbstbestimmung versteht. Diese Freiheit müsse geschützt werden, auch vor Exzessen 
der Redefreiheit, wie sie etwa rassistische oder antisemitische Hetzreden sowie Pornografie darstellten.

Gegen den gemäßigten Protektionismus wendet Carse ein, dass Pornografie Frauen sehr wohl erheblichen Schaden zufügen könne. Sie unterscheidet hierfür drei Arten: Pornografie könne Frauen erstens bei der Herstellung, zweitens in Darstellung oder Inhalt und drittens durch Verbreitung und Konsum schaden. Den Schaden, den die bei der Herstellung von Pornografie beteiligten Frauen erfahren, thematisiert Carse nicht. Der frauenfeindliche Gehalt steht für Carse ebenso wie für die gemäßigten Protektionisten außer Frage, nur rechtfertige er allein noch nicht die Einschränkung der Redefreiheit. Es müsse bewiesen werden, dass er sich auch schädlich auf die Nutzer und über diese auf die Gesellschaft auswirkt. Pornografie schade jedoch insofern, als sie eine Ungleichheit der Geschlechter propagiere und als natürliche Geschlechterdifferenz festschreibe:

Pornographische Materialien und die Cewohnheiten und Praktiken, die mit ihrem Konsum häufig einhergehen, stellen in sich eine Verletzung der Würde von Frauen dar, nicht zuletzt deshalb, weil Frauen als bloße Objekte gesehen werden, als entmenschlichte und entpersonalisierte Instrumente zur Befriedigung männlicher Wünsche und Launen. (Carse 2000, S. 187f.)

Wo liegen nun die Probleme in dieser Darstellung? Carse definiert Pornografie so, dass in ihr Frauen vorkommen müssen, die zu Sexualobjekten degradiert werden, und dass diese Erniedrigungen gutgeheißen oder sogar empfohlen werden. Schwule Pornografie zum Beispiel gibt es gemäß dieser Definition gar nicht.

Carse stellt dem negativen Freiheitsbegriff der absoluten Protektionisten einen positiven entgegen, der auf Autonomie und Selbstbestimmung basiert, in deren Namen untergeordnete Freiheiten wie die Redefreiheit auch mal eingeschränkt werden können. Ihr Argument lautet also: Pornografie beschneidet über die Formung der Vorstellungen von Geschlecht und Geschlechterdifferenz die Autonomie und Selbstbestimmung der Frauen, deshalb wäre eine Einschränkung der Redefreiheit in diesem Falle gerechtfertigt. Carse scheint mir hier von einem überdehnten Autonomiebegriff auszugehen. Gemäß ihrem Argument wäre Autonomie ein Freisein von den Vorstellungen der Gesellschaft, in der das Subjekt lebt. Eine alternative Annahme wäre, dass jedes Subjekt durch die Vorstellungen der Gesellschaft geformt wird. Da diese Vorstellungen zum Teil widersprüchlich sind, tut sich jedoch die Möglichkeit auf, 
zwischen den Vorstellungen und Rollenbildern zu wechseln oder sie sogar gegeneinander auszuspielen.

Carse wischt den Vorwurf der Obszönität etwas rasch als vage vom Tisch. Ich möchte dagegen in dieser Arbeit versuchen, im Begriff des Obszönen ein Kernmoment der Pornografie herauszuschälen, das in Carses einseitig auf Schaden fokussierter Definition verloren geht. Der Anstößigkeitsrestriktionismus definiert, dass sexuell explizites Material, um obszön zu sein, zwei Kriterien erfüllen muss: Es muss erstens nach den Maßstäben, die in einer Gesellschaft gelten, von einer durchschnittlichen Person als anstößig beurteilt werden. Es verstößt also gegen die herrschenden Konventionen des sogenannten guten Geschmacks, verletzt das gesunde Sittlichkeitsempfinden. Um die Wissenschafts- und Kunstfreiheit zu schützen, darf das Material zweitens auch keinen echten Wert für Wissenschaft oder Kunst darstellen.

Mir geht es hier darum, dass diese Definition eine Ausschlussbewegung vollzieht, bei der am Ende das als Obszönität dasteht, was eine Gesellschaft nicht mehr in ihre Vorstellungen einer natürlichen Sexualität integrieren kann. Das Obszöne wäre somit identifiziert als das sexuell explizite Material, von dem in einer gesellschaftlichen Runde niemand mehr sagt, dass es schön, normal, natürlich, Kunst oder zu wissenschaftlichen Zwecken eben notwendig ist. Genau daraus nährt sich der verbotene Reiz des pornografischen Materials, auch wenn es effektiv gar nicht verboten ist: Im Moment des Konsumierens weiß man genau um die soziale Nichtakzeptabilität dieses Konsums. Der Reiz der Übertretung sozialer Konventionen ist derart in die Pornografie eingeschrieben, dass er ein wesentliches Merkmal der Pornografie ausmacht. Dieses Merkmal erklärt, weshalb zu verschiedenen Zeiten in verschiedenen Gesellschaften je andere Dinge als Pornografie galten und gelten. Obszön ist sozusagen der Überschuss an sexuellem Begehren, der nicht sinnstiftend innerhalb gesellschaftlicher Konventionen Platz findet. Indem Carse dieses Moment der Pornografie außer Acht lässt, verfehlt sie den Kern des Störfaktors Pornografie.

\subsection{Vorgehen}

Meine Leitfragen sind: Hat Pornografie einen transgressiven Charakter? Und wenn ja, worin besteht er? Mir geht es im Folgenden um keine Wertung des Phänomens Pornografie, also nicht um die Beantwortung der Frage: Ist Pornografie aus ethischer Perspektive gut oder schlecht? Ich werde auch keine 
soziologischen Untersuchungen vornehmen, also weder Statistiken auswerten noch Menschen zu ihren Erfahrungen mit und Einschätzungen zu Pornografie befragen. Schon gar nicht habe ich irgendwelche pädagogischen Intentionen; es geht mir nicht darum, beispielsweise Empfehlungen abzugeben, in welchem Alter Jugendliche in welcher Form mit Pornografie in Kontakt kommen sollten oder nicht. Alle diese Fragen werden zwar in den von mir untersuchten Debatten aufgeworfen, mich interessiert allerdings die hinter diesen Debatten liegende Ambivalenz in Bezug auf Pornografie. Was ist der Grund dafür, dass die Pornografie immer wieder Anlass zu diesen Debatten gibt?

Die vorliegende Arbeit ist insofern eine philosophische, als sie sich auf einer grundsätzlichen Ebene Gedanken über den Begriff Pornografie macht. Wenn ich den transgressiven Charakter der Pornografie nachzuweisen versuche, möchte ich in erster Linie zeigen, weshalb die Rede von Pornografie notwendigerweise ein transgressives Element voraussetzt.

Entsprechend sind mein Material in dieser Arbeit theoretische und analytische Texte zu Pornografie und Sexualität. Ich werde keine direkte Bildoder Filmanalysen vornehmen. Zur Verdeutlichung werden zwar manchmal Beschreibungen pornografischer Inhalte herangezogen, aber es geht mir um eine Analyse von Sekundärtexten und nicht von primären Quellen - weil die Definition von Pornografie kontext- und diskursabhängig ist. Wenn ich also den transgressiven Charakter der Pornografie ergründen will, muss ich mich in erster Linie mit den Diskursen rund um die Pornografie beschäftigen. Oft fallen in diesem Zusammenhang Aussagen wie: »Pornografie ist die Theorie, Vergewaltigung die Praxis«; »Pornografie beraubt uns unserer Sexualität«; »Pornografie verdirbt die Jugend«. In solchen Sätzen stecken versteckte Essenzialisierungen sowie ein Determinismus, der meiner Ansicht nach dem Thema nicht gerecht wird. Beides scheint mir die Debatte rund um Pornografie zu prägen, weshalb ich im Folgenden dagegen argumentieren möchte. Ich werde also nicht empirisch beweisen, dass solche Aussagen falsch sind, sondern diskurskritisch aufzeigen, welche Vorstellungen von Sexualität und Pornografie sich in ihnen verbergen.

Als Erstes geht es mir darum, den transgressiven Charakter der Pornografie theoretisch zu begründen. Dazu dienen mir in Kapitel 2 philosophische Schriften zu Sexualität und Pornografie, mit denen ich mich anhand eines kritisch-hermeneutischen Ansatzes auseinandersetzen werde. In Kapitel 3 geht es dann um Transgression in der feministischen Pornografiekritik. Hier beschäftige ich mich vor allem mit pornografiekritischen Texten aus den letzten zehn, fünfzehn Jahren, die insbesondere das Phänomen der Por- 
nografisierung kritisieren. Zum Vergleich ziehe ich wichtige klassische Texte der feministischen Pornografiekritik hinzu. Anschließend befasse ich mich in Kapitel 4 mit Transgression in alternativen Pornografien. Hier werde ich Stellungnahmen von Menschen, die an der Produktion alternativer Pornografien beteiligt sind, einbeziehen, aber auch Analysen aus der Queer Theory. Ich werde in den Kapiteln 3 und 4 diskursanalytisch arbeiten, denn es geht mir dort um die Frage: Wo spielt Transgression in diesen Debatten eine Rolle? Dabei werde ich mich vorwiegend auf die Metaebene konzentrieren und weniger zu den in den Debatten vorgebrachten Argumenten direkt Stellung beziehen. Ein Problem besteht darin, dass sich diese Texte nicht alle auf dieselben pornografischen Formen beziehen. Denn Pornografie bedient sich bekanntlich verschiedener Medien. Es gibt pornografische Texte, Bilder und Filme. Pornografie findet sich zwischen Buchdeckeln, am Kiosk, im Sexshop, im $\mathrm{Mu}$ seum oder im Internet. Dort, wo die Autoren und Autorinnen der von mir behandelten Texte diese Unterschiede thematisieren, werde ich ebenfalls den medialen Aspekt hervorzuheben versuchen, damit nicht eventuell wichtige Unterschiede verloren gehen. Dennoch geht es mir bei allen Unterschieden zwischen den verschiedenen medialen Formen von Pornografie um ein verbindendes Element, das diese als pornografisch auszeichnet.

Im Schlussteil fasse ich die Erkenntnisse noch einmal zusammen. Und ich frage in einem Ausblick nach den Folgen der Pornografisierung für eine neue Ethik der Lüste.

\subsection{Ziel}

Mein Ziel ist es, überzeugende Argumente dafür zu liefern, dass Transgression ein wesentlicher Bestandteil der Pornografie ist - und zwar sowohl in der Mainstream-Pornografie als auch in den zu ihr alternativen Formen. Selbst wenn Sexismus, Gewalt und Heteronormativität in der MainstreamPornografie eine Realität sind, bietet sie bedeutsame Möglichkeiten zur Überschreitung. 


\section{Das Verhältnis von Pornografie und Transgression}

\section{1 Überblick}

In diesem Kapitel stelle ich meine zentrale These vor, die besagt, dass Pornografie einen transgressiven Charakter hat. Im Überblick stecke ich als Erstes den begrifflichen und theoretischen Rahmen ab, innerhalb dessen ich Pornografie und deren Verhältnis zur Transgression analysiere. Obwohl ich die Begriffe Pornografie und Transgression hier in einer deskriptiven Weise definieren werde, tue ich dies in einem normativen, politisierten Feld. Sowohl Pornografie wie auch Transgression sind in einer nicht auf Anhieb durchsichtigen Weise an Normen gebunden, mit deren Übertretung sie spielen. Grenze und Überschreitung, Verbot und Übertretung, Tabu und Tabubruch - diese Begriffspaare sind meines Erachtens für das Verständnis von Pornografie zentral. Sie stellen jedoch nicht nur die Wissenschaft, sondern auch die Gesellschaft vor die Herausforderung, einen analytischen Standpunkt zur Pornografie zu bewahren. Denn je nachdem, ob einem die Norm oder deren Verletzung sympathischer ist, liegt die Verdammung oder Verklärung der Pornografie nahe.

Damit sind wir mitten im Thema dieses Kapitels. In einem ersten Schritt werde ich den begrifflichen Rahmen klären und sowohl für Pornografie als auch für Transgression einfache, alltagssprachliche Definitionen zum Ausgangspunkt nehmen. Bevor ich allerdings auf den transgressiven Charakter der Pornografie selbst zu sprechen komme, werde ich das Verhältnis von Normierung und Transgression in Bezug auf Sexualität diskutieren. Denn meine These vom transgressiven Charakter der Pornografie setzt ein Verständnis von Sexualität voraus, das von einem Zusammenspiel normativer und transgressiver Elemente ausgeht. Dieses Zusammenspiel analysiere ich, indem ich Konzeptionen, welche Sexualität eher als Gegenstand von Normie- 
rung beschreiben, mit solchen vergleiche, die in ihr vor allem eine Quelle von Handlungen der Überschreitung sehen. Basierend auf dieser Gegenüberstellung wende ich mich dann verschiedenen Analysen zur Pornografie zu, die zeigen, wie diese zwischen einem normierten, warenförmigen Ausdruck von Sexualität und der Möglichkeit zur Überschreitung sexueller Beschränkungen schwankt.

\subsection{Definitionen}

\subsubsection{Pornografie}

Der Begriff Pornografie leitet sich ab vom griechischen pornographos, was wiederum eine Zusammensetzung von porne und graphein ist. Porne heißt Hure und graphein heißt schreiben, pornographos bedeutet also über Huren schreibend. Wie viel ist von dieser ursprünglichen Bedeutung des Begriffs in der Alltagssprache erhalten geblieben? Der Duden beschreibt Pornografie als eine sprachliche oder bildliche Darstellung sexueller Akte unter einseitiger Betonung des genitalen Bereichs und unter Ausklammerung der psychischen und partnerschaftlichen Aspekte der Sexualität. (Dudenredaktion o.J.b) Auffälligerweise definiert der Duden Pornografie nicht einfach über die Fokussierung einer Darstellung auf den Genitalbereich, sondern nennt als Bedingung zusätzlich das Ausblenden der sozialen und emotionalen Aspekte von Sexualität. Damit bleibt er nahe bei der ursprünglichen Bedeutung des Begriffs. Im Ausdruck »über Huren schreibend« steht die Darstellung von Frauen als in erster Linie sexuell verfügbaren Wesen und nicht als gleichberechtigten Partnerinnen im Vordergrund.

Jedoch droht hier bereits ein moralisierender Blick auf das Phänomen Pornografie. Es fällt schwer, in der Reduktion von Frauen auf sexuelle Verfügbarkeit keine verurteilenswürdige Abwertung zu sehen. Ein anderer möglicher Zugang wäre jedoch jener über die Ästhetik. Legitimiert würde dieser Zugang durch Betonung des graphein im Wort Pornografie, das ja sowohl schreiben als auch bildlich darstellen heißen kann. Ist das Pornografische also eine ästhetische Kategorie? Ist sie als künstlerischer Ausdruck selbst Kunst?

Der zeitgenössische Kunsttheoretiker Arthur Danto schreibt: »Etwas überhaupt als Kunst zu sehen verlangt nicht weniger als das: eine Atmosphäre der Kunsttheorie, eine Kenntnis der Kunstgeschichte. Kunst ist eine Sache, deren Existenz von Theorien abhängig ist.« (Danto 1999, S. 207) Wenn Wis- 
sen über Kunsttheorie und eine Kenntnis des kunsthistorischen Kontextes unabdingbar sind, um ein Kunstwerk als solches zu erkennen, was heißt das für die Definition von Pornografie? Wissen wir, dass wir es mit Pornografie zu tun haben, bevor wir beschlossen haben, dass wir es damit zu tun haben?

Die Definition der Pornografie ist ebenso wie die der Kunst abhängig von theoretischen und historischen Kontexten. Was unter Pornografie verstanden wird, ändert sich im Lauf der Zeit; Bilder, die zu einer bestimmten Zeit anstößig erscheinen, können in einem anderen Kontext völlig unproblematisch sein. Was ist aber jeweils nötig, damit in einem historischen Kontext etwas als Pornografie verstanden wird? Es ist, analog zur Kunst, ein gewisses theoretisches Wissen über ebendiesen Kontext erforderlich, genauer: über die in diesem Kontext geltenden Regeln, die definieren, was darstellbar ist, ohne gegen den guten Geschmack, die Sitte, die herrschende Moral etc. zu verstoßen.

Wie die Kunst wird also Pornografie gerahmt von Diskursen, die sie definieren und so erst erkennbar machen. Im Gegensatz zum mal affirmativen, mal kritischen Verhältnis der Kunst zum herrschenden Diskurs scheint sich die Pornografie jedoch innerhalb dieses Diskurses durch einen Verstoß auszuzeichnen. Sie wird vom herrschenden Diskurs als anstößig, problematisch empfunden. Nicht zufällig hat es unterschiedliche strafrechtliche Konsequenzen, ob etwas Kunst oder ob etwas Pornografie ist.

Pornografie ist also etwas, was zwar nur innerhalb eines bestimmten Diskurses wahrnehmbar ist, aber im gleichen Akt der Wahrnehmung an die Ränder dieses Diskurses oder darüber hinaus verwiesen wird. Diese Positionierung der Pornografie am Rand eines Diskurses, als eigentliche Grenze eines bestimmten Diskurses möchte ich genauer in den Blick nehmen. Sie lässt sich meiner Ansicht nach am besten mithilfe des Begriffs der Transgression charakterisieren.

\subsubsection{Transgression}

Der Begriff Transgression leitet sich vom lateinischen transgressio her, was Überschreitung, Übergang bedeutet. Laut dem Duden kennt das Deutsche keinen alltagssprachlichen Gebrauch des Begriffs; er nennt bloß zwei fachspezifische Bedeutungen: In der Geografie bezeichnet Transgression das Vordringen des Meeres über größere Gebiete des Festlands und in der Biologie das Auftreten von Genotypen, die in ihrer Leistungsfähigkeit die Eltern- und 
Tochterformen übertreffen (Dudenredaktion o.J.c). Immerhin finden wir in beiden Bedeutungen das Motiv der Überschreitung wieder.

Die Online-Enzyklopädie Wikipedia nennt dagegen alltagssprachliche Bedeutungen. So bedeute Transgression allgemein und je nach Zusammenhang Sünde, Verletzung, Verstoß, Überschreitung oder Übertretung; zudem beschreibe es das Überschreiten von Grenzen der Geschlechterrollen durch Verhaltensweisen, die traditionell als soziale Norm dem anderen Geschlecht zugeschrieben werden; schließlich bezeichne Transgression in der Linguistik den situationsbedingten Gebrauch einer für den Sprecher nicht identitätsstiftenden Sprachvarietät (Wikipedia 2015). Transgression scheint also ein Überschreiten von Grenzen, Normen und Identitäten zu beschreiben. Zudem verweist die Wikipedia auf das Cinema of Transgression, eine UndergroundfilmBewegung der späten 70er- und frühen 8oer-Jahre, die den Begriff programmatisch im Namen führte. Diese Bewegung, zu der unter anderem die USFilmemacher Nick Zedd oder Richard Kern zählten, war ideologisch und personell eng mit der Punk-Bewegung verbunden und berief sich auf avantgardistische Künstler und Filmemacher wie Andy Warhol, John Waters und Kenneth Anger. 1985 definierte Zedd unter dem Pseudonym Orion Jeriko in seinem Manifest des Cinema of Transgression den Begriff Transgression folgendermaßen:

Since there is no afterlife, the only hell is the hell of praying, obeying laws, and debasing yourself before authority figures, the only heaven is the heaven of sin, being rebellious, having fun, fucking, learning new things and breaking as many rules as you can. This act of courage is known as transgression. We propose transformation through transgression - to convert, transfigure and transmute into a higher plane of existence in order to approach freedom in a world full of unknowing slaves. (Sargeant 1995, S. 28)

Transgression wäre laut diesem Manifest also ein Akt der Auflehnung gegen Autoritäten, ein Akt der Befreiung. Sünde, Rebellion und Regelverstöße sollen Transformationen zu einer freieren Existenzweise einleiten. Co-Autorin Stephanie Watson weist jedoch darauf hin, dass es dem Cinema of Transgression nicht nur um Tabubrüche ging:

However it would be over simplified and inaccurate to say that these films do not highlight the connection between the maintenance of limits and the subjugation of areas of existence which are socially viewed as alternative, superfluous, or negative for a variety of reasons; these arise because the so- 
cioeconomic and systematic patterns of language and thought, which are seen to represent and to formulate social reality, can not tolerate or account for their own »failings « which allow them to function. (Ebd., S. 34)

Indem das Cinema of Transgression sich mit von der Gesellschaft abgelehnten Verhaltensweisen und Individuen befasst, macht es gleichzeitig Prozesse deutlich, durch die sich eine gesellschaftliche Realität als konform beziehungsweise nicht konform konstituiert. In den Akten der Transgression wird der herrschende Diskurs erst erkennbar.

Gemäß dem bisher Gesagten umfasst der Begriff Transgression Akte der Auflehnung gegen Autoritäten, Normen, Konventionen und Tabus. Neben der intendierten Auflehnung haben diese Akte auch die Funktion, die Grenzen des herrschenden Diskurses sichtbar zu machen.

Normen, Grenzen, herrschende Diskurse: Diese Begriffe und ihr Bezug zur Pornografie bedürfen der weiteren Erläuterung. Ich stelle im Folgenden einige Analysen vor, die auf die Konstruktion und Normierung der menschlichen Sexualität fokussieren. Denn um aufzuzeigen, wie Transgression und Pornografie zusammenhängen, muss zuerst klar werden, welche Normierungen das heutige Verständnis von Sexualität prägen. Die Basis für meine Rekonstruktion bilden die Schriften Michel Foucaults.

\subsection{Normative Aspekte der Sexualität}

\subsubsection{Das Subjekt und die Wahrheit des Sex}

Das Werk des Philosophen und Diskursanalytikers Michel Foucault ist für diese Arbeit zentral. Er beschreibt, wie Sexualität produziert und reguliert wird. Ich werde zuerst auf Foucaults Subjektkonzeption eingehen und dann seine Schriften zur Sexualität analysieren.

Foucault geht in historischen Analysen der Frage nach, welchen Grenzen der Mensch als erkennendes Subjekt im Lauf der Geschichte unterworfen war. Diese Grenzen des Wissbaren sieht er je nach Epoche anders gezogen. Der Grund dafür seien die jeweiligen Machtverhältnisse, innerhalb derer bestimmt wird, was wissbar ist und was nicht, was sagbar ist und was nicht. Neue Erkenntnisse können laut Foucault jedoch umgekehrt auch Machtbalancen aus dem Gleichgewicht bringen. Das Zusammenspiel der Erkenntnis- 
se und der Bedingungen, unter denen diese Erkenntnisse zustande kommen, nennt Foucault den »Macht/Wissen-Komplex« (Foucault 1976, S. 39).

In Überwachen und Strafen analysiert Foucault Verschiebungen im Macht/Wissen-Komplex am Beispiel des Strafvollzugs des 18. Jahrhunderts in der Entwicklung zu einer modernen Justiz. Bei dieser Entwicklung verlaufe eine wichtige Verschiebungsachse vom Körper hin zur Seele (vgl. ebd., S. 42). Sei im 18. Jahrhundert noch vor allem auf die Einschreibung der Strafe in den Körper der Verurteilten Wert gelegt worden, bemühe sich die Justiz heute besonders um die Seele der Verurteilten. Statt sie grausam zu martern, solle die Justiz sie bessern und zurück auf den Pfad der Tugend führen.

Im modernen Strafvollzug ist es laut Foucault nicht mehr die Macht des Königs, die straft, sondern die Macht juristischer, medizinischer und psychiatrischer Instanzen. Damit werde die Macht, die vorher am Ort des Königs noch genau lokalisiert werden konnte, zunehmend diffus. Aber sie durchdringe die Gesellschaft viel stärker. In Form von Disziplinartechniken niste sie sich in immer mehr Bereichen in der Gesellschaft ein: "Denn sie definieren eine bestimmte politische und detaillierte Besetzung des Körpers, eine neue >Mikrophysik` der Macht; und seit dem 17. Jahrhundert haben sie nicht aufgehört, immer weitere Gebiete zu erobern - so als wollten sie den gesamten Gesellschaftskörper einnehmen.«(Ebd., S. 178) Foucault behauptet hier, diese »Mikrophysik der Macht« zeichne sich dadurch aus, dass sie lokal agiere, neue Kategorien von Bevölkerungsgruppen entwickle und gleichzeitig Techniken erfinde, um auf diese einzuwirken. Das Volk sei nun nicht mehr einfach beherrscht und unterworfen, nein, eine Bevölkerung werde reguliert, Schulkinder würden diszipliniert, Soldaten gedrillt et cetera. Eine nicht zentral angesiedelte, sondern verstreute Macht könne die Bevölkerung in einem viel größeren Ausmaß kontrollieren. Die ganze Gesellschaft erliege einem Zwang zur Normalisierung: »An die Stelle der Male, die Standeszugehörigkeiten und Privilegien sichtbar machten, tritt mehr und mehr ein System von Normalitätsgraden, welche die Zugehörigkeit zu einem homogenen Gesellschaftskörper anzeigen, dabei jedoch klassifizierend, hierarchisierend und rangordnend wirken.« (Ebd., S. 237) Wer nicht der Norm entspreche, werde ausgegrenzt. Dieses Bündel lokaler Machtstrategien, die Mikrophysik der Macht, erzeugt in Foucaults Analyse binär angeordnete Klassen von Subjekten: normale und abweichende, gesunde und kranke, vernünftige und wahnsinnige.

Mir ist hier wichtig, wie Foucault das Subjekt immer in Abhängigkeit von Normen denkt, die dessen Erfahrungshorizont eingrenzen. Es handelt nicht 
in einer Sphäre der Freiheit, unbeeinflusst von der Gesellschaft, sondern ist immer schon in Machtbeziehungen zu anderen Subjekten verstrickt. Aus Foucaults Erkenntnissen darüber, wie Machtdiskurse über Körper Einfluss auf Subjekte nehmen, ergeben sich Konsequenzen für das Verständnis von Sexualität. Denn wenn das Subjekt sich in Abhängigkeit von den herrschenden Macht/Wissen-Formationen bildet, ist auch die dem Subjekt mögliche Sexualität durch diese geprägt. Die Konstellationen im Macht/Wissen-Komplex schreiben Subjekten eine bestimmte Sexualität zu oder definieren sie über eine bestimmte Sexualität.

Die Klassifizierung von Subjekten als normal/abnormal oder vernünftig/unvernünftig macht nicht vor deren Sexualverhalten halt. Ein Sexualverhalten kann offensichtlich in einer historischen Epoche als vernünftig und normal gelten, in einer anderen als abweichend und krank identifiziert werden. Das Sexualverhalten von Subjekten ist also weniger eine private als eine politische Frage. Sexuelle Handlungen werden nicht autonom in einen leeren Raum hinaus ausgeführt, sondern finden immer im Einklang mit oder in Opposition zu herrschenden Normen statt.

Doch wie steuert eine Gesellschaft die Sexualität der Individuen, die an ihr teilhaben? In Der Wille zum Wissen (Foucault 1977) wehrt sich Foucault gegen die Repressionshypothese des Sex. Darunter versteht er ein Konzept, das davon ausgeht, dass die Sexualität seit Jahrhunderten unterdrückt werde und von dieser Unterdrückung befreit werden müsse. Zwar bestreitet Foucault nicht, dass Sexualität in ihrer Geschichte häufig durch Verbote und Zensur eingeschränkt wurde. Er vermutet jedoch, dass dieselben Mächte, die an der Repression der Sexualität beteiligt waren, in der Forderung nach deren Befreiung am Werk sind:

Alle diese negativen Elemente - Verbote, Verweigerungen, Zensuren, Verneinungen - die die Repressionshypothese in einem großen zentralen Mechanismus zusammenfasst, der aufVerneinung zielt, sind zweifellos nur Stücke, die eine lokale und taktische Rolle in einer Diskursstrategie zu spielen haben: in einer Machttechnik und in einem Willen zum Wissen, die sich keineswegs auf Repression reduzieren lassen. (Ebd., S. 22)

Hier stellen sich zwei Fragen: Was ist in der Forderung nach Befreiung der Sexualität eigentlich dasjenige, das befreit werden soll? Und wie wird diese Befreiung vollzogen?

Dem Subjekt soll laut Foucault eine Wahrheit des Sex entlockt werden, die versteckt und unterdrückt ist. Diese Wahrheit werde durch eine Vielzahl 
von Diskursen ans Licht gebracht, die sich über das Subjekt legten. Medizinische, psychiatrische und kirchliche Instanzen produzierten verschiedene Diskurse und innerhalb dieser Diskurse ein passendes Objekt, das mit dem zu untersuchenden Subjekt nicht mehr identisch sei. Der medizinische Diskurs sucht nach Krankem, der psychiatrische nach Pathologien, der kirchliche nach sündigem Verhalten. Das zu untersuchende Subjekt wird also laut Foucault erst zum kranken, pathologischen, sündigen Subjekt gemacht. Ihm lasse sich keine Wahrheit entlocken, weil es als solches durch ebendiese Diskurse überhaupt erst konstituiert werde. Wo kein Diskurs sei, sei auch kein Subjekt. Eine Wahrheit des Sex könne also ebenfalls nur eine von den beteiligten Diskursen konstituierte Wahrheit sein:

Man kann nicht davon ausgehen, dass es einen bestimmten Bereich der Sexualität gibt, der eigentlich einer wissenschaftlichen, interesselosen und freien Erkenntnis zugehört, gegen den jedoch die - ökonomischen und ideologischen - Anforderungen der Macht Sperrmechanismen eingerichtet haben. Wenn sich die Sexualität als Erkenntnisbereich konstituiert hat, so geschah das auf dem Boden von Machtbeziehungen, die sie als mögliches Objekt installiert haben. (Ebd., S. 119)

Es gibt offenbar keine objektive Wahrheit über Sexualität, die sich entdecken lassen würde. Die Wahrheit des Sex ist eine konstruierte. Verschiedene gesellschaftliche Gruppen haben ein Interesse an der Definitionsmacht über den Körper und seine Begierden. Wenn ich davon ausgehe, dass schon hinter der Einführung der Sexualität als Erkenntnisobjekt Machtverhältnisse stecken, heißt das gleichzeitig, dass das Nachdenken über Sexualität nicht in einem politisch neutralen Bereich operiert. Auf dieser Grundlage ist meine im Überblick gemachte Aussage zur Schwierigkeit des analytischen Schreibens über Pornografie zu verstehen. Die Verquickung von analytischen und normativen Aussagen im Nachdenken über Sexualität ist demnach schon im Untersuchungsgegenstand angelegt.

Doch gab es nicht schon eine Sexualität vor deren Einführung als Erkenntnisobjekt? In den zwei folgenden Bänden von Sexualität und Wahrheit (Foucault 1986a, Foucault 1986b) widmet sich Foucault ganz diesem Thema, sprich: der Frage, wie geschlechtliche Beziehungen etwa in der Antike zu denken sind, bevor die Kategorie Sexualität eingeführt wurde. 


\subsubsection{Die Regulierung sexueller Beziehungen zwischen Männern}

Foucault stellt für die Antike eine Problematisierung geschlechtlicher Beziehungen zwischen Männern in einem moralischen und politischen Diskurs fest. Diese Feststellung ist aus zwei Gründen nicht banal: Erstens wurden geschlechtliche Beziehungen zwischen Frauen nicht problematisiert, die antike Sexualmoral war laut Foucault eine Männermoral, »in der die Frauen nur als Objekte oder bestenfalls als Partner vorkommen, die es zu formen, zu erziehen und zu überwachen gilt, wenn man sie in seiner Macht hat, und deren man sich zu enthalten hat, wenn sie in der Macht eines andern (Vater, Gatte, Vormund) sind.«(Foucault 1986a, S. 33) Wo Frauen nur als Objekte für Männer vorkommen, sind gleichgeschlechtliche Beziehungen unter Frauen unproblematisch.

Zweitens kritisiert Foucault mit dieser Feststellung die Vorstellung, Homosexualität sei in der Antike frei und unbehelligt von Verboten gelebt worden. Er schränkt ein, dass nur jene geschlechtlichen Beziehungen zwischen Männern problematisiert wurden, die sich zwischen freien Bürgern abspielten. Geschlechtliche Beziehungen mit Sklaven oder männlichen Prostituierten seien kein Gegenstand der Problematisierung gewesen. Weshalb diese Einschränkung? Moralische Problematisierung unterscheidet das sittlich angemessene vom unangebrachten Verhalten. Sie operiert also mit Binaritäten. Doch statt einer Binarität in der Objektwahl des geschlechtlichen Begehrens sei in der Antike eine Unterscheidung von Aktivität und Passivität moralisch relevant gewesen. Autonome moralische Entscheidungen trafen laut Foucault in der Antike nur freie Bürger - also besitzende Männer - , alle anderen wurden als zu solchen Entscheidungen unfähig und daher für unmündig erklärt. Da bei der Aufnahme geschlechtlicher Beziehungen zwischen freien Bürgern und Unfreien allein auf die Bedürfnisse der freien Bürger Rücksicht habe genommen werden müssen, hätten sich keine weiteren moralischen Probleme ergeben.

Foucault sieht allerdings auch die Beziehungen zwischen freien Bürgern durch dieselbe Binarität zwischen Aktivität und Passivität geprägt. Dies sei insofern problematisch gewesen, dass die freien Bürger, sofern sie geschlechtliche Beziehungen miteinander eingegangen seien, dabei jeden Anschein von Passivität hätten vermeiden müssen, um ihr gesellschaftliches Ansehen nicht zu gefährden. Um dieses Problem zu entschärfen, seien nur Beziehungen zwischen Männern und Knaben gesellschaftlich voll akzeptiert gewesen, denn Knaben befinden sich erst auf dem Weg zwischen der Unmün- 
digkeit der Kindheit und der Mündigkeit der Erwachsenen (vgl. ebd., S. 247). Dieses Zwischenstadium zwischen Mündigkeit und Unmündigkeit lässt laut Foucault zu, dass der beteiligte Knabe ohne Gesichtsverlust das passive Objekt der Begierde des beteiligten Erwachsenen, der sein geschlechtliches Begehren aktiv verfolgt, sein kann.

Wie Foucault aufzeigt, bringt die gesellschaftliche Einschränkung der möglichen Gegenstände geschlechtlichen Begehrens zwischen Männern jedoch neue Probleme mit sich. Denn aus den Knaben als Objekte der Begierde werden im Lauf der Zeit erwachsene Männer, die als freie Bürger respektiert und geachtet werden wollen bzw. müssen. Um politische Instabilität zu vermeiden, dürfe die Erniedrigung durch Passivität während der Adoleszenz nicht allzu drastische Formen annehmen. Der Knabe sollte sich laut Foucault zwar dem Begehren seines erwachsenen Liebhabers unterwerfen, aber erst nach bestimmten Ritualen des Sich-Entziehens, und er sollte auch kein eigenes Vergnügen dabei empfinden (ebd., S. 268). Vom erwachsenen Liebhaber sei erwartet worden, dass er auf diese Zusammenhänge Rücksicht nehme und seine Zudringlichkeiten auf ein Maß beschränke, das die Ehre des Knaben nicht längerfristig beschädige.

Für mich sind hier zwei Erkenntnisse Foucaults besonders relevant: Sexuelle Beziehungen zwischen Männern waren auch in der Antike Gegenstand gesellschaftlicher Regulierung. Und sie waren über eine Binarität von Aktivität und Passivität strukturiert. Im dritten Band von Sexualität und Wahrheit (Foucault 1986b) untersucht Foucault Unterschiede im Denken über Sexualität zwischen Hellenismus und Antike. Einen bedeutenden Unterschied stellt laut Foucault die höhere Wertschätzung der Ehe dar (vgl. ebd., S. 194f.). Da gerade die Stoiker den Frauen im Prinzip dieselben Fähigkeiten zuschrieben wie den Männern, habe sich die Stellung der Frau in der Ehe als bloße Befehlsempfängerin, auf die keine besondere Rücksicht genommen werden müsse, nicht mehr länger rechtfertigen lassen (vgl. ebd. , S. 211f.). Wie gestaltet sich nun diese Aufwertung der Ehe und die sich daraus ergebende Vorrangigkeit der Ehefrau? Foucault beschreibt diese Aufwertung als Neugestaltung der Ehe nach dem Vorbild geschlechtlicher Beziehungen zwischen Männern. Wie der erwachsene Liebhaber seinen jugendlichen Geliebten, so habe der Ehemann seine Ehefrau zwar anleiten und in guter Lebensführung unterweisen, aber eben neu auch respektieren und ehren sollen. Außerehelicher Geschlechtsverkehr etwa sei mit Rücksicht auf die Gefühle der Ehefrau einzuschränken gewesen. Geschlechtliche Beziehungen unter Männern seien zwar weiterhin erlaubt und angesehen gewesen, aber plötzlich als eher weniger wertvoll als die 
monogame Beziehung mit der Ehefrau erschienen. Denn weil in der strukturell gegebenen Passivität des Knaben laut Foucault für diesen immer etwas potenziell Entehrendes lag und der vom Begehren getriebene Liebhaber stets Gefahr lief, die Grenzen des Schicklichen zu überschreiten, sei die Ehe als sicherer Hafen für geschlechtliche Beziehungen vorzuziehen gewesen (vgl. ebd., S. 281). Da die Ehe auf Langfristigkeit angelegt ist, der Geschlechtsverkehr moralisch unproblematisch ist und dabei sogar noch für den Staat wertvoller Nachwuchs entsteht, sprechen nun drei gewichtige Gründe für die Ehe gegenüber der instabilen und moralisch ambivalenten gleichgeschlechtlichen Beziehung.

Wie Foucault beobachtet, waren Gefahren im Zusammenhang mit Sexualität in der Antike quasi nur im Bereich der Knabenliebe, und zwar zum Schutz des Knaben und dessen Ehre, thematisiert worden. Allgemeiner seien sexuelle Praktiken im Rahmen der Diätetik Thema gewesen, richtiger Zeitpunkt und Häufigkeit der sexuellen Handlungen seien im Dienste der körperlichen Gesundheit diskutiert worden (vgl. Foucault 1986a, S. 150). Im Hellenismus akzentuierte sich laut Foucault diese Sorge um den Körper. Da Seelenruhe und Ausgeglichenheit wichtige Werte der hellenistischen Philosophie darstellten, seien sexuelle Handlungen als gefährlicher Energieverlust und als Schwächung des Körpers wahrgenommen worden (vgl. Foucault 1986b, S. 157). Die Ehe habe sich als Rahmen für eine gewisse Regelmäßigkeit der sexuellen Handlungen empfohlen, die vor übermäßiger Erregung der Sinne bewahre. Diese neue Perspektive auf sexuelles Begehren als Unruhestifterin im sozialen Gefüge macht sie, wie Foucaults Analysen zeigen, im Laufe der Zeit immer mehr zum Gegenstand von Normierung und Kontrolle.

Es sind also zwei Verschiebungen, die im Hellenismus einen veränderten Status der geschlechtlichen Beziehungen unter Männern zur Folge haben: Ein vorher exklusiv den Männern vorbehaltenes Freundschaftsmodell wird auf die Ehe übertragen; und die Gefährlichkeit der Sexualität wird neu entdeckt.

Auf der Suche nach dem Zusammenspiel von Pornografie und Transgression habe ich bis jetzt mit Foucault herausgearbeitet, wie Normen sexuelle Subjekte hervorbringen. Das Subjekt handelt nicht in einer Sphäre der Freiheit, unbeeinflusst von der Gesellschaft, sondern ist immer schon in Machtbeziehungen $\mathrm{zu}$ anderen Subjekten verstrickt. Sein Erfahrungshorizont ist durch die herrschenden Normen eingeschränkt. Dieser Macht/Wissen-Komplex schreibt Subjekten eine bestimmte Sexualität zu. Sexuelle Handlungen werden nicht autonom in einem leeren Raum ausgeführt, 
sondern finden immer im Einklang mit oder in Opposition zu herrschenden Normen statt.

Seit dem Hellenismus wird sexuelles Begehren zunehmend als Gefahr für den Körper und die Seele des Individuums, aber auch für das soziale Gefüge wahrgenommen. Es wächst der Bedarf, es zu kontrollieren und einzugrenzen. Sexuelle Beziehungen zwischen Männern waren seit der Antike Gegenstand besonderer Regulierung. Zur besseren Kontrolle wurde im Hellenismus das den Männern vorbehaltene Freundschaftsmodell der Antike auf die Ehe übertragen. Damit wirkt die antike Strukturierung sexueller Beziehungen zwischen Männern über die Binarität zwischen Aktivität und Passivität bis heute prägend für Vorstellungen von Sexualität.

Diesen Prägungen möchte ich im Folgenden nachgehen. Denn was Pornografie mit dem Überschreiten sexueller Normen zu tun hat, lässt sich erst verstehen, wenn klar ist, was heute sexuelle Normen ausmachen. Dies möchte ich anhand der Stichworte Zweigeschlechtlichkeit und Intimität verhandeln.

\subsubsection{Zweigeschlechtlichkeit und die Objektivierung der Frau}

Zweigeschlechtlichkeit ist eine Norm, die für das Denken über Sexualität fast unhintergehbar scheint. Differenzen im sexuellen Begehren oder in sexuellen Praktiken werden heute reflexartig der Geschlechterdifferenz untergeordnet beziehungsweise in deren Rahmen eingeordnet. Foucault dreht dieses Verhältnis um. In einem unter dem Titel Das Spiel des Michel Foucault erschienenen Gespräch (Foucault 2003, S. 391-429) erläutert er diese ungewohnte Sicht auf das Verhältnis von Geschlecht und Sexualität:

Sollte im Grunde das Geschlecht, das eine Instanz zu sein scheint, die ihre Cesetze und ihre Zwänge hat, von wo aus sich ebenso das männliche Ceschlecht wie das weibliche Ceschlecht definieren lassen, nicht im Gegenteil etwas sein, das durch das Sexualitätsdispositiv produziert worden wäre? Das, worauf der Sexualitätsdiskurs als Erstes angewandt würde, wäre nicht das Ceschlecht, sondern das wäre der Körper, die Sexualorgane, die Lüste, die ehelichen Beziehungen, die Verhältnisse zwischen den Individuen [...] eine heterogene Ganzheit, die letztlich nur durch das Sexualitätsdispositiv aufgedeckt wurde, das zu einem gegebenen Zeitpunkt als Schlussstein seines eigenen Diskurses und vielleicht seines eigenen Funktionierens die Idee des Ceschlechts hervorgebracht hat. (Ebd., S. 409f.) 
Foucault führt damit Zweigeschlechtlichkeit auf das »Sexualitätsdispositiv« zurück. Dieses lege das Fundament, auf dem Zweigeschlechtlichkeit erst entstehen könne.

Wenn Foucault recht hat, geht der Begriff Zweigeschlechtlichkeit über die Beschreibung eines biologischen Faktums hinaus. Was ist denn unter Zweigeschlechtlichkeit eigentlich zu verstehen?

Der Soziologe Pierre Bourdieu behauptet, dass sich Zweigeschlechtlichkeit vor allem im Habitus ausdrücke. In seiner Theorie der männlichen Herrschaft beschreibt er, wie in der sozialen Interaktion der Geschlechter Wahrnehmungs- und Bewertungsschemata im Spiel sind, die den Habitus der Geschlechter entscheidend prägen. Eine besondere Rolle spiele dabei der Blick:

Daher ist der Blick nicht ein einfaches, allgemeines und abstraktes Objektivierungsvermögen, wie Sartre meint. Er ist ein symbolisches Vermögen, dessen Wirksamkeit abhängt von der relativen Position dessen, der wahrnimmt, und dessen, der wahrgenommen wird, sowie dem Grad, in dem die Wahrnehmungs- und Bewertungsschemata von dem, auf den sie angewandt werden, gekannt und anerkannt werden. (Bourdieu 2005, S. 115)

Bourdieu spricht von einer Distanz zwischen dem praktisch erlebten und dem legitimen Körper, die den Habitus prägt und je nach Geschlecht und Position im sozialen Raum stark variieren könne. Unter der männlichen Herrschaft werde insbesondere Weiblichkeit über das Wahrgenommenwerden durch Männer definiert:

Die männliche Herrschaft konstituiert die Frauen als symbolische Objekte, deren Sein (esse) ein Wahrgenommenwerden (percipi) ist. Das hat zur Folge, dass die Frauen in einen andauernden Zustand körperlicher Verunsicherung oder besser, symbolischer Abhängigkeit versetzt werden: Sie existieren zuallererst für und durch die Blicke der anderen, d.h. als liebenswürdige, attraktive, verfügbare Objekte. (Ebd., S. 117)

Die männliche Herrschaft zeichne sich durch einen Mechanismus aus, der Frauen auf einen Objektstatus reduziere. Denn laut Bourdieu sind auch Schönheits- und Modediktate nicht der Ursprung weiblicher Objektivierung und Selbstobjektivierung. Dieser liege vielmehr in der grundsätzlichen Konstruktion von Weiblichkeit über das Wahrgenommenwerden innerhalb der herrschenden männlichen Kategorien. Indem nun Frauen sich diesen männlichen Kategorien entsprechend $\mathrm{zu}$ verhalten versuchten, stützten sie 
umgekehrt wieder die männliche Herrschaft. Wie Bourdieu analysiert, hat dies auch Folgen für die Männer, die über die Sozialisation auf ihre dominierende Rolle innerhalb des Systems der männlichen Herrschaft vorbereitet werden. Der Versuch der Frauen, die mit Weiblichkeit verbundenen Erwartungen zu erfüllen, bringe wiederum die Männer in die Position, dass sie die mit Männlichkeit verbundenen Erwartungen erfüllen müssten. In diesem Sinne trügen beide Geschlechter zur Aufrechterhaltung der männlichen Herrschaft bei:

Da die auf Geschlechtsdifferenzierung gerichtete Sozialisation die Männer dazu bestimmt, Machtspiele zu lieben, und die Frauen dazu, die sie spielenden Männer zu lieben, ist das männliche Charisma zu einem Teil der Charme der Macht, der verführerische Reiz, den der Besitz der Macht von selbst auf die Körper ausübt, deren Triebe und Wünsche selbst politisch sozialisiert worden sind. (Ebd., S. 141)

Bourdieu zeigt hier analog zu Foucault auf, wie Triebe, Wünsche sowie intime Interaktionen zwischen den Geschlechtern wie Verführung oder Charme Ergebnis einer politischen Sozialisation sind. Er geht insofern über Foucault hinaus, als er aufzeigt, wie diese Sozialisation Habitus und Wahrnehmung von Männern und Frauen entscheidend prägt, sodass die herrschenden Geschlechterverhältnisse von beiden Geschlechtern unbewusst immer weiter reproduziert werden. Sexuelles Begehren zwischen den Geschlechtern ist sowohl ein Produkt von Normierung wie auch ein Motor für das Fortbestehen der Norm. Da unter der männlichen Herrschaft Weiblichkeit über Wahrgenommenwerden hergestellt wird, basieren die sexuellen Beziehungen zwischen den Geschlechtern auf dem Objektstatus der Frau. Die von Foucault behauptete Übertragung einer ursprünglich gleichgeschlechtliche Beziehungen unter Männern strukturierenden Aktiv/passiv-Binarität auf die Ehe findet ihre Entsprechung in Bourdieus Theorie vom Objektstatus der Frau unter der männlichen Herrschaft.

Neben der Zweigeschlechtlichkeit ist Intimität ein zweiter wichtiger Bestandteil heutiger sexueller Normen. Wie entstand das Konzept der Intimität, und wie funktioniert es? Dies möchte ich mithilfe der Analysen der Soziologen Richard Sennett und Niklas Luhmann zeigen. 


\subsubsection{Intimität und die Ablehnung des Obszönen}

Das Konzept der Intimität steht in einer besonderen Beziehung zum Thema der vorliegenden Arbeit, dem transgressiven Charakter der Pornografie. Denn in der Pornografie überschreitet die Sexualität den ihr zugewiesenen Rahmen der Intimität. Doch wie kam es, dass Sexualität überhaupt als etwas Intimes konzipiert wurde?

Luhmann datiert die Entstehung des Konzepts der Intimität auf das 18. Jahrhundert, als die Sexualität verstärkt in den Code der Liebe einbezogen worden sei (vgl. Luhmann 1982, S. 139ff.). Er beschreibt die Liebe als semantischen Code, der es Individuen und Gesellschaften erlaube, persönliche von unpersönlichen Beziehungen zu unterscheiden. Im Wandel der Zeit nehme der Code historisch spezifische Formen an und ziehe die Trennlinien dieser Unterscheidung anders, mit entsprechenden Folgen für das liebende Subjekt. Eine zentrale These Luhmanns ist, dass nicht ein ahistorisches Gefühl der Liebe eine historisch spezifische Sprache finde, sondern dass im Gegenteil historische Macht- und Gesellschaftsordnungen bestimmte Codes hervorbrächten, die ihrerseits in den Subjekten das Gefühl der Liebe erst erzeugten (vgl. ebd., S. 23). Die lange Zeit als tierisch abgewertete Sexualität wird laut Luhmann im 18. Jahrhundert allmählich mit den Idealen der Liebe und der Ehe verkoppelt, ein Interesse an Sexualität wird nicht mehr a priori moralisch verurteilt. Das habe Folgen für die Klassendifferenzen: »Die Neuformierung eines Code speziell für Intimbeziehungen unter Einbeziehung der sexuellen Komponente als wesentlich wird über Verstärkung der funktionalen Ausdifferenzierung zugleich einer Neutralisierung der Schichtdifferenzen Vorschub leisten.«(Ebd., S. 147) Luhmann behauptet hier, dass ein Teil der Klassendifferenzen eingeebnet wird, wenn Sexualität kein ausschließliches Kennzeichen der Unterschicht mehr ist, da die neue Verkoppelung von Sexualität und Intimbeziehungen schichtübergreifend festgestellt werden kann. Der Einbezug der Sexualität mache in Intimbeziehungen die Konkurrenz zwischen Liebe und Freundschaft zugunsten der Liebe entscheidbar, die Sexualität bezahle dafür jedoch den Preis der Kasernierung. Die Zulassung von Sexualität in Intimbeziehungen habe auch den Zweck, außereheliche Sexualität als Störfaktor für Intimität auszuschalten.

Wie Luhmann festhält, hat dies Konsequenzen für die Auffassungen von Pornografie und dem Obszönen: "Das, was unter diesen Begriffen abgelehnt werden kann, bedarf nun der Einschränkung und wird entsprechend mit Komplikationen belastet, die dann wieder dazu anreizen können, auf der 
Grenze zu balancieren.« (Ebd., S. 151) Das Interesse an Sinnlichkeit wird also laut Luhmann nicht mehr komplett abgelehnt, soll aber auf die Intimbeziehung beschränkt bleiben. So beschreibe das Obszöne nun nicht mehr den gesamten Bereich der Sinnlichkeit, sondern nur noch den Bereich der Sinnlichkeit außerhalb der Intimbeziehung: „Das Obszöne disqualifiziert sich durch das fehlende Interesse an der Person, oder genauer: durch die Auswechselbarkeit der Bezugsperson.«(Ebd.) Dieser durch die Intimbeziehung gezähmte Bereich des Obszönen macht es laut Luhmann der Liebe möglich, ihre Orientierung auf ein Individuum zu feiern inklusive des Kitzels, dass sich Sinnlichkeit potenziell auch auf andere Individuen richten könnte oder schon gerichtet hat: "Was man als Liebe sucht, was man in Intimbeziehungen sucht, wird somit in erster Linie dies sein: Validierung der Selbstdarstellung.« (Ebd., S. 208)

Luhmann ist also wie Foucault der Auffassung, dass historische Machtund Gesellschaftsordnungen intime Beziehungen und die damit verbundenen Gefühle regulieren. Sie tun dies über Codierung; so wird seit dem 18. Jahrhundert die zuvor als tierisch abgewertete Sexualität aufgewertet und in den Code der Liebe einbezogen. Dadurch werden Klassendifferenzen eingeebnet. Sexualität bezahlt dafür allerdings den Preis der Einsperrung in den Liebescode, außereheliche Beziehungen werden immer weniger toleriert. Die Ablehnung des Obszönen wird konstitutiv für heutige Intimbeziehungen.

Seit dem 18. Jahrhundert ist laut Luhmann also Sexualität über das Konzept der Intimität mit der Liebe verkoppelt. Jedoch ist das Konzept der Intimität seither nicht unverändert geblieben. Richard Sennett beschäftigt sich mit dem Wandel im Verhältnis von Intimität und Öffentlichkeit seit dem 19. Jahrhundert. Er schlägt vor, Erotik und Sexualität zu unterscheiden. Unter Erotik versteht er ein soziales Verhalten, das er von der Sexualität als persönlichem Zustand abgrenzt. Obwohl Erotik von der Gesellschaft des 19. Jahrhunderts mit Ängsten und Tabus belegt gewesen sei, habe sie sich in klaren gesellschaftlichen Formen, Handlungen und Codes geäußert (vgl. Sennett 1983, S. 35). Der private Zustand der Sexualität war laut Sennett davon abgegrenzt als etwas, was zwei Menschen miteinander tun, wenn sie eben nicht in der Öffentlichkeit, sondern intim sind; die sogenannte sexuelle Befreiung unserer Zeit bringe nun ein Verschwinden der Erotik als sozialer Dimension der Sexualität mit sich.

Dieser Wegfall der sozialen Dimension der Sexualität steht für Sennett beispielhaft für die Ausbreitung des Narzissmus. Wenn sexuelles Handeln nicht mehr in einen sozialen Kontext eingebunden sei, erscheine es als blo- 
ße Erweiterung des Selbst. Das Motiv, sexuelle Beziehungen einzugehen, sei dann nicht mehr, in einen Raum sozialer Beziehungen einzutreten, sondern nur noch, mehr über sich selbst zu erfahren. Analog kommt es laut Sennett allgemein in Beziehungen zu anderen zu einem »Markt der Selbstoffenbarungen« (ebd., S. 34), wo Menschen Intimitäten nach dem Tauschprinzip enthüllten, ohne wirklich am Leben des anderen Anteil zu nehmen. Dahinter stecke der Wunsch nach Authentisierung der eigenen Persönlichkeit, der leicht in einen Zwang zur Selbstrechtfertigung kippen könne. So führe der Narzissmus die sexuelle Befreiung in die Authentizitätsfalle.

Sennetts These ist also, dass in der heutigen Gesellschaft die Trennung von öffentlicher und privater Sphäre aufgehoben ist. Im Gegensatz zur Gesellschaft des 19. Jahrhunderts, wo das Individuum seine persönlichen Interessen und familiären Beziehungen in einer klar abgetrennten privaten Sphäre gelebt habe und der öffentliche Raum für den Austausch über öffentliche Fragen und den Ausbau der geschäftlichen und gesellschaftlichen Beziehungen reserviert gewesen sei, sehe der heutige Mensch die Öffentlichkeit sozusagen als Erweiterung des eigenen Selbst an. Sie interessiere ihn nur in dem Maße, als er seine privaten Neigungen darin gespiegelt sehe. Daraus resultiert laut Sennett ein Verlust der res publica, verstanden als das gemeinsame Sichverständigen der Bürger über Dinge, die alle betreffen. Des Weiteren drohe eine Tyrannei der Intimität, also die Vorstellung des Individuums, dass die Welt dazu da sei, auf seine privaten Wünsche einzugehen, was unvermeidlich zu Frustrationen führe. Die Welt werde dann als kalt und lieblos wahrgenommen, weil sie dem Einzelnen nicht die Wärme und Aufmerksamkeit entgegenbringt, die das Individuum im 19. Jahrhundert nur von seiner privaten Sphäre erwartet habe (vgl. ebd., S. 34).

Sennett sieht also wie Foucault die sexuelle Befreiung kritisch. Die Sexualität sei zwar früher in eine private Sphäre verbannt und die sozialen Beziehungen seien durch die Codes der Erotik reguliert gewesen, doch die Aufhebung dieser Grenze habe zu einer Tyrannei des Narzissmus geführt, der nun unsere sozialen Beziehungen mit dem Anspruch auf Authentisierung der eigenen Persönlichkeit belaste (vgl. ebd., S. 36). Politisch ist dieser Prozess von Bedeutung, weil die Codes und Regeln der öffentlichen Sphäre den Kitt ausmachen, der unsere Gesellschaft zusammenhält. Wenn es klar ist, dass das Intime in der Öffentlichkeit nichts zu suchen hat, geht es im öffentlichen Raum um die res publica, um Dinge, die alle betreffen; wird dagegen heute von der Öffentlichkeit die Befriedigung privater Bedürfnisse erwartet, schwinden das Interesse und die Sorge dafür, was die Gesellschaft zusammenhält. 
Was heißt dies nun für die Normierung von Sexualität? Wenn die Öffentlichkeit nur noch als Spiegel für private Neigungen fungiert, übertragen sich narzisstische Wünsche nach Selbstbestätigung auf die ganze Gesellschaft, werden zum Gegenstand der öffentlichen Debatte. Die Tatsache, dass moderne Subjekte die gesellschaftliche Validierung ihrer privaten Wünsche einfordern, lässt mit Foucault darauf schließen, dass sie darauf angewiesen sind, über die Sexualität die Wahrheit ihres einzigartigen Subjektseins bestätigt zu bekommen.

Nun möchte ich die Ergebnisse diese Kapitels zusammenfassen: Erst in der bürgerlichen Moderne entsteht die Sexualität als privilegierter Ort, an dem die Wahrheit des Subjekts vermutet wird. Dies heißt aber nicht, dass nicht schon früher sexuelle Beziehungen Gegenstand von Regulierungen gewesen wären. Seit dem Hellenismus wird sexuelles Begehren zunehmend als gefährlich für Individuum und Gesellschaft wahrgenommen. Ein Ausdruck davon ist die Übertragung des in der Antike den Männern vorbehaltenen Freundschaftsmodells auf die Ehe.

Wesentliche Bestandteile heutiger sexueller Normen sind Zweigeschlechtlichkeit und Intimität. Die sexuelle Norm der Zweigeschlechtlichkeit ist das Ergebnis eines sexuellen Begehrens, das auf einem Objektstatus der Frau basiert. Die Norm der Intimität entstand durch eine Verkopplung der Sexualität mit der Ehe. Ein ihr wesentliches Element besteht in der Selbstvalidierung des sexuellen Subjekts. Seit dem 18. Jahrhundert wird die Sexualität in der Ehe kaserniert. Das macht die Ablehnung des Obszönen konstitutiv für Intimbeziehungen. Da in Intimbeziehungen eine Validierung der Selbstdarstellung erwartet wird, müssen die Intimbeziehung und ihre Sexualität exklusiv sein. In der ehelichen Sexualität enthüllt sich die individuelle Wahrheit des Subjekts und fordert Bestätigung ein.

Die narzisstischen Ansprüche des modernen Subjekts haben Konsequenzen auf das Verhältnis von öffentlicher und privater Sphäre. Die Sicht auf Sexualität als einen Ort der Selbstoffenbarung ist bedingt durch den Wegfall einer sozialen Dimension der Erotik. Der Wunsch nach Authentisierung der eigenen Persönlichkeit in der Sexualität belastet eine ursprünglich soziale Beziehung. Die Forderung nach gesellschaftlicher Validierung privater Wünsche wird auf die Öffentlichkeit ausgeweitet.

Doch wie individuell sind die in intimen Beziehungen enthüllten Wahrheiten wirklich? Intime Interaktionen sind das Ergebnis politischer Sozialisation, die den Habitus und die Wahrnehmung der Geschlechter prägt. Im 
Ausagieren dieser Prägung werden die herrschenden Geschlechterverhältnisse weiter reproduziert.

Nach diesen Betrachtungen über die Normierung von Sexualität stelle ich im nächsten Kapitel Positionen vor, die Akte der Transgression im Bereich der Sexualität theoretisieren. Sie nehmen in der Regel die Normierungen der Sexualität zum Ausgangspunkt ihrer Überlegungen, üben Kritik am Subjektbegriff der bürgerlichen Moderne, sehen aber in der Sexualität mehr als nur das Produkt gesellschaftlicher Normen, insbesondere auch einen Weg zur Infragestellung und Überschreitung dieser Normen.

\subsection{Transgressive Aspekte der Sexualität}

\subsubsection{Erotismus und Transgression}

Als Erster hat der französische Philosoph Georges Bataille Mitte des 20. Jahrhunderts ausführlich zu Transgression gearbeitet. Trotz seiner an zeitgenössische Debatten nicht direkt anschließbaren Begrifflichkeit sind seine Überlegungen für den Zweck der vorliegenden Abhandlung sehr hilfreich.

Bataille entwickelt seinen Begriff der Transgression innerhalb seines Konzepts des Erotismus. Der Erotismus beschreibt für Bataille die menschliche Sexualität im Gegensatz zur animalischen. Er bezeichne jene Aspekte der Sexualität, die über die tierischen Aspekte der Sexualität hinausgehen - die Aspekte, die exklusiv menschlich sind. Bataille nennt etwa das Schamgefühl, das Inzestverbot und die Keuschheit.

Was an diesen drei Beispielen auffällt, ist, dass sie alle mit Einschränkungen oder Verboten zu tun haben. Für Bataille zeichnet sich der Erotismus, menschliche Sexualität, dadurch aus, dass er durch Verbote geregelt ist. Als weiteres Beispiel dafür nennt er das mit der Ehe einhergehende Verbot der außerehelichen Sexualität. Interessanterweise sieht Bataille diese Verbote nicht als Abwertung von Sexualität. Im Gegenteil werde durch diese Verbote menschliche Sexualität im Vergleich zur tierischen aufgewertet: „C'est là justement ce qui sépare l'homme de l'animal: c'est la limite opposé à la libre activité sexuelle qui donna une valeur nouvelle à ce qui ne fut, pour l'animal, qu'une irrésistible impulsion, fuyante et pauvre de sens. (Bataille 1976, S. 40) Indem die Ehe und ihre Regeln der animalischen Sexualität Grenzen setzen, sind sie dem Erotismus nicht entgegengesetzt, sondern Teil davon. Da sich für Bataille Sexualität jedoch grundsätzlich der Regulierung entzieht, fun- 
gieren die Regeln des Erotismus als Barrieren, die insbesondere den ausgesperrten Bereich erotisch aufladen. Die eingegrenzten Bereiche würden dagegen tendenziell von erotischem Gehalt entleert, um neue Funktionen zu übernehmen. So würden im Beispiel der Ehe dann der materielle Aspekt beziehungsweise der Sicherheitsaspekt wichtiger. Erst der Regelverstoß eröffne letztlich das unbegrenzte Feld des Erotismus: »Or l'histoire de l'érotisme n'est nullement celle de l'activité sexuelle admise dans les limites définies par les règles: l'érotisme n'englobe en effet qu'un domaine délimité par l'infraction aux règles. «(Ebd., S. 108) Im Eingehen der Ehe sieht Bataille einen Übergang von der tierischen zur menschlichen Sexualität: Die Ehe sei das Eingeständnis des Menschen, eine Sexualität zu haben, die in Schach gehalten werden müsse. Rund ums Hochzeitsfest komme es deshalb zu Exzessen und Transgressionen, weil erst das Errichten der Schranken die Sexualität so richtig freisetze.

Batailles scharfer Trennung zwischen einer menschlichen und einer tierischen Sexualität liegt ein spezifisches Menschenbild zugrunde. Der Mensch sei ein Tier, das das von der Natur Gegebene negiere: »Il change ainsi le monde extérieur naturel, il en tire des outils et des objets fabriqués qui composent un monde nouveau, le monde humain." (Ebd., S. 43) Gleichzeitig negiere der Mensch das Tierische in sich, indem er sich erziehe und seinen tierischen Bedürfnissen Grenzen setze. Diese Grenzziehungen eröffneten dem Menschen dafür eine neue Möglichkeit: die Überschreitung der Grenzen. Dies habe Folgen für den Bereich des Erotismus: "Linterdit ne change pas la violence de l'activité sexuelle mais, en fondant le milieu humain, il en fait ce que l'animalité ignorait: la transgression de la règle.« (Ebd., S. 47) Erst durch das Installieren eines verbotenen Bereichs könne Sexualität einen Akt der Transgression darstellen. Es entstehe eine Opposition zwischen dem Respekt vor Grenzen und der Gewalt der Transgression, die diese überschreite: »Ce qui importe essentiellement c 'est qu'existe un milieu, si limité fût-il, où l'aspect érotique est impensable, et des moments de transgression où l'érotisme atteint la valeur de renversement la plus forte.« (Ebd., S. 48) Wie das Hochzeitsfest bezeichnet für Bataille zum Beispiel das Fest allgemein eine Situation, in der die Regeln des Alltags, des profanen Lebens in Batailles Worten, außer Kraft gesetzt sind. Anlässlich des Festes fänden verschiedene Verstöße gegen die Regeln des profanen Lebens statt, wie Verschwendung, Rausch et cetera. Bedeuten diese Transgressionen damit eine Rückkehr zum negierten animalischen Wesen des Menschen? Im Gegenteil, findet Bataille, das Fest befreie das Gottähnliche im Menschen: 
Ce qui est nié dans la vie profane (par les interdits et par le travail) est un état de dépendance de l'animal, soumis à la mort et à de très aveugles besoins. Ce qui est nié par la vie divine est toujours la dépendance, mais cette fois c'est le monde profane dont la servilité lucide et volontaire est contestée. (Bataille 1976, S. 80)

Bataille unterscheidet hier zwei verschiedene Abhängigkeiten, die der Mensch negiere: einerseits die Abhängigkeit von tierischen Bedürfnissen, die der Mensch im profanen Leben negiere; andererseits die Abhängigkeit des freiwilligen Gehorsams, die der Mensch im Fest negiere. Ebendiese letztere Negation des freiwilligen Gehorsams zeichne das gottähnliche Leben aus. Transgression, verstanden als Verstoß gegen die Ordnung des profanen Lebens, stürze den Menschen ins gottähnliche Leben.

Die Beziehung der Transgression zum gottähnlichen Leben hat zur Folge, dass das die Transgression begleitende Begehren laut Bataille immer einen Aspekt des Schreckens und der Furcht mit sich trägt. Das Begehren, das sich in der Transgression verausgabt, laufe dabei Gefahr, alles zu verlieren. Der Erotismus sei ein Heranführen des Menschen an den Abgrund des Todes, doch auf eine Weise, die Genuss bereite. Im Fest finde der Mensch so viel Freude, weil im Exzess und der Verschwendung stets der Abgrund, der Ruin lauere. Auch Kunstwerke oder die Riten der Religion könnten den Menschen an diesen Abgrund führen, damit er ihn genießen könne: »Nous ne pourrons sans cette audace opposer à la pauvreté de la vie animale les richesses de la religion et de l'art.« (Ebd., S. 95) Die Jagd oder der Krieg haben für Bataille ebenfalls den Charakter des Festes, wo der Übertritt gewisser Verbote erlaubt sei. Die Ritualhaftigkeit dieser Übertritte rücke auch sie in die Nähe des Religiösen.

Dans la sphère humaine, l'activité sexuelle se détache de la simplicité animale. Elle est essentiellement une transgression. Ce n'est pas, après l'interdit, le retour à la liberté première. La transgression est le fait de l'humanitè que l'activité laborieuse organise. La transgression est elle-même organisée. L'érotisme est dans l'ensemble une activitée organisée, c'est dans la mesure où il est organisé qu'il change à travers le temps. (Bataille 1987, S. 108)

Der Erotismus und mit ihr verbunden die Transgression sind laut Bataille also organisierte Aktivitäten, deren Formen im Laufe der Zeit variieren. Sie sind für ihn zwar anthropologische Konstanten, treten jedoch in historisch unterschiedlichem Kleid auf. 
Batailles Konzept der Transgression liefert wertvolle Einsichten: Grenzziehungen sind etwas genuin Menschliches. Erst das Ziehen von Grenzen macht allerdings auch deren Überschreitung möglich. Grenzziehungen auf dem Gebiet der Sexualität laden den ausgegrenzten Bereich erotisch auf. Akte der Transgression - das Überschreiten von Grenzen - in der Sexualität sind darum ebenso gewaltförmig wie lustvoll. Gemeinsam sind den Akten der Transgression in der Sexualität, im festlichen Ritual, im Krieg oder im religiösen Ritus die Befreiung des Subjekts von Abhängigkeit. Doch wie funktioniert das libidinöse Besetzen von Grenzen und ihre Überschreitung in einem historisch spezifischen gesellschaftlichen Kontext genau?

Der Soziologe Chris Jenks hat Batailles Werk auf diese Frage hin untersucht. Er bringt Batailles Definition von Transgression folgendermaßen auf den Punkt:

Transgression confirms limits, it shows a consciousness of limits not their absence. As such it can also integrate with power structures and resistance, it produces places for people, expectations and a sense of dependency, which is how we often come to speak about morality. (Jenks 2003, S. 95)

Jenks stellt mit Bataille hier Transgression nicht als eine zerstörerische Kraft vor, sondern als eine Kraft, die Grenzen bewusst macht und damit bestärkt. Da Grenzen oft gesellschaftlich gegeben seien, stünden transgressive Akte damit automatisch in einem Verhältnis zu Machtstrukturen. So steckten transgressive Akte gesellschaftliche Räume ab, die dann von einer Moral regiert werden könnten. Bataille gehe es um ein Umstürzen der Hierarchien, die implizit in Binaritäten wie moralisch/amoralisch, rational/irrational et cetera stecken, er zweifle die Annahme der bürgerlichen Gesellschaft an, dass gute und normale Menschen in erster Linie vernünftig agieren und ihre sexuellen Bedürfnisse unter Kontrolle haben: »For Bataille, in line with Freudian and post-Freudian developments in psychoanalysis, prefers to see the erotic, the sexual, as foremost or at least on a par with reason in the organisation of human conduct.« (Ebd., S. 97) Bataille setze den Einfluss des Sexuellen in Bezug auf das menschliche Verhalten mit der Vernunft gleich. Dies hat laut Jenks für die bürgerliche Gesellschaft zur Folge, dass Transgression ein Umstürzen der Hierarchien bedeutet. Die herrschende Klasse begehre, was sie sozial ausschließe, das gesellschaftlich Abgewertete erfülle die erotischen Fantasien der Bourgeoisie und verleite zur Transgression. Jenks beschreibt Transgression als Ergebnis des Antagonismus zwischen bürgerlicher Klasse und Arbeiterklasse: 
Power, fear and intimidation are clear components of this complex relation, yet this is transformed, symbolically, into a desire, a fascination (think of the Kray twins), an eroticisation (think of Mozart's eidetic composition and scatological diversions), and finally a way of letting-off (and think here of the carnival's drunkenness, debauchery, overeating, defecating, belching and farting). (Ebd., S. 173)

Transgression beschreibe hier den Übertritt von einer Ordnung in die andere. Jenks insistiert, dass diese karnevalesken Institutionen der Transgression nicht äußeren Zwängen entsprängen; sie seien individuelle Wege des Umgangs mit selbst auferlegten Grenzen:

Constraint is a constant experience in our action, it needs to be to render us social. Interestingly enough, however, the limits to our experience and the taboos that police them are never simply imposed from the outside; rather, limits to behaviour are always personal responses to moral imperatives that stem from the inside. This means that any limit on conduct carries with it an intense relationship with the desire to transgress that limit. (Ebd., S. 7)

Gesellschaftlich auferlegte und internalisierte moralische Zwänge setzten das Individuum immer wieder in ein libidinöses Verhältnis zu Grenzen und ihrer Überschreitung.

Mit seinem Konzept von Transgression orientiert sich Jenks stark an Bataille, indem er feststellt, dass transgressive Akte Grenzen nicht einfach negierten, sondern in der Regel bestärkten und manchmal erst erzeugten. Er geht jedoch in einem wichtigen Punkt über Bataille hinaus, indem er darauf aufmerksam macht, dass die durch Grenzen erzeugten Binaritäten moralisch/amoralisch, rational/irrational etc. nicht gleichwertig, sondern hierarchisch geordnet sind. Durch die libidinöse Besetzung des Ausgegrenzten geraten Machtverhältnisse ins Wanken. Damit benennt er einen politischen Aspekt der Transgression.

Bei Jenks wird nicht ganz klar, ob Transgression immer als revolutionäre Geste gelesen werden muss. Wenn ja, wie geht das mit Batailles Behauptung zusammen, dass Transgression Grenzen deutlich mache und bestärke? Wie ist es möglich, dass Transgression Grenzen überwindet und gleichzeitig bestärkt? 


\subsubsection{Sexualität an der Grenze des Diskursiven}

Auch Florian Zappe sieht Normierungen als binäre Systeme. Sie zeichneten sich durch Grenzziehungen aus und machten damit auch erst deren Überschreitung möglich: »Normgrenzen sind Grenzen wie alle anderen auch. Sie definieren sich durch ihr dialektisches Anderes, dessen Existenz sie nicht in Frage stellen können, weil sie sich sonst die Definitionsgrundlage ihrer eigenen Existenz entziehen würden.« (Zappe 2013, S. 49) Grenzen seien normativ konstruiert und kontextabhängig. Entsprechend sei auch ihre Überschreitung und damit Transgression abhängig von historischen, gesellschaftlichen und kulturellen Bedingungen: »Die Transgression definiert sich über ihre skandalöse Wirkung im öffentlichen Raum.« (Ebd., S. 54) Um als Transgression zu gelten, dürfe diese Überschreitung jedoch nicht zufällig oder aus Unkenntnis geschehen; zur Transgression gehört laut Zappe die bewusste dissidente Haltung dessen, der gegen die Normen verstößt:

In ihrem Gestus als bewusste, öffentliche und verbotene Überschreitung von Grenzen, Regeln und Tabus ist das Ziel der Transgression immer, die herrschende Ordnung anzugreifen, ihre Begrenzungen zu überwinden und ihre Macht zu unterlaufen. Sie hat daher immer auch eine (gesellschafts)politische Komponente, ist dabei aber auch immer mit dem schon beschriebenen Dilemma konfrontiert: Der Gefahr, unfreiwillig und entgegen der eigentlich intendierten subversiven Absicht, auch einen affirmativen Effekt zu bewirken. (Ebd.)

Hier findet sich das schon bei Jenks festgestellte Dilemma wieder, dass Transgression zwischen Umsturz und Bestärkung der herrschenden Ordnung schwankt. Zappe schlägt deshalb vor, zwei Modelle der Transgression $\mathrm{zu}$ unterscheiden, von denen er besonders das erste vom angesprochenen Dilemma der Affirmation von Grenzen betroffen sieht. Er nennt es das moderne oder humanistische Modell, das seine Wurzeln im politischen Radikalismus liberaler Prägung habe, für den der Konflikt zwischen Individuum und repressiver Gesellschaft zentral sei:

Das Modell der Transgression, das ich hier als das »moderne« oder »humanistische« einführen möchte, teilt mit diesem liberalen politischen Radikalismus zwei wesentliche Merkmale: Den Clauben an ein potentiell authentisches und autonomes Subjekt sowie die Verwurzelung im binären Denken. (Ebd., S. 57) 
Moderne oder humanistische Konzepte der Transgression basieren also laut Zappe auf der Vorstellung eines autonomen Subjekts. In ihnen schwinge immer die Vorstellung mit, dass dem Menschen von der Gesellschaft eine Art falsches Bewusstsein auferlegt werde, von dem er sich durch transgressives Verhalten zugunsten einer wahren oder authentischen Subjektivität befreien könne. Vom modernen oder humanistischen Modell der Transgression unterscheidet Zappe ein postmodernes Modell der Transgression. Dieses verabschiede sich von der Privilegierung des von der Mehrheitskultur ausgegrenzten Außen. Gemäß diesem Modell eröffne Transgression auf der Normgrenze einen hybriden Zwischenraum, wo sich Innen und Außen kontaminieren:

Bei den auf das Hybride abzielenden Transgressionen kann es nicht darum gehen, einen Ort außerhalb der den gesellschaftlichen Normalisierungsprozessen unterworfenen Spielräumen von Identität und Erfahrung in einem authentischen Jenseits zu suchen - eben weil dieser ebenfalls als Entwurf verstanden wird. Vielmehr wird die Kategorie des Zwischen, die sich erst durch die gewaltsame Überschreitung (hier sei an den Unterschied zwischen Schwellen- und Grenzerfahrung erinnert) der Grenze eröffnet, als möglicher Ort des Widerstandes angesehen. (Ebd., S. 59f.)

Die Kategorie des Zwischen macht in Zappes Konzeption einen Ort auf, wo Normierungs- und Authentizitätsansprüche unterlaufen werden und etwas Neues entstehen kann. Dieses Neue sei jedoch hybride und nicht stabil:

Da Crenzziehungsakte ebenso wie Transgressionen als performativ zu verstehen sind, sind die im durch die Überschreitung eröffneten »dritten Raum« entstandenen Hybridisierungen ebenfalls nicht stabil und prinzipiell jederzeit veränderbar. Anders als die Kategorien im binären System können sie ob ihres Charakters als Vermischungen keine Fiktion von Reinheit, Stabilität und Essentialität aufbauen. Sie müssen permanent neu ausgehandelt werden. (Ebd., S. 64)

Um dieses postmoderne Modell der Transgression besser verständlich $\mathrm{zu}$ machen, verweist Zappe auf kunsttheoretische Diskurse. In der Kunst ist die Geste der Transgression gemäß Zappe ein Kennzeichen der Avantgarde. So haben wir sie ja auch beim Cinema of Transgression kennengelernt. Da sich Avantgarde als Gegenkultur verstehe, setze sie auf Strategien der Überschreitung dessen, was in einer bestimmten Zeit als Kunst verstanden werde: "Somit ist Avantgarde Grenzgang, ein Wandeln auf und über Grenzen. Jede avantgardistische Geste kann als transgressiv bezeichnet werden, aber nicht 
jede transgressive Geste ist im Umkehrschluss avantgardistisch." (Ebd., S. 65) Nicht jede transgressive Geste sei avantgardistisch, da sich Transgression auch außerhalb künstlerischer Programme wie der Avantgarde finde. Transgression sei aber für die Avantgarde eine zentrale Strategie, weil sie sich ästhetisch über Geschmacksgrenzen hinwegsetze und die Trennung von Kunst und lebensweltlichem Alltag in Frage stelle: »Der Versuch, die Trennlinie von Kunst- und Lebenspraxis zu überschreiten, verleiht jeder avantgardistischen Geste zunächst unabhängig von Form und Inhalt transgressiven Charakter.« (Ebd., S. 69) Transgression stelle Trennlinien in Frage, um ästhetisch Neues zu kreieren.

Zappe bringt in unsere Diskussion der Transgression eine wichtige Unterscheidung ein: Er differenziert zwischen modernen oder humanistischen Konzepten der Transgression, die auf der Vorstellung eines autonomen Subjekts basieren, und einem postmodernen Konzept der Transgression, das auf Hybridität abzielt. Im postmodernen Konzept eröffnet Transgression auf der Normgrenze einen Zwischenraum, der durchlässig sowohl gegenüber dem Ein- wie dem Ausgegrenzten ist, sodass etwas Neues entstehen kann. Zappe interessiert sich also im Gegensatz zu Jenks weniger für das Umstürzen von Hierarchien, sondern eher für das Durchlässigwerden von Grenzen zur Produktion neuer Identitäten und Erfahrungen, wodurch wiederum Hierarchien unterlaufen werden können. In diesem Konzept hilft also Transgression den Subjekten, sich gegenüber neuen Identitäten und Erfahrungen zu öffnen.

Für mein Vorhaben ist Zappes Konzeption wichtig, weil sie im Gegensatz zu Bataille nicht mehr essenzialisierend einen Erotismus voraussetzt. Denn Bataille konstruiert diesen in seinen überwältigenden und zerstörerischen Formen als letztlich antisozialen Trieb, der von der Gesellschaft in zivilisierte Formen gezwängt werden muss durch Normen, deren Übertretung dann sanktioniert wird. Wenn ich mich dagegen an Zappes Konzeption halte, reicht es anzunehmen, dass die bloße Existenz von Normen und gesellschaftlich sanktionierten Formen der Sexualität wiederum Formen der Sexualität heraufbeschwört, die ebendiese Normen in Frage stellen und deren Übertretung mit Begehren besetzen.

Mit der Kritik an modernen oder humanistischen Konzepten der Transgression knüpft Zappe an Foucaults These an, wonach die bürgerliche Moderne in der Sexualität die wahre Identität des Subjekts vermutet und diese dadurch selbst produziert. Doch gibt es in Foucaults Konzeption überhaupt einen Platz für das Aufbegehren gegen diese Identitätsentwürfe des Subjekts in der Sexualität? Gemäss Foucault kanalisiert die Moderne Lust in einem binä- 
ren System von Normierungen, die laut Zappe als Grenzziehungen auch deren Überschreitung möglich machen: »Wenn Sexualität ein zentrales Feld der Produktion von Individualidentitäten ist, kann sie natürlich auch als Schauplatz für Überschreitungen dienen, die sich gegen diese Entwürfe richten.« (Ebd., S. 48)

In seiner Vorrede zur Überschreitung (Foucault 2001) stellt Foucault die These auf, dass die moderne Sexualität sich an der Grenze des Diskursiven befindet. Während Sexualität in der christlichen Welt des Mittelalters in ein umfassendes mystisches und spirituelles Konzept eingebunden gewesen sei, sei sie in der Sprache der Moderne so weit entmystifiziert worden, dass sie nur noch eine Grenze markiere, den Tod Gottes:

So zeichnet sich auf dem Grunde der Sexualität, ihrer durch nichts jemals begrenzten Bewegung (denn von ihrem Ursprung an und in ihrer Ganzheit ist diese Bewegung beständiges Begegnen der Crenze), und dieser Reden über Cott, die das Abendland seit so langer Zeit gehalten hat - ohne sich je klarzumachen, dass »wir der Sprache nicht ungestraft das Wort hinzufügen können, das über die Wörter hinausgeht « und dass wir durch dieses Wort an die Grenzen jeder möglichen Sprache versetzt werden -, eine einzigartige Erfahrung ab: die Erfahrung der Überschreitung. (Foucault 2001, S. 324)

Foucault verankert die Möglichkeit, Überschreitung zu erfahren, in der Sexualität. Dadurch greift er einen Kerngedanken Batailles auf. Wie Bataille behauptet Foucault, dass erst im Moment des Überschreitens die Grenze wahrhaft existiere:

Die Überschreitung treibt die Grenze bis an die Grenze ihres Seins; sie bringt sie dazu, im Moment ihres drohenden Verschwindens aufzuwachen, um sich in dem wiederzufinden, was sie ausschließt (genauer vielleicht, sich darin zum ersten Mal zu erkennen), und um ihre tatsächliche Wahrheit in der Bewegung ihres Untergangs zu erfahren. (Ebd., S. 325)

Foucault versteht hier Transgression nicht als ein Überschreiten von einem negativen Pol zu einem positiven Pol hin. Transgression sei affirmativ, sie bejahe das Begrenzte, das Unbegrenzte und vor allem die Grenze selbst. Im Denken der Grenze, im Reden über Transgression komme jedoch das sprechende Subjekt selbst an eine Grenze, an die Grenzen seiner Sprache. Dies habe Konsequenzen: Wenn Sexualität die Erfahrung der Überschreitung ermögliche, das Sprechen über diese Erfahrung das Subjekt aber an die Grenzen seiner Sprache führe, dann führe Sexualität das Subjekt an die Grenze 
der Auflösung seiner selbst. Sexualität - und damit folgt Foucault Bataille enthülle nicht eine animalische Wahrheit des Subjekts, sondern bringe die moderne Subjektkonstitution ins Wanken:

Durch sie kommunizieren wir folglich nicht mit der geordneten und glücklich profanen Welt der Tiere; vielmehr ist sie ein Riss: er läuft nicht um uns herum, um uns einzugrenzen oder zu bezeichnen, sondern um die Grenze in uns zu ziehen und uns selbst als Grenze zu entwerfen. (Ebd., S. 320f.)

In der Sexualität, so wie sie in der Moderne konzipiert wird, findet sich laut Foucault der Auftrag, eine nicht dialektische Sprache zu entwickeln, die nicht über Widersprüche funktioniert. Er fasst zusammen:

Vielleicht ist das Auftauchen der Sexualität in unserer Kultur ein Ereignis von vielfältigem Wert: Sie ist an den Tod Cottes und an jene ontologische Leere gebunden, die dieser an den Crenzen unseres Denkens hinterlassen hat. Sie ist ebenso an das noch stimmlose und tastende Auftauchen einer Form des Denkens gebunden, in der das Fragen nach der Grenze an die Stelle einer Suche nach der Totalität tritt und in der die Ceste der Überschreitung die Bewegung von Widersprüchen ersetzt. Sie ist schließlich an eine Infragestellung der Sprache durch sich selbst gebunden in einer Zirkularität, die die »skandalöse « Cewalt der erotischen Literatur, weit davon entfernt, sie zu brechen, von ihrer ersten Verwendung von Wörtern an kundtut. (Ebd., S. 340)

Foucault macht also die Entstehung der Sexualität in der Konzeption der bürgerlichen Moderne an drei Faktoren fest: Ein Faktor ist der Verlust des Eingebundenseins in eine göttliche Ordnung. Ein zweiter ist der Übergang von einem dialektischen Denken hin zu einem Denken der Grenzen und ihrer Überschreitung. Ein dritter Faktor ist eine zirkuläre Sprachkritik, von der er die erotische Literatur durchdrungen sieht.

Für mich ist wichtig, dass Foucault, der in vielen Texten die Normiertheit von Sexualität betont, in diesem Text der Sexualität transgressiven Charakter attestiert. Zudem konzipiert er Transgression nicht als Überschreitung einer Grenze zwischen zwei Polaritäten, sondern als Bejahung des Ortes der Grenze, in der die Widersprüche für einen Moment aufgehoben sind. Das entspricht dem postmodernen Modell der Transgression bei Zappe. Als weiteren interessanten Punkt erachte ich, dass laut Foucault in der Sexualität der Keim zur Auflösung des Subjektverständnisses der bürgerlichen Moderne liegt. In diesem Punkt trifft sich Foucault nämlich mit dem Begründer der Psychoana- 
lyse Sigmund Freud und dessen Konzeption von Sexualität. Mit dieser möchte ich mich als Nächstes auseinandersetzen.

\subsubsection{Triebunterdrückung durch Kulturanforderungen}

Einen Angriff auf das Subjektverständnis der bürgerlichen Moderne stellt schon die Tatsache dar, dass Freud sich ausführlich mit der frühkindlichen Sexualität und deren Auswirkungen auf die Psyche des erwachsenen Menschen beschäftigt. In seiner Konzeption zeigt sich eine Parallele zu Bataille: Freud postuliert ein primäres Ichgefühl, das allumfassend ist. Im Lauf der Entwicklung schrumpft dieses, indem es die Außenwelt von sich abscheidet: »Unser heutiges Ichgefühl ist also nur ein eingeschrumpfter Rest eines weit umfassenderen, ja - eines allumfassenden Gefühls, welches einer innigeren Verbundenheit des Ichs mit der Umwelt entsprach." (Freud 2009, S. 35) Die Bewegung geht gemäß Freud also von einem umfassenden primären Ichgefühl hin zu einem durch die Errungenschaften der Zivilisation eingegrenzten. Damit gleicht sie der von Bataille postulierten zivilisatorischen Einhegung eines ursprünglich alles bejahenden Erotismus. Freud zufolge sind Menschen von Natur aus "polymorph pervers« veranlagt:

Es ist lehrreich, dass das Kind unter dem Einfluss der Verführung polymorph pervers werden, zu allen möglichen Überschreitungen verleitet werden kann. Dies zeigt, dass es die Eignung dazu in seiner Anlage mitbringt; die Ausführung findet darum geringe Widerstände, weil die seelischen Dämme gegen sexuelle Ausschreitungen, Scham, Ekel und Moral, je nach dem Alter des Kindes noch nicht aufgeführt oder erst in Bildung begriffen sind. (Freud 1991, S. 93)

Fehlten diese »Dämme«, tendierten auch Erwachsene zu sexuellen Überschreitungen, was Freud am Beispiel der Prostitution deutlich macht:

Die nämliche polymorphe, also infantile Anlage beutet dann die Dirne für ihre Berufstätigkeit aus, und bei der riesigen Anzahl der prostituierten Frauen und solcher, denen man die Eignung zur Prostitution zusprechen muss, obwohl sie dem Berufe entgangen sind, wird es endgültig unmöglich, in der gleichmäßigen Anlage zu allen Perversionen nicht das allgemein Menschliche und Ursprüngliche zu erkennen. (Ebd.)

In diesem Zitat geht es mir nicht um das darin enthaltene fragwürdige Frauenbild. Ich finde hier wichtig, dass Freud deutlich macht, dass die »seelischen 
Dämme« gegen sexuelle Überschreitungen fehlen können; das heißt, sie sind nicht im Menschen angelegt, sondern stellen kulturelle Errungenschaften dar. Freud zufolge ist unsere Kultur auf Triebunterdrückung aufgebaut. Die sexuellen Triebe des Individuums verschwänden durch diese Unterdrückung jedoch nicht, sondern würden abgelenkt, sublimiert. Insbesondere die perversen, also nicht der Fortpflanzung dienenden sexuellen Triebe würden im günstigsten Fall zur Kulturarbeit verwendet. So bilde sich ein stufenförmiges Modell der Kulturentwicklung:

Mit Bezug auf diese Entwicklungsgeschichte des Sexualtriebes könnte man also drei Kulturstufen unterscheiden: eine erste, auf welcher die Betätigung des Sexualtriebes auch über die Ziele der Fortpflanzung hinaus frei ist; eine zweite, auf welcher alles am Sexualtrieb unterdrückt ist bis auf das, was der Fortpflanzung dient, und eine dritte, auf welcher nur die legitime Fortpflanzung als Sexualziel zugelassen wird. Dieser dritten Stufe entspricht unsere gegenwärtige »kulturelle« Sexualmoral. (Freud 2009, S. 118)

Bereits die zweite Kulturstufe schließt laut Freud gleichgeschlechtliche und andere sexuelle Triebe, die nicht auf die Fortpflanzung gerichtet sind, aus. Dies zwinge die Individuen zur Sublimierung dieser Triebe. Individuen, bei denen solche Triebe besonders ausgeprägt vorkämen, gelinge diese Sublimierung jedoch nicht vollkommen. Sie lebten dann die Triebe im Versteckten aus oder würden neurotisch. Den unterschiedlichen Ausprägungen des Sexualtriebs beim Individuum werde die Kulturentwicklung demnach nicht gerecht.

Es ist eine der offenkundigen sozialen Ungerechtigkeiten, wenn der kulturelle Standard von allen Personen die nämliche Führung des Sexuallebens fordert, die den einen dank ihrer Organisation mühelos gelingt, während sie den anderen die schwersten psychischen Opfer auferlegt, eine Ungerechtigkeit freilich, die zumeist durch Nichtbefolgung der Moralvorschriften vereitelt wird. (Ebd., S. 119)

Dieselben Folgen zeitige in drastischerem Ausmaß die Einschränkung der sexuellen Triebe auf die legitime, also innerhalb der Ehe stattfindende, Fortpflanzung. Die kulturelle Verurteilung aller Individuen zur Abstinenz, die nicht gerade innerhalb einer Ehe ein Kind zeugen wollten, führe zu Doppelmoral oder Krankheit. Zudem tendiere die Kultur dazu, nicht bloß Nützliches $\mathrm{zu}$ fordern, sondern sie stelle auch strenge Anforderungen in anderen Bereichen: »Schönheit, Reinlichkeit und Ordnung nehmen offenbar eine besondere Stellung unter den Kulturanforderungen ein.« (Ebd., S. 59) Mit diesen umfas- 
senden Regulierungen gehen die Kulturanforderungen für Freud oft zu weit. Die strengen kulturellen Regulierungen des Sexualtriebs seien nicht durchzusetzen. So müsse die Kultur letztendlich viele Überschreitungen der von ihr aufgestellten Regeln tolerieren. Die Regeln der Kultur würden jedoch über die Installierung eines Über-Ich im Individuum verankert und verinnerlicht. Bei den Regeln entgegengesetzten Wünschen oder gar der Nichtbefolgung der Regeln melde sich das Über-Ich in Form von Schuldbewusstsein.

Für Freud befinden sich die individuellen Triebe und die Kultur in einem dauernden Kampf. Es ist der Kampf des Lustprinzips gegen das Realitätsprinzip. Allzu hohe Ansprüche der Kultur an das Individuum förderten die Herausbildung von Neurosen, denn Aggressions- und Sexualtriebe verschwänden durch Unterdrückung nicht, sondern verwandelten sich: »Wenn eine Triebstrebung der Verdrängung unterliegt, so werden ihre libidinösen Anteile in Symptome, ihre aggressiven Komponenten in Schuldgefühl umgesetzt.« (Ebd., S. 101) Alles in allem fragt sich Freud, ob die kulturelle Sexualmoral die Opfer wert ist, die sie den Individuen auferlegt.

Wir finden also bei Freud eine Konzeption von Sexualität vor, die zwar starken Einschränkungen und Umformungen unterliegt, aber die nicht dauerhaft und ohne schädliche Auswirkungen unterdrückt werden kann. Entsprechend sind Überschreitungen, Transgressionen aller Art vorprogrammiert. Diese Transgressionen werden allerdings nicht von einem autonomen Subjekt vorgenommen, sondern von einem Subjekt, das in sich gespalten und zerrissen ist. Dass diese Zerrissenheit des Subjekts auch eine geschichtliche Komponente hat, lässt sich mit Herbert Marcuse aufzeigen. Kultur ist beim Philosophen Marcuse keine abstrakte Größe, sondern hat eine konkrete historische Gestalt. Freuds Konzeption liefert Marcuse die Erklärung dafür, wie Herrschaft durch Selbstunterdrückung unterstützt wird:

Das unfreie Individuum introjiziert seine Herren und deren Befehle in seinen eigenen psychischen Apparat. Der Kampf gegen die Freiheit wiederholt sich in der Seele des Menschen als Selbstunterdrückung des unterdrückten Individuums, und die Selbstunterdrückung wiederum stützt die Herrschenden und ihre Institutionen. (Marcuse 1979, S. 23)

Das Individuum bewahre allerdings Erinnerungen an einen Zustand der Freiheit im Unbewussten; daraus nähre sich der Anspruch, diesen Zustand wiederzuerlangen. Schon Freud spricht von der Überstrenge der Kulturanforderungen. Marcuse führt nun den Begriff der zusätzlichen Unterdrückung ein. Er bezeichnet damit die durch die geschichtliche Form der sozialen Herr- 
schaft geforderten Triebverzichte. Davon ist die primäre Unterdrückung der Triebe, die Kulturentwicklung überhaupt erst ermöglicht, zu unterscheiden.

Und mehr noch, während jede Form des Realitätsprinzips ein beträchtliches Maß an unterdrückender Triebkontrolle erfordert, führen die spezifischen historischen Institutionen des Realitätsprinzips und die spezifischen Interessen der Herrschaft zusätzliche Kontrollausübungen ein, die über jene hinausgehen, die für eine zivilisierte menschliche Cemeinschaft unerlässlich sind. Diese zusätzliche Lenkung und Machtausübung, die von den besonderen Institutionen der Herrschaft ausgehen, sind das, was wir als zusätzliche Unterdrückung bezeichnen. (Ebd., S. 39f.)

Das Realitätsprinzip kann laut Marcuse verschiedene historische Formen annehmen. Die aktuelle historische Form des Realitätsprinzips benennt Marcuse als Leistungsprinzip. Denn die heutige Gesellschaft sei nach dem Prinzip ihrer ökonomischen Leistungsfähigkeit geschichtet. Das Leistungsprinzip zwinge das Individuum, seine Triebenergie in Arbeit umzuleiten. Auch für die Organisation der Sexualität habe das Leistungsprinzip Konsequenzen. Die Libido konzentriere sich auf genitale Sexualität: »Dieser Prozess erreicht die sozial notwendige Desexualisierung des Körpers: die Libido wird in einem Teil des Körpers konzentriert, wodurch fast der ganze übrige Körper zum Gebrauch als Arbeitsinstrument frei wird.« (Ebd., S. 48)

Wie bei Freud entwickelt das Individuum auch in Marcuses Konzept aus einer ursprünglich polymorph-perversen Sexualität eine der Fortpflanzung dienende gesellschaftlich akzeptierte Sexualität und daneben mit Tabus belegte sexuelle Perversionen. Letztere haben laut Marcuse eine tiefe Verbindung zur Fantasie, da sie gegen das Realitätsprinzip ankämpfen:

In Herausforderung einer Cesellschaftsordnung, der die Sexualität als Mittel zu einem nützlichen Zweck dient, verteidigen die Perversionen die Sexualität als Zweck an sich; sie stellen sich damit außerhalb des Herrschaftsgebietes des Leistungsprinzips und bedrohen es in seinen Crundfesten. (Ebd., S. 50)

Marcuse greift Freuds Begriff des primären Narzissmus auf, der für ein Gefühl der Unbegrenztheit und Verbundenheit mit allem steht. Seiner Ansicht nach lässt sich auf diesem von Freud auch ozeanisch genannten Gefühl ein anderes Verhältnis zur Welt begründen, eines, welches das Leistungsprinzip umgehen könnte. 
Das verblüffende Paradox, dass der Narzissmus, der im allgemeinen als egoistischer Rückzug vor der Wirklichkeit verstanden wird, hier mit der Verbundenheit mit dem All in Zusammenhang gebracht wird, verrät die neuen Tiefen des Begriffs: jenseits aller unreifen Autoerotik bezeichnet der Narzissmus eine fundamentale Bezogenheit zur Realität, die eine umfassende existentielle Ordnung schaffen könnte. (Ebd., S. 146f.)

Marcuse schlägt vor, das Realitätsprinzip von der zusätzlichen Unterdrückung zu befreien. Dies würde eine Neuorganisation der Arbeitsverhältnisse ermöglichen, in denen die Menschen freier und weniger verdinglicht wären. In den sexuellen Beziehungen würde in der Konsequenz das Tabu auf die Verdinglichung des Körpers gelockert, der Körper würde resexualisiert, die Institution der monogamen und patriarchalen Familie würde verschwinden. Dennoch würde diese Befreiung der Libido nicht zur völligen Aufhebung der Kultur führen, Marcuse spricht in diesem Zusammenhang von der Selbstsublimierung der Sexualität: »Diese Formulierung besagt, dass die Sexualität unter bestimmten Bedingungen höchst kultivierte menschliche Beziehungen begründen kann, ohne der repressiven Organisation unterworfen $\mathrm{zu}$ sein, wie sie die heute geltende Kultur über die Triebe verhängt.« (Ebd., S. 176)

Wie fügen sich die hier bei Marcuse und Freud herausgearbeiteten Elemente in meine auf Foucault und Bataille aufbauende Konzeption von Sexualität und Transgression ein? Auf den ersten Blick scheinen sich Freuds und Foucaults Auffassungen von Sexualität $\mathrm{zu}$ widersprechen. Freud und in seiner Nachfolge Marcuse gehen beide von einem gegebenen Sexualtrieb aus, der durch Kulturanforderungen eingeschränkt wird. Während Freud bloß vorschlägt, die Kulturanforderungen grundsätzlich etwas zu lockern, um die Herausbildung von Neurosen zu vermindern, verleiht Marcuse dieser Forderung eine konkrete historische Gestalt. Seine These ist, dass das Individuum vom Realitätsprinzip in der aktuellen historischen Form des Leistungsprinzips dazu gezwungen wird, seine Triebenergie in Arbeit für andere umzuleiten und die Libido auf gegengeschlechtliche genitale Sexualität zu beschränken. Marcuses Ansicht nach müssen wir diese historische Form der Anforderungen des Realitätsprinzips nicht hinnehmen. Er plädiert für ein von zusätzlicher Unterdrückung befreites Realitätsprinzip, das sowohl die Entfremdung des Individuums von seiner Arbeit wie auch Monogamie und Patriarchat aufheben würde.

Mit Foucault lassen sich diese Aussagen als Beispiele für die sogenannte Repressionshypothese lesen, die besagt, in der modernen bürgerlichen Ge- 
sellschaft werde die Sexualität des Individuums unterdrückt und müsse befreit werden. Dieser Hypothese hält Foucault entgegen, dass Sexualität in der bürgerlichen Gesellschaft durch einen Willen zum Wissen erst produziert werde. Meines Erachtens sind jedoch diese beiden Thesen einander nur scheinbar entgegengesetzt. Über den Begriff der Transgression lassen sie sich annähern.

Auf der einen Seite impliziert die Repressionshypothese bei Freud und Marcuse nicht automatisch einen liberalen oder humanistischen Transgressionsbegriff, um Zappes Terminologie zu gebrauchen. Denn erstens betonen sowohl Freud als auch Marcuse, wie unter den gegenwärtigen Kulturanforderungen bereits von der Triebstruktur ausgelöste Transgressionen stattfinden, etwa in der Herausbildung von Neurosen oder gewaltförmigen Ausbrüchen. Zweitens reden beide nicht einer vollständigen Befreiung des Sexualtriebs das Wort, wie es dem liberalen oder humanistischen Modell der Transgression entsprechen würde, in welchem sich das autonome Subjekt durch transgressives Handeln von falschem Bewusstsein befreit. Wie bei Freud fehlen auch bei Marcuse die zwei Grundpfeiler dieses Modells: der Glaube an ein autonomes Subjekt und das Denken innerhalb einer binären Struktur. Zappes postmodernes Modell der Transgression, das von einem gespaltenen Subjekt ausgeht, das im Akt der Transgression einen hybriden Zwischenraum eröffnet, scheint Freuds und Marcuses Konzeptionen besser zu entsprechen.

Auf der anderen Seite macht Foucault in seiner Vorrede zur Überschreitung klar, dass Sexualität für ihn mehr ist als bloß ein Produkt von Normen der bürgerlichen Moderne, sondern auch den Verlust des Eingebundenseins des Menschen in eine göttliche Ordnung markiert. Sexualität führt das Subjekt laut Foucault an die Grenze seiner eigenen Auflösung. So ist auch in Foucaults Konzeption Sexualität der Ort, wo über Transgressionen das autonome bürgerliche Subjekt in Frage gestellt ist.

\subsubsection{Subjektivierung und Geschlechtsidentität}

Als wesentliche Bestandteile heutiger sexueller Normen habe ich Intimität und Zweigeschlechtlichkeit herausgearbeitet. Wie lässt sich Transgression in Bezug auf diese beiden Elemente denken? Antworten darauf liefern Ansätze der Philosophin und Geschlechtertheoretikerin Judith Butler, die ich im Folgenden vorstellen möchte.

Butler untersucht, wie Machtstrukturen in der Gesellschaft die psychische Struktur von Individuen prägen. Über die psychische Struktur beeinflussen 
sie deren Körperwahrnehmung und soziale Interaktion. Ausgangspunkt von Butlers politischer Theorie ist der Machtbegriff, wie ihn Foucault in Überwachen und Strafen verwendet. Laut Foucault ist Macht nicht instrumentell; sie kann nicht von einem oder mehreren Einzelnen gezielt über andere ausgeübt werden (vgl. Foucault 1976, S. 38). Er sieht alle Individuen eingebunden in dezentrale Machtstrukturen, innerhalb derer sich Macht zwar verlagern kann, aus denen jedoch kein gänzlicher Ausbruch möglich ist: »Der Mensch, von dem man uns spricht und zu dessen Befreiung man einlädt, ist bereits in sich das Resultat einer Unterwerfung, die viel tiefer ist als er.« (Ebd., S. 42) Hier knüpft Butler an. Sie spricht von Subjektivation, das heisst vom Subjekt, das im Wortsinn gesellschaftlichen Kräften unterworfen ist, gegen die es sich nicht wehren kann: "Subjektivation besteht eben in dieser grundlegenden Abhängigkeit von einem Diskurs, den wir uns nicht ausgesucht haben, der jedoch paradoxerweise erst unsere Handlungsfähigkeit ermöglicht und erhält.« (Butler 2001, S. 8) Diese gesellschaftlichen Kräfte prädefinieren laut Butler Identitätskonstanten des Subjekts, wie zum Beispiel dessen Geschlechtsidentität. Doch wie kann ein gesellschaftlicher Diskurs Geschlechtsidentität prädefinieren, die doch scheinbar vor allem durch anatomische Differenz definiert ist?

Butler wendet sich ab vom Konzept der Unterscheidung eines diskursiven oder kulturellen Geschlechts (Gender) von einem biologischen Geschlecht (Sex). Diese Trennung war ein zentraler Punkt der feministischen Kritik am biologischen Determinismus, der aus einer anatomischen Differenz verschiedene gesellschaftliche Rollen für die Geschlechter ableitet. Die Sex/GenderUnterscheidung gesteht Männern und Frauen bei der gesellschaftlichen Interpretation ihres biologischen Geschlechts zwar einen viel größeren Spielraum zu, als dies der biologische Determinismus tut, jedoch bleibt bei allem Interpretationsspielraum die biologische Geschlechterdifferenz selbst unangetastet. Butlers Vermutung ist nun, dass der Ausschluss der biologischen Geschlechterdifferenz aus der diskursiven Sphäre politische Motive hat. Wer profitiert davon, die biologische Geschlechterdifferenz in eine vordiskursive Sphäre zu verlegen?

Eine Antwort auf diese Frage bedingt, dass das biologische Geschlecht nicht als eine unveränderliche anatomische Konstante für einen Diskurs über Geschlechtsidentität gesehen wird, sondern als Effekt dieser Diskurse ins Auge gefasst wird. Butler stellt also die Frage: 
Wie müssen wir dann die »Ceschlechtsidentität« reformulieren, damit sie auch jene Machtverhältnisse umfasst, die den Effekt eines vordiskursiven Ceschlechts (sex) hervorbringen und dabei diesen Vorgang der diskursiven Produktion selbst verschleiern? (Butler 1991, S. 24)

Dazu reformuliert Butler das alte philosophische Problem der personalen Identität. Statt nach einem inneren Merkmal für die kontinuierliche Identität der Person in der Zeit zu suchen, fragt sie nach gesellschaftlichen Regulierungsverfahren, welche die kulturelle Intelligibilität von personaler Identität sicherstellen. Butler geht davon aus, dass eine kontinuierliche personale Identität eher einem gesellschaftlichen Ideal und damit gesellschaftlichen Standards und Normen verpflichtet ist als einer inneren Konstante. Personen müssen über längere Zeiträume hinweg immer wieder als dieselben identifiziert werden können, ihre Identität muss gewissen Standards entsprechen, welche die Gesellschaft ablesen und verstehen kann. Um diese Verstehbarkeit der personalen Identität sicherzustellen, greift die Gesellschaft zu bestimmten Regulierungsverfahren. So weit hat auch schon Foucault gedacht. Neu ist Butlers Behauptung, die Intelligibilität der personalen Identität werde über das Konstrukt der Geschlechtsidentität sichergestellt. Geschlechtsidentität wäre dann das Instrument, mit dem die Gesellschaft die Identität der Person reguliert. Diese Regulierung geschieht nach Butler über eine nicht erreichbare Norm, ein regulatives Ideal.

Welches ist nun das regulative Ideal der Geschlechtsidentität? Was macht die für die Gesellschaft intelligible personale Identität aus? Laut Butler ist die Identität einer Person dann verstehbar, wenn ein stabiles Kontinuum bestehe zwischen anatomischem Geschlecht (Sex), Geschlechtsidentität (Gender), sexuellem Begehren und sexueller Praxis (vgl. ebd., S. 38): Das heiße für eine Person mit männlicher Anatomie, dass sie eine männliche Geschlechtsidentität auszubilden habe, demzufolge Frauen begehre und mit Frauen schlafe. Eine Person mit weiblicher Anatomie habe entsprechend eine weibliche Identität zu entwickeln, Männer zu begehren und mit Männern zu schlafen. Personen, die in einem oder mehreren der vier Fixpunkte Sex, Gender, Begehren und Praxis aus dem beschriebenen Kontinuum ausbrechen, werden gemäß Butler ausgegrenzt, da ihre Identität von der Gesellschaft nicht mehr verstanden wird. Personen, die aufgrund solcher Diskontinuitäten keine verstehbare Identität mehr hätten, also aus den gesellschaftlichen Kategorien herausfielen und dementsprechend bekämpft würden, seien im Wortsinn queer, also schräg, komisch, sie stünden quer zur Normalität: 
Die Cespenster der Diskontinuität und Inkohärenz, die ihrerseits nur auf dem Hintergrund von existierenden Normen der Kohärenz und Kontinuität denkbar sind, werden ständig von jenen Gesetzen gebannt und zugleich produziert, die versuchen, ursächliche oder expressive Verbindungslinien zwischen dem biologischen Geschlecht, den kulturell konstituierten Geschlechtsidentitäten und dem »Ausdruck« oder »Effekt« beider in der Darstellung des sexuellen Begehrens in der Sexualpraxis zu errichten. (Ebd.)

Mich interessiert bei Butler, wie sie die bisher erarbeiteten Thesen zur Normierung von Sexualität entscheidend erweitert. Foucault Sexualität als Ort, an dem in der bürgerlichen Moderne die Wahrheit des Subjekts gesucht wird. Butler rückt die Bedingungen, unter denen ein Individuum zum geschlechtlich bestimmten Subjekt wird, ins Zentrum ihrer Analyse. Sie kritisiert die Verlegung der Geschlechtsidentität in eine vordiskursive Sphäre als politisch motiviert. Mit Bourdieu habe ich bereits die Zweigeschlechtlichkeit als wesentlichen Bestandteil heutiger sexueller Normen benannt. Sie ist das Ergebnis eines sexuellen Begehrens, das auf einem Objektstatus der Frau basiert. Butler beschreibt den Prozess der Subjektivierung als Unterwerfung unter ein regulatives Ideal der Geschlechtsidentität. Wie vollzieht sich diese Unterwerfung genau, und wie trägt sie zur Herausbildung des Subjekts bei?

Zur Beantwortung dieser Frage nimmt Butler Bezug auf den Abschnitt über Herrschaft und Knechtschaft in Hegels Phänomenologie des Geistes (Hegel 1970, S. 145-177). Sie sieht den Knecht als Körper des Herrn, da der Herr seinen eigenen Körper und dessen potenzielle Arbeitsfähigkeit verleugne und den Knecht an dessen Stelle einsetze (vgl. Butler 2001, S. 38). Da der Knecht dem Erzeugnis seiner Arbeit seine Signatur aufpräge, sei es für den Herrn schwierig, dieses als seins zu betrachten. Selbst nach der Enteignung trage das Erzeugnis die Signatur des Knechts auf sich. Der Herr könne den Knecht also nur wirklich enteignen, indem er diese Signatur überschreibe. Des Knechts Lektüre dieser Signatur sei deshalb eine Lektüre der Auslöschung (vgl. ebd., S. 41). Der Knecht gewinne eine Erkenntnis seiner selbst über das Anerkennen seiner eigenen Auslöschung. Dies ist laut Butler die Erfahrung der absoluten Furcht, die der Knecht dem Herrn voraushat und die ihn auch nicht verlässt, wenn er sich aus dem Herrschaftsverhältnis befreit hat. Sie äußere sich beim befreiten Knecht nun als unglückliches Bewusstsein, dem der Knecht vergeblich zu entfliehen versuche (vgl. ebd., S. 44). Die Flucht führe zuerst in die Eigensinnigkeit. Da ein durch die Arbeit des Körpers geformtes Ding am Ursprung der absoluten Furcht stehe, beziehe sich das unglückliche 
Bewusstsein in Ablehnung dieses Körpers auf sich selbst: Der Knecht flüchte sich in die Selbstreflexivität (vgl. ebd., S. 45). Diese produziere Normen als Verteidigung gegen die Furcht, was bei Hegel Genese der ethischen Sphäre genannt werde; die Normen der ethischen Sphäre, exemplifiziert in Kants Kategorischem Imperativ, würden selbst so absolut, wie die Furcht es war, vor der sie schützen sollten. Aufgrund seiner Absolutheit verkomme Kants kategorischer Imperativ zu etwas rein Begrifflichem und tauge nicht mehr, um die vom Körper ausgehende Furcht im Zaum zu halten. Die wandelbare Sphäre der Körperlichkeit stehe der unwandelbaren Sphäre der Begrifflichkeit entgegen (vgl. ebd., S. 47f.). Um diesem Zwiespalt zu entkommen, versuche der Knecht seinen Körper in den Dienst der Unwandelbarkeit zu stellen, und zwar in der Andacht. Die Andacht verwandle allerdings nur den Körper in das Unwandelbare und führe zu neuem Eigensinn. Butler nennt diesen Vorgang »das Kollabieren der Andacht in Narzissmus« (ebd., S. 50). Die Andacht bedeutet laut Butler also das Opfern des Wandelbaren an das Unwandelbare, die permanente Bezeugung von Dankbarkeit, um die absolute Furcht zu bannen, die sich hier in einer letzten Form als endlose Schuldigkeit präsentiert. Das Unwandelbare werde geheiligt durch eine dauernd wiederholte Handlung der Opferung. Für Butler ist der Körper ständig in Gefahr, von anderen untergeordnet und beherrscht zu werden. Der endliche Charakter des Körpers rufe diese Gefahren und damit auch die Ängste davor hervor. Diese versuche die Gesellschaft loszuwerden und beginne deshalb damit, den Körper abzuwerten. Butler beobachtet also ein paradoxes Muster insofern, als zur Vermeidung der Gefährdung des Körpers der Körper selbst geopfert wird. Diese paradoxe Bewegung der Gesellschaft zur Abwehr des Körpers führe jedoch nicht zum Ziel: »Jede Anstrengung zur Überwindung des Körpers, der Lust und des Handelns erweist sich als nichts anderes denn als Bekräftigung ebendieser Züge des Subjekts.«(Butler 2001, S. 54) In der rituellen Opferung des Körpers offenbare sich Narzissmus, da darin der eigene Körper libidinös besetzt werde.

Butlers Hegel-Interpretation ist für die Frage nach einem transgressiven Charakter der Sexualität deshalb interessant, weil sie die kulturelle Rolle des Körpers als Schnittstelle zwischen Ökonomie, gesellschaftlichen Normen und Trauerarbeit beleuchtet. Transgressive Akte im Rahmen der Sexualität machen die Wandelbarkeit der Körperlichkeit gegenüber der Unwandelbarkeit der ethischen Normen deutlich. Sie sind die Gespenster der Diskontinuität, die das regulative Ideal der Geschlechtsidentität heimsuchen, sie bekämpfen die Kulturanforderungen, die den Körper usurpieren. Doch wie kann ein 
durch Kulturanforderungen wie etwa das regulative Ideal der Geschlechtsidentität gebildetes Subjekt überhaupt die Handlungsfähigkeit zu den erwähnten transgressiven Akten erlangen? Schließt die Normiertheit des Subjekts und seiner Sexualität nicht das Potenzial zu transgressivem Handeln aus? Um diese Fragen zu beantworten, müssen wir Butlers Konzept der Subjektivation in Bezug auf die Handlungsfähigkeit näher betrachten.

\subsubsection{Subversive Handlungsspielräume}

Wir haben bereits gesehen, wie Judith Butler die Sex/Gender-Unterscheidung hinterfragte, indem sie die Setzung der biologischen Geschlechterdifferenz als vordiskursiv zu einem Effekt der herrschenden Verhältnisse erklärte. In der Folge entbrannte unter Feministinnen ein Streit über die Handlungsfähigkeit des Subjekts (vgl. Benhabib et al. 1993). Wie kann ein Subjekt politisch autonom handeln, wenn ihm sein Platz im Machtdispositiv bereits zugewiesen ist? Ist ein Subjekt wirklich nicht mehr als ein Schnittpunkt von Diskursen?

Butler antwortet auf diese Kritik, indem sie festhält, dass selbstverständlich keine Macht ohne Subjekte bestehen könne. Sie stellt jedoch in Frage, dass das Subjekt damit auch Ursache der Macht sein muss. Kehren wir also nochmals zurück zu ihrer Beschreibung der Relation von Subjekt und Macht im Prozess der Subjektivation. Subjektivation meint bei ihr eine doppelte Bewegung: einerseits das Unterworfenwerden durch Macht, andererseits die Subjektbildung (vgl. Butler 2001, S. 8). Erst das Unterworfensein unter die Macht mache das Subjekt zum Subjekt. Diese Formulierung bleibt allerdings paradox: Welches Subjekt soll sich denn einer Macht unterwerfen, wenn dieser Akt die Subjektbildung erst ermöglicht?

Butler spricht an dieser Stelle von einer Aneignung der Macht durch das durch sie gebildete Subjekt. Im Verlauf dieser Aneignung wende sich die Macht gegen sich selbst. Die Macht, die ursprünglich das Subjekt gebildet habe, sei später von diesem nur noch als ausgeübte Macht zu denken. Das von der Macht gebildete Subjekt "verdunkelt [...] seine eigenen Entstehungsbedingungen; es verschleiert Macht mit Macht« (ebd., S. 28). So bleibt das Subjekt gemäß Butler an die Bedingungen der ursprünglichen Macht gebunden; es kann diese Bedingungen entweder durch Fortschreiben oder durch Widerstand ausagieren, die Art des Ausagierens ändert jedoch nichts an der Gebundenheit des Subjekts an die ursprüngliche Macht. Das Subjekt verhält sich in dieser Gebundenheit an die Macht ambivalent, und 
laut Butler ist es nun gerade diese Ambivalenz, die einen gewissen Handlungsspielraum eröffnet. Innerhalb der Wiederholungsstruktur des ewigen Aneignens und Ausübens von Macht, zwischen Fortschreiben von und Widerstand gegen Macht liegt für Butler eine Differenz, ein Zwischenraum, der Handlungsfähigkeit ermöglicht.

Analog zu Foucault erachtet Butler Macht nicht als instrumentell, sondern als strategische Situation. Dies bedeute für das Subjekt, dass sowohl Anpassung an als auch Widerstand gegen Macht die bestehenden Abhängigkeitsverhältnisse fortschrieben und zementierten. Butlers weitergehende Beobachtung ist nun, dass diese Fortschreibung sowohl im einen als auch im anderen Fall durch wiederholte Handlungen geschehe: »Die Bedingungen der Macht müssen ständig wiederholt werden, um fortzubestehen, und das Subjekt ist der Ort dieser Wiederholung, einer Wiederholung, die niemals bloß mechanischer Art ist.« (Ebd., S. 20) Egal ob das Subjekt sich anpasse oder ob es Widerstand leiste, durch einen bloß einmaligen Akt könne sich kein Verhältnis fortschreiben, es brauche eine konstante Bestätigung dieser Verhältnisse. Diese Bestätigung sei nur in der Wiederholung möglich.

Nun trägt jede Wiederholung einen Keim der Differenz in sich. Wie schon Kierkegaard herausgearbeitet hat (vgl. Kierkegaard 1991), kann nämlich eine Handlung nicht wiederholt werden, ohne dass sich zwangsläufig Unterschiede einschleichen. Die wiederholte Handlung ist nie vollkommen mit sich selbst identisch. Hier setzt Butler an: Sie sieht diesen Keim der Differenz als machtfreie Zone, in der freie Variation möglich sei. Diese freie Variation müsse natürlich im eng gesteckten Rahmen der Wiederholung bleiben, doch sie sei immerhin möglich. In der performativen Differenz, die während der Wiederholung entstehe, öffne sich ein Raum für die Ausgestaltung der eigenen Identität.

Identität ist gemäß Butler nicht immer schon da und wird auch nicht bloß von der Gesellschaft zugeteilt, sondern bildet sich in wiederholten performativen Akten. Sie schreibt über das Werden des Subjekts: »Dieses >Werden< ist keine einfache oder kontinuierliche Sache, sondern eine ruhelose Praxis der Wiederholung mit all ihren Risiken, etwas, das sein muss, aber nicht abgeschlossen ist und am Horizont des gesellschaftlichen Seins schwankt.« (Butler 2001, S. 33f.)

Identität ist für Butler weder eine Form angeborener Innerlichkeit noch ein Bündel von Zuschreibungen der Gesellschaft, sondern in der Wiederholung performativ ausgestaltete Differenz (vgl. Butler 1991, S. 206). Als Differenz bezeichnet sie die kleinen Unterschiede, die bei der Wiederholung der 
performativen Akte zwischen den einzelnen Akten erkennbar sind. Das Konzept stützt sich auf Jacques Derridas Begriff der différance: »[S]o bezeichnen wir mit différance jene Bewegung, durch die sich die Sprache oder jeder Code, jedes Verweisungssystem im allgemeinen historisch als Gewebe von Differenzen konstituiert.«(Derrida 1990, S. 90) Innerhalb ihrer Theorie der wiederholten performativen Akte skizziert Butler Möglichkeiten, wie sich das zwischen Anpassung und Widerstand changierende Subjekt zur Macht verhalten kann. Was sind das für Möglichkeiten, und was bedeuten sie in Bezug auf den transgressiven Charakter der Sexualität?

Wie bereits ausgeführt, wird Geschlechtsidentität reguliert durch ein gesellschaftliches Ideal im Kontinuum von Sex, Gender, Begehren und Praxis. Von diesem Ideal abweichende, diskontinuierliche Geschlechtsidentitäten müssen folglich entweder verleugnet werden, oder die Abweichung muss öffentlich gemacht werden. Letzteres ruft gesellschaftliche Sanktionen auf den Plan, durch welche die Abweichung erst als kriminell, krankhaft oder unsittlich erkannt wird. Das gegen die zugeschriebene Geschlechtsidentität revoltierende Subjekt findet sich unmittelbar in der nächsten gesellschaftlich zugeschriebenen Kategorie wieder.

Ein partielles Entkommen aus diesen Kategorien skizziert Butler in ihrer Theorie der wiederholten performativen Akte. In jeder Wiederholung stecke die Möglichkeit der Differenz. Im performativen Ausagieren dieser Differenz, beispielsweise in der Parodie, lasse sich eine Art subversiver Rebellion gegen die Definitionsmacht durchführen (vgl. Butler 1991, S. 214f.). Dabei werde das regulative Ideal nicht negiert oder direkt bekämpft, es erscheine sozusagen überrepräsentiert und überdeutlich. Dies entlarve den regulativen Charakter des Ideals, was dem Subjekt Spielraum gebe, dessen Identitätszuschreibungen zwar nicht zu entgehen, doch immerhin spielerisch mit diesen umzugehen.

Homosexuelle Gruppenidentität lässt sich beispielsweise recht gut als Bündel von Zuschreibungen erklären, die dann performativ ausagiert werden. Dies geschieht von der ausgrenzenden Gruppe der Heterosexuellen aus in Form von Stereotypen, um die Ausgrenzung möglichst sicher und stabil zu halten. Von den Homosexuellen selbst ausgehend funktionieren die $\mathrm{Zu}-$ schreibungen als Codes, um innerhalb der Gruppe erkennbar und anerkannt zu sein. Ein Subjekt kann innerhalb dieser Beispielgruppe der Homosexuellen auch gegen diese Zuschreibungen rebellieren, es entgeht damit nicht deren Macht, da es dann gezielt konträr zu diesen Zuschreibungen agieren muss und innerhalb der Gruppe zum Außenseiter oder zur Außenseiterin 
wird. Wie sieht in einer solchen Situation Butlers Weg des performativen Ausagierens der Differenz aus? Butler schlägt als Beispiel Drag vor, die parodistische Aneignung von Kleidung, Gesten und Verhaltensweisen des jeweils anderen Geschlechts: »Indem die Travestie die Geschlechtsidentität imitiert, offenbart sie implizit die Imitationsstruktur der Geschlechtsidentität als solcher - wie auch ihre Kontingenz.« (Ebd., S. 202) Doch wird demnach im Phänomen Drag nicht gerade die Zweigeschlechtlichkeit bestätigt? Butler gibt zu, dass Drag die Geschlechterrollen manchmal bloß zementiere, anstatt sie durchlässig zu machen. Sie unterstreicht, »dass es keine zwangsläufige Verbindung zwischen Drag und Subversion gibt und dass Drag so gut im Dienst der Entnaturalisierung wie der Reidealisierung übertriebener heterosexueller Geschlechtsnormen stehen kann« (Butler 1997, S. 178).

Drag wirkt dann subversiv, wenn beispielsweise ein schwuler Mann als Dragqueen sich die weibliche Geschlechtsidentität aneignet, durch gezieltes Übertreiben der als weiblich geltenden Eigenschaften aber nicht in dieser neuen Identität stecken bleibt, sondern in der übertriebenen Performance den künstlichen Charakter dieser Eigenschaften hervorhebt. Statt sich über Frauen lustig zu machen, stellt er die Natürlichkeit von Weiblichkeit in Frage. Nebenbei gibt er einen Kommentar zum Klischee des weibischen Schwulen ab, mit dem homosexuelle Männer häufig konfrontiert sind. Die kritische Spiegelfunktion der Dragqueen zerstört Mythen von Männlichkeit. Drag kann folglich laut Butler durch das Ausnützen von Differenzen in der wiederholten Performanz der homosexuellen Identität subversiv auf die Instabilität der Grenze zwischen hetero- und homosexueller Identität hinweisen (vgl. ebd., S. 317). Dies eröffne einen Freiheitsraum jenseits dieser beiden Pole, der die Polarität selbst gefährde. Eine ähnliche Rolle schreibt Butler Transmenschen $\mathrm{zu}$, welche die rigiden Vorstellungen weiblicher und männlicher Geschlechtsidentitäten hin zum Konzept einer Vielfalt von Geschlechtern verflüssigen könnten.

In Bezug auf die Ausgangsfrage nach der Handlungsfähigkeit von Subjekten heißt das, dass auch das in seiner Sexualität normierte Subjekt die Möglichkeit zur Transgression hat - und zwar indem es den Umstand ausnützt, dass die Grenzen, die es definieren, kontinuierlich neu gezogen und bestärkt werden müssen. Dies geschieht durch Wiederholung. Durch Differenzen in den performativen Akten der Wiederholung werden diese Grenzen porös und es öffnet sich ein Handlungsspielraum auf der Grenze, ganz wie in Zappes postmodernem Modell der Transgression. Butler schlägt mit dem Beispiel Drag eine Strategie vor, welche die Diskontinuität von Gender und 
Sex thematisiert. Innerhalb des regulativen Ideals der Geschlechtsidentität lassen sich mit der postulierten Kontinuität von Sex, Gender, Begehren und sexueller Praxis noch eine Reihe von Diskontinuitäten denken. Daraus speist sich der transgressive Charakter der Sexualität.

Butler geht in Die Macht der Geschlechternormen (2009) noch einen Schritt weiter. Sie beschreibt dort Sexualität und Geschlechtsidentität nicht als etwas, was wir haben, sondern als eine Form von Enteignung:

Wenn wir von meiner Sexualität oder meiner Geschlechtsidentität sprechen, wie wir es tun (und tun müssen), meinen wir also etwas Kompliziertes. Genau genommen ist weder das eine noch das andere ein Besitz, vielmehr sind beide als Modi der Enteignung zu verstehen, als Formen des Daseins für einen Anderen oder sogar kraft eines Anderen. (Butler 2009, S. 38)

Das heißt, dass wesentliche Erfahrungen, die unsere Sexualität und unsere Geschlechtsidentität ausmachen, von anderen abhängig sind. Ohne Bezugnahme auf jemanden außerhalb von uns wissen wir nicht, was unsere Sexualität oder Geschlechtsidentität ausmacht. Sexualität besteht also nicht nur aus Normen, die wir ausagieren, sondern auch aus einer konstitutiven Verletzlichkeit, Fremdheit, Angewiesenheit auf andere, aus Wünschen, Bedürfnissen und Ängsten, die uns selber alle nicht ganz klar und bewusst sind. Mit dieser Einsicht liegt Butler nahe bei Freuds und Marcuses Modell der individuellen Triebstruktur, deren Herausbildung dem Subjekt nicht durchsichtig ist, aber die gerade deshalb der Einhegung in gesellschaftliche Normgrenzen widersteht. Sexualität als Form des Daseins für oder kraft eines anderen: Damit formuliert Butler sowohl den transgressiven Charakter der Sexualität als auch das Scheitern der Konstruktion eines autonomen Subjekts.

Wie dieses Kapitel gezeigt hat, ist unsere heutige Vorstellung von Sexualität untrennbar verbunden mit der Subjektkonzeption der bürgerlichen Moderne. Diese Subjektkonzeption definiert Sexualität nicht mehr über Interaktionen zwischen Individuen, sondern verortet sie im Innern der Individuen, sucht in ihr eine Wahrheit über das Subjekt selbst. Sexualität nicht als Ensemble von Interaktionen, sondern als Identitätsmerkmal zu sehen, hat weitreichende Folgen. Die Regulierung der Sexualität eines Subjekts findet weniger über eine Privilegierung oder Sanktionierung sozialer Kontakte statt, sondern über die Einübung gesellschaftliche Normen.

Die Bedingung für die kulturelle Verstehbarkeit des Subjekts ist dessen Unterwerfung unter ein regulatives Ideal der Geschlechtsidentität. In wiederholten performativen Akten muss es die Kohärenz von Sex, Gender, Begehren 
und sexueller Praxis immer wieder aufs Neue herstellen. Diese Kohärenz ist deshalb immer wieder vom Scheitern bedroht, was Raum für bewusste oder unbewusste Transgressionen schafft.

Transgression bedeutet das Überschreiten von Grenzen. Im Bereich der Sexualität sind Grenzen und der ausgegrenzte Bereich erotisch aufgeladen. Das Überschreiten dieser Grenzen bringt gesellschaftliche Hierarchien ins Wanken. Da die in den Grenzen des Subjekts eingehegte Sexualität nicht vollständig in den gesellschaftlichen Normen aufgeht, entsteht ein transgressiver Charakter der Sexualität, eine Tendenz zur Überschreitung der ihr auferlegten Normen. Dieser transgressive Charakter der Sexualität erregt und ängstigt Subjekt und Gesellschaft gleichermaßen, stachelt Angst- und Lustfantasien an. Denn die dem Individuum abgeforderten Einschränkungen des Begehrens sind nicht von Dauer, die unterdrückten Triebe treten in verwandelter Form wieder zutage. Ein Ausdruck davon ist die Pornografie, die sowohl von gesellschaftlichen Normen im Bereich der Sexualität als auch von deren Überschreitung erzählt.

Doch inwiefern ist Pornografie ein Ausdruck kulturell unerwünschter Aggressions- und Sexualtriebe? Welche Folgen hat die Ablehnung der mit dem Liebescode unvereinbaren Aspekte der Sexualität als obszön für die gesellschaftliche Funktion der Pornografie? Erzählen die Transgressionen der Pornografie vom Scheitern oder befestigen sie die bedrohte Kohärenz der Geschlechtsidentität? Welche Transgressionen ermöglicht die Pornografie, und was ist das politische Potenzial dieser Transgressionen?

Um die Beantwortung dieser Fragen geht es im folgenden Kapitel. Dazu werde ich in einem ersten Schritt aufzeigen, wie mit der Konzeption des bürgerlichen Subjekts ein angstbesetztes Interesse am Begehren dieses Subjekts entsteht. Dieses eint widersprüchliche Tendenzen des 18. Jahrhunderts wie die Pathologisierung der Masturbation auf der einen Seite und den Boom pornografischer Schriften auf der anderen Seite. In einem zweiten Schritt möchte ich dann untersuchen, in welchem Verhältnis die pornografische Utopie zum Begehren des Subjekts steht. 


\subsection{Pornografie zwischen Normierung und Transgression}

\subsubsection{Das Problem der Masturbation}

Pornografie definiert sich dadurch, dass sie die sozialen und emotionalen Aspekte der Sexualität ausblendet. Dennoch ist sie abhängig von einem gesellschaftlichen Diskurs, der sie erst erkennbar macht. Wie gestaltet sich also die gesellschaftliche Prägung der Pornografie? Meine These ist es, dass analog zur Sexualität auch die Pornografie sowohl Aspekte der Normierung wie auch der Transgression aufweist. Doch in welchem Verhältnis stehen Normierung und Transgression im Fall der Pornografie zueinander?

Pornografie und sexuelle Praxis sind in der Regel miteinander verbunden durch den Akt der Masturbation. Deshalb scheint mit das Thema Masturbation ein Schlüssel zu sein, um zu verstehen, wie die Problematisierung von Sexualität und von Pornografie verschränkt ist. Wie Foucault herausgearbeitet hat, wird Sexualität seit der Zeit des Hellenismus zunehmend als gefährlich für Individuum und Gesellschaft wahrgenommen. Im Falle der Masturbation kam es im 19. Jahrhundert zu einer eigentlichen Flut von Schriften, in denen vor den Gefahren der Masturbation gewarnt wurde. Wie ist diese Entwicklung zu erklären?

Kehren wir zurück zum ersten Band von Foucaults Sexualität und Wahrheit (1977), wo es im letzten Teil um Regierungstechniken geht, die zur Bevölkerungskontrolle angewandt werden. Hier kreuzen Rassen- und Sexualitätsdiskurse sich im Begriff der Entartung. Die Theorie der Entartung lieferte laut Foucault im 19. Jahrhundert die Erklärung sowohl für die durch Vererbung von Krankheiten entstehenden Perversionen als auch für die Krankheiten, die durch sexuelle Perversionen der Vorfahren verursacht worden sein sollen: "Der Komplex Perversion-Vererbung-Entartung bildete den festen Knotenpunkt der neuen Technologien des Sexes.«(Ebd., S. 143) Foucault beschreibt diese Sorge um den eigenen Sex als Phänomen, das vornehmlich die bürgerlichen Familien heimsuchte. Diese Sorge habe sich etwa in der Hysterisierung der bürgerlichen Ehefrau geäußert, aber auch in der Dämonisierung der Masturbation:

Und der Heranwachsende, der in geheimer Lust seine künftige Substanz vergeudet, das onanierende Kind, das die Ärzte und Erzieher vom Ende des 18. bis zum Ende des 19. Jahrhunderts so beunruhigte - das war nicht das Kind des Volkes, der künftige Arbeiter, dem man die Disziplinen des Körpers hät- 
te beibringen müssen; das war der Kollegial, das von Dienern, Hofmeistern und Couvernanten umgebene Kind, das weniger physische Kräfte als intellektuelle Fähigkeiten zu verlieren drohte: eine moralische Aufgabe und die Verpflichtung, seiner Familie und seiner Klasse eine gesunde Nachkommenschaft zu sichern. (Ebd., S. 145f.)

Die Technologie des Sexes dürfe deshalb nicht als Mittel missverstanden werden, das vom Bürgertum erfunden worden sei, um die Arbeiterklasse zu unterdrücken, sondern es sei dem Bürgertum darum gegangen, sein Fortbestehen als Klasse zu sichern und sich von anderen Klassen abzuheben. Das Fortbestehen der eigenen Klasse wurde also laut Foucault an gesunde Sexualpraktiken geknüpft: »Was sich konstituiert hat, ist eine politische Disposition des Lebens - und zwar nicht in einer Unterwerfung des anderen, sondern in einer Selbstaffirmation.«(Ebd., S. 148) Dieses Sexualitätsdispositiv sei dem Proletariat vom Bürgertum erst übergestülpt worden, als hygienische, ökonomische und soziale Probleme dies notwendig gemacht hätten.

Der Kulturhistoriker Thomas Laqueur macht analog zu Foucault und Sennett das frühe 18. Jahrhundert als Schlüsselmoment aus, an dem Sexualität aufhört, als Phänomen sozialer Interaktion thematisiert zu werden, sondern anfängt, eine Wahrheit über das Subjekt zu erzählen. An der zu diesem Zeitpunkt plötzlich einsetzenden Problematisierung der Masturbation in medizinischen Handbüchern, Erziehungsratgebern und Gerichtsurteilen verdeutlicht er diese Entwicklung:

The Jewish tradition, classical Antiquity, and Christian teaching all regarded sexuality as a deeply social phenomenon, one that had to be understood in terms of the human relationship to a transcendental order. What mattered was with whom one had sex, how, and when. Then, sometime around 1712 , the question of autoeroticism became exigent because the relationship between the individual and a newly emerging social order became deeply problematic. Masturbation is a moral problem of the modern self, a reflection of the very deepest problems of modern life. (Laqueur 2003, S. 248f.)

Ein Diskurs, der Masturbation als problematische sexuelle Praktik einstufte, sei also erst im 18. Jahrhundert entstanden. Ihm zugrunde liege die Verschiebung der Sexualität weg von einem Phänomen der sozialen Interaktion hin zu einer Frage des Selbst. Im 18. Jahrhundert sei das vorher klare Verhältnis von Individuum und Gesellschaft plötzlich problematisch geworden. La- 
queur treibt deshalb die Frage um, was denn das 18. Jahrhundert plötzlich so bedrohlich fand an der Masturbation:

The answer in brief is that three things seem to have been regarded as the core horrors of sex with oneself: it was secret in a world in which transparency was of a premium; it was prone to excess as no other kind of venery was, the crack cocaine of sexuality; and it had no bounds in reality, because it was the creature of the imagination. (Ebd., S. 21)

Das Geheime, das Exzessive und die Einbildungskraft: Wie ich noch zeigen werde, werden diese drei Aspekte auch bei der Pornografie als bedrohlich empfunden. Ihr Zusammenhang mit Transgression wird ebenfalls zu klären sein. Laqueurs These ist, dass Masturbation als Praktik die Schattenseiten von Begriffen bündelt, die für das Sexualitätsdispositiv des bürgerlichen Subjekts konstitutiv wurden. Masturbation sei das Laster der Individualisierung:

Masturbation thus became the vice of individuation for a world in which the old ramparts against desire had crumbled; it pointed to an abyss of solipsism, anomie, and socially meaningless freedom that seemed to belie the ideal of moral autonomy. It was the vice born of an age that valued desire, pleasure, and privacy but was fundamentally worried about how, or if, society could mobilize them. It is the sexuality of the modern self. (Ebd., S. 210)

Im 18. Jahrhundert sei aufgrund des Wegfalls anderer Autoritäten die Regierung und Regulierung des Selbst zentral geworden. Wo das Individuum nicht mehr in eine göttliche Ordnung eingebunden ist, wird gemäß Laqueur Selbstkontrolle zur Bürgerpflicht. Masturbation dagegen bedeute, seine Sexualität der Kontrolle zu entziehen.

Die Gesellschaft des 18. Jahrhunderts hat laut Laqueur an der Stelle der alten Autoritäten eine Ökonomie des Begehrens installiert, in der private Laster das Gemeinwohl fördern. Auch aus dieser Sicht werde nun Masturbation zum Problem. Denn im privaten Laster Masturbation stoße das Begehren weder auf begrenzende Gegenkräfte, noch trage es etwas zum Gemeinwohl bei. Schließlich sei es nicht auf Austausch angewiesen.

Mit der Masturbation wird nach Laqueur auch Pornografie zum Problem: "Pornography, >writing of harlots`, as we shall see, was also a creature of the revolution of desire that drove both the new consumer culture and the new vice of masturbation.« (Ebd., S. 287) Wie Laqueur ausführt, prägen die Bedrohlichkeit des Geheimen, des Exzesses und der Einbildungskraft die ambivalente Einstellung des 18. Jahrhunderts zur Literatur generell. Das private 
Lesen von Literatur habe gleichzeitig mit der Verbreitung von gedruckter Pornografie einen Boom erlebt. Die in Literatur und Masturbation schlummernde Gefahr sei jedoch nicht die des Verwechselns der Fiktion mit der Realität. Sie liege in der Konkurrenz der Fiktion zur Realität. »The danger lay in representational excess, in fiction or artifice coming to supplant nature with its inbuilt structure of constraints.« (Ebd., S. 322) Fiktion überschreitet die Grenzen der Realität, sie eröffnet einen Raum der Freiheit jenseits der begrenzten Möglichkeiten der individuellen Existenz.

Es ist also genau das Transgressive an Literatur und an masturbatorischen Fantasien, die beides so gefährlich machen. Entsprechend wurden pornografische Schriften laut Laqueur bekämpft: "If masturbation was the evil doppelgänger of the imagination, then pornography was the moral nadir of imaginative fiction, the bad seed of a potentially wholesome family." (Ebd., S. 339) Es erstaunt Laqueur deshalb auch nicht, dass analog zum weiblichen Lesen gerade auch weibliche Masturbation als Gefährdung der gesellschaftlichen Ordnung angesehen wurde. »In short, masturbation is the act through which women signaled their rejection of the normative sexual order.« (Ebd., S. 372)

Anfangs des 20. Jahrhunderts beginnt sich laut Laqueur die Art der Problematisierung der Masturbation zu ändern. Er macht als Angelpunkt die Schriften Freuds aus. Laut Freud benennt Masturbation ein Zwischenstadium zwischen infantiler und erwachsener Sexualität. Dass sie nichtsdestotrotz auch bei Erwachsenen weit verbreitet ist, hat mit den Kulturanforderungen zu tun. Indem diese Sexualität nur zu Fortpflanzungszwecken erlauben, begrenzen sie den Raum der gesellschaftlich erlaubten Sexualität zu stark und verurteilen so einen großen Teil der Bevölkerung zur Abstinenz. Eine Folge des Zwangs zur Abstinenz ist laut Freud deshalb die trotz kultureller Ächtung weite Verbreitung der Masturbation. Diese bringe Probleme mit sich:

Sie verdirbt ferner den Charakter durch Verwöhnung auf mehr als eine Weise, erstens, indem sie bedeutsame Ziele mühelos, auf bequemen Wegen, anstatt durch energische Kraftanspannung erreichen lehrt, also nach dem Prinzipe der sexuellen Vorbildlichkeit, und zweitens, indem sie in den die Befriedigung begleitenden Phantasien das Sexualobjekt zu einer Vorzüglichkeit erhebt, die in der Realität nicht leicht wiedergefunden wird. (Freud 2009, S. 128)

Hier treffen wir nochmals die alte Befürchtung der Asozialität der Masturbation an. Da Masturbierende auf niemanden als sich selbst angewiesen sind, 
ist ihr Weg zur Befriedigung der bequemere. Und wenn das Sexualobjekt in der Fantasie größere Vorzüge aufweist als in der Realität, lohnt sich der Aufwand nicht, es in der Realität suchen zu gehen?

Freud konstruiert die gesellschaftlich erwünschte genitale Sexualität des Erwachsenen in Abhängigkeit vom frühkindlichen Masturbationsverbot. Durch die gesellschaftliche Tabuisierung des frühkindlichen Spiels mit den Geschlechtsorganen ergibt sich überhaupt erst der Fokus auf genitale Sexualität. Damit eröffnen sich laut Laqueur zwei Szenarien. Im ersten helfe Masturbation beim Einüben der Heterosexualität: »In one of these, the twocentury-long medical attack on masturbation is redirected toward slowly but surely harnessing the sexual energies of autoeroticism, which, in this version, is no longer a deadly vice but the training ground for heterosexuality.« (Laqueur 2003, S. 392)

Wenn aber Heterosexualität vom Meistern der Masturbation abhängt, eröffnet sich für Laqueur ein zweites Szenario, in dem Masturbationspraxen auch Wege aufzeigen könnten zur Einübung oder Entdeckung einer alternativen Sexualität. Deshalb hätten unter anderem Feministinnen, Lesben und Schwule in der zweiten Hälfte des 20 . Jahrhunderts das positive Potenzial der Masturbation entdeckt. Die Redefinition von Masturbation als Selbstliebe habe den Weg freigemacht für marginalisierte Gruppen, die darin einen Weg gefunden hätten, sich mit ihrer gesellschaftlich abgewerteten Sexualität $\mathrm{zu}$ versöhnen und $\mathrm{zu}$ einem positiven Selbstwertgefühl zu finden. Laqueur erklärt sich damit auch das bessere Verhältnis zur Pornografie, das sexuelle Minderheiten im Gegensatz zur heterosexuellen Mehrheit hätten. Denn in der Angst vor der Verbreitung der Masturbation habe immer auch eine Angst vor den homosozialen Wegen, auf denen dies geschehe, gesteckt. Laqueur vergleicht die Sicht der sexpositiven Feministin und Sexualaufklärerin Betty Dodson auf Masturbation mit Ansichten des Philosophen Jean-Jacques Rousseau:

For the philosophe, masturbation represented the pollution of the self by the social world; the private and inner world that each of us carries around was thus no longer serviceable for its social role as a place of refuge and moral reflection. For Dodson, masturbation represents the true self, and we only need to ask for something from the public sphere if it offers a supplement to what we can have alone. (Ebd., S. 402)

Bei Rousseau habe sich das Selbst gegen Masturbation als eine Form der Verunreinigung durch die Gesellschaft wehren müssen; bei Dodson hingegen 
zeige sich erst in der Masturbation das wahre Selbst. Damit macht Laqueur sowohl Rousseau als auch Dodson zu Beispielen für seine These, dass aus Sexualität als Gegenstand sozialer Interaktion eine Wahrheit des Selbst geworden sei, welches die Öffentlichkeit nur noch als Erweiterung seiner selbst sehe.

Ich möchte hier Laqueurs Ausführungen noch einen Aspekt hinzufügen. Ich finde es wichtig, bei der Masturbation den Aspekt der sexuellen Routine nicht zu vergessen. Masturbation macht etwas mit dem Körper, übt etwas ein, formt ihn. In allen von Laqueur gesammelten Warnungen vor Masturbation steckt bereits die Idee, dass diese das Selbst formt. Die sie begleitenden Fantasien ergeben ein sexuelles Narrativ des Subjekts, eine sexuelle Identität. Das Transgressive solcher Fantasien trägt gleichzeitig eine Spaltung in dieses sexuelle Narrativ und in das Subjekt selbst hinein. Laqueur formuliert diese Spaltung so:

Potentially autarkic solitary sexual pleasure touches the inner lives of modern humanity in ways that we still do not understand. It remains poised between self-discovery and self-absorption, desire and excess, privacy and loneliness, innocence and guilt as does no other sexuality in our era. (Ebd., S. 420)

Laqueur beschreibt hier die sexuelle Praktik der Masturbation als einen Akt auf der Grenze, im Spannungsfeld der Binaritäten Selbsterforschung und Selbstversunkenheit, Begehren und Exzess, Privatheit und Einsamkeit, Unschuld und Schuld. Das macht sie zu einem prädestinierten Ort für das Auftreten transgressiver Aspekte der Sexualität. Auch wenn sich jemand scheinbar ganz im Rahmen des regulativen Ideals der Geschlechtsidentität bewegt, liegt in der Masturbation immer die Gefahr für eine Transgression dieses Rahmens.

Laqueur zeigt auf, wie im historischen Moment, als sich ein bürgerliches Subjekt konstituiert, das ohne Bezug auf äußere Autoritäten eigenverantwortlich und rational handelt, Masturbation ein Problem wird. Denn mit der bürgerlichen Subjektkonzeption werden Werte wichtig wie Transparenz, Rationalität und die Fähigkeit, sich selbst Grenzen zu setzen. Masturbation dagegen geschieht im Geheimen, kann vergleichsweise exzessiv betrieben werden und beruht auf der Einbildungskraft. Damit bündelt Masturbation die transgressiven Aspekte der Sexualität des bürgerlichen Subjekts in einer Weise, die erst die plötzliche Problematisierung und Pathologisierung dieser sexuellen Praktik erklärt. Im nächsten Kapitel werde ich anhand der For- 
schungen des Literaturwissenschaftlers Steven Marcus aufzeigen, wie sich im viktorianischen England die Panik rund um Masturbation auf die Pornografie ausgewirkt hat.

\subsubsection{Die Pornografie der Viktorianer}

Steven Marcus beschäftigt sich mit der sexuellen Kultur des viktorianischen England, also der Regierungszeit der Königin Viktoria von 1837 bis 1901. Wie Laqueur betont, erlebt zu dieser Zeit die allgemeine Panik vor den Auswirkungen der Masturbation einen Höhepunkt. Gleichzeitig nimmt die Produktion pornografischer Literatur ein industrielles Ausmaß an. Marcus' These ist, dass die Pornografie jener Epoche ein Spiegel bestimmter Obsessionen ist, die auch die Naturwissenschaften, die Medizin oder die Ökonomie in jener Zeit prägten. Ein Beispiel für seine These findet Marcus in den Schriften des viktorianischen Arztes und Sexualforschers William Acton. Deren Ausgangspunkt ist die These, dass Kinder asexuell sind. Diese behauptete Asexualität des Kindes sehe Acton allerdings von allen Seiten bedroht:

So wie in der Pornographie jede Person, jeder Cegenstand oder Cedanke als Auslöser sexueller Aktivität fungieren kann, so ist Acton nahezu keine Erfahrung unverdächtig, vorzeitig die Lust der Kleinen wecken zu können. Und obwohl er mit Besorgnis beargwöhnt, was die raison d'être von Pornographie ausmacht, findet doch hier wie dort der gleiche Vorgang statt - die restlose Sexualisierung der Realität. (Marcus 1979, S. 33)

Die spezifisch viktorianische Panik, dass alles Auslöser für sexuelle Aktivität sein kann, ist ein Spiegel der utopischen Welten der Pornografie, für die Marcus den Neologismus Pornotopia kreiert, als Zusammenzug von Pornografie und Utopia. Pornotopia zeichne sich aus durch die Unbestimmtheit von Ort und Zeit. Alles in Pornotopia Vorgefundene habe einzig den Zweck, Anlass für Sex zu sein. Bei Acton hat die naturwissenschaftliche Erforschung der Sexualität laut Marcus einen Punkt erreicht, an dem dieselben Fantasien bearbeitet werden wie in der Pornografie. Die Verwandtschaft der von Acton beschworenen Welt mit Pornotopia beschreibt Marcus so:

In beiden Welten herrscht ein gespaltenes oder geteiltes Bewusstsein; beide sind mehr von der Logik der Phantasie und Assoziation als von der Logik der Ereignisse oder der Cedanken geprägt. Beide sind Welten ohne Psychologie, 
verankert in Organen und Physiologie, in denen alle Materie wandelbar ist. (Ebd., S. 49)

Den Kampf der Rationalität mit den assoziativen Welten der Pornografie stellt Marcus bei einem anderen Viktorianer vor, dem Bibliografen und Sammler Henry Spencer Ashbee. Unter dem Pseudonym Pisanus Fraxis verfasste dieser die erste englischsprachige Bibliografie pornografischer Schriften. Dies findet Marcus nur schon als Unternehmung bemerkenswert, weil die Intention des Bibliografierens von Pornografie ständig von ihrem Gegenstand durchkreuzt werde:

Pornographie ist zum Beispiel die am wenigsten »geordnete« Literaturform; nicht nur ihre Inhalte sind »unordentlich «, sondern der gesamte Zusammenhang, von den Büchern selbst bis hin zu den Umständen der Veröffentlichung und des Sammelns, ist geradezu ein Modell für fehlende Organisation und Kontrolle - eine wahrhaft »schmutzige«, chaotische Angelegenheit. (Ebd., S. 67)

Entsprechend sei Ashbees Versuch einer Systematisierung der Pornografie so ausgewuchert, dass das Ergebnis wiederum sehr chaotisch gewesen sei. Gleichzeitig sei er laut Marcus in seiner Wiedergabe des Inhalts der pornografischen Schriften in Erzähl- und Ausdrucksmuster dieser Schriften selber verfallen. Sowohl die erzählerischen Konventionen wie auch das Unordentliche der Pornografie hätten auf Ashbees Bibliografie übergegriffen. Marcus insistiert, dass Pornografie trotz ihrer chaotischen Editionsumstände auf eine sehr konventionalisierte Erzählform angewiesen sei:

Wie das Kriminalstück oder der Hollywood-Film ist die Pornographie eine extrem konventionalisierte Ausdrucksform. Die Abweichungen von der Konvention sind auf eine begrenzte Anzahl von Formeln beschränkt. Was darüber hinausgeht, verletzt die Konvention und führt zum Misserfolg, nicht zur Umwälzung des Cenres. (Ebd., S. 72)

Ein herausragendes Beispiel für die Konventionen viktorianischer Pornografie ist für Marcus My Secret Life, eine umfangreiche Autobiografie des ausschweifenden Lebens eines anonymen viktorianischen Autors. In My Secret Life wird laut Marcus eine Sexualität präsentiert, wie sie für Pornografie typisch ist:

Eines der wichtigen Kennzeichen der Sexualität des Autors - und der Art von Sexualität, die in der Pornographie gefeiert wird - ist ihre Ausrichtung an 
abstrakten, strikt quantitativen Verwirklichungsformen: Sexualität als endlose Akkumulation von Erlebnissen. Diese Erlebnisse sind wie die in der Pornographie beschriebenen sowohl voneinander verschieden als auch einander gleich. Der Zwang zur Abwechslung ist monoton, ebenso mechanisch wie trist. (Ebd., S. 173)

Marcus behauptet, dass in der Pornografie Sexualität einem Zwang zur Abwechslung unterliegt, dessen Gründe unerhellt bleiben. Er nimmt explizit Bezug auf Freuds Triebtheorie: »Triebe sind konstant und üben Herrschaft durch Wiederholung aus. Zugleich steckt in jeder Triebbefriedigung ein unerfüllter Rest: ein offener, uneingelöster Wunsch, der Stachel ungesättigter Verheißung.« (Ebd., S. 174) Das Rätsel, das den Trieb antreibe, könne in der Triebbefriedigung nicht gelöst werden. Es bleibe unbewusst und stachle den Trieb zur Wiederholung an. Erlösung gebe es nicht: »Die Idee der Erfüllung trägt unvermeidlich die Vorstellung von Vollendung, von Befriedigung, von einem Ende in sich. Die pornographische Phantasie, die solchen Vorstellungen widersteht, ist eben darin antiliterarisch.« (Ebd., S. 179) In solcher Antiliterarizität liegt laut Marcus die Modernität des Werks. Indem My Secret Life ein Dokument des endlosen Wiederholungszwangs der Triebe sei, stehe es außerhalb der Literatur der viktorianischen Epoche:

Weder das Interesse des Autors noch die Sprache, deren er sich bedient hat, um dieses Interesse auszudrücken, haben in der Kultur seiner Epoche einen Rückhalt. Der Diskurs der sexuellen Erfahrung ist dem Viktorianismus fremd. Als der Autor sich für ihn entschied, wählte er gleichzeitig den Austritt aus der zeitgenössischen Kultur, die die offizielle Sprache beherrschte; doch vermochte er sich ihr nicht vollständig zu entziehen. (Ebd., S. 178)

Die für die Pornografie konstitutive Entdeckung der Triebe hat laut Marcus ihre Wurzeln im literarischen Kult der Empfindsamkeit, der eine menschliche Natur postuliert, die mit Moral und Gesellschaft in Konflikt treten kann. Selbstreflexion oder innere Konflikte, die in der nicht pornografischen Literatur wichtig sind, würden in der Pornografie allerdings ausgespart: »Diese Aussparungen und Verkürzungen sind im System der Pornographie unabdingbar. Sie malt eine Welt, in der Gewissensbisse und tatsächliche Konflikte nicht vorkommen. Die Freiheit, die sie vorstellt, wird durch einen Ausschluss erreicht: die Hälfte der menschlichen Natur wird ignoriert.« (Ebd., S. 189) Auch die Sprache der Pornografie ist laut Marcus von diesen Ausschlüssen, dieser Verarmung an weltlichem Gehalt betroffen. Dies mache sie klischee- 
haft, ohne sprachliche Originalität: „Sprache ist für die Pornographie nichts als ein Hilfsmittel, ein notwendiges Übel; ihre einzige Funktion besteht darin, averbale Bilder, Phantasien in Gang zu setzen. Das adäquate Ausdrucksmedium der Pornographie, sofern es überhaupt ein solches gibt, ist der Film.« (Ebd., S. 188) In der Einschränkung aller Erfahrung auf sexuelle Erfahrung zeigt sich laut Marcus die Vision von Pornotopia, die Wirklichkeit wird zu einem Wunschbild verdünnt.

Von der verkürzten Darstellungsweise der Pornografie besonders betroffen seien die Frauen: „Obwohl die Frauen in diesem Roman als durchaus verschieden in Charakter, Habitus und Reaktionsweise eingeführt werden, werden sie alsbald auf eine gemeinsame >Identität $<$ reduziert. Sie sind alle dasselbe: das Objekt für den Mann.« (Ebd., S. 193) Die Frauenfeindlichkeit der Pornografie erklärt Marcus, indem er ebenfalls auf Freuds Triebtheorie zurückgreift. Grund für den Sexismus der Pornografie sei die Rache des Pornografen an der Mutter für die Trennung von der nährenden Brust: »In jedem Pornographen steckt ein Säugling, der nach der Brust schreit, von der man ihn getrennt hat.« (Ebd., S. 234) In der Pornografie stecke letztlich eine infantile Unersättlichkeit. Die Formen, die die pornografischen Fantasien annähmen, variierten zwar historisch, aber die Fantasien selbst seien im kindlichen Sexualleben begründet: »Die Phantasien, die in der Pornographie erscheinen, sind nicht an spezifische geschichtliche Konstellationen geknüpft; sie sind Phantasien des kindlichen Sexuallebens, gesammelt und reorganisiert in den Masturbations-Tagträumen der Adoleszenz.« (Ebd., S. 241)

In My Secret Life gehören die Objekte der Begierde des Ich-Erzählers zum größten Teil einer ihm untergeordneten Klasse an. Welche Funktion hat für Marcus der Klassenaspekt in der Pornografie?

Abermals können wir beobachten, wie sich die »Verdinglichung «-um einen Marxschen Begriff zu verwenden - der menschlichen Beziehungen mit jenen generellen und pornographischen Phantasien verbindet, in denen Menschen zu Objekten versteinern, deren einziger Sinn und Zweck es ist, unsere eigenen Bedürfnisse zu befriedigen. Die Vorherrschaft der Klasse geht Hand in Hand mit der Macht des Cedankens und ermöglicht der Phantasie, sich in Verhalten umzusetzen. (Ebd., S. 137)

In seiner Darstellung der Arbeiterklasse mischten sich beim Autor von $M y$ Secret Life die Vorurteile der herrschenden Klasse mit einer Erotisierung und zum Teil sogar Bekundung echter Sympathie für die Arbeiterklasse. Die Texte durchziehe eine typisch viktorianische Gespaltenheit, in der sexuellen Praxis 
würden einerseits die herrschenden Normen kritisiert, andererseits auch im verdinglichten Umgang kritiklos übernommen:

Fraglos lässt sich innerhalb der viktorianischen Kultur eine subversive Cegenbewegung beobachten: Widerstand gegen die rigide Reglementierung der Empfindungen, der Triebe und des kulturellen Unbewussten, gegen ein Sittlichkeits- und Realitätsprinzip, das auf »systematische Ordnung« angelegt war und das auf »Rationalität« baute - abgespalten von dieser Rationalität bildeten sich eine »geheime Kultur« und eine »andere Moral «, die insbesondere in abweichenden sexuellen Praktiken und ausgreifenden sexuellen Phantasien ihren Ausdruck suchten. Diese Cegenbewegung bediente sich einer Reihe zentraler Wertbilder der offiziellen Kultur. (Ebd., S. 151)

Hier findet sich bei Marcus Freuds Begriff des Realitätsprinzips wieder, das gerade durch seine rigiden Kulturanforderungen eine geheime Kultur abweichender sexueller Fantasien und Praktiken erzeugt. Die Pornografie dieser geheimen Kultur spiegelt laut Marcus diese Kulturanforderungen und schreibt diese zugleich fort. Sie schwanke zwischen Kritik und unhinterfragter Übernahme gesellschaftlicher Normen: "Pornographie kann allenfalls in dem Sinne subversiv sein, dass sie die Diskrepanz, die in der Gesellschaft zwischen den offen proklamierten Idealen und den heimlich gehegten Wünschen oder den heimlich ausgeübten Lastern besteht, enthüllt.« (Ebd., S. 202) Damit gleicht sie der von Butler analysierten Strategie des Drag. Obwohl Pornografie gesellschaftliche Normen häufig parodiert oder umkehrt, lädt sie gemäß Marcus deren Beständigkeit erotisch auf: »Pornographie ist heimisch in der Heuchelei, der Ungerechtigkeit; sie nistet sich ein in den gesellschaftlichen Verhältnissen und mästet sich an ihnen. Sie ist selbst ein Bestandteil des augenblicklichen Zustandes, und eines ihrer treibenden, obschon unausgesprochenen Interessen ist es, diesen Zustand aufrechtzuerhalten.« (Ebd., S. 203) Dieses Interesse an der Aufrechterhaltung des momentanen Zustandes schwäche die subversive Kraft der Pornografie.

Marcus' Analysen zur Pornografie sind für mich ein wichtiges Bindeglied $\mathrm{zu}$ den Untersuchungen von Laqueur und Foucault. Ihnen gemeinsam ist, dass sie auf die Wichtigkeit des Begehrens und der Lokalisierung dieses Begehrens im Subjekt hinweisen. Diese Lokalisierung bildet die Grundlage für die Subjektkonzeption der bürgerlichen Moderne, sie findet ihren Niederschlag in Medizin und Ökonomie; sie begründet aber auch Ängste vor Sexualität, Körpern und insbesondere Masturbation. Wie Marcus zeigt, spiegelt die Pornografie des 19. Jahrhunderts dieses angstbesetzte Interesse am begehren- 
den Subjekt. Die Transgressionen, von denen sie erzählt, sprengen einerseits die gesellschaftlichen Konventionen ihrer Zeit, andererseits bestärken sie diese Konventionen, laden sie erotisch auf. Pornografie ist also in einem Sinne transgressiv, wie wir dies aus den Konzeptionen von Jenks und Bataille kennen: Sie hebt gesellschaftliche Konventionen nicht bloß auf, sondern ist auch an deren Aufrechterhaltung beteiligt. Da in der Aufhebung beispielsweise von Klassenschranken Pornografie Hierarchien umstürzt und heimliches Begehren der gesellschaftlichen Eliten sichtbar macht, hat sie auch ein politisches Potenzial.

Marcus' These von der Pornografie als Ausdruck einer infantilen Allmachtsfantasie lässt sich in Bezug setzen zur Narzissmusinterpretation Marcuses. Marcuse wehrt sich dagegen, unter Narzissmus nur unreife Autoerotik zu verstehen. Für ihn bezeichnet Narzissmus eine fundamentale Bezogenheit zur Realität, die die Macht des Leistungsprinzips ein Stück weit brechen und zu einer Überwindung der genitalen Organisation der Sexualität führen könnte. Die der Pornografie zugeschriebene Allmachtsfantasie würde somit eine Rückkehr zur allumfassenden Libido des noch nicht durch das Realitätsprinzip eingeschränkten Individuums möglich machen.

Pornografie als Ausdruck geheimer Allmachtsfantasien: In dieser Auffassung finden sich Laqueurs Kernelemente des Geheimen, der Fantasie und des Exzesses wieder, die im 18. Jahrhundert am bürgerlichen Subjekt und insbesondere an der Masturbation als so bedrohlich empfunden wurden. Besonders offenkundig werden die Allmachtsfantasien der Pornografie in den Schriften des Marquis de Sade, die als Nächstes im Fokus stehen.

\subsubsection{Organisierte Transgression und utopisches Begehren}

Sades Schriften stellen eine zentrale Herausforderung für das Nachdenken über Pornografie dar. In seinen in der zweiten Hälfte des 18. Jahrhunderts entstandenen Texten wechseln sich explizite Beschreibungen sexueller und gewalttätiger Ausschweifungen mit philosophischen Dialogen und Pamphleten $\mathrm{ab}$. Ich möchte im Folgenden verschiedene Interpretationen seiner Schriften aufgreifen. Neben Max Horkheimer und Theodor W. Adorno haben sich auch Simone de Beauvoir, Pierre Bourdieu, Georges Bataille und Susan Sontag mit Sade befasst.

Für Horkheimer und Adorno sind die in Sades Schriften beschriebenen Transgressionen Ausdruck einer verabsolutierten bürgerlichen Vernunft, Exzesse eines totalitären Subjekts. Sie behaupten, in Sades Schriften realisiere 
sich das totalitäre Programm der Aufklärung: »Das Werk des Marquis de Sade zeigt den >Verstand ohne Leitung eines anderen<, das heißt, das von Bevormundung befreite bürgerliche Subjekt.« (Horkheimer/Adorno 1969, S. 93) In einer scharfen Kritik an Immanuel Kant stellen sie Sade als jemanden vor, der den kalkulierenden, planenden, organisierenden Charakter der bürgerlichen Vernunft in einer faschistischen Welt sexueller Ausschweifungen auf die Spitze treibt. Dabei bringen sie Sades pornografische Bilder mit anderen durchorganisierten Sphären der bürgerlichen Existenz in Zusammenhang, wie beispielsweise der Welt des Sports:

Die modernen Sportsriegen, deren Zusammenspiel genau geregelt ist, so dass kein Mitglied über seine Rolle einen Zweifel hegt und für jeden ein Ersatzmann bereit steht, finden in den sexuellen teams [sic!] der Juliette, bei denen kein Augenblick ungenützt, keine Körperöffnung vernachlässigt, keine Funktion untätig bleibt, ihr genaues Modell. (Ebd., S. 95)

Horkheimer/Adorno stellen Sade auch in eine Reihe mit den »dunklen Schriftstellern der bürgerlichen Frühzeit« (ebd., S. 97) wie Niccolò Machiavelli oder Thomas Hobbes, die dem Interesse des Individuums an Selbsterhaltung großes Gewicht beimaßen. Da sich aus der Vernunft keine inhaltlichen Ziele ableiten lassen, tendiert sie gemäß Horkheimer/Adorno dazu, sich als scheinbar objektivierende Instanz über alles Chaotische, Natürliche, Affekthafte aufzuschwingen. Hinter der Maske der Vernunft agiere das sich für autonom haltende Subjekt im Interesse seiner Selbsterhaltung.

Horkheimer/Adorno stellen Sade in einen Zusammenhang mit Nietzsche. Wie dieser feiere er die Ungleichheit: »Es gibt die Schwachen und die Starken, es gibt Klassen, Rassen und Nationen, welche herrschen, und es gibt die, welche unterlegen sind.«(Ebd., S. 105) Die grausame Herrschaft der Starken über die Schwachen halte Sade deshalb wie Nietzsche nicht für legitimationsbedürftig. Wenn jemand ein Unrecht begehe, dann höchstens der Schwache, der seine Schwäche nicht einsehen wolle und dadurch Strafe verdient habe. In Sades Welt ist laut Horkheimer/Adorno Mitleid eine Sünde, sie wird als weibisch und kindisch abgelehnt und steht im Gegensatz zur Effizienz der männlichen Tüchtigkeit, die sich seit der Antike einen bevorzugten Platz unter den bürgerlichen Tugenden gesichert hat. Dabei sei gerade die sehr bürgerliche Empfindung des Mitleids ein Zeichen dafür, wie sehr die Aufklärung die bürgerliche Gesellschaft schon in Richtung Faschismus überschritten habe: »Indem Mitleid die Aufhebung des Unrechts der Nächstenliebe in ihrer 
Zufälligkeit vorbehält, nimmt es das Gesetz der universalen Entfremdung, die es mildern möchte, als unabänderlich hin.« (Ebd., S. 110)

Sades Heldin Juliette begehe ihre Sakrilege gegen die Nächstenliebe nicht aus Lust am Tabubruch, an der Grenzüberschreitung; sie gehe ganz auf in der tüchtigen Organisation des Sakrilegs: »Selbst noch Unrecht, Hass, Zerstörung werden zum Betrieb, seitdem durch Formalisierung der Vernunft alle Ziele den Charakter der Notwendigkeit und Objektivität als Blendwerk verloren haben. Der Zauber geht aufs bloße Tun, aufs Mittel über, kurz, auf die Industrie.« (Ebd., S. 112)

Horkheimer/Adorno heben insgesamt den bürokratischen, mechanischen Aspekt der Sade'schen Exzesse hervor. Damit machen sie den totalitären Anspruch der Allmachtsfantasie sichtbar, deren Ausdruck die Pornografie ist.

Simone de Beauvoir dagegen betont bei Sade die Rolle der Fantasie, der Imagination. Dieser komme deshalb eine so große Bedeutung zu, weil die imaginierten Akte in der Ausführung stets hinter der fantasierten Befriedigung zurückblieben: »Der Augenblick des Pläneschmiedens ist für den Libertin ein ganz besonderer Anblick, weil er die unweigerliche Widerlegung seiner Pläne durch die Wirklichkeit noch außer acht lassen kann.« (de Beauvoir 1964, S. 45) Die realen Objekte des Begehrens könnten nur in ihrer Abwesenheit ganz begriffen werden; seien sie anwesend, stellten sie auch bei größter Passivität Widerstände gegen die Ausführung der pornografischen Fantasie dar. So seien in der Realität nur Annäherungen an das in der Erotik Imaginierte möglich: »Sade hat mit der Erotik das Imaginäre gewählt: nur im Imaginären kann er sich in Sicherheit niederlassen, ohne Gefahr zu laufen, enttäuscht $\mathrm{zu}$ werden.« (Ebd.) Sade ist für de Beauvoir nicht die vollkommen asoziale Figur, als die er sich inszeniert. Da seine sexuellen Bedürfnisse ganz offensichtlich nicht mit der herrschenden Moral in Einklang zu bringen gewesen seien, sei Sade von Schuldgefühlen getrieben gewesen. In diesen Schuldgefühlen bleibe er der Gesellschaft verbunden - de Beauvoir sieht Sades Werk als großangelegten Versuch, sich vor der Gesellschaft für seine Bedürfnisse $\mathrm{zu}$ rechtfertigen:

Wie schon oben erwähnt, verfolgte er mit seinem Schreiben in erster Linie die Absicht, sein Gewissen zu beruhigen; um aber ein gutes Gewissen haben zu können, musste er seine Mitmenschen veranlassen, ihn freizusprechen, ja, sein Tun zu billigen. Er behauptet nicht in seinen Schriften, sondern plädiert, und um sich verständlich machen zu können, übernimmt er die seiner Gesellschaft geläufigen literarischen Formen und die anerkannten Meinun- 
gen. In einem rationalistischen Jahrhundert herangewachsen, hält er das folgerechte Denken für die wirksamste Waffe. (Ebd., S. 48)

Sades Stilmittel ist laut de Beauvoir die Parodie. In den philosophischen Wortgefechten zwischen den Darstellungen sexueller Ausschweifungen und Überschreitungen versuche Sade die Exzesse zu rationalisieren. Diese Rationalisierungen läsen sich wie Parodien auf aufklärerische Diskurse. Dieser subversive Einsatz von Parodie solle die leere Instrumentalität hinter dem humanistischen Anspruch der Aufklärung sichtbar machen. Was also Horkheimer/Adorno in Sades Schriften diagnostizierten, ist für de Beauvoir ein gezielter subversiver Einsatz des Stilmittels der Parodie. Wie sie aufzeigt, nimmt im Denken der Aufklärung die Natur die Stellung ein, die vorher Gott eingenommen hatte. Sade spiegle der Aufklärung nun die Verklärung der Natur zurück: »Sade ist der einzige, der erkannt hat, dass die Sexualität auch Egoismus, Tyrannei und Grausamkeit ist: er erfasst einen naturgegebenen Trieb als Einladung zum Verbrechen.«(Ebd., S. 59) Damit trifft sich de Beauvoirs Analyse mit Marcus' Befund über das Verhältnis von Pornografie zum literarischen Kult der Empfindsamkeit, wo die menschliche Natur in Konflikt mit Anforderungen der Moral und der Gesellschaft gerät. Indem sie die Diskrepanz zwischen proklamierten Idealen und heimlichen Lastern enthüllt, spiegelt die Pornografie herrschende Denkmuster und Moralvorstellungen. Sade wendet in seinen Schriften den Kult der Natur gegen dessen Anhänger. Entsprechend durchzieht Sades Schriften laut de Beauvoir eine entschiedene Ablehnung der Natur:

Mit einer Strenge, die der eines Kant entspricht und in der gleichen puritanischen Tradition wurzelt, muss für Sade das freie Handeln von jeglicher Sensibilität gelöst sein; wenn es durch affektive Beweggründe bestimmt wäre, würde es uns wiederum zu Sklaven der Natur, nicht aber zu autonomen Wesenheiten machen. (Ebd., S. 74)

In seinem Insistieren auf Autonomie der Subjekte und freies Handeln lässt sich Sades Konzeption einem liberalen oder humanistischen Modell der Transgression zuordnen, um Zappes Terminologie aufzunehmen. Die transgressiven Akte stellen für Sade einen Weg dar, wie sich das Subjekt von der Bestimmtheit durch die Natur befreien kann. Der Traum des autonomen Subjekts befeuert also auch Sades Libertins, die sich eben dadurch, dass sie sich von ihren Trieben leiten lassen, über die Natur aufschwingen. In Butlers Konzeption haben wir Parodie als Möglichkeit zur Transgression im Dienst 
einer Verflüssigung von Normen kennengelernt. Im Gegensatz dazu bleibt Sades Einsatz der Parodie einem Modell der Transgression verhaftet, in dem sich autonome Subjekte aus ihrer Unterdrückung durch gesellschaftliche Normen befreien und in einen Raum jenseits dieser Normen vorstoßen.

Realisiert sich in Sades Schriften folglich ein utopisches Begehren, das sich über gesellschaftliche Konventionen bloß mokiert, da es Lust explizit im Bruch dieser Konventionen sucht? Sowohl Horkheimer/Adorno als auch de Beauvoir weisen darauf hin, dass sich Sades Texte durchaus als Weiterführung aufklärerischer Logiken lesen lassen. Die Organisiertheit der Exzesse und ihre rationalistische, argumentative Rechtfertigung sprechen dafür, dass Sades Schriften, wie andere pornografische Werke auch, herrschende Normen in Frage stellen und gleichzeitig fortschreiben. De Beauvoir betont, wie gerade die Wirklichkeit einer Realisierung pornografischer Allmachtsfantasien immer wieder Widerstände entgegensetzt. Reale Menschen als Objekte des Begehrens lassen sich nicht widerstandslos in das Ausführen pornografischer Szenarien integrieren. Diese Erkenntnis findet sich auch in Batailles Sade-Interpretation, die als Nächstes Thema ist.

\subsubsection{Die Relationalität des Begehrens}

Bataille findet an Sades Denken wertvoll, dass es den Exzess zum Thema macht. Denn wir alle erlebten Momente des Exzesses, die das Fundament unseres Lebens aufs Spiel setzten, und das Ignorieren dieser Momente würde ein Verkennen dessen, was wir sind, bedeuten. Doch für Bataille begeht Sade einen fundamentalen Denkfehler, indem er die wechselseitige Abhängigkeit der Menschen negiert: "Jamais l'indépendance d'un homme ne cessa d'être mieux qu'une limite apportée à l'interdépendance, sans laquelle aucune vie humaine n'aurait lieu.« (Bataille 1987, S. 168) Welche Bedeutung hat das Denken der wechselseitigen Abhängigkeit der Menschen für das Konzept des Erotismus, und was folgt daraus für die Pornografie?

Laut Jenks versteht Bataille unter Erotismus eine Bejahung des Lebens einschließlich Sex, Gewalt und Tod. Da diese Bejahung den Menschen überfordere, kreiere dieser die beiden Sphären des Profanen und des Sakralen. Das Profane sei die zivilisierte Welt der Regeln, das Sakrale die Welt der Transgression auf das Göttliche hin. Obszön werde genannt, was aus beiden Sphären herausfalle, die transgressive Kraft des Eros, der Sexualität mit all ihren Risiken. Der Theoretiker Julien Servois bringt Batailles Obszönitätsbegriff folgendermaßen auf den Punkt: 
Le qualificatif obscène n'a aucune signification morale chez Bataille: il est l'expression d'un dégoût provenant de la défaillance primordiale, de l'impuissance de l'homme à vivre sans réserve dans la violence. L'homme ne rejette pas l'obscène au nom de la conscience de sa dignité propre, mais seulement en raison de sa faiblesse. (Servois 2009, S. 41)

Wie Jenks ebenfalls aufzeigt, bewertet Bataille die obszöne Kraft des Eros positiv, sie ist die ursprüngliche, bejahende Kraft; die negative ist die nach Besitz strebende Kraft der bürgerlichen Welt. Am Beispiel der Nacktheit lässt sich Batailles Obszönitätsbegriff gut demonstrieren: »La nudité est pas toujours obscène et elle peut apparaître sans rappeler l'inconvenance de l'acte sexuel. C'est possible, mais en règle générale, une femme se dénudant devant un homme s'ouvre à ses désirs le plus incongrus." (Bataille 1976, S. 129) Für das Tier sei Nacktheit normal, erst der Mensch rücke mit der Begrenzung der Sichtbarkeit des nackten Körpers diesen in den Bereich des Erotischen. Obszön sei Nacktheit also nicht per se, sondern erst in Abhängigkeit von gesellschaftlichen Normen, welche die Sichtbarkeit des nackten Körpers regulierten. Das Obszöne bezeichne erst mal kein Objekt, sondern eine Relation; doch diese Relation sei instabil. Denn was als obszön erscheine, wechsle je nach Zeit, Ort und Gelegenheit. Das Obszöne liege demzufolge in der Beziehung zwischen dem als obszön bezeichneten Objekt und der dieses als obszön bezeichnenden Person. Es stecke den verbotenen Bereich der Sexualität ab.

Wenn das Obszöne eine Relation bezeichnet, ist auch das mit ihm verbundene Begehren relational. Bataille betont, wie das auf einen anderen Menschen gerichtete Begehren die Beziehung $\mathrm{zu}$ diesem verändert. Indem ein Mensch einen anderen begehre, werde dieser zu seinem Objekt der Begierde. Dieses Objektwerden eines Subjekts bedeutet laut Bataille, dass das Subjekt ein Stück seiner Souveränität aufgibt, um Teil einer erotischen Totalität zu werden, eine Funktion dieser Totalität. Bataille zieht einen Vergleich zum Sklavenwesen der Antike: Dass die Sklaven Menschen und keine Dinge seien, sei den alten Griechen bewusst gewesen. Die Sklaverei sei als Fiktion zu verstehen, die es den Griechen möglich machte, sich anderer Menschen wie eines Werkzeugs zu bedienen. Bataille sagt über die Sklaven: „Mais dans la mesure où ils ont ainsi aliéneé une partie de leurs droits à la totalité souveraine, ces mêmes êtres acquièrent la possibilité d'être une fonction de cette totalité, ainsi la fonction érotique.« (Ebd., S. 120) Das Sklavenwesen der Antike habe also auf einem bewussten Aberkennen von Rechten und einer entsprechenden Reduktion von Subjekten auf einen Objektstatus beruht. Dieselben Übergriffe 
nehmen laut Bataille Subjekte vor, wenn sie andere Subjekte begehren. Das Überschießen des Begehrens verlange eine gewisse Passivität des Objektes dieses Begehrens: „Si l'on veut, le désir cherche toujours un objet mobile et vivant et un autre fixe et mort. Et ce qui caractérise l'érotisme n'est pas le mobile vivant mais le fixe mort, qui seul est détaché du monde normal.« (Ebd., S. 124f.)

Und weshalb eignen sich speziell die Frauen und nicht auch die Männer zur Reduktion auf einen Objektstatus? Dies begründet Bataille mit der passiven Attitüde der Frauen, die sich dem aggressiven, männlichen Begehren anbieten. Entsprechend stellt er die These auf, dass nur die Reduktion der Frauen auf ein Besitztum die erotischen Möglichkeiten des Begehrens hervorgebracht habe: »La jalousie est peut-être la plus appauvrissante des vertus et il est certain qu'elle s'oppose au bonheur. Mais l'enrichissement de l'érotisme voulut cette réduction des femmes à l'objet d'une possession.« (Ebd., S. 121) Die Konsequenz dieser passiven Attitüde der Frauen sei die Prostitution. Die Prostituierte zeuge als Figur von dieser schambesetzten Reduktion der Frau auf ein Besitztum: "Il est nécessaire en effet qu'un être soit envisagé comme une chose afin que le désir compose une figure qui lui réponde.« (Ebd., S. 124) In dieser strikten Geschlechterordnung haben die Männern den aktiven, die Frauen den passiven Anteil an der Relation des Begehrens. Hier äußert sich in Batailles Geschlechtskonzeption eine gesellschaftlich konstruierte Aktiv/passiv-Binarität, die er essenzialisiert.

Wie Bourdieu feststellt, prägt diese Aktiv/passiv-Binarität auch in Sades Schriften das Geschlechterverhältnis. Aus seiner Sicht hat Sade die von Claude Lévi-Strauss beschriebene Ökonomie des Frauentausches auf die Spitze getrieben:

Das Inzest-Tabu, in dem Lévi-Strauss den Gründungsakt der Gesellschaft sieht, da es den Imperativ des Austauschs, im Sinne einer Kommunikation von Ebenbürtigen unter den Männern, impliziert, ist das Korrelat der Instituierung der Gewalt, durch die die Frauen als Subjekte des Austausches und der Allianz negiert werden, Beziehungen, die zwar durch sie zustande kommen, aber nur, indem sie die Frauen auf den Status von Objekten oder, besser, von symbolischen Instrumenten der männlichen Politik reduzieren: Dazu verurteilt, als Zeichen des Vertrauens zu zirkulieren und so dauerhafte Beziehungen zwischen den Männern herzustellen, werden sie auf den Status von Produktions- und Reproduktionsmitteln des symbolischen und sozialen Kapitals reduziert. (Bourdieu 2005, S. 80) 
Die Weise, wie Sade Frauenkörper zwischen Männern zirkulieren lasse, decke die gewaltsame Objektivierung auf, die in der allgemeinen Zirkulation der Frau zur Stabilisierung der männlichen Ökonomie und Herrschaft stecke. Bourdieu wehrt sich gegen die rein semiologische Sicht von Lévi-Strauss, dem ebendiese Gewalt des Frauentauschs entgehe. Mit dem Frauentausch sei der Status der Frau als Objekt und Ware im männlichen Herrschaftssystem bereits festgelegt. Sades gewaltförmige sexuelle Arrangements machten diesen objekthaften Status der Frau auf radikale Weise deutlich.

Auch der Publizist Roger Willemsen setzt in einem Beitrag in der Aufsatzsammlung Die nackte Wahrheit: zur Pornographie und zur Rolle des Obszönen in der Gegenwart die mit dem Obszönen verbundene Verdinglichung in einen Zusammenhang mit der kapitalistischen Gesellschaft. Er macht darauf aufmerksam, dass an der Pornografie nicht die Nacktheit der Frau Anlass zur Empörung gebe, sondern dass die erniedrigende Art und Weise der Darstellung und der Einbettung in einen inhaltlichen Zusammenhang obszön erscheine. Genau diese Techniken und Inhalte sind aber im gesellschaftlichen Umgang mit Frauen und Sexualität omnipräsent. Die Gesellschaft versucht also die sie durchdringende Obszönität abzuspalten und als Pornografie gleichzeitig zu konsumieren und abzulehnen. Willemsen sieht damit die kapitalistische Gesellschaft heimgesucht von ihrem immanenten Warencharakter. Das Obszöne in der Pornografie »kopiert die gesellschaftlichen Lustverbote, um die Illusion zu erzeugen, sie würden gebrochen. Die erotische Potenz des Verbots gibt im Bruch seine Erregung frei.« (Willemsen 1997, S. 147)

Im Fall der Pornografie treffen also Aspekte der bürgerlichen Form von Sexualität als Besitz und Ware auf Aspekte der transgressiven, obszönen Kraft der Sexualität. In Anlehnung an Bataille sind dies jedoch nicht etwa einfach zwei Seiten derselben Medaille, sondern die bürgerliche Form von Sexualität ist als Reaktion zu verstehen, um die ursprüngliche, Angst auslösende transgressive Kraft der Sexualität unter Kontrolle zu bringen. Doch es bleibt ein Überschuss, der sich als Obszönes der Reduktion von Sexualität auf eine Ware entzieht.

Sexuelles Begehren liegt demnach nicht gänzlich in einem Bereich außerhalb rationaler oder gesellschaftlicher Kontrolle. Wie die Filmwissenschaftlerin Elisabeth Cowie betont, ist sexuelles Begehren abhängig von gesellschaftlichen Normen:

However, the opposition control/beyond control arises only once »control « is imposed - which, one might argue, following Lévi-Strauss, is the moment of 
the emergence of human society as such. The »beyond control« is the desire, including or especially sexual desire. It is defined by what it is not - namely, socially organized sexuality. (Cowie 1992, S. 134)

Sexuelles Begehren definiere sich also über den Ausschluss und damit in $\mathrm{Ab}$ hängigkeit von sozial organisierter Sexualität. Begehren hänge insbesondere auch ab vom Begehren des anderen, wobei der andere keine reale Person sein müsse:

This need not be any real person's desire, and indeed the difficulty of harmoniously realizing one's wishes with a sexual partner is one of the major reasons for the success of pornography, of ready-made scenarios which figure wishes without the danger of being found »not good enough« encountered in actual sexual relations. (Ebd., S. 146)

Pornografie erfüllt Wünsche ohne das Risiko der Ablehnung, mit dem in realen sexuellen Beziehungen gerechnet werden muss. Letztlich ist es dies, was Bataille mit der Verdinglichung innerhalb der Relation des Begehrens anspricht und was auch Sades Schriften durchzieht: Das schrankenlose Begehren lässt sich nur im Imaginären erfüllen, weil ein reales Objekt des Begehrens nie so passiv ist, dass es dem Begehren keine Bedrohung mehr entgegensetzen würde. Das Begehren entsteht zwar innerhalb eines sozialen Kontextes, es lässt sich aber nur in einem imaginären Kontext vollständig realisieren. Diese Realisationsmöglichkeit bietet die Pornografie.

\subsubsection{Das Verlangen nach Überschreitung}

Die Möglichkeiten dieses imaginären Kontextes zur Realisierung von Begehren, den die Pornografie bereitstellt, hat Susan Sontag analysiert. Sie befasst sich in ihrem Essay On Pornography (1982) fast ausschließlich mit Pornografie als literarischer Gattung. Eines der ersten Merkmale dieser Gattung, das ihr auffällt, ist das Pathos. Wie Marcus herausgearbeitet hat, parodiert Pornografie als Stilmittel sowohl gesellschaftliche Normen als auch deren Sprache; auch de Beauvoir beobachtet in Sades pornografischen Schriften einen subversiven Einsatz von Parodie. Laut Sontag ist Pornografie selbst jedoch immun gegen Parodie. Das Funktionieren der Pornografie setze eine gewisse Ernsthaftigkeit, ein gewisses Pathos des Dargestellten voraus:

Denn Pornographie kann sich nicht selbst parodieren. Es gehört zum Wesen der pornographischen Phantasie, dass sie überkommene Schemata der Per- 
sonenzeichnung, des Schauplatzes und der Handlung vorzieht. In der Pornographie dominiert der Typus, nicht das Individuum. (Sontag 1982, S. 65)

Viele Beispiele Sontags für literarisch hochwertige Pornografie stammen aus der französischsprachigen Literatur. Sie schätzt an diesen Beispielen, dass sie ein Konzept von Sexualität haben, das aus ihrer Sicht nicht auf dem freudianischen Repressionsmodell basiert: »Die französischen Autoren scheinen davon auszugehen, dass `das Obszöne tief im menschlichen Bewusstsein verankert ist und nicht als eine Folge der Abneigung einer kranken Gesellschaft gegen den Körper betrachtet werden kann.« (Ebd., S. 71) Deshalb greift sie Batailles Konzeption der Sexualität auf; indem dieser die erotische Erfahrung in Verbindung mit Überschreitung und Tod bringe, gehe er über die Schriften eines Marquis de Sade hinaus:

Man hat in der Tat den Eindruck, dass die ermüdende Tendenz zur Wiederholung, die in Sades Schriften sichtbar wird, die Folge seines Ausweichens vor dem unausweichlichen Ziel oder Hafen eines wahrhaft konsequenten Wagnisses der pornographischen Phantasie ist. Wenn die pornographische Phantasie konsequent ist, das heißt, wenn sie allein auf den Cenuss der Übertretung ausgerichtet ist und nicht auf den bloßen Cenuss als solchen, dann ist der Tod das einzig mögliche Ende ihrer Odyssee. (Ebd., S. 76)

Im Universum der pornografischen Fantasie zähle nur der erotische Imperativ. Alles, was in ihr vorkomme, werde auf seine erotische Verwendbarkeit reduziert:

Daher lässt sich die Weigerung der Pornographie, permanente Unterschiede zwischen den Geschlechtern zu machen oder irgendwelche sexuellen Prioritäten oder sexuellen Tabus gelten zu lassen, »strukturell« erklären. Die Bisexualität, die Missachtung des Inzest-Tabus und ähnliche charakteristische Züge der pornographischen Literatur dienen dem Zweck einer Vervielfachung der Möglichkeiten des sexuellen Austauschs. (Ebd., S. 81)

Ein Zweck der Pornografie sei es, die Vielfalt der Möglichkeiten des sexuellen Austauschs darzustellen. Dadurch stelle Pornografie ein wichtiges Mittel für den Menschen bereit, sich als Individuum zu überschreiten:

Das Verlangen des Menschen nach Überschreitung des »Persönlichen« ist nicht weniger stark als sein Verlangen, Person, Individuum zu sein. Diesem Verlangen jedoch kommt unsere Cesellschaft nur wenig entgegen. Sie hält vorwiegend dämonisierende Vokabulare bereit, wo es darum geht, dieses 
Verlangen zu umschreiben und Denk- und Verhaltensschemata zu entwerfen. (Ebd., S. 84)

Pornografische Schriften enthalten also gemäß Sontag Vokabulare, die über eine Wahrheit der menschlichen Existenz sprechen: das Verlangen nach Transgression, Überschreitung. Wer von Pornografie nichts wissen wolle, schneide sich demzufolge von Erkenntnisquellen über seine Existenz ab: »Das, was man die Dichtung der Überschreitung nennen könnte, ist zugleich Ausdruck eines Wissens. Derjenige, der die Übertretung begeht, bricht nicht nur ein Gesetz. Er begibt sich an einen Ort, den die anderen nicht kennen; und er weiß etwas, das die andern nicht wissen.« (Ebd., S. 85) Letztlich wirft Sontag den Kritikern der Pornografie Borniertheit vor. Die Frage nach dem Umgang mit Pornografie sei eine Frage nach dem Umgang mit Wissen:

Es kann sein, dass jede Erweiterung der Erfahrungen und des Bewusstseins ohne sorgfältige und umfassende seelische Vorbereitung für die meisten Menschen verderblich ist. Dann aber müssen wir fragen, was das leichtfertige und unbegrenzte Vertrauen rechtfertigt, das wir der schier unbegrenzt scheinenden Verfügbarkeit von Wissen anderer Art entgegenbringen und das aus unserer optimistischen Einwilligung in die Umwandlung und Erweiterung der menschlichen Kapazität durch die Maschine spricht. (Ebd., S. 86)

Sontag stellt hier die Frage, warum Menschen der Erweiterung von Wissen in gewissen Bereichen sehr unkritisch gegenüberstehen und in anderen sehr kritisch. Diese Frage scheint im Licht der heutigen Verfügbarkeit und Manipulierbarkeit von Wissen über Internet und Social Media fast noch drängender. Es geht Sontag also um den Umgang mit Wissen und darum, wie Wissen auf unser Bewusstsein einwirkt:

Die Frage ist nicht, ob Bewusstsein oder ob Wissen; die Frage ist: wie steht es mit der Beschaffenheit des Bewusstseins und des Wissens. Und das wiederum lädt zum Nachdenken ein über die Beschaffenheit oder Qualität des menschlichen Subjekts - und damit über die problematischste aller Normen. (Ebd., S. 87)

Pornografie dient Sontag zufolge dazu, die Normen des menschlichen Subjekts $\mathrm{zu}$ hinterfragen. Mit dieser Meinung begibt sie sich in die Nähe von Foucault, der in der Sexualität die Möglichkeit lokalisiert, wo sich das Subjekt selbst in Frage stellen und überschreiten kann, bis an die Grenzen der Sprache. Wie ist aus dieser Perspektive die heute dominierende, nicht sprachliche 
Form der Pornografie zu beurteilen, die in Form von Bildern und Videos im Internet zirkuliert? Ist, wie Marcus vermutet, der Film das eigentlich adäquate Ausdrucksmittel der Pornografie?

\subsubsection{Die Interaktion zwischen Medium und Subjekt}

Foucault behauptet, das Sexualitätsdispositiv der bürgerlichen Moderne sei von einem Willen zum Wissen angetrieben. Auch Sontag betont die Bedeutung der Pornografie als Erkenntnisquelle. Laut der Philosophin Svenja Flasspöhler sind das Sexualitätsdispositiv und die Pornografie zwar beides spezifische Diskursformationen der bürgerlichen Moderne, aber sie dienen nicht demselben Zweck: »Während das Sexualitätsdispositiv die Utopie des heterosexuellen, fortpflanzungswilligen und monogamen Körpers als Regulativ an den Himmel hängt, birgt der Pornofilm eine ganz andere Art von Utopie - nämlich diejenige einer Lustmaschine.« (Flasspöhler 2007, S. 210) Das Sexualitätsdispositiv reguliere die Körper über ein Ideal des normierten Gesellschaftskörpers. Die Pornografie hingegen versuche, einen scheinbar unregulierten Triebkörper zur Darstellung zu bringen, der durch die Ideale des Sexualitätsdispositivs aus der zivilisierten Gesellschaft verdrängt werde. Dieser Versuch sei utopisch, weil uns dieser Triebkörper nie real zur Verfügung stehe:

Ein Körper aber, der nichts anderem als der Lust verpflichtet ist (eine Lust, die immer wieder in Gang gesetzt wird, um die Erregung des Betrachters aufrechtzuerhalten), führt die vermeintliche»Wahrheit « des Triebkörpers in einem Zuge ad absurdum - bzw. lässt ihn umschlagen in einen utopischen Lustmaschinenkörper. (Ebd., S. 81)

Flasspöhler behauptet, dass dieser Lustmaschinenkörper das erste Mal in Sades Werk auftritt. Sades Materialismus strebe nichts anderes als Erregung an. Damit bilde er die bessere Vorlage, um Pornografie zu verstehen, als Foucaults Sexualitätsdispositiv, in dem Lust nur ein Nebeneffekt des Willens zum Wissen sei. Im Unterschied zum Pornofilm zeichneten sich Sades Schriften durch eine Offenheit aus, die das Publikum zum Komplizen der in ihnen begangenen Transgressionen mache:

Der Sade-Leser bringt sich durch die mit der überschreitenden Imagination verbundene Angst-Lust zum Höhepunkt; der Pornofilmbetrachter dagegen hat seine Angst fest im Griff, weil die Apparatur das Reale (zumindest an- 
scheinend) ansichtig werden lässt, ohne dass es ihm jemals tatsächlich gefährlich werden könnte. (Ebd., S. 186f.)

Der Medienwechsel von der Schrift zum Film habe für die Pornografie entscheidende Konsequenzen. Sades Schriften versuchten, das Reale der Sexualität auszusprechen, und sorgten gerade dadurch für Erregung. Gleichzeitig überbiete sich Sade mit immer unglaublicheren Transgressionen, die einen Vorstellungsraum aufmachten, den die Lesenden mit ihrer Fantasie füllen müssten. So vollzögen diese die gleichzeitig Angst und Lust auslösenden Überschreitungen in ihrer Vorstellungskraft selbst mit. Dem Pornofilm dagegen gelinge es als Medium der bewegten Bilder in einer viel umfassenderen Weise, das Reale der Sexualität darzustellen, sodass es keinen Raum gebe, welcher der Vorstellungskraft der Betrachter überlassen bleibe. Das Reale der Sexualität werde durch die Apparatur gezähmt und auf Distanz gehalten:

Der postmoderne Masturbator vollendet sich nicht mehr vor dem Hintergrund einer Angst-Lust, sondern gerade vor dem Hintergrund einer Domestizierung des angstgenerierenden Realen: Erregend ist, was in den Bereich des Sichtbaren, und das heißt: aus dem Bereich der Todesdrohung hinaus gelangt. (Ebd., S. 212f.)

Die Apparatur des Pornofilms hole also das angstgenerierende Reale der Sexualität ans Licht und streiche dadurch das für das moderne Subjekt konstitutive unerfüllbare Verlangen danach aus. Die Schriften Sades erregten, weil sie einen Raum öffneten für das Begehren, der Pornofilm dagegen errege, weil er die Illusion vermittle, die mit dem Begehren verkoppelte Angst unter Kontrolle zu haben. So bezeichnet Flasspöhler den Pornofilm auch als rückwärtsgewandte Utopie, die dem modernen Subjekt eine repräsentativtransparente Sexualität ohne unbewusste Ängste oder Lüste vorgaukle: »Der Pornofilm überführt das von Sade auf den Plan gerufene Verlangen also zurück in die klassische, repräsentative Transparenz: Das durch das Verlangen eingeführte Unbewusste ist ad acta gelegt.« (Ebd., S. 250)

Für Horkheimer/Adorno sind die in Sades Schriften beschriebenen Transgressionen Ausdruck einer verabsolutierten und totalitär gewordenen bürgerlichen Vernunft. Flasspöhler dagegen sieht bei Sade die der Pornografie eigene Utopie des Körpers als Lustmaschine verwirklicht. Der Leser werde zum Komplizen der dargestellten Transgressionen, die Imagination dieser Überschreitungen generiere eine erregende Angst-Lust. Dagegen liege der Reiz des heutigen Pornofilms vielmehr in der Kontrolle der mit Sexualität verbun- 
denen Ängste - eine eher rückwärtsgewandte Utopie, wie Flasspöhler findet. Während Horkheimer/Adorno das Durchorganisierte, Mechanische in Sades Pornografie betonen, hebt Flasspöhler deren im Gegensatz zum Pornofilm stehende Offenheit für das Imaginieren der Überschreitung hervor.

Eine ähnliche Position gegenüber dem Pornofilm vertritt der Philosoph Slavoj Žižek. Er führt diesen als Beispiel für das Phänomen der Interpassivität an. Dies erstaunt auf den ersten Blick, weil das Nutzen von Pornografie besonders im Fall der Internetpornografie in der Regel unter dem Stichwort Interaktivität reflektiert wird. Doch Žižek sieht dies anders: »Pornofilme sind nicht länger mehr in erster Linie die Mittel, um den Zuschauer für seine oder ihre einsame Befriedigung zu erregen - sondern das Starren auf den Bildschirm, wo >die action ist‘, reicht völlig aus.« (Žižek 2008, S. 38) Das Subjekt könne beunruhigende Aspekte der Sexualität wie Passivität und Genuss an die Pornografie auslagern:

Im Fall der Interpassivität bin ich im Gegenteil passiv durch den Anderen. Ich trete dem Anderen den passiven Aspekt (das Genießen) meiner Erfahrung ab, während ich aktiv engagiert bleiben kann (ich kann abends weiterarbeiten, während der Videorekorder sich passiv für mich vergnügt; ich kann finanzielle Arrangements für das Vermögen des Verstorbenen treffen, während die Klageweiber für mich trauern). (Ebd., S. 39)

Die tiefere Ursache der Interpassivität sei dabei die Furcht vor der verstörenden Erfahrung des Genießens. Indem das Genießen an Apparate ausgelagert werde, müsse das Subjekt sich dem Risiko des Genießens nicht aussetzen und habe trotzdem seine Pflicht zu genießen erfüllt. Laut Žižek ist die Gesellschaft heute allgemein von einem Imperativ des Genießens geprägt; da dieser Imperativ die Menschen überfordere, wählten sie interpassive Formen des Genießens.

Wie für Žižek ist auch für Flasspöhler Pornografie im Falle des Pornofilms nicht transgressiv, sondern präsentiert eine Utopie der Regression. Ich halte diese Sicht jedoch für reduktionistisch. Welche Reaktion Pornofilme auslösen, hängt wesentlich von der Struktur des Begehrens des betrachtenden Subjekts ab, dieses lässt sich durch die Distanz erzeugende Apparatur nicht einfach ausstreichen. Flasspöhler hat recht damit, dass ein wesentlicher Aspekt der Attraktivität von Pornofilmen darin besteht, dass das Subjekt seine Angst vor der Sexualität meistern kann: Es kann in ihnen Angst auslösende Szenarios auf eine ungefährliche und Lust erzeugende Weise durchspielen. Pornofilme bieten sozusagen dem Subjekt einen gewissen Schutz vor dem 
transgressiven Charakter der Sexualität, aber das heißt nicht, dass sie selbst nicht transgressiv sind. Filmische Fetischpornografie kann zum Beispiel den Rahmen einer gesellschaftlich akzeptierten Sexualität sprengen. Ohne unbewusstes Begehren nach dem in der Pornografie präsentierten Fetisch wird sie das Subjekt nicht affizieren. Dem diesen Fetisch begehrenden Subjekt bietet die Pornografie dagegen die Gelegenheit zur Überschreitung seiner gelebten Sexualität.

Eine Gegenposition zu Flasspöhlers These ließe sich auch bei Butler finden. In Butlers Darstellung ist das Subjekt schon ein sexuelles Wesen respektive durch sexuelle Beziehungen bestimmt, bevor es sich selbst als sexuelles Wesen begreift. Es kann sein eigenes Bestimmt- und Geformtsein durch Sexualität und sexuelle Beziehungen reflexiv nicht vollständig durchdringen, was sich natürlich bei der Wahl der Sexualpartner und der Gestaltung der sexuellen Beziehung zu ihnen bemerkbar macht, nämlich als Passivität, als ein - bis zu einem gewissen Grade - Ausgeliefertsein an seine Begierden. Das Subjekt hat keine volle Kontrolle darüber, was es begehrt und was es erregt. Pornografie erinnert das Subjekt daran, dass es sein Begehren nicht unter Kontrolle hat, es ist nicht Herr über diese Erfahrung.

Die Diskursformation Pornografie lässt sich also nicht so scharf vom Sexualitätsdispositiv abgrenzen, wie Flasspöhler das möchte. Die Ideale der Transparenz, die Suche nach dem wahren Kern der Sexualität, die Flasspöhler dem Pornofilm zuschreibt, sind auch Bestandteile des Sexualdispositivs. Flasspöhler behauptet, die Lust sei nur ein Nebenprodukt des Willens zum Wissen. Doch im Willen zum Wissen steckt die Lust auf das Reale der Sexualität bereits drin, auf welcher der Pornofilm dann basiert.

Flasspöhler erkennt hingegen meiner Meinung nach richtigerweise, dass in Sades Schriften die Lesenden dazu eingeladen werden, mit ihrer Imagination an Transgressionen teilzunehmen. Erregend ist dabei gerade das AngstLust bereitende Balancieren auf der Grenze des gesellschaftlich Akzeptablen. Dies geht mit Zappes postmodernen Modell von Transgression konform. Sade selber verfolgt in der Rhetorik seiner Schriften dagegen ein liberales oder humanistisches Modell der Transgression, sein literarisches Personal befreit sich in der Überschreitung von falschen gesellschaftlichen Normen hin zu einem authentischen, seiner Natur gemäßen Existenz. Nur machen die Lesenden selbst diese Bewegung nicht mit, sie verbleiben auf der Grenze, weil nur dieses Balancieren den Mechanismus der Angst-Lust in Gang hält.

Mit der Interaktion zwischen pornografischen Inhalten und dem diese nutzenden Subjekt beschäftigt sich auch Sven Lewandowski. Er nimmt die 
Annahme der Cultural Studies zum Ausgangspunkt, dass die Bedeutung medialer Inhalte nicht einseitig durch das Senden des Inhalts festgelegt werden kann, sondern in der Rezeption des Inhalts erst geschaffen wird. Demnach ist das Pornografische an pornografischen Inhalten nicht einfach da, sondern entsteht erst durch die Interaktion des Subjekts mit den Inhalten. Diese Annahme erklärt, weshalb unterschiedlich explizites Material pornografisch oder auch nicht gelesen werden kann. Doch ist, wer Pornografie nutzt, in der Interaktion mit pornografischem Material vollkommen frei? Lewandowski bestreitet dies. Er sieht die Wahl des Ausgangsmaterials als unbewusst determiniert an. Denn die Nutzung von Pornografie unterscheide sich von der Nutzung anderer medialer Inhalte darin, dass das in der Pornografie angesprochene Sexuelle wesentlich mit dem Unbewussten des Subjekts verknüpft sei. Da sexuelle Erregung über mehrheitlich unbewusste Begehrensstrukturen gesteuert werde, seien diese Strukturen für die Interaktion mit Pornografie prägend.

Die Freiheit der Bedeutungs- und Sinnkonstruktion aufseiten des Nutzers wird also weniger durch das Ausgangsmaterial beschränkt als dadurch, dass er in seinen Wahrnehmungs- und Deutungsweisen nicht vollkommen frei ist, sondern diese im Dienste innerpsychischer Kompromissbildungen stehen. Kurz gesagt: Die massenmedialen Produkte mögen zwar polysem sein, die Art und Weise, wie Rezipienten Bedeutungen konstruieren, ist jedoch nicht kontingent. (Lewandowski 2012, S. 37)

Die Nutzenden erkennten und deuteten Pornografie also entlang »innerpsychischer Kompromissbildungen«. Was meint Lewandowski damit? Schon Marcus hat darauf hingewiesen, dass Pornografie von einer Logik der Fantasie und Assoziation geprägt ist. Lewandowski vergleicht Pornografie mit dem Traum, der gemäß psychoanalytischen Konzepten bewussten und unbewussten Wünschen der Träumenden eine Bühne bietet. Laut Freud kommen diese Wünsche und Wunscherfüllungen im Traum jedoch in entstellter Form daher, um auf das träumende Subjekt nicht so verstörend zu wirken, dass dieses aufwachen würde. Damit stelle der Trauminhalt einen Kompromiss zwischen den Wünschen des Subjekts und dem Ziel des ungestörten Schlafs dar. Analog stellt nun laut Lewandowski der Inhalt der Pornografie eine Kompromissbildung dar zwischen sexuellen Wünschen und dem Bestreben des Subjekts, durch die Drastik der Darstellungen nicht abgestoßen und aus der sexuellen Erregung herauskatapultiert zu werden. Lewandowski schreibt: »Und wie der Traum alles vermeiden muss, was den Schlaf stören könnte, 
so müssen pornographische Darstellungen alles vermeiden, was die sexuelle Erregung des Betrachters (zer-)stören könnte.« (Ebd., S. 27) Die sexuelle Erregung sei also analog zum Schlaf das Vehikel für verdrängte Wünsche. Deren Erfüllung dürfe aber nicht in einer Form dargestellt sein, die so viel Angst oder Abscheu errege, dass die sexuelle Erregung zunichtegemacht werde.

Die sexuelle Erregung ermöglicht - gleich wie sie zustande kommt -ähnlich wie der Schlaf eine Herabsetzung der Wirksamkeit zensierender psychischer Instanzen und erlaubt dadurch ein Zulassen von Begehrensformen, sexuellen Praktiken und Phantasien, die zwar noch immer Kompromissbildungen darstellen, aber wesentlich stärker an Unbewusstes und Verdrängtes rühren, als es der Vorstellungswelt des Bewusstseins möglich ist. (Ebd., S. 28)

Der Reiz der Pornografie entsteht nach Lewandowski durch ein besonderes Zusammenspiel latenter Darstellungen und latenter Fantasien. Latente, dem Subjekt also nicht ganz bewusste sexuelle Fantasien kämen in der Pornografie auf eine latente, also nicht allzu bedrohlich-manifeste Weise zur Darstellung. Der Hinweis auf dieses Zusammenspiel latenter Fantasien und latenter Darstellungen erklärt meiner Meinung nach die Beliebtheit der Pornografie. Denn es erstaunt, dass die transgressiven Aspekte der Pornografie nicht deren Beliebtheit mindern, sondern erhöhen. Die Latenz der pornografischen Darstellungen und die Latenz der sexuellen Fantasien des Pornografie nutzenden Subjekts ermöglichen jedoch, dass die in der Interaktion mit Pornografie erlebte Transgression lustvoll und nicht beängstigend wirkt. Außerdem senkt die von Lewandowski analog zum Schlaf gesetzte sexuelle Erregung die moralischen Hemmungen zur Transgression herab.

Lewandowskis These überzeugt auch in Bezug auf das Wiederholende, Regelmäßige, das einen Großteil pornografischer Inhalte auszeichnet. Das Routinemäßige des sexuellen Aktes hat in erster Linie eine Funktion der Bestätigung: Der Akt findet wirklich statt, die Vereinigung wird wirklich vollzogen. Zudem ist es charakteristisch für Pornografie, dass sie eine bekannte Geschichte mit neuem Personal und neuem Dekor erzählt. Es dürfe, wie Lewandowski behauptet, nicht zu viel Unerwartetes im Ablauf des Aktes vorkommen, um die Identifikation des Subjekts mit der Szene und dessen Erregungskurve nicht zu unterbrechen. Die oft als langweilig empfundenen Close-ups der mechanisch wirkenden Bewegungen hätten dieselbe Funktion: die Verbindung der Körper mit ihrer Totalität sichtbar zu machen. Paradigmatisch sei der Close-up auf das im Orgasmus verzerrte Gesicht des Mannes, bevor in 
einem nächsten Close-up sein ejakulierender Penis gezeigt wird. Die rituelle Aufspaltung dieses einen Momentes in zwei aufeinanderfolgende macht eine schwierig darstellbare Angelegenheit, nämlich den Orgasmus, versteh- und nachvollziehbar und verankert ihn fester in der darstellenden Person.

Lewandowski deutet die Betonung aggressiver Komponenten in der zeitgenössischen Pornografie als Reaktion auf die Intimisierung sexueller Verhältnisse und die Delegitimierung aggressiver Verhaltensweisen in der Gesellschaft:

In der Pornographie nimmt das Objekt die aggressiven sexuellen Strömungen und Äußerungen willig an, so dass der Konflikt zwar implizit zur Darstellung, aber nicht explizit zum Ausbruch kommt. Zudem wird ein Raum für Geschlechtsphantasmata entfaltet, die im sexuellen Alltag kaum mehr auf Anschlussfähigkeit hoffen dürfen. (Ebd., S. 41f.)

Pornografie gibt also laut Lewandowski kulturell illegitimen Anteilen der Sexualität Raum. Die stereotypen Geschlechterrollen der MainstreamPornografie wären dann sogar ein Beleg für den Wandel der Geschlechterrollen in der Gesellschaft. Lewandowski vermutet, dass die Abwertung von Frauen in der heterosexuellen Pornografie eine Funktion habe:

In einem gewissen Sinn fungiert das Pornographische als ein Selbstverständigungsdiskurs über heterosexuelle Männlichkeit im Zeitalter ihrer Bedrohung. Gezeigt wird nicht nur hegemoniale Männlichkeit in sexuellen Interaktionen, sondern eine (Re-) Konstruktion hegemonialer Männlichkeit durch sexuelle Interaktionen. (Ebd., S. 56)

In der Mainstream-Pornografie finde also eine Ermächtigung der heterosexuellen Männlichkeit statt, die mit der Unterwerfung des weiblichen Körpers, der Domestizierung der weiblichen Sexualität erkauft werde. Diese Abwehr des Weiblichen in der Pornografie liest Lewandowski auch als Abwehr von homosexuellem Begehren. Homosexuelles Begehren scheine für eine stabile heterosexuelle männliche Identität derart bedrohlich zu sein, dass sexuelle Handlungen zwischen Männern oder anale Penetration von Männern durch Frauen in der heterosexuellen Mainstream-Pornografie tabu seien. Latentes homosexuelles Begehren beim heterosexuellen Nutzer dürfe sich in dieser Pornografie deshalb nicht explizit manifestieren, sondern komme als Kompromissbildung in Gruppensexfantasien, wo mehrere Männer gleichzeitig oder nacheinander mit derselben Frau verkehrten, oder in der pornografischen Standardfantasie der analen Penetration von Frauen zum Ausdruck: 
Charakterisiert man Analverkehr als prototypisch männlich homosexuell konnotierte Praktik, so ließen sich anale Penetrationen von Frauen durchaus als latent homosexuelle Handlungen verstehen. Sie wären eine perfekte Kombination von Heterosexualität auf Ebene der Objektwahl und Homosexualität auf Ebene der sexuellen Praktiken, also eine recht gelungene Kompromissbildung im Sinne von Freud. (Ebd., S. 62)

Pornografie muss offenbar ein Kompromiss von transgressiven Aspekten und bewahrenden, zensierenden, rückversichernden Aspekten sein, um zu funktionieren. Es geht um ein Überschreiten der Realität ins Reich der Wünsche, des Begehrens, doch gesellschaftliche Zensurregeln bleiben in Kraft. Die transgressive Kraft des Begehrens muss wie im Traum auch in der Pornografie maskiert werden, um für das begehrende Subjekt aushaltbar zu sein. Soll Pornografie ihre spezifische Funktion erfüllen, nämlich dem zum Großteil unbewussten sexuellen Begehren des Subjekts Inhalte zur Interaktion anzubieten, bleibt eine gewisse Maskierung der transgressiven Kraft dieses Begehrens unumgänglich.

\section{$2.6 \quad$ Fazit}

Kapitel 2 diente der Vorstellung meiner zentralen These: Pornografie hat einen transgressiven Charakter. Es wurde der begriffliche und theoretische Rahmen abgesteckt, von dem aus ich im Weiteren die Phänomene der Pornografisierung und der alternativen Pornografien analysieren werde.

Ich habe die Untersuchung mit der begrifflichen Feststellung begonnen: Pornografie ist abhängig von einem Diskurs, innerhalb dessen sie definiert und so erst erkennbar wird. Im Gegensatz zu anderen Begriffen zeichnet sich Pornografie jedoch innerhalb dieses Diskurses durch einen Verstoß aus, sie wird vom herrschenden Diskurs als anstößig, problematisch gewertet. Pornografie ist also innerhalb dieses Diskurses nicht öffentlich darstellbar, sie nimmt eine Position an dessen Rändern ein. Wir begegnen ihr also immer erst in einer Bewegung der Überschreitung dieses Diskurses - das ist der transgressive Charakter der Pornografie. Transgressiv im Sinne des Überschreitens von Normen, des Brechens von Tabus.

Inwiefern Normen mit Sexualität und Pornografie zusammenhängen, bedurfte weiterer Erklärungen. Mit Foucault habe ich beschrieben, wie unser heutiges Verständnis von Sexualität mit einer bestimmten Subjektkonzepti- 
on zusammenhängt. Das Subjekt handelt nicht in einer Sphäre der Freiheit, unbeeinflusst von der Gesellschaft, sondern ist immer schon in Machtbeziehungen $\mathrm{zu}$ anderen Subjekten verstrickt. Sein Erfahrungshorizont ist durch die herrschenden Normen eingeschränkt. Dieser Macht/Wissen-Komplex schreibt Subjekten eine bestimmte Sexualität zu. Sexuelle Handlungen werden nicht autonom in einen leeren Raum hinaus ausgeführt, sondern finden immer im Einklang mit oder in Opposition zu herrschenden Normen statt.

Nun waren sexuelle Beziehungen auch schon in der Antike Gegenstand von Regulierung. Doch erst in der bürgerlichen Moderne entsteht die Sexualität als privilegierter Ort, an dem die Wahrheit des Subjekts vermutet wird. Seit dem Hellenismus wird sexuelles Begehren zunehmend als Gefahr für den Körper und die Seele des Individuums, aber auch für das soziale Gefüge wahrgenommen. Es wächst der Bedarf, sie zu kontrollieren und einzugrenzen. Ein zunehmender Wille zur Regulierung von Körpern und Reproduktion bringt, verbunden mit bestimmten Techniken des Geständniszwangs, erst eine Sexualität hervor, die den Kern unseres Wesens ausmachen soll.

Sexuelle Beziehungen zwischen Männern waren seit der Antike Gegenstand besonderer Regulierung. Im Hellenismus wurde das Männern vorbehaltene Freundschaftsmodell der Antike auf die Ehe übertragen. Damit wirkt die antike Strukturierung sexueller Beziehungen zwischen Männern über die Binarität zwischen Aktivität und Passivität bis heute prägend für Vorstellungen von Sexualität.

Bei Bourdieu bin ich dieser Binarität noch weiter nachgegangen. Er zeigt auf, wie intime Interaktionen das Ergebnis politischer Sozialisation sind, die den Habitus und die Wahrnehmung der Geschlechter prägt. Im Ausagieren dieser Prägung werden die herrschenden Geschlechterverhältnisse - die männliche Herrschaft - weiter reproduziert. Bereits im Inzesttabu sieht Bourdieu den Frauentausch und damit die Reduktion der Frau auf einen $\mathrm{Ob}$ jektstatus zur Stabilisierung der männlichen Herrschaft angelegt. Sexuelles Begehren zwischen den Geschlechtern ist sowohl Produkt von Normierung wie auch Motor für das Fortbestehen der Norm. Da unter der männlichen Herrschaft Weiblichkeit über Wahrgenommenwerden hergestellt wird, basieren nicht nur Pornografie, sondern grundsätzlich die sexuellen Beziehungen zwischen den Geschlechtern auf dem Objektstatus der Frau.

Neben der Zweigeschlechtlichkeit ist Intimität ein zweiter wichtiger Bestandteil heutiger sexueller Normen. Luhmann erachtet die Ablehnung des Obszönen als konstitutiv für heutige Intimbeziehungen. Da in Intimbeziehungen heute eine Validierung der Selbstdarstellung erwartet wird, müssen 
die Intimbeziehung und ihre Sexualität exklusiv sein. In der ehelichen Sexualität enthüllt sich die individuelle Wahrheit des Subjekts und fordert Bestätigung ein. Laut Sennett ist die Sicht auf Sexualität als Ort der Selbstoffenbarung gleichbedeutend mit dem Wegfall einer sozialen Dimension der Sexualität. Der Wunsch nach Authentisierung der eigenen Persönlichkeit in der Sexualität belastet eine ursprünglich soziale Beziehung mit einem narzisstischen Anspruch.

Zusammengefasst fußt also die herrschende Geschlechterordnung auf einem Sexualdispositiv, das eine Erfindung der bürgerlichen Moderne ist und mit der Erfindung des bürgerlichen Subjekts zusammenfällt. Sexualität ist nicht mehr primär Gegenstand sozialer Interaktion, sondern dient der Authentisierung der Persönlichkeit in der ehelichen Zweierbeziehung.

In einem zweiten Schritt habe ich dann dieses Sexualdispositiv zum Ausgangspunkt genommen für Überlegungen, die in der Sexualität auch einen Weg zur Infragestellung und Überschreitung von Normen sehen. Bei Bataille habe ich folgende Theoretisierung der Transgression gefunden: Grenzziehungen sind etwas genuin Menschliches, sie heben den Menschen vom Tier ab. Erst durch das Ziehen von Grenzen wird auch deren Überschreitung möglich. Grenzziehungen auf dem Gebiet der Sexualität laden den ausgegrenzten Bereich erotisch auf. Das Überschreiten der Grenze in der Sexualität in einem Akt der Transgression ist darum ebenso gewaltförmig wie lustvoll. Mit Jenks habe ich darauf aufmerksam gemacht, dass die durch Grenzen erzeugten Binaritäten oft hierarchisch geordnet sind. Überschreitungen dieser Grenzen stürzen Hierarchien um. Indem das Ausgegrenzte libidinös besetzt wird, geraten Machtverhältnisse ins Wanken. Dies verleiht der Transgression eine politische Komponente.

Zappe habe ich in meiner Diskussion der Transgression eine wichtige Unterscheidung zu verdanken: Er differenziert zwischen modernen oder humanistischen Konzepten der Transgression, die auf der Vorstellung eines autonomen Subjekts basieren, und einem postmodernen Konzept der Transgression, das auf Hybridität abzielt. Im postmodernen Konzept eröffnet Transgression einen Zwischenraum auf der Normgrenze, der durchlässig sowohl gegenüber dem Ein- wie dem Ausgegrenzten ist, sodass neue Identitäten und Erfahrungen entstehen. Dies erlaubt eine weniger politische und mehr private Deutung der Transgression: Sie ermöglicht Subjekten, sich für neue Identitäten und Erfahrungen zu öffnen.

Um Zappes postmodernes Konzept der Transgression enger mit dem herrschenden Sexualitätsdispositiv zu verkoppeln, bin ich anschließend 
nochmals zu Foucault zurückgekehrt. Er konzipiert Transgression nicht als Überschreitung einer Grenze zwischen zwei Polaritäten, sondern als Bejahung des Ortes der Grenze, in der die Widersprüche für einen Moment aufgehoben sind und eine Totalität aufscheint. Damit liegt in der Sexualität der Keim zur Auflösung des Subjektverständnisses der bürgerlichen Moderne. Interessanterweise kommt Freud zum selben Befund: Denn Freud fragt sich, ob die gegenwärtige Sexualmoral die Opfer wert ist, die sie den Individuen auferlegt. In seiner Konzeption unterliegt Sexualität zwar unumgänglicherweise starken Einschränkungen und Umformungen, aber sie kann nicht dauerhaft und ohne schädliche Auswirkungen unterdrückt werden. Entsprechend sind in dieser Konzeption von Sexualität Transgressionen aller Art vorprogrammiert. Diese Transgressionen werden allerdings nicht von einem autonomen Subjekt ausagiert, sondern im Gegenteil von einem Subjekt, das in sich gespalten und zerrissen, das nicht Herr im eigenen Haus ist.

Wie Freud geht auch Marcuse von einem gegebenen Sexualtrieb aus, der durch Kulturanforderungen eingeschränkt wird. Während Freud grundsätzlich vorschlägt, die Kulturanforderungen zu lockern, um die Herausbildung von Neurosen zu vermindern, verleiht Marcuse dieser Forderung eine konkrete historische Gestalt. In der aktuellen historischen Form wird das Individuum vom Realitätsprinzip des Leistungsprinzips dazu gezwungen, seine Triebenergie in entfremdete Arbeit umzuleiten und die Libido auf gegengeschlechtliche genitale Sexualität zu beschränken. Ein von zusätzlicher Unterdrückung befreites Realitätsprinzip würde die Entfremdung des Individuums von seiner Arbeit wie auch Monogamie und Patriarchat aufheben.

Über ihren Begriff der Transgression habe ich so die Positionen Freuds und Foucaults einander angenähert. Freud und Marcuse betonen, dass unter den gegenwärtigen Kulturanforderungen bereits von der Triebstruktur ausgelöste Transgressionen stattfinden, etwa in der Herausbildung von Neurosen oder gewaltförmigen Ausbrüchen. Beide reden nicht einer vollständigen Befreiung des Sexualtriebs das Wort, wie es dem liberalen oder humanistischen Modell der Transgression entsprechen würde, in welchem sich das autonome Subjekt durch transgressives Handeln von falschem Bewusstsein befreit. Foucault thematisiert Transgression als Bejahung der Grenze in der Überschreitung, als Aufhebung der Polaritäten. Sexualität führt in dieser Konzeption das Subjekt an die Grenze seiner eigenen Auflösung. Wie bei Freud und Marcuse ist also auch bei Foucault Sexualität ein Ort, an dem sich das autonome bürgerliche Subjekt über Transgressionen selber in Frage stellt. 
Was mich bei Freud und Marcuse interessiert hat, ist der Perspektivenwechsel auf die Begehrensstruktur des in Herrschaftsstrukturen eingebundenen Subjekts. Butler sieht das Begehren eingebunden mit dem biologischen Geschlecht, der Geschlechtsidentität und der sexuellen Praxis in ein regulatives Ideal der Heteronormativität. Dieses Ideal garantiert die soziale Anerkennung der personalen Identität. Daraus folgt letztlich, dass wesentliche Erfahrungen, die individuelle Sexualität und Geschlechtsidentität ausmachen, von anderen abhängig sind. Da die Normen des regulativen Ideals steter Wiederholung bedürfen, eröffnet sich ein Spielraum für das Subjekt. Es kann diese Akte der Wiederholung verweigern oder abändern. Solche Spielräume ermöglichen also eine Transgression der Normen. Butlers Bestehen darauf, dass das Subjekt nicht frei über seine Sexualität verfügt, lässt sich auch so lesen, dass der Sexualität des Subjekts eine konstitutive Verletzlichkeit eingeschrieben ist: Sie ist uns fremd, besteht aus Wünschen, Bedürfnissen und Ängsten, die uns selber nicht ganz durchsichtig sind. Mit dieser Interpretation ist Butlers Konzeption wieder nahe bei Freuds und Marcuses Modell der individuellen Triebstruktur, deren Bildung dem Subjekt nicht durchsichtig ist, aber die gerade deshalb der Einhegung in gesellschaftliche Normgrenzen widersteht. Sexualität als Form des Daseins für oder kraft eines anderen: Damit sind sowohl der transgressive Charakter der Sexualität als auch das Scheitern der Konstruktion eines autonomen Subjekts angesprochen.

Unsere heutige Vorstellung von Sexualität ist also untrennbar verbunden mit der Subjektkonzeption der bürgerlichen Moderne. Diese Subjektkonzeption definiert Sexualität nicht mehr über Interaktionen zwischen Individuen, sondern verortet sie im Innern der Individuen, sucht in ihr eine Wahrheit über das Subjekt selbst. Sexualität nicht als Ensemble von Interaktionen, sondern als Identitätsmerkmal zu sehen, hat weitreichende Folgen. Die Regulierung der Sexualität findet nun weniger über die Privilegierung oder Sanktionierung sozialer Kontakte statt, sondern es werden über Selbsttechnologien gesellschaftliche Normen eingeübt. Da die in den Grenzen des Subjekts eingehegte Sexualität nicht vollständig in den gesellschaftlichen Normen aufgeht, entsteht ein transgressiver Charakter der Sexualität, eine Tendenz zur Überschreitung der ihr auferlegten Normen. Dieses Transgressive der Sexualität erregt und ängstigt Subjekt und Gesellschaft gleichermaßen, stachelt Angstund Lustfantasien an. Einen Ausdruck finden diese Fantasien in der Pornografie, die sowohl von gesellschaftlichen Normen im Bereich der Sexualität wie von deren Überschreitung erzählt. 
Im nächsten Schritt habe ich dieses Spannungsfeld zwischen Transgression und Normierung, in dem sich die Pornografie befindet, weiter ausgelotet. Mit Laqueur zeigte ich auf, wie mit der Entstehung einer bürgerlichen Subjektkonzeption Masturbation ein Problem wird. Das Geheime, die sie begleitenden Fantasien und der Exzess sind bedrohliche Aspekte des bürgerlichen Subjekts, sie entstehen aber als solche erst mit ihm. Denn Transparenz, Rationalität und die Fähigkeit, sich selbst Grenzen zu setzen, sind Werte, die erst mit der bürgerlichen Subjektkonzeption wichtig werden. Masturbation bündelt die transgressiven Aspekte der Sexualität des bürgerlichen Subjekts in einer Weise, die erst ihre plötzliche Problematisierung und Pathologisierung erklärt.

Für das zeitgleiche Auftreten der Pathologisierung der Masturbation und der Ausbreitung pornografischer Schriften fand ich bei Marcus Erklärungen. Seine Analysen zeigen, wie die Pornografie des 18. Jahrhunderts von einem angstbesetzten Interesse am begehrenden Subjekt durchzogen ist, das auch Medizin und Naturwissenschaften dieser Zeit dominiert. Die Transgressionen, von denen diese Pornografie erzählt, sprengen einerseits die gesellschaftlichen Konventionen ihrer Zeit, andererseits bestärken sie diese Konventionen, laden sie erotisch auf. Da in der Aufhebung beispielsweise von Klassenschranken Pornografie Hierarchien umstürzt und heimliches Begehren der gesellschaftlichen Eliten sichtbar macht, hat sie auch ein politisches Potenzial. Pornografie selbst ist ein Ausdruck geheimer Allmachtsfantasien, hier finden sich Laqueurs Kernelemente des Geheimen, der Fantasie und des Exzesses wieder, die das 18. Jahrhundert am bürgerlichen Subjekt und insbesondere an der Masturbation so bedrohlich fand.

Besonders bedrohlich wirken auch heute noch die pornografischen Allmachtsfantasien des Marquis de Sade. Die gewaltsame Objektivierung der Frau in der Zirkulierung von Frauenkörpern zwischen Männern ist in seinen Schriften auf die Spitze getrieben. Die durchorganisierten Akte der Transgression in Sades Schriften sind laut Horkheimer/Adorno Ausdruck einer verabsolutierten bürgerlichen Vernunft. Sie sind keine Akte der Freiheit, sondern Exzesse eines totalitären Subjekts. Für de Beauvoir ist die Lehre aus Sades Schriften, dass das Begehren des bürgerlichen Subjekts utopisch ist. Die transgressiven Akte stellen einen Weg dar, wie sich das Subjekt von der Bestimmtheit durch die Natur befreien kann. Entsprechend befreien sich die Akteure in der Überschreitung falscher gesellschaftlicher Normen hin zu einer authentischen, ihrer Natur gemäßen Existenz. Pornografie erfüllt Wünsche ohne das Risiko der Ablehnung, mit dem in realen sexuellen Beziehungen 
gerechnet werden muss. Auch Bataille spricht davon, wie innerhalb der Relation des Begehrens Verdinglichung stattfindet. Das schrankenlose Begehren lässt sich nur im Imaginären erfüllen, weil ein reales Objekt des Begehrens nie passiv genug ist, um dem Begehren keine Bedrohung entgegenzusetzen. Das Begehren entsteht zwar innerhalb eines sozialen Kontextes, es lässt sich aber nur in einem imaginären Kontext vollständig realisieren. Diese Realisationsmöglichkeit bietet die Pornografie.

Laut Sontag ist ein Zweck der Pornografie, die individuellen Möglichkeiten des sexuellen Austauschs zu vervielfachen. Dadurch stellt Pornografie eine wichtige Möglichkeit für den Menschen bereit, sich als Individuum zu überschreiten. Pornografische Schriften enthalten Vokabulare, die über eine Wahrheit der menschlichen Existenz sprechen: das Verlangen nach Transgression, Überschreitung. Wer von Pornografie nichts wissen will, schneidet sich demzufolge von Erkenntnisquellen über seine Existenz ab. Letztlich dient sie dazu, die Normen des menschlichen Subjekts in Frage zu stellen.

Sontag hat mit ihren Thesen schriftliche Formen von Pornografie im Fokus. Deshalb wollte ich herausfinden, ob diese auch für bildliche und filmische pornografische Darstellungen gelten. Für Flasspöhler hat der Medienwechsel von schriftlicher Pornografie zum Pornofilm Konsequenzen in Bezug auf Transgressivität. Schriftliche Pornografie generiere bei den Lesenden eine Angst-Lust, da sie die beschriebenen Transgressionen in der Fantasie mitvollzögen; Pornofilme dagegen präsentierten eine Utopie der Regression. Sie vermutet, dass ein wesentlicher Aspekt der Attraktivität von Pornofilmen darin besteht, dass die Betrachtenden Angst auslösende Szenarien auf eine ungefährliche und Lust erzeugende Weise durchspielen können. Pornofilme bieten dem Subjekt also einen gewissen Schutz vor dem transgressiven Charakter der Sexualität. Trotzdem behauptete ich mit Judith Butler: Das Subjekt ist nicht Herr über die Erfahrung der Stimulation durch Pornografie. Aber wie funktioniert das Zusammenspiel von Stimulation und Triebstruktur genau?

Zur Beantwortung dieser Frage war Lewandowski hilfreich. Er hält fest, dass Pornografie ein Kompromiss von transgressiven Aspekten und bewahrenden, zensierenden, rückversichernden Aspekten sein muss, um zu funktionieren. Es geht um ein Überschreiten der Realität ins Reich der Wünsche, des Begehrens, doch gesellschaftliche Zensurregeln bleiben in Kraft. Die transgressive Kraft des Begehrens muss wie im Traum auch in der Pornografie maskiert werden, um für das begehrende Subjekt aushaltbar zu sein. Soll Pornografie ihre spezifische Funktion erfüllen, nämlich dem zum Großteil unbewussten sexuellen Begehren des Nutzers Inhalte zur Interaktion anzu- 
bieten, bleibt eine gewisse Maskierung der transgressiven Kraft dieses Begehrens unumgänglich.

Ich fasse zusammen: Pornografie hat einen transgressiven Charakter, sie bietet dem bürgerlichen Subjekt der Moderne die Möglichkeit, sich zu überschreiten. Dies tut sie, indem sie dem Subjekt eine Utopie präsentiert, wo sein Begehren auf keinen Widerstand stößt. Damit die Angst-Lust erzeugende Transgression, welche die Pornografie ermöglicht, für das Subjekt nicht $\mathrm{zu}$ bedrohlich wirkt, tritt sie in maskierter Form auf. Solche Maskierungen sind eine Weise, wie sich gesellschaftliche Normen in die Pornografie einschleichen; eine andere Weise besteht darin, dass Pornografie gesellschaftlich nicht akzeptables Begehren widerspiegelt. So behauptet die feministische Aktivistin Lynne Segal:

What we do not find in pornography - hence its provocation - are the acceptable male emotions associated with the approved discourses on male sexuality. Sex restrained by love and marriage, sex which is »protective«, »respectable« and »faithful«, reverses into its opposite: sex greedy for immediate, unlimited, self-centred gratification. (Segal 1992b, S. 68)

Segal betont die unterschiedliche gesellschaftliche Akzeptabilität der mit männlicher Sexualität verbundenen Gefühle. Ist denn Pornografie einfach ein Ventil für gesellschaftlich nicht akzeptierte Emotionen in Verbindung mit Sexualität? Laut Segal ist die Verbindung komplizierter: »The mirroring themes of the acceptable and transgressive discourses on sexuality suggest a dialectical relation between the two. (Ebd.) Doch wie sieht nun diese dialektische Beziehung aus? Um dies herauszufinden, müsste man laut Segal die in realen heterosexuellen Beziehungen vorkommenden ungestillten Sehnsüchte und Fantasien psychoanalytisch und in ihrem sozialen Kontext analysieren. Ich wähle in dieser Arbeit einen anderen Weg. Über zwei zeitgenössische Debatten - jene zur Pornografisierung und jene zu alternativen Pornografien - möchte ich der von Segal angesprochenen Dialektik auf den Grund gehen. 



\section{Transgression in der feministischen Pornografiekritik}

\section{1 Überblick}

Im Folgenden möchte ich mich mit zwei zeitgenössischen Debatten rund um Pornografie befassen, die auf ihre Weise kritisch auf die in der Pornografie gespiegelten Normen reagieren: erstens mit der feministischen Kritik an der sogenannten Pornografisierung der Gesellschaft, zweitens mit der Diskussion um alternative Pornografien. Bei der Pornografisierung geht es darum, dass Pornografie über neue Medien und Popkultur immer mehr Platz in unserem Alltag einnimmt. Dies macht eine von feministischer Seite geäußerte Kritik an der Objektivierung von Frauen in der Pornografie virulenter. Hier untersuche ich, welche Rolle der transgressive Charakter der Pornografie in dieser Debatte spielt.

Unter dem Stichwort alternative Pornografien lässt sich eine Bewegung zusammenfassen, die sich gegen den Sexismus, die Heteronormativität, die normativen Körper und die Warenförmigkeit der Sexualität in der Mainstream-Pornografie wendet. Sie versucht, ihr eine eigene Pornografie entgegenzusetzen, frei von normativen Körperbildern und warenförmiger Sexualität. Hier interessiert mich, in welchem Verhältnis dieser Versuch zum transgressiven Charakter der Pornografie steht.

Sowohl die Pornografisierungsdebatte als auch die Diskussion um alternative Pornografien sind geprägt vom Widerstand gegen Sexismus und Rassismus - einem Gedankengut, das in diesen Debatten manchmal als reaktionär bezeichnet wird. Bevor wir uns detaillierter mit diesem Widerstand beschäftigen, möchte ich nochmals festhalten, dass Transgression nicht gleichzusetzen ist mit einer progressiven Kraft: »Transgression is neither progressive nor reactionary, it is an amalgamation of both." (Sargeant 1995, S. 37) Der transgressive Charakter der Pornografie hat unter anderem zur Folge, 
dass sie sich in Grenzbereichen auch des guten Geschmacks oder der politischen Korrektheit einnistet. Die rassistischen und sexistischen Inhalte vieler Pornos stellen entsprechend eine Erotisierung der Grenzen des in unserer Gesellschaft Sag- und Zeigbaren dar.

Inwiefern steht das Phänomen Pornografisierung in einem Zusammenhang mit dem transgressiven Charakter der Pornografie? Um diese Frage zu klären, befasse ich mich im Kapitel 3.2 in einem ersten Schritt mit der feministischen Kritik an der Pornografisierung selbst und setze diese in einem zweiten Schritt in den größeren Rahmen der feministischen Pornografiekritik generell. Meine These ist hier, dass die feministische Kritik an der Pornografisierung Themen und Argumente der feministischen Pornografiekritik wiederaufnimmt, die einen unvoreingenommenen Blick auf Pornografisierung erschweren.

\subsection{Die feministische Kritik an der Pornografisierung}

\subsubsection{Der Begriff Pornografisierung}

Wie wird das Phänomen Pornografisierung in der feministischen Kritik gefasst? Ich werde mich zunächst mit verschiedenen Definitionen von Pornografisierung auseinandersetzen und zu verstehen versuchen, welchen Prozess der Begriff beschreibt. Insbesondere interessiert mich, ob sich die beiden Begriffe Pornografisierung und Sexualisierung voneinander unterscheiden lassen oder ob sie eigentlich dasselbe beschreiben. Als zentrales Thema der feministischen Kritik an Pornografisierung wird sich Objektivierung erweisen, die wiederum eng mit einer bestimmten Vorstellung eines pornografischen Blicks verbunden ist. Die Kritik an Objektivierung ist zudem verknüpft mit einer Kritik an wirtschaftlichen und gesellschaftlichen Entwicklungen. Grundsätzlich stellt sich am Ende die Frage, ob das Phänomen Pornografisierung ein Neudenken des Pornografischen selbst notwendig macht.

Woher stammt der Begriff Pornografisierung und wie wird er verwendet? Der Begriff selbst ist eine Substantivierung des Verbs pornografisieren. Dieses stellt eine Zusammensetzung dar aus dem Begriff Pornografie und dem Suffix -isieren, das laut Duden (Dudenredaktion o.J.a) in Bildungen mit Substantiven oder Adjektiven ausdrückt, dass eine Person oder Sache in einen bestimmten Zustand gebracht wird, zu etwas gemacht wird oder dass eine Person oder Sache mit etwas versehen wird. Der Begriff Pornografisie- 
rung meint offenbar, dass eine Person oder Sache entweder zu Pornografie gemacht wird oder mit Pornografie angereichert wird.

Der Begriff Pornografisierung ist eine Übertragung der englischen Wortschöpfung pornification. Seltener wird im Englischen dagegen der Begriff pornographisation verwendet, wie umgekehrt im Deutschen seltener der Begriff Porno- oder Pornifizierung gebraucht wird. Gemäß dem Chambers Dictionary bedeutet pornification »the spread of sexualized imagery and attitudes from pornography (into everyday life)« (Harrap 2014, S. 1207). Es geht also um die Ausbreitung von sexuellen Bildern und pornografischen Verhaltensweisen im Alltag. Anders definiert das Collins English Dictionary pornification: »The perceived pervasion of society in general or an aspect of it by the imagery, language, and attitudes associated with pornography.« (Collins 2014, S. 1545) Hier scheint Pornografisierung eher eine Sichtweise $\mathrm{zu}$ beschreiben, welche die Gesellschaft als von Pornografie durchdrungen wahrnimmt.

Im akademischen Kontext das erste Mal verwendet wurde der Begriff pornographication 1996 vom Medienwissenschaftler Brian McNair, der das Phänomen im Rahmen eines in den 1980er-Jahren einsetzenden Trends, Sexualität in der Öffentlichkeit zu thematisieren, fasst:

The trend was both a response to, and part of, cultural phenomena referred to earlier: the expansion of the pornography industry, and the diversification of its market to incorporate not just gays but also »normal« heterosexual women; the »pornographication of the mainstream«, as reflected in $\mathrm{Ba}$ sic Instinct and other Hollywood films; the increasing use of pornographic iconography in artistic activity, including massively popular forms such as Madonna's musical and video performances, or the more restricted works of Mapplethorpe and Koons. (McNair 1996, S. 22f.)

McNair nennt hier drei Punkte: Expansion und Diversifikation der Pornoindustrie, Pornografisierung der Mainstream-Kultur, zunehmender Einsatz pornografischer Bilder in der Kunst. Da McNair bei Punkt zwei auf Hollywood-Filme referiert und bei Punkt drei neben Werken von Mapplethorpe und Koons auch Musikvideos von Madonna als Beispiele aufzählt, scheinen mir die beiden nicht klar voneinander abgrenzbar.

Mit der Unterscheidung von Punkt eins und zwei arbeitet hingegen auch die Geschlechterforscherin Karen Boyle. Sie plädiert für eine differenzierte Analyse des Trends der Pornografisierung. Die zunehmende Verfügbarkeit und Masse pornografischen Materials müsse unterschieden werden von einer sexualisierten Popkultur, die pornografisches Material bloß zitiere: 
Through such quotation, pornography achieves a mainstream currency and visibility, but whilst popular culture may be »pornified « as a result, it does not become pornography. To properly understand how pornographic quotation of this kind functions depends on understanding the differences as well as similarities between these pop culture examples and the hard-core they reference. (Boyle 2010, S. 2)

Trotz der Ähnlichkeiten empfiehlt Boyle also, zwischen der Ausweitung des Angebots der Pornoindustrie selbst und dem verstärkten Einsatz pornografischer Bilder in künstlerischen Werken zu unterscheiden.

Auch die Publizistin Myrthe Hilkens nimmt diese Unterscheidung zwischen einer sexualisierten Populärkultur und der Pornografie selbst auf. Ihre Definition von Pornofizierung fasst den Begriff der Mainstream-Kultur aber weiter:

Einfach gesagt ziele ich mit dem Begriff»Pornofizierung «auf den Vormarsch ursprünglich pornografischer Phänomene in die Mainstream-Kultur. Man denke an die zuvor genannte kahlgeschorene Vagina als Modetrend, den Stringtanga in Kindergrößen, Stangentanzkurse für Kinder oder Sexspielzeug in Drogerieregalen. Mir geht es nicht um die Sexualisierung verschiedener Medien an sich, sondern um Pornofizierung auch als Teil unserer Lebenswelt und damit des öffentlichen Raums. Cleichermaßen ziele ich auf den Einfluss eines manchmal pornografischen Schönheitsideals - große Brüste, strammer Hintern, Barbievagina - auf das weibliche Selbstbild. Und auf das Maß, in dem Pornografie, auch dank des Internets, heutzutage in unserem Leben gegenwärtig ist, und was das für Folgen hat. (Hilkens 2010, S. 110)

Hilkens definiert Pornofizierung also als Eindringen der Pornografie selbst, aber auch ihrer ästhetischen Standards in den öffentlichen Raum. Pornografie breche aus einer je individuellen privaten Sphäre aus und erobere den öffentlichen Raum. Damit gehe Pornofizierung über eine mediale Sexualisierung hinaus und habe direkte Auswirkungen auf unsere Lebenswelt selbst.

Es stellt sich das Problem der Abgrenzung des Begriffs der Pornografisierung vom Begriff der Sexualisierung. Wenn Hilkens von sexualisierten Medien spricht, bezieht sie sich auf den Report on the Sexualization of Girls der American Psychological Association (2007) und zählt vier Arten sexualisierter Bilder auf: 
Es geht um Darstellungen, in denen: der Wert einer Person einzig und allein anhand ihrer sexuellen Attraktivität oder ihres sexuellen Verhaltens gemessen wird und nicht aufgrund anderer Merkmale; eine Person mit einer Norm verglichen wird, deren Maßstab für körperliche Attraktivität »sexy sein« ist; jemand sexuell vergegenständlicht und als ein Objekt für den sexuellen Cebrauch gesehen wird statt als Person mit eigenem Verhalten, Gefühlen, Entscheidungen und Wünschen; oder wenn Sexualität auf unangebrachte Weise praktiziert wird, wie bei dem Missbrauch von Kindern für Kinderpornografie. (Hilkens 2010, S. 109f.)

Sexualisierte Bilder bemessen laut Hilkens den Wert einer Person nur anhand ihrer sexuellen Attraktivität oder ihres sexuellen Verhaltens. Sie nähmen Sexyness zum Maßstab für körperliche Attraktivität, sie reduzierten Personen auf Objekte für den sexuellen Gebrauch oder stellten unangebrachte sexuelle Praktiken dar.

Mit der Kulturwissenschaftlerin Feona Attwood lässt sich feststellen, dass unter dem Stichwort Sexualisierung ein ganzes Bündel von Themen untersucht wird:

This paper reviews and examines emerging academic approaches to the study of »sexualized culture «, a rather clumsy phrase used to indicate a number of things; a contemporary preoccupation with sexual values, practices and identities; the public shift to more permissive sexual attitudes; the proliferation of sexual texts; the emergence of new forms of sexual experience; the apparent breakdown of rules, categories and regulations designed to keep the obscene at bay; our fondness for scandals, controversies and panics around sex; all those manifestations that in our era »Sex [...] has become the Big Story«. (Attwood 2006, S. 2)

Es geht gemäß Attwood also bei der Sexualisierung auch um die Art, wie Sexualität in der Öffentlichkeit thematisiert wird - die Obsessionen und Paniken der Öffentlichkeit rund um Sexualität.

Die Geschlechterforscherinnen Susanna Paasonen, Kaarina Nikunen und Laura Saarenmaa beschreiben in einem gemeinsamen Aufsatz Pornografisierung als ein Konzept, das bestimmte technologische und mediale Entwicklungen fasst: "Discarding references to degeneracy, this book makes use of the concept of pornification in investigating the intertwining processes of technological development, shifts in modes of representation and the cultural visibility of cultures of sexuality.«(Paasonen/Nikunen/Saarenmaa 2007, S. 2) 
Sie unterscheiden drei Ebenen des Phänomens Pornografisierung: Auf der ersten Ebene sind damit die technologische Entwicklung der Medien und die Anpassungen der Industrie gemeint. Pornografie ist laut den Verfasserinnen ein kulturelles Produkt, das medial vermittelt wird und in Massen produziert wird. Entsprechend stecke hinter der Pornografie eine Industrie, die mit ihren Produkten Geld verdienen wolle und daher ein Interesse daran habe, neue mediale Vertriebskanäle, die sich durch technologische Fortschritte ergeben, umgehend zu nutzen.

Auf der zweiten Ebene sprechen sie die Regulierungsfunktion der Medien an. Hand in Hand mit der technologischen Innovation in den Medien gingen die Versuche, die Verbreitung von Pornografie durch diese Medien zu regulieren. In den letzten Jahren und Jahrzehnten sei nun eher eine schleichende Deregulierung der Medien zu beobachten, wodurch sexuelle Bilder mehr und mehr in die Massenmedien einsickerten. Paasonen/Nikunen/Saarenmaa machen jedoch darauf aufmerksam, dass die vermehrte mediale Verbreitung sexueller Bilder auch normierende und regulierende Wirkungen haben könne, die der offiziellen Deregulierungstendenz zuwiderliefen.

Auf der dritten Ebene geht es ihnen um den sogenannten Porno-Chic, der das Phänomen Pornografisierung inmitten des Trends zur Sexualisierung der Gesellschaft verortet. Hierbei betreffe die Pornografisierung einen ganz bestimmten Aspekt der Sexualisierung, indem sie nämlich einen gewissen Porno-Chic in die Massenkultur einbringe, der oft in ironisch gebrochenem Retro-Style daherkomme. Dazu gehören für Paasonen/Nikunen/Saarenmaa aber beispielsweise auch Akteurinnen und Akteure der Pornoindustrie, die ins allgemeine Unterhaltungsgeschäft wechseln und damit die strengen Grenzen zwischen Pornokultur und Massen-Unterhaltungskultur aufweichen. Umgekehrt schmückten sich Unterhaltungskünstler gern mit dem »verruchten« Porno-Chic, um sich interessanter zu machen.

Im Unterscheiden der Ausbreitung der Pornografie selbst von ihrem zitatförmigen Auftreten in der Massenkultur sind Paasonen/Nikunen/Saarenmaa nahe bei Boyles Definition von Pornografisierung. Sie sind jedoch etwas präziser und geben mehrere interessante Hinweise. Zum Beispiel knüpfen sie die Ausbreitung der Pornografie selbst an die Industrie, die sie hervorbringt, die ein finanzielles Interesse daran hat, technologische Innovationen sofort zu nutzen. Die unter dem Stichwort Pornografisierung beschriebene Ausbreitung der Pornografie passiert folglich nicht einfach so, sondern wird von ökonomischen Interessen und technologischen Innovationen vorangetrieben. Mit der Deregulierung der Medien sprechen Paasonen/Nikunen/Saarenmaa 
an, dass politische Kräfte auf die Verbreitung von Pornografie Einfluss nehmen. Wenn die staatliche Regulierung von Medien abnimmt, versuchen ökonomische Player Einfluss auf die nicht oder nicht mehr regulierten Sparten der Medien zu nehmen.

Die Entstehung eines Porno-Chics in der Massenkultur ergibt Sinn vor dem Hintergrund, dass die Pornoindustrie ein Interesse daran hat, die Grenze zwischen Porno- und Massenkultur aufzuweichen. Denn für die Pornoindustrie ist es finanziell interessant, ihre Sichtbarkeit zu vergrößern. Die technologische Entwicklung der Medien, deren Deregulierung und die Entstehung eines Porno-Chics in der Massenkultur verändern Paasonen/Nikunen/Saarenmaa zufolge auch unser Verständnis der Pornografie selbst: »Pornification figures transformations in the cultural position and status of both soft-core and hardcore pornographies, which require a rethinking of the very notion of the pornographic.« (Ebd.) Die Pornografisierung erfordert offenbar ein Neudenken des Pornografischen, da sie den gesellschaftlichen Status der Pornografie fundamental verändert. In diesem Befund treffen sich Paasonen/Nikunen/Saarenmaa mit Attwood, die im Nachdenken über Sexualisierung zum Schluss kommt:»What sex means and the way it means is changing dramatically.« (Attwood 2006, S. 5) Analog zur Veränderung des gesellschaftlichen Status der Pornografie durch die Pornografisierung behauptet Attwood einen veränderten Stellenwert der Sexualität durch die Sexualisierung der Gesellschaft.

Ein Neudenken des Pornografischen, ein veränderter Stellenwert der Sexualität: Dies sind Hinweise darauf, dass sich im bisher vorgestellten Modell der Beziehung von Sexualität und Pornografie gerade etwas verändert. Wenn Sexualität von Normen eingehegt ist und Pornografie sich an den Grenzen dieser Normen positioniert, macht das Phänomen Pornografisierung darauf aufmerksam, dass sich diese Normen aufweichen und pornografische Elemente nicht mehr so rigoros wie bisher aus dem Raum der gesellschaftlich akzeptierten Sexualität verbannt werden. Damit würde Pornografie ihren transgressiven Charakter ein Stück weit verlieren, da pornografische Elemente leichter in eine gesellschaftlich akzeptierte Form von Sexualität eingebunden werden können.

Ich vermute, dass die Unschärfen in der Definition der Pornografisierung wie auch der Sexualisierung in der Natur der zu definierenden Phänomene liegen. Paasonen/Nikunen/Saarenmaa und Attwood legen nahe, dass wir uns gerade in einer Zeit befinden, in der sich die Bedeutung von Sexualität und Pornografie stark wandelt. Wenn wir diesen Befund ernst nehmen und Se- 
xualisierung respektive Pornografisierung als Ursprünge dieses Wandels analysieren wollen, muss sich die Definition durch Rückschlüsse aus den beobachteten Veränderungen im Bereich der Sexualität oder Pornografie ergeben. Für den Anfang scheint es mir sinnvoll, festzuhalten, dass die Phänomene Pornografisierung und Sexualisierung eine analoge Bewegung beschreiben. Sexualisierung beschreibt eine zunehmende Durchdringung des öffentlichen Diskurses und unseres Alltags mit Sexualität, Pornografisierung bezeichnet die analoge Durchdringung mit Pornografie. Pornografisierung ist damit als ein Teilbereich der Sexualisierung zu verstehen: Die Analyse von Pornografisierung beschäftigt sich mit Sexualisierung insofern, als die beobachteten Diskurse und Praktiken sich in irgendeiner Form auf Pornografie zurückführen lassen. Ein häufig genanntes Beispiel ist der bei Frauen weitverbreitete Trend zur Enthaarung der Intimzone, die sich auf die Körpernormen der Pornografie zurückführen lässt. Dies ist aber nicht bei allen Diskursen und Praktiken, in denen sich Sexualisierung manifestiert, der Fall, deshalb ist der unter dem Titel Pornografisierung fokussierte Bereich kleiner als der als Sexualisierung gefasste.

Aufgreifen möchte ich für die weitere Analyse die Unterscheidung, innerhalb der Pornografisierung, der Ausbreitung der Pornografie selbst von ihrem zitatförmigen Einfließen in die Massenkultur. Zudem behalte ich den engen Zusammenhang von Pornografisierung mit ökonomischen Tendenzen im Auge, welche die Grenze zwischen Öffentlichkeit und Privatheit unterlaufen. Als Drittes nehme ich den Hinweis auf eine Aufweichung der Normgrenze und einen teilweisen Verlust des transgressiven Charakters der Pornografie durch die Pornografisierung in die weitere Diskussion mit.

\subsubsection{Bedingungen für Pornografisierung}

Welche Auswirkungen hat das Phänomen Pornografisierung aus der Sicht feministischer Kritik? Die Publizistin Natasha Walter hält etwa die Masse und Zugänglichkeit der Mainstream-Pornografie für eine Gefahr. Das per Mausklick verfügbare unüberschaubare Angebot der Internet-Pornografie sei Ursache für Beziehungs- und familiäre Probleme: »The over-use of pornography does threaten many erotic relationships, and this is a growing problem. "Walter 2010, S. 114) Nicht nur der zwanghafte Gebrauch, sondern auch die pornografischen Inhalte selbst seien ein Problem. Ein Großteil der MainstreamPornografie sei frauenverachtend: "What's more, too much pornography does still rely on or promote the exploitation of women. Even if you can find porn 
for women and couples on the internet, nevertheless a vein of real contempt for women characterises so much pornography.« (Ebd.) Frauenverachtende pornografische Inhalte haben laut Walter also reale Folgen für die Erotik in Paarbeziehungen. Doch wie funktioniert dieser Transfer pornografischer Inhalte in die Paarbeziehung? Die Geschlechterforscherin Julia Long beschreibt anhand des sogenannten facial cumshot, wie Pornografisierung ihrer Meinung nach funktioniert:

Far from an image that exists only in the realms of fantasy, the practice of men ejaculating on a woman's face begins as a material practice; an act of abuse upon the female porn performer. From there, as the image is shared homosocially among male consumers, it is given a name, it is brought into existence as part of a range of possible and desirable acts within a sexual repertoire; part of a potential sexual script. Through further instances of cultural references, it becomes discursively established as both a concept and reality in relation to and influencing current sexual norms. (Long 2012, S. 121f.)

Damit wendet sich Long gegen das Argument, pornografische Praktiken hätten über das Fiktionale des Mediums hinaus keine Realität. Denn die filmische Abbildung setze die vorgängige Ausübung der Praktik voraus. In einem zweiten Schritt gewinne die Praktik Realität als unter Männern geteiltes und diskutiertes Bild. Indem in einem dritten Schritt weitere Medien den Diskurs um die Praktik aufnähmen, werde sie zu einem kulturellen Referenzpunkt und verankere sich fest in der gesellschaftlichen Vorstellung der Realität. Ebendiese Normalisierung bestimmter sexueller Praktiken durch Pornografie zeichne das Phänomen Pornografisierung aus.

Ich möchte diese Analyse anreichern, indem ich eine Untersuchung von Susanna Paasonen zur affektiven Ebene der Wirkung von Pornografie hinzunehme. In ihrer Analyse von extremer Pornografie und deren Verbreitung stützt sie sich auf das von der Geschlechterforscherin Sarah Ahmed entwickelte Konzept der affect stickiness (Ahmed 2010). Laut Paaonen rufen pornografische Bilder starke emotionale Reaktionen hervor und bleiben deshalb im Gedächtnis haften. Ebenso hafte die emotionale Reaktion aber an den Bildern. Da Emotionen eine starke soziale Komponente hätten, wollten sie geteilt, mitgeteilt werden; so trügen sie zur Verbreitung der Bilder bei. Die nüchterne Analyse der Bilder werde jedoch durch die Wertung und Kategorisierung, die in der Emotion enthalten sei, erschwert oder gar verunmöglicht. Denn diese Bewertungen blieben an den Bildern und insbesondere an den 
Körpern der Darstellenden haften: "The performing bodies function as evidence of the realness of that which has taken place and recorded in detail, and they are the anchors to which articulations of disgust, dirt and nastiness stick.«(Paasonen 2010, S. 75f.)

Damit habe ich nun einige wesentliche Elemente isoliert, die den Prozess der Pornografisierung bedingen: erstens pornografische Inhalte, gemeint sind sexuelle Inhalte, die starke emotionale Reaktionen auslösen; zweitens Körper, welche die Realität pornografischer Inhalte garantieren können; drittens ein homosozialer Raum, der das Teilen pornografischer Inhalte und der damit verbundenen Emotionen erlaubt; und viertens Medien, die auf die pornografischen Inhalte anspielen, die affektiven Reaktionen darauf ausbeuten und beides in einen kulturellen Referenzrahmen einbetten.

Im Folgenden möchte ich auf ein zusätzliches Element eingehen, das im Prozess der Pornografisierung eine große Rolle spielt: den pornografischen Blick.

\subsubsection{Der pornografische Blick}

Jugendliche und ihre sexuelle Entwicklung stehen besonders im Fokus der feministischen Kritik an der Pornografisierung. Walter beschäftigt vor allem die Tatsache, dass pornografische Bilder heute die Vorstellungen von Sex im Kopf der Jugendlichen bestimmten, bevor diese selber sexuelle Erfahrungen machten:

While once someone could live their whole lives without ever seeing anyone but themselves and their own partners having sex, now the voyeur's view of sex has been normalised, even for children. For an increasing number of young people, pornography is no longer something that goes alongside sex, but something that precedes sex. (Walter 2010, S. 107)

Mittels Pornografisierung werde also der Blick des Voyeurs auf Sex in den Köpfen der Jugendlichen verankert, bevor diese selbst aktiv an einer sexuellen Interaktion beteiligt gewesen seien. Dieser Blick habe einen verzerrenden Effekt auf das spätere sexuelle Erleben der Jugendlichen. Derselben Meinung ist die Geschlechterforscherin Gail Dines. Sie macht sich Sorgen über den Einfluss, den Pornografie auf die sexuelle Entwicklung junger Männer nimmt:

Nowadays the average age for first viewing porn is just eleven years. This means that, unlike before, porn is actually being encoded into a boy's sexual 
identity so that an authentic sexuality - one that develops organically out of life experiences, one's peer group, personality traits, family and community affiliations - is replaced by a generic porn sexuality limited in creativity and lacking any sense of love, respect, or connection to another human being. (Dines 2010, S. xi)

Dines baut hier eine interessante Gegenüberstellung auf: Auf der einen Seite steht eine als authentisch definierte Sexualität, die sich organisch aus der Persönlichkeit, den Erfahrungen und dem Umfeld eines Individuums ergebe, auf der anderen Seite eine als künstlich definierte Porno-Sexualität, deren Kreativität begrenzt sei und weder Liebe noch Respekt gegenüber anderen Menschen beinhalte. Dines betont allerdings, dass Pornografie in einem kulturellen Kontext stattfinde, der Jungen und Männer bereits auf die ihrer Ansicht nach Frauen degradierenden Botschaften der Pornos vorbereite:

What porn does is to take these cultural messages about women and present them in a succinct way that leaves little room for interpretations. While there are some media images that can be read in a number of ways (called polysemic in media studies) by different people, gonzo porn, particularly - with its overt contempt for women and incessant story line of how women like to be humiliated and debased - delivers a clear message to men, who have already developed a somewhat pornographic gaze by virtue of being brought up in a society filled with sexist pop culture images. (Ebd., S. 86)

Pornografie liefere also kulturelle Geschlechterstereotypen in verknappter Form mit wenig Interpretationsspielraum. Dines zeigt hier, wie zwei Formen der Pornografisierung miteinander verknüpft sind und die Sexualität von Jugendlichen negativ beeinflussen. Zuerst führe die Unterwanderung der Popkultur durch sexistische Bilder bei Jugendlichen zur Entwicklung eines pornografischen Blicks; dann sorge die Ubiquität der Pornografie selbst zur Verfestigung der sexistischen Wertungen, die in diesem pornografischen Blick enthalten seien. Da im Leben der meisten Männer eine Gegenideologie zur herrschenden Geschlechterungleichheit fehle, seien sie der erotischen Aufladung dieser Ungleichheit durch Pornografie ausgeliefert: »While porn is by no means the only socializing agent, thanks to its intense imagery and effect on the body, it is a powerful persuader that erodes men's ability to see women as equal and as deserving of the same human rights that they themselves take for granted.«(Ebd., S. 98) 
Auch die feministische Autorin Kat Banyard beobachtet, wie über Celebrity-Kultur, Modetrends und Werbung eine schleichende Normalisierung von Striptease-Clubs, Pornografie und Prostitution Einzug hält. Dies hat ihrer Meinung nach verheerende Auswirkungen auf Kinder und Jugendliche, insbesondere Mädchen: »They are learning that sexuality is a performance they must act out for others, not a genuine desire of their own. Young boys are taught that women are sexual objects that you do things to, not human beings to be treated with respect and dignity like themselves." (Banyard 2010, S. 177)

Was Frauen betrifft, ist Dines ebenfalls der Meinung, dass sich die Standards der Pornografie negativ auf deren Körperbewusstsein und deren Sexualität auswirkten:

Students (particularly female students) tell me regularly that when they have sex all they can think about is what they look like. Are their stomachs looking too big, do their breasts look good and so on? This is what's going on. And women internalize that plasticized look from the media. What options do they have, given that pornified images have crowded out other images of femininity? Women need never look at porn to be affected by it because they get porn ideology lite delivered to them via women's media too. (Dines et al. 2010, S. 27f.)

Damit bringt Dines ihre Sicht der Pornografisierung auf den Punkt: Eine Gesellschaft ist dann pornografisiert, wenn man nie Pornografie konsumiert hat und dennoch ihren Auswirkungen nicht entgehen kann.

Zusammenfassend möchte ich hier die Elemente des pornografischen Blicks festhalten: Es ist der Blick des Voyeurs, nicht des Teilnehmers an der sexuellen Interaktion. Gespeist wird er von den sexistischen Bildern der Popkultur und fokussiert durch die sexistischen Botschaften der Pornografie selbst. Er ist objektivierend und nicht empathisch. Mit dieser Objektivierung, die im pornografischen Blick liegt, und deren geschlechterspezifischen Auswirkungen möchte ich mich als Nächstes auseinandersetzen.

\subsubsection{Objektivierung, Selbstobjektivierung und Empowerment}

Auch Julia Long thematisiert den pornografischen Blick, indem sie behauptet, dass Sexualisierung verschieden auf Jungen und Mädchen wirke: Mädchen würden durch die Sexualisierung der Gesellschaft dazu angehalten, sich selbst als Objekte zu sehen, während Jungs sich eher als sexuelle Subjekte se- 
hen sollen (vgl. Long 2012, S. 130). Long kritisiert auch konservativ-religiöse Kräfte, die einen scharfen Unterschied zwischen Kindern, die vor jeglichem Kontakt mit sexueller Thematik geschützt werden müssten, und Erwachsenen, denen sexuelle Bilder keinen Schaden zufügten, machten:

To construct the issue in oppositional terms between notions of »adult « and »child« is to ignore feminist sholarship which critiques many aspects of normative »adult «sexuality. Feminist approaches, attending to questions of sexual politics, identify that, through processes of sexualisation, girls are interpellated as sexual objects, which feminists argue is undesirable for adult women, not just girl children. (Ebd., S. 127)

Long lehnt also sexuelle Objektivierung von Frauen generell ab, egal welchen Alters. Sie stellt diese in einen Zusammenhang mit der Art und Weise, wie Frauen in den Medien repräsentiert werden (vgl. ebd., S. 135). Wenn Frauen präsent seien, dann immer noch häufig als leicht bekleidete Dekorationselemente, während das handelnde und sprechende Personal überwiegend männlich sei. Entsprechend zweifelt sie McNairs These von der Überwindung patriarchaler Strukturen durch eine Demokratisierung des Sex in den Medien stark an.

Die Medienwissenschaftlerin Susan J. Douglas steht dieser These von der Demokratisierung des Sex ebenfalls skeptisch gegenüber. Sie weist darauf hin, dass im Rahmen der Sexualisierung Frauen medial eine scheinbare Ebenbürtigkeit zu den Männern zugeschrieben werde:

So the media began to highlight this message: it's through sex and sexual display that women really have the power to get what they want. And because the true path to power comes from being an object of desire, girls and women should now actively choose - even celebrate and embrace - being sex objects. That's the mark of a truly confident, can-do girl: one whose objectification isn't imposed from without, but comes from within. (Douglas 2010, S. 156)

Die Sexindustrie und die Medien verkauften also den Frauen ihre eigene Objektivierung als Selbstermächtigung. Den Frauen werde versprochen, dass sie, wenn sie den pornografischen Blick auf sich selbst anwendeten und danach strebten, den Normen dieses Blicks zu entsprechen, sich durch deren Erfüllung stark und mächtig fühlen würden. Deshalb findet es Douglas so wichtig, die Inhalte, über die Sexualisierung medial geschieht, unter die Lupe zu nehmen: 
So the question of whether the sexualization of our culture is good or bad for females may not quite be the right one. More important is how girls and women have been sexualized, how that's different from the way men have been, and what the consequences might be. Because while an increased frankness about sex in the media might indeed seem to be a liberal, even progressive advance from the days when The Catcher in the Rye and Lady Chatterley's Lover were censored, the content of this media, the way girls and women appear in them, may often be as sexist as it ever was. (Ebd., S. 186)

Douglas' These ist, dass die Medien heute den Frauen bloße Machtfantasien verkaufen, anstatt sie real zu ermächtigen. Sie versprächen ihnen Macht durch Selbstobjektivierung, durch die Erfüllung von Normen und vor allem durch Konsum:

Yet the images we see on television, in the movies, and in advertising also insist that purchasing power and sexual power are much more gratifying than political or economic power. Buying stuff - the right stuff, a lot of stuff - emerged as the dominant way to empower ourselves. (Ebd., S. 5)

TV-Serien wie Sex and the City präsentierten ein auf den ersten Blick emanzipiertes Frauenbild mit lauter unabhängigen, beruflich erfolgreichen und sexuell befreiten Frauen. Doch bei genauerem Hinschauen stecke dahinter ein stark mit ästhetischen Normen aufgeladenes Frauenbild, das enorm von Konsum abhängig sei. Für breite Schichten von Frauen sei das in der Serie präsentierte Ideal finanziell gar nicht erreichbar.

In dieser Feststellung trifft sich Douglas mit Attwood, die ansonsten der Rede von der Sexualisierung der Gesellschaft kritischer gegenübersteht und eher für eine präzise Analyse der Praktiken plädiert, durch die Sexualität heute ins Alltagsleben eingebunden wird. Unter dem Stichwort classy sex analysiert Attwood einen Lifestyle, der sich aus einem ganzen Bündel solcher Praktiken zusammensetze. Dieser Lifestyle bestehe aus einem postmodernen, konsumhaften, ästhetischen Umgang mit Sexualität, der an eine bestimmte soziale Schicht gebunden sei, idealtypisch repräsentiert etwa durch die Hauptfiguren von Sex and the City. Diese lebten eine sexuelle Freiheit aus, die insofern classy sei, als sie nicht schmutzig, sondern ein Zeichen von gutem Geschmack und Selbstvervollkommnung sei, eine Freiheit bourgeoiser Bohemiens. Der Erfolg eines erotischen Romans wie zum Beispiel 50 Shades of Grey sei nur auf dem Hintergrund dieses spezifischen Lifestyles einer sozialen Klasse zu verstehen: 
For example, literary erotica, a form of sexual representation which has become extremely popular with female audiences, depends precisely on its distinction from pornography, a distinction which is constructed not only in the literary conventions of the texts, but in their location in smart bookshops. (Attwood 2006, S. 11)

Der Erfolg eines solchen Romans entspringe also nicht einem früher verborgenen und jetzt befreiten Interesse von Frauen an Pornografie, sondern dem Umstand, dass in der heutigen Kultur das Lesen eines solchen Romans für Frauen eine Möglichkeit darstelle, ihre Zugehörigkeit zu einer bestimmten sozialen Schicht zu markieren. Ebenfalls mit diesem sexuellen Lifestyle verbunden sei die Konstruktion von etwas, was Attwood Autosexualität nennt. Darunter versteht sie das Erleben von Sex als Luxus, den man sich gönnt, mit dem man sich verwöhnt, auf den man ein Anrecht hat. Diese Sicht auf Sex hat meiner Meinung nach viel mit der gestiegenen Akzeptanz von Pornografie zu tun.

Neben dem Verkauf von Machtfantasien setzen viele Medien laut Douglas eine weitere zentrale Strategie zur Maskierung von Sexismus ein: das Stilmittel der ironischen Übertreibung. "This is the final key component to enlightened sexism: irony, the cultivation of the ironic, knowing viewer and the deployment of ironic sexism. (Douglas 2010, S. 14) Indem die Medien Sexismus übersteigerten und als Karikatur präsentierten, behaupteten sie, dass eigentlich gar kein Sexismus mehr existiere, den man bekämpfen müsse. In RealityTV-Formaten wie Der Bachelor werde Sexismus als lustiges Spiel dargestellt, in welchem der umschwärmte Junggeselle sowie die ihn umschwärmenden Damen bereitwillig ironisch überzogene Geschlechterstereotypen durchspielten. Das Vergnügen des Fernsehpublikums an diesem Format rühre zu einem guten Teil daher, dass es die Inszeniertheit des Spiels in einem Akt der belustigten Distanzierung von den Protagonistinnen und Protagonisten durchschauen und sich ihnen überlegen fühlen könne.

But the bacteria that comes in with this inoculation is girls policing one another and themselves, reinforcing norms about being »nice« and »hot«. And this ridicule-as-power also gives girls permission to look forward to noxious girl-on-girl violence - the catfight - and to watch shows that, in the end, are about female competition and consumerism as the ultimate privilege and delight. (Ebd., S. 15) 
Douglas und Long sehen die im Rahmen der Sexualisierung der Medien propagierte Selbstobjektiverung der Frauen durchwegs negativ. Sich selbst sexistischen Normen zu unterwerfen und Machtfantasien nachzuleben, sei keine wirkliche Ermächtigung von Frauen. Eine neutralere Haltung nimmt demgegenüber die Geschlechterforscherin Paula-Irene Villa ein. Sie sieht im Gegensatz zu Douglas und Long gerade in der Selbstpornografisierung junger Frauen durchaus eine Empowerment-Strategie: »Ich schlage vor, pornografische Strategien vor allem als eine angemessene Artikulation der Ängste, Wünsche, Realitäten und Fantasien von jungen Menschen im Rahmen neoliberaler Ökonomisierungen des Sozialen zu sehen. Dessen Credo lautet: Bloß kein Opfer sein!« (Villa 2012, S. 62) Im Rahmen der Ökonomisierung der Gesellschaft seien junge Menschen einem ständigen Leistungs- und Selbstoptimierungsdruck ausgesetzt. Um diesem Druck standzuhalten, setzten gerade junge Frauen Pornografisierung als performative Strategie zur eigenen Ermächtigung ein. Villa hat hier meiner Meinung nach vor allem die Selbstpornografisierung von Frauen aus tieferen sozialen Schichten im Blick. Während Douglas und Long etwas paternalistisch den sexistischen Normen nachlebenden Frauen die Emanzipation absprechen, zieht Villa die Möglichkeit in Betracht, dass die betreffenden Frauen in einer pragmatischen Wahl zwischen schlechten Optionen, verursacht durch Prekarisierungsstrategien einer neoliberalen Wirtschaft, mit der Selbstpornografisierung vielleicht die für sie beste Wahl getroffen haben.

Im gesamtgesellschaftlichen Kontext sieht die Politikwissenschaftlerin Julia Jäckel das Phänomen der Selbstpornografisierung kritischer. Diese schwanke zwischen Empowerment und Selbstregulierung: "Das pornografisierte Selbst entwirft sich damit zugleich als Subjekt und Objekt, kann dadurch den (männlichen) Blick von außen verwerfen, stabilisiert gleichzeitig aber auch die herrschenden Geschlechternormen." (Jäckel 2012, S. 127) Da eine eigenständige Artikulation weiblichen Begehrens in der Popkultur schwierig sei, blieben Versuche, mittels Selbstpornografisierung die herrschenden Geschlechternormen herauszufordern, ambivalent. Jäckel bilanziert: »Damit steht der Diskurs der Pornografisierung auch im Kontext einer gesellschaftlichen Debatte um den Zugriff und die Verfügbarkeit von Frauenkörpern.«(Ebd., S. 132)

Die Kulturwissenschaftlerin Rosalind Gill nimmt die Rede von Empowerment innerhalb der Sexualisierungsdebatte ebenfalls kritisch ins Visier. Dabei weist sie vor allem darauf hin, dass ein bewusster Umgang mit medial vermittelten sexualisierten Bildern, wie er zum Beispiel im Rahmen von Se- 
xualaufklärung an der Schule erlernt werden könne, nicht automatisch dazu führe, diese Bilder als bestärkend wahrzunehmen. Es sei möglich, genau zu wissen, wie sexualisierte Bilder zustande kämen und wozu sie dienen sollten, und sich durch diese Bilder trotzdem eingeschüchtert oder irritiert zu fühlen. Die Rede von Empowerment gehe also von einem überholten Subjektbegriff aus: "It relies upon the idea of subjectivity as coherent, rather than split or contradictory, with the assumption that affect follws knowldege in rather a neat and obedient manner.« (Gill 2012, S. 740) Empowerment werde so zum Vehikel, um im Rahmen einer allgemeinen Tendenz zur Verlagerung von Macht auf Techniken der Selbstregulierung die Leute selbst für ihre Reaktion auf mediale Inhalte verantwortlich zu machen, ganz nach dem Motto: Wer den Anblick von nackter Haut nicht als ermächtigend empfinde, sei selber schuld. Umso mehr plädiert Gill dafür, die fehlende Verknüpfung der Sexualisierungsdebatte mit Macht- und Unterdrückungsdiskursen zu hinterfragen: "Sexualisation does not operate outside of processes of gendering, racialization and classing, and works within a visual economy that remains profoundly ageist, (dis)ablist and heteronormative.« (Ebd., S. 741)

In einem Punkt sind sich die erwähnten Autorinnen einig: Der Diskurs um Objektivierung und Selbstpornografisierung ist nicht von ökonomischen und medialen Diskursen zu trennen. Die sexuell befreite Frau, welche die Medien in sexualisierten Bildern präsentieren, ist eine Frau, die sich in hohem Maße den Normen des pornografischen Blicks unterwirft. Inwieweit sie diese Unterwerfung dennoch als ermächtigend oder befreiend erlebt, hängt davon $\mathrm{ab}$, welche Optionen sie sonst noch hatte. Selbstpornografisierung ist jedoch medial eng an Konsum gekoppelt, die Erfüllung der Normen des pornografischen Blicks ist nur möglich infolge des Kaufs bestimmter Dienstleistungen und Produkte. Die in der Debatte um Pornografisierung wichtigen Elemente Selbstobjektiverung und Empowerment sind Techniken, die im Rahmen eines bestimmten Wirtschaftssystems stattfinden. Diesen Zusammenhang möchte ich im Folgenden noch genauer beleuchten. Pornografisierung muss vor dem Hintergrund wirtschaftlicher Zusammenhänge analysiert werden. Dines zum Beispiel vertritt die These, dass das Unterwandern des Mainstreams durch Pornografie ein von langer Hand geplanter Coup der Sexindustrie sei: "Porn should not be understood as an avant-garde sart form creativity and playfulness of independent directors, performers, and producers. It needs to be understood as a business whose product evolves with a specifically capitalist logic.« (Dines 2010, S. 46) Der Pornografisierung liege eine spezifische kapitalistische Logik zugrunde: 
As a major industry, the porn business does not just construct and sell a product; it constructs a world in which the product can be sold: the technologies, the business models, the enthusiastic consumers, the compliant performers, the tolerant laws, even the ideologies that proclaim porn to be the apogee of empowerment and liberation. (Ebd.)

Aus dieser Perspektive ist Pornografisierung ein von der Sexindustrie gesteuerter Prozess mit dem Ziel, mehr Produkte zu verkaufen, mehr Gewinn zu machen. Die sexualisierte Medienwelt, die technologischen Fortschritte und die gelockerten rechtlichen Rahmenbedingungen, die zusammen laut Paasonen Pornografisierung ermöglichen, und sogar die Ideologie der sexuellen Befreiung sind für Dines bloße Elemente einer ausgefeilten Verkaufsstrategie.

Die Geschlechterforscherin Clarissa Smith überzeugt die kapitalismuskritische Klage über die Pornografisierung, der die Warenförmigkeit von Körper und Sex in der heutigen Zeit angelastet wird, allerdings nicht. Die Ansicht, dass in einer kapitalistischen Welt ausgerechnet Sex nicht kommerzialisiert sein solle, sei lächerlich; sie stütze sich auf die falsche Vorstellung ab, dass Sex Ausdruck einer inneren Wahrheit einer Person sei, die von der Welt abgeschottet werden könne. Smith beobachtet den Einsatz des Begriffs der Pornografisierung mit Sorge. Sie greift auf eine Idee von Stuart Hall (vgl. Hall et al. 1978) zurück, indem sie behauptet, was die unter dem Schlagwort Pornografisierung subsumierten Phänomene verbinde, sei einzig eine rhetorische Strategie, eine Panik im Geist des Betrachters. Diese von Panik unterfütterte Rhetorik drohe unseren Blick auf die konkreten Phänomene zu verstellen. Solange zum Beispiel die Geschehnisse in Abu Ghraib der Pornografisierung der Gesellschaft angelastet werden könnten, müsse man sich nicht mit den realen, machtpolitischen Hintergründen befassen, die den Angriff auf den Irak und die Anwendung von Folterpraktiken legitimiert hätten.

Smith hebt hervor, dass McNair den Begriff Pornografisierung eingeführt habe, um einen ideologischen Bruch in der Haltung der Gesellschaft zu Sexualität und Pornografie zu markieren:

Thus he saw a fascination with sex and sexuality as a potentially transgressive force against the traditional boundaries of public and private, an expansion of the sexual sphere, a »democratization of desire«, which through the rise of new technologies gave access to the means of sexual expression and the pluralizing of sexual cultures to include those (e.g. gays, lesbians, trans- 
people and other so-called »perverts«) who had been specifically excluded from sexual self-definition. (Smith 2010, S. 104)

Durch das Aufgreifen des Begriffs durch feministische Pornografiekritikerinnen habe der Begriff dieses radikale Potenzial verloren und sei stattdessen mit den auf feministischer Seite traditionell negativen Assoziationen zu Pornografie befrachtet worden. Smith argumentiert, dass der Begriff der Pornografisierung mehr verdecke als erkläre: »The problem with pornographication is that it is a conceptual sledgehammer which draws very particularly form earlier arguments proposed by both moralists and feminists such as Dworkin - that so long as a cultural item >smells like porn then that's what it is. « (Ebd., S. 107)

Eine eher soziologisch-systemtheoretische Sicht auf Pornografisierung findet sich bei Sven Lewandowski. Er behauptet, dass seit den 1970er-Jahren die Gesellschaft die Bekämpfung der Pornografie mehr oder weniger aufgegeben und ihr einen Platz in der Gesellschaft zugewiesen habe, auf dem sie möglichst nicht störe. Es dominiere die Haltung, Pornografie solle sich auf sexuelle Stimulierung in privaten Räumen beschränken und nicht etwa Gesellschaftskritik üben:

Konsensmoralische Ausrichtung ist gewissermaßen der Preis, den die Pornographie dafür zahlt, in relativer Ruhe gelassen zu werden. Und sie zahlte diesen Preis, zunächst jedenfalls, durchaus gern, da die Zivilisierung des Pornographischen den Zugang zu neuen Käuferschichten, vor allem zu neuen Konsumentinnen versprach, die sich vom klassischen pornographischen Angebot eher abgestoßen fühlten. (Lewandowski 2012, S. 259)

Dieser gesellschaftsliberale Konsens sei in den letzten Jahren aufgekündigt worden, da ihm von zwei Seiten Bedrohungen erwüchsen: Auf der einen Seite greife eine neue Besorgnis um die Sexualität von Kindern und Jugendlichen um sich, die vor dem gefährlichen Einfluss der Pornografie zu schützen seien; auf der anderen Seite widersetze sich die Pornografie durch die Expansion ins Internet mittlerweile der Kontrolle einer nationalstaatlich orientierten Gesellschaft. Für Lewandowski markiert also der Beginn des Prozesses der Pornografisierung das Ende des in seinen Worten "Post-Pornographischen Zeitalters«. Er verkoppelt den Prozess mit dem Aufstieg des Neoliberalismus (vgl. ebd., S. 260). Auch er benennt die neuen Medien als wesentlichen Motor für Pornografisierung. Die Sorge um den Körper und die Sexualität von Minderjährigen ist ihm zufolge jedoch nicht Effekt der Pornografisierung, 
sondern deren Voraussetzung. Sie mache das Thema Pornografie erst wieder zum Gegenstand gesellschaftlicher Ängste. Lewandowski stellt damit implizit die Frage, ob der Einsatz des Begriffs Pornografisierung nicht dazu diene, gesellschaftliche Ängste auf das Phänomen Pornografie zu lenken, die eigentlich woanders ihren Ursprung haben.

Zusammenfassend lässt sich festhalten, dass es eine gesellschaftliche Tendenz gibt, die sich mit dem Begriff Pornografisierung umschreiben lässt. Der Begriff beschreibt das Anreichern oder Verwandeln von etwas in Pornografie. Innerhalb der Pornografisierung lassen sich zwei Aspekte unterscheiden: einerseits die stärkere Verbreitung der Pornografie selbst, die mit technologischen Innovationen und dem Wegfall gesetzlicher Regulierungen zusammenhängt - andererseits das zitatförmige Einfließen von pornografischen Inhalten in die Massenkultur.

Pornografisierung ist ein Prozess, der sich über verschiedene Stationen vollzieht. Zuerst werden reale Körper pornografisch abgebildet. Dann werden diese Abbildungen in homosozialen Räumen geteilt. In den Medien findet eine Bezugnahme auf sie statt. Am Ende des Prozesses stehen die Praktiken der Menschen selbst, die pornografische Bilder und Handlungsweisen inkorporieren. Dabei stützt sich Pornografisierung auf die spezifische Affizierungsweise der pornografischen Inhalte, die affektiv am Betrachter haften bleiben.

Die Kritik an der Pornografisierung sorgt sich vor allem um die Jugendlichen, die unter deren Einfluss einen pornografischen Blick auf sich und andere entwickelten. Dieser enthalte sexistische Wertungen, sei objektivierend und nicht empathisch. Aber auch Erwachsenen werde über Pornografisierung Selbstobjektivierung als Ermächtigung verkauft. Per Konsum werde ein ermächtigter und sexuell befreiter Lifestyle versprochen. Sexualisiertes Reality-TV gebe klassenspezifischen Machtfantasien Raum. Weiter wird behauptet, dass die der Pornografisierung zugeschriebene Selbstobjektivierung nur ein Teilaspekt der Selbstoptimierung sei, die die herrschende Wirtschaftsordnung des Neoliberalismus seinen Teilnehmenden abverlange. Die Angst vor der Pornografisierung sei ein Symptom für die von dieser Wirtschaftsordnung geschürten Ängste um Körper, Jugend und Gesundheit.

Ich verstehe die Sexindustrie nicht als alleinige Urheberin des Prozesses Pornografisierung. Sie hat wohl eher geschickt deregulierte oder dank technologischen Innovationen entstandene, noch unregulierte mediale Räume besetzt. Die Sexindustrie ist Teil eines deregulierten, globalisierten Kapitalismus, der den an ihm teilnehmenden Subjekten Strategien der Selbstre- 
gulierung und Selbstoptimierung abverlangt. Sie reiht sich damit ein in eine Reihe gesellschaftlicher Akteure, die das Subjekt dazu anhalten, bestimmte Normen einzuüben, um ein sexuelles Subjekt zu werden. Die im Rahmen der Pornografisierungskritik formulierte Kritik der Selbstobjektivierung, der die Pornografisierung Vorschub leiste, ist aus meiner Perspektive als Analyse korrekt. In der negativen Bewertung, die in dieser Kritik mitschwingt, vermute ich allerdings eine idealisierte Konzeption des sexuellen Subjekts.

In einem nächsten Schritt möchte ich besser verstehen, wie die Pornografisierungskritik mit der allgemeinen Kritik an der Pornografie verknüpft ist. Denn eine Analyse, die von einer negativen Wertung von Pornografie ausgeht, läuft Gefahr, diese Wertung auf die gesellschaftliche Tendenz der Pornografisierung zu übertragen. Es stellt sich also die Frage, ob die Kritik an der Pornografisierung eine einseitige Pornografiekritik als Ballast mit sich schleppt, die den Zugang zu den erwähnten Inkorporationsweisen pornografischer Inhalte verstellt.

\subsection{Die feministische Kritik an der Pornografie}

\subsubsection{Das Recht auf sexuelle Selbstbestimmung}

Die feministische Kritik an Pornografie ist nicht neu, sondern hat eine Geschichte. Sie weist bereits bestimmte Standardargumente und -themen auf. Mich interessiert nun, inwieweit die Kritik an der Pornografisierung an diese Tradition anknüpft. Wie ordnet sich die Kritik an Pornografisierung selbst in die Geschichte der Pornografiekritik ein? Gibt es gemeinsame Topoi der Kritik? Gibt es methodische Ähnlichkeiten? Gibt es Ähnlichkeiten in der Rhetorik?

Ein wichtiger Referenzpunkt der aktuellen Pornografisierungskritik sind die Schriften der feministischen Aktivistin und Autorin Andrea Dworkins. Dworkin beschreibt in ihrem Werk, wie die männlich dominierte Gesellschaft Frauen das Recht auf sexuelle Selbstbestimmung systematisch abspreche:

Die Ideologie männlicher Sexualherrschaft behauptet, Männer seien kraft ihrer Penisse den Frauen überlegen; der körperliche Besitz der Frau sei ein natürliches Recht des Mannes; Sexualität bedeute de facto Eroberung und Besitz der Frau, in erster Linie, aber nicht ausschließlich, phallische Eroberung und phallischer Besitz; die Benützung des weiblichen Körpers für sexu- 
elle und reproduktive Zwecke sei ein normales Recht der Männer; der sexuelle Wille der Männer könne die entscheidenden Merkmale der weiblichen Sexualität angemessen und im Sinne der Natur definieren und damit die gesamte Identität der Frau. (Dworkin 1990, S. 243)

Dieselbe phallozentrische Ideologie macht für Dworkin das Wesen der Pornografie aus. Daraus folgert sie, dass der Zweck der Pornografie die Bestätigung und Verbreitung dieser frauenfeindlichen Ideologie sei.

Dworkin geht auf die wörtliche Bedeutung von Pornografie zurück und versteht sie als schriftliche oder bildliche Darstellung von Huren. Pornos sagen laut Dworkin Männern, dass Frauen Huren sind, damit Männer mit gutem Gewissen Frauen als Huren behandeln können. Damit verbindet sie die Debatte über Pornografie mit der Debatte über Prostitution. Das Patriarchat degradiere jede Frau zur Hure, da sie nicht selber über ihre Sexualität verfügen könne:

Die Frau als Hure existiert innerhalb des objektiven und realen Systems männlicher sexueller Herrschaft. Die Pornographie selbst ist für das männliche Sexualsystem objektiv, real, zentral. Die Bewertung der weiblichen Sexualität in der Pornographie ist objektiv und real, weil Frauen so gesehen und so bewertet werden. (Ebd., S. 241)

Dworkin dekonstruiert damit den Gegensatz zwischen reproduktiver und hedonistischer Sexualität. Was konservative und liberale Vorstellungen von Sexualität eine, sei die phallische Kontrolle über den Körper der Frau. Dworkin betont, dass das Sexualdispositiv, das die Männer den Frauen überstülpten, die männliche Vorherrschaft über die Frauen sichern solle. Es gehe in diesem Sexualdispositiv um Macht.

Diese Beobachtung rückt Dworkin in die Nähe von Foucault und dessen Macht-, Körper- und Sexualtheorien. Allerdings wehrt sie sich gegen Sexualund Entwicklungspsychologen, die den Aktiv/passiv-Gegensatz der Antike in die Sexualität von Mann und Frau hineinlegen. Dworkin erklärt sich die Tatsache, dass sich Knaben zu frauenverachtenden Männern entwickeln, folgendermaßen: „Der Knabe erfährt die Gewalt der Männer als ihr Opfer oder als ihr Zeuge.« (Ebd., S. 64) Ein Junge, der die Schwäche der Mutter und sein Versagen, sie vor dem Vater zu beschützen, erlebe, werde automatisch selbst einmal stark sein wollen und selber die als weiblich verstandene Schwäche verachten. In einer patriarchalen Welt sei es für einen Knaben nichts als logisch, an der Macht des Patriarchats partizipieren zu wollen, auch wenn er 
dafür Weiblichkeit abwerten müsse: „Der Knabe flüchtet ins Mannesleben, in die Macht. Es ist seine Entscheidung, die er aufgrund der gesellschaftlichen Bewertung seiner Anatomie trifft.«(Ebd.)

Dworkin zeigt auf, wie Frauen im Patriarchat systematisch der Subjektstatus abgesprochen werde - im Gegensatz zum Mann, der als Subjekt behandelt und dazu ermutigt werde, alles, was ihn umgebe, als Objekte für seinen Gebrauch und zu seinem Vergnügen anzusehen. Die Vorstellung, dass eine Frau ein Ding ist, das Männer besitzen und nach Belieben benutzen können, war gemäß Dworkin lange Zeit unumstritten. In besonderem Maße wende sich diese Vorstellung gegen Frauen, wenn sie vergewaltigt würden. Indem der Mann die Vergewaltigung als physiologische Reaktion auf den von einem Objekt ausgehenden Reiz darstelle, werde die Schuld für die Vergewaltigung der Frau zugeschrieben. Nachdem die Frau also vom Mann zu einem Ding ganz nach seinem Wunsch geformt worden sei, gebe er ihr die Schuld dafür, ein Objekt des Begehrens zu sein und bei ihm Begehren auszulösen: »Die Liebe für ein Sexualobjekt oder das Begehren eines Sexualobjekts oder die Besessenheit von einem Sexualobjekt werden in der männlichen Kultur als eine Reaktion auf die Eigenschaften des Objektes selbst gesehen.« (Ebd., S. 138)

Die Frau selbst ist laut Dworkin das fetischisierte Objekt, und alles an ihr könne fetischisiert werden, ohne dass sie mit ihrem Verhalten darauf Einfluss nehmen könne. Damit hält sie Batailles Theorie des Erotismus den Spiegel vor, die ein Objektwerden der Frau als notwendig für die Relation des Begehrens setzt. Die Gewalt, die in pornografischen Darstellungen oft an Frauen ausgeübt werde, sei nur der bildliche Ausdruck der in der Gesellschaft allgemein akzeptierten Wahrheit, dass Frauen kein Recht darauf hätten, Sexualität zu verweigern. Indem sie den Frauen eine generelle Tendenz zum Masochismus unterschöben, legitimierten die Männer ihre Anwendung von Zwang in der Sexualität. Laut Dworkin spiegelten sich Realität und Fiktion aneinander: Pornografie stelle etwas ausdrücklich dar, was in der Gesellschaft sowieso vorhanden sei, und indem sie dieses darstelle, verstärke und verankere sie es in der Gesellschaft.

Doch auch Frauen seien nicht unschuldig an ihrer Objektivierung in Pornografie und Sexualität. Dworkin beschuldigt sie der Selbstverdinglichung und der Komplizenschaft:

Kann es Ceschlechtsverkehr ohne Verdinglichung geben, und kann es Verdinglichung ohne jene weibliche Komplizenschaft geben, die sie gedanklich und auch tatsächlich aufrechterhält: kann es Verdinglichung ohne die Frau 
selbst geben, die sich zum Objekt macht - die mit Kunst und Anstrengung ein Ding wird, das weniger als menschlich ist, so dass er mehr als menschlich sein kann, hart, herrscherlich, König? (Dworkin 1993, S. 184)

Frauen strengten sich sehr an, ein begehrenswertes Objekt zu werden, und trügen so zur Aufrechterhaltung verdinglichender Geschlechterverhältnisse bei. Mit diesem Vorwurf nimmt Dworkin Bourdieus Analyse vom weiblichen Sein als ein Wahrgenommenwerden vorweg. Wie aus dem obigen Zitat hervorgeht, wurzelt ihre Pornografiekritik in einer sehr kritischen Auffassung von heterosexuellem Sex, insbesondere von Geschlechtsverkehr:

Aber der Hass auf Frauen ist als solcher eine Quelle sexuellen Vergnügens für Männer. Geschlechtsverkehr scheint die reinste Form jener Verachtung zu sein, die Form sexualisierter Hierarchie; er erfordert keine Leidenschaft und kein Herz, weil er Macht ohne Erfindungsgabe ist und die Arroganz derer artikuliert, die das Ficken besorgen. Ceschlechtsverkehr ist der reine, sterile, formale Ausdruck männlicher Frauenverachtung; aber jene Verachtung kann sehr pervers sein, sie kann die vielfältigsten Formen sadistischer sexueller Praktiken annehmen, die direkten Ceschlechtsverkehr vermeiden. Jede Art Verletzung des weiblichen Körpers kann für Männer zu Sex werden; das ist die zentrale Wahrheit über Pornographie. (Ebd., S. 181f.)

Dworkin konstruiert hier Geschlechtsverkehr als sexuellen Übergriff. Sexualität erscheint als Bühne für das Ausleben von Frauenhass, Pornografie als Medium der Erotisierung von Gewalt gegen Frauen.

Dworkin macht darauf aufmerksam, dass sich Geschlechtsverkehr nicht in einer rein privaten Sphäre abspiele, er werde durch staatliche Gesetze reguliert. Legaler Geschlechtsverkehr werde von illegalem unterschieden. Die Legalität des Geschlechtsverkehrs sei an dessen Vollzug innerhalb einer bürgerlichen Ehe zwischen Mann und Frau gebunden; die Ehe könne gar für ungültig erklärt werden, wenn kein Vollzug des Geschlechtsverkehrs stattgefunden habe. Auf diese Weise sei das staatstragende, männliche bürgerliche Subjekt für seine Aufrechterhaltung auf Geschlechtsverkehr angewiesen. Die Infragestellung des Geschlechtsverkehrs ist für Dworkin damit ein legitimes Anliegen eines Feminismus, der das Gesellschaftsmodell, das auf dem bürgerlichen männlichen Subjekt beruht, ins Wanken bringen möchte.

Sowohl das Wachstum der Sexindustrie als auch der technologische Fortschritt werden von Feministinnen in der aktuellen Debatte als Treiber von Pornografisierung identifiziert. Schon Dworkin nennt diese Faktoren: 
Immer mehr männliche Konsumenten brennen darauf, immer mehr Celd für Pornographie auszugeben - für die Darstellung von Frauen als wertlose Huren. Pornographie wird heute über Kabelfernsehen verbreitet, sie wird heute über Video für den Hausgebrauch vermarktet. Die Technik selbst verlangt die Schaffung von immer mehr porneia, um den durch die Technik eröffneten Markt zu befriedigen. (Dworkin 1990, S. 242)

Frauen würden erst wirklich frei sein, wenn einmal keine Pornografie mehr existiere. Die Stärke von Dworkins Analyse ist die konsequente Orientierung an der sexuellen Selbstbestimmung der Frau. Das Patriarchat hält seine Vorherrschaft über die Frau dadurch aufrecht, dass es ihr die Autonomie über ihre Sexualität systematisch verweigert. Das männliche Sexualdispositiv, das in der Pornografie verbreitet wird, habe die Aufgabe, die männliche Vorherrschaft sichern, indem Frauen darin nur als Objekt und nie als Subjekt vorkommen. Als Objekt von Sexualität könnten Frauen durchgehend in einem Status der Einschüchterung gehalten werden, denn, was immer sie täten, alles könne als Einladung zu einem sexuellen Übergriff gelesen werden. Letztlich legitimiere so Pornografie Gewalt an Frauen.

Auch Dworkins These, dass Pornografie Gewalt an Frauen sexualisiere, ist überzeugend. Das Ziel der Pornografie ist es, beim Benutzer Erregung hervorzurufen. Falls also in Pornografie Gewalt gegen Frauen vorkommt, wird sie auf sexualisierte Weise vorkommen, sodass zumindest männliche Benutzer sie erotisch finden. Das Interessante an Dworkins These liegt für mich darin, dass sie auf die Rahmung von Gewalt aufmerksam macht. Wie Judith Butler (2010) herausgearbeitet hat, wird in allen medial vermittelten Realitäten Gewalt auf eine bestimmte Weise gerahmt, gewisse Aspekte an ihr werden durch die Rahmung herausgehoben, andere unterdrückt. Dies ist auch in der Pornografie der Fall. Zu Recht weist Dworkin darauf hin, dass das Leid der Opfer von gewaltförmiger Sexualität in der Pornografie unterdrückt oder sogar in einer luststeigernden Weise umgedeutet wird. Sven Lewandowski schreibt zum Phänomen der gewaltförmigen Sexualität in Pornos:

Ein Teil dessen, was als Hass auf das Weibliche erscheint, ist also Ausfluss der Tatsache, dass die einzige Form, in der die Pornographie männliche Selbstermächtigung denken kann, die Ermächtigung über die Frau und die Unterwerfung des weiblichen Körpers ist. Der inszenierte Hass auf das Weibliche ist Teil der Abwehr einer Verschmelzung mit ihr. (Lewandowski 2012, S. 58) 
Pornografie ist laut Lewandowski ein Selbstverständigungsdiskurs krisenhafter heterosexueller Männlichkeit. Die Abwehr von Weiblichkeit und homosexuellem Begehren werde in der Pornografie häufig mit der Herabsetzung von Frauen erkauft. Demnach wäre aber das Vorkommen von gewaltförmiger Sexualität in der Pornografie in erster Linie ein Symptom für die reale Krise heterosexueller Männlichkeit und nicht ein Propagandainstrument frauenfeindlicher Ideologie. Doch auch Dworkin sagt, dass die Abwertung von Frauen für heranwachsende Knaben die Voraussetzung für das Partizipieren an der Macht des Patriarchats ist. Was ist nun der Unterschied zwischen ihrer Optik und der Lewandowskis?

Der Unterschied liegt im transgressiven Charakter der Pornografie. Nicht nur die heterosexuelle Männlichkeit des heranwachsenden Knaben, sondern auch die des erwachsenen Mannes ist und bleibt krisenhaft und bedarf der Stabilisierung. Da diese Stabilisierung im Alltag schwierig einzufordern ist, wird sie in der Pornografie gesucht. Der wachsende Kontrast der pornografischen Szenarien zum Alltagsleben erfordert vom Betrachter allerdings einen größeren Akt der Transgression. Dies erhöht wiederum ihren Reiz. Lewandowski schreibt dazu:

Die Unterkomplexität (internet-)pornographischer Skripte bildet ein Cegenbild zur Überkomplexität der modernen Cesellschaft. Die Attraktivität internetpornographischer Angebote, die soziale und sexuelle Verhältnisse auf einfache und unterkomplexe Weise darstellen, beruht nicht zuletzt auf diesem Gegenbildcharakter, der die eskapistische Funktion pornotopischer Welten unterstreicht. (Ebd., S. 142)

Transgressive Aspekte der Sexualität werden von Dworkin zurückgewiesen. Deutlich macht dies ihre Rezeption der Werke des Marquis de Sade, die Dworkin als exemplarisch für die Gewalttätigkeit der Pornografie liest: »Sade enthüllt die Richtigkeit der Gleichung: Die Macht des Pornographen ist die Macht des Vergewaltigers/Schlägers, ist die Macht des Mannes." (Dworkin 1990, S. 123) Sie stellt rhetorisch eine Einheit zwischen De Sades Leben und Werk her. Den Verteidigern Sades wirft sie Blindheit gegenüber der Frauenfeindlichkeit, die sich in seinem Leben und Werk manifestieren, vor. Aufgrund der sexistischen Stereotype, die Sade mit den Figuren Justine oder Juliette fortschreibt, kann Dworkin in seinen Schriften nichts Revolutionäres entdecken. Sie wirft auch Bataille vor, in seiner Darstellung von Sexualität Zwang und Gewalt zu romantisieren: 
Der intellektuelle Anspruch, der an das Werk gestellt wird, ist Batailles Enthüllung eines sexuellen Geheimnisses: die authentische Verbindung zwischen Sexualität und Tod. Manchmal gilt diese Offenbarung als der Wert hochwertiger Pornographie schlechthin. Aber in Wirklichkeit hat Bataille mehr verschleiert als enthüllt. Er hat die Bedeutung von Zwang in der Sexualität verschleiert. Er hat die Tatsache verschleiert, dass es keinen männlichen Begriff von Sexualität gibt ohne Zwang als ihren wesentlichen Antrieb. Er hat dies erreicht durch die Romantisierung des Todes. (Ebd., S. 210)

So recht Dworkin mit ihrem Kommentar zu Batailles Romantisierung des Todes hat, so starr bleibt ihre Sicht von männlicher und weiblicher Sexualität. Ihre Analyse orientiert sich zwar an der sexuellen Selbstbestimmung der Frau, da aber das Patriarchat in Dworkins Darstellung den Frauen diese sowohl real als auch in der Pornografie umfassend abspricht, bleibt wenig Raum dafür, wie eine autonome weibliche Sexualität überhaupt zu denken wäre. Den Objektstatus der Frauen, den Dworkin überwinden möchte, werden sie in ihrer Analyse deshalb kaum los. Weibliche Sexualität gerät so zur Negativfolie auf die durchgängig als gewaltförmig und auf Dominanz ausgerichtet beschriebene männliche Sexualität - sie erscheint als sanft, empathisch, natürlich, auf Reziprozität ausgerichtet. Damit verbleibt Weiblichkeit auf der passiven Seite einer Binarität, die Dworkin eigentlich überwinden will.

Aktivistin Cindy Jenefsky und Geschlechterforscherin Ann Russo analysieren Dworkins Pornografiekritik im Verhältnis zu ihren früheren Werken. Sie stellen fest, dass Dworkin in ihrem Frühwerk noch sexuell libertäre Positionen vertrat, die sie jedoch, von der Frauenfeindlichkeit der 68er-Bewegung abgestoßen, bald aufgab:

Second, all of Dworkin's subsequent work rejects the sexual libertarianism which still lingers in the »Androgyny «section of Woman Hating. In fact, such a rejection is an implicit and persistent premise in the remainder of her books. Like the Women's Liberation Movement generally, Dworkin's feminism, including that of Woman Hating, originates in part in a repudiation of the sexism of the sexual revolution of the sixties. However, it is not until after Woman Hating, when Dworkin stops articulating new paradigms, that she also drops her concern with sexual repression. (Jenefsky/Russo 1998, S. 43)

So fehlt ein positiver Gegenentwurf Dworkins zum Sexismus der realen Welt. Jenefsky und Russo sehen die Stärke von Dworkins Schriften deshalb vor allem in ihrer bedingungslosen Parteinahme für die Opfer von Sexismus. Die- 
se Parteinahme vermöge rhetorisch zu überzeugen, schließe jedoch andere Sichtweisen aus:

But in Dworkin's essentializing interpretation, she defines pornography strictly from the perspective of those harmed by it. All other perspectives are excluded from her texts. She thereby requires her audience to step into her world as she sees it, rather than presenting her world in relation to the perspectives of others. (Ebd., S. 86)

Diese einseitige Parteinahme mache es schwierig, Dworkins Schriften in einen akademischen Diskurs einzubetten. Denn aus der Perspektive der Opfer von Sexismus spielen für Dworkin in der akademischen Diskussion wichtige Differenzierungen keine entscheidende Rolle:

Although Dworkin acknowledges the distinction between pornography that uses real women for its production and that which does not, she does not confine such exploitation to photographic media. Although ancient Greek pornography, for instance, did not require a woman for its production - no specific sexual act had to be committed in order for it to exist - the fact is, claims Dworkin, pornography and prostitution have always been »one and the same thing « as »far back as we know«. (Ebd., S. 67)

Die einseitige Parteinahme für die Frauen als Opfer von Sexismus prägt auch Dworkins Diskussion von schwuler Pornografie. Dworkin konstruiert männliche Homosexualität in der Pornografie als Konspiration mit dem heterosexistischen Patriarchat. Schwule Pornografie erscheint ihr als Exzess der phallozentrischen Pornografie, als Streben der Pornografie danach, die Frau nicht nur abzuwerten, sondern ganz aus der sexuellen Fantasie zu verbannen. Sie äußert sich auch zur in der schwulen Pornografie verbreiteten Sexualisierung des offensichtlich heterosexuellen Mannes. Als Beispiel führt sie das in einer Gay-Zeitschrift abgebildete Foto eines mithilfe der Zeitschrift Playboy masturbierenden Heteromannes an. Der Effekt dieses Fotos sei, dass der schwule Mann visuell an die männliche Überlegenheit über Frauen erinnert werde und diese zusammen mit dem dargestellten Heteromann genieße. Das Foto diene schlicht zur Bestätigung der Macht des Phallus:

Die Erinnerung an das Weibliche oder die Anwesenheit von Frauen ist an sich schon Teil der sexuellen Erregung, weil Überlegenheit Macht bedeutet und weil Macht in der männlichen Vorstellung sexuell erregend ist. In der Pornographie wird der schwule Mann ebenso wie der heterosexuelle Mann 
angeregt, seine sexuelle Überlegenheit über Frauen zu erleben und zu genießen. (Dworkin 1990, S. 59)

Dworkins Argumentation verfehlt hier einen zentralen Punkt schwuler Pornografie. Pornografie suggeriert eine Welt universeller sexueller Verfügbarkeit. Der Pornokonsument weiß, dass, wer auch immer in dieser Welt auftaucht, zu sexuellen Handlungen bereit sein wird. Mir geht es an dieser Stelle um die unterschiedliche Bedeutung, die eine Welt voll sexuell verfügbarer Männer für Schwule hat. Die Pornografie bietet eine Lösung an für sehr reale Hindernisse, auf die schwules Begehren im Alltag stößt. Als marginalisierte Sexualität ist dieses Begehren im Alltag stets in Gefahr, auf Zurückweisung oder sogar Gewalt zu stoßen. Die Utopie, welche die Pornografie dieser Realität schwuler Existenz entgegensetzt, hat deshalb einen befreienden und damit tendenziell politischen Charakter.

Vor diesem Hintergrund lese ich Dworkins Beispiel des sich mit einem Playboy-Heft vergnügenden Heteromannes als befreiende Fantasie schwulen Begehrens. Diese Fotografie stellt für schwule Männer eine gefahrlose Möglichkeit dar, einen heterosexuellen Mann attraktiv und erotisch $\mathrm{zu}$ finden. Von den lesbischen Fantasieszenarien, welche die heterosexuelle Pornografie durchziehen, unterscheidet sich das schwule Fantasieren über Heteromänner darin, dass hier derjenige zum sexuellen Objekt gemacht wird, der sonst immer Subjekt, aber nie Objekt des Begehrens ist. Gerade im Rahmen von Dworkins Theorie der sexuellen Objektivierung erscheint ihre Deutung dieses Beispiels als Fantasie der Teilhabe an der männlichen Herrschaft über Frauen abwegig. Es geht im Gegenteil darum, dass sogar derjenige, der diese Herrschaft ausübt, zum Objekt sexuellen Begehrens werden kann: eine subversive Fantasie, die männliche Herrschaft gerade nicht bestätigt, sondern unterminiert. Solche Gelegenheiten zur Transgression, die Pornografie bietet, sind bei Dworkin kein Thema.

Zusammenfassend formuliert, orientiert sich Dworkin in ihrer Analyse am Recht der Frauen auf Autonomie und sexuelle Selbstbestimmung. Entsprechend kritisiert sie die Objektivierung von Frauen durch Pornografie. Sie argumentiert überzeugend, dass Pornografie Gewalt an Frauen sexualisiert und damit legitimiert. Außer der Opferperspektive hat sie allerdings keine anderen Sichtweisen anzubieten. Bei ihr fehlt ein Entwurf davon, wie denn eine nicht sexistische Sexualität aussehen könnte. Dworkin ignoriert transgressive Aspekte der Sexualität oder weist diese entschieden zurück, da sie 
auf Gewalt und Zwang beruhten. Schwule Pornografie deutet sie einseitig als konspirativ mit dem heterosexistischen Patriarchat.

\subsubsection{Der Schutz der Redefreiheit}

Die Rezeption der feministischen Pornografiekritik bezieht sich häufig auf die Werke von Andrea Dworkin und Catharine MacKinnon. Welche Rolle spielen diese zwei Autorinnen im Rahmen der gesamten Anti-PornografieBewegung? Dazu stütze ich mich auf die historische Aufarbeitung der Geschlechterforscherin Carolyn Bronstein ab (vgl. Bronstein 2011, S. 18ff.)

Der Ursprung der Anti-Porno-Bewegung liegt laut Bronstein im Umstand, dass Exponentinnen der Frauenbefreiungsbewegung - Susan Griffin, Susan Brownmiller, Robin Morgan - in der Gesellschaft eine Epidemie sexueller Gewalt von Männern an Frauen wahrnahmen. Bronstein zufolge war ihre zentrale Beobachtung, dass diese sexuelle Gewalt nicht nur Leid verursache, sondern Frauen darüber hinaus in einer Position der Machtlosigkeit halte. Die Bedrohung durch und die Angst vor sexueller Gewalt hielten Frauen davon ab, sich dieselben Freiheiten zu erlauben, die Männern zustünden. Medial vermittelte Bilder männlichen Begehrens verstärkten diese sexuelle Gewalt als Instrument patriarchaler Kontrolle. Diese Anfang der 1970er-Jahre gemachte Beobachtung fällt laut Bronstein in eine Zeit, in der die Porno-Branche aufgrund gesetzlicher Liberalisierungen stark expandierte. Zusammen mit dem kulturellen Umbruch, den die sexuelle Revolution mit sich brachte, habe dies, was man eine erste Welle der Sexualisierung der Gesellschaft nennen könnte, ergeben. Darauf hätten die genannten Exponentinnen der Frauenbefreiungsbewegung reagiert und sich mobilisiert.

Wie Bronstein hervorhebt, habe sich etwa die Organisation Women Against Violence Against Women (WAVAW) anfänglich explizit nicht grundsätzlich gegen Pornografie ausgesprochen, um nicht gewalttätige Darstellungen von Sex von der Kritik auszunehmen und nicht pornografische Gewaltdarstellungen in Mainstream-Medien potenziell einzuschließen. Sie seien auch gegen Gesetze zur Einschränkung der Meinungsfreiheit gewesen und hätten stattdessen aktivistische Formen wie etwa Boykotte bevorzugt. Im Gegensatz dazu hätten die in der Organisation Women Against Pornography (WAP) organisierten Feministinnen einen eher juristischen Hintergrund gehabt; sie seien mit dem in der Rechtslehre dominierenden Dogma des klassischen Liberalismus unzufrieden gewesen, der in seiner abstrakten Konzeption des Rechtssubjekts reale Ungleichheiten zwischen den Geschlechtern ignoriere. Pornogra- 
fie sei aus Sicht dieser Aktivistinnen ein Instrument zur Durchsetzung von Ungleichheit zwischen Männern und Frauen und deshalb in deren Fokus geraten.

Wie Bronstein beschreibt, wurde Ende der 70er-Jahre, nach der Auflösung anderer Fraktionen, faktisch Women Against Pornography die führende Gruppierung der Frauenbefreiungsbewegung. Nach der Barnard-Konferenz zu Sexualität 1982 sei die Spaltung der Frauenbewegung in Anti- und ProSex-Feministinnen offensichtlich geworden.

Diese spätere Phase der Anti-Porno-Bewegung, die stark von Dworkin und MacKinnon geprägt gewesen sei, werde heute zum Maßstab für die ideologische Ausrichtung der Bewegung als Ganzes genommen, kritisiert Bronstein: The MacKinnon-Dworkin ordinance did position women as powerless, and it sought special government protection on the basis of the inferiour social status that pornography supposedly created for all women as a sex class." (Ebd., S. 335) Dieses Bild der Frau als Opfer sei das Gegenteil des Frauenbildes in den Anfängen der Bewegung. Dieser sei es anfänglich gerade darum gegangen, Frauen ihre Macht und Handlungsfähigkeit bewusst zu machen. Zudem weist Bronstein darauf hin, wie sehr sich im Lauf der Zeit der Fokus des Kampfs der Bewegung von Gewalt auf Sex verschoben habe.

Bronstein verzichtet in ihrem Buch auf eine Differenzierung zwischen den Positionen MacKinnons und Dworkins, da sie vor allem auf deren gemeinsame Eingaben für Gesetzesänderungen zum Schutz von Frauen vor Pornografie Bezug nimmt. Mir scheinen Dworkins Schriften noch stark von der ursprünglichen Empörung der Frauenbewegung über sexuelle Gewalt an Frauen und den durch diese verursachten Status der Unfreiheit der Frauen geprägt. Allerdings lässt sich bei Dworkin tatsächlich die Reduktion der Frau auf den Opferstatus beobachten. Es finden sich bei ihr kaum Perspektiven zu dessen Überwindung.

Wofür steht die Juristin MacKinnon ein? Sie tritt gegen eine Rechtssprechung an, die ihrer Meinung nach einseitig Freiheit - vor allem Meinungsfreiheit - gegenüber sozialer Gleichheit und Schutz vor sexueller oder Rassendiskriminierung privilegiert. Die Freiheit, die durch diese Bevorzugung geschützt werde, sei vor allem die Freiheit der Mächtigen; die Rede- und Meinungsfreiheit schütze in erster Linie die Rede und die Meinung derjenigen, die sowieso buchstäblich das Sagen hätten. Pornografie sei, so MacKinnon, ein Thema, an dem sich dieses Kollidieren von Freiheitsrechten mit dem Anspruch auf soziale Gleichheit exemplarisch aufzeigen lasse. Das Recht auf freie Meinungsäußerung werde hier auf dem Buckel von Frauen ausgetra- 
gen, die selbst von diesem Recht keinen Gebrauch machen könnten. Indem die Pornografie das Recht auf freie Rede für sich in Anspruch nehmen könne, bringe es Frauen zum Schweigen. Falls die Meinungsäußerung der Pornografie geschützt sei, welche Meinung werde damit geschützt? Für MacKinnon ist die Antwort klar: Pornografie propagiere Frauenhass und sorge damit für die Erniedrigung und Entwürdigung nicht nur der an ihrer Herstellung beteiligten Frauen, sondern generell aller Frauen. Denn die Bilder, die dank der Pornografie in der Gesellschaft kursierten, wärfen ein entstellendes Licht auf weibliche Körper, Sexualität und Selbstbestimmung.

MacKinnon nimmt also Dworkins These von der Pornografie als Propagandainstrument des Patriarchats auf und verknüpft sie mit einer Kritik am Recht auf freie Meinungsäußerung. Sehen wir uns ihre Argumentation im Einzelnen an: "Like law, pornography does what it says." (MacKinnon 1994, S. 28) MacKinnon versucht zu beweisen, warum Pornografie nicht einfach eine Meinung, eine Idee unter anderen ist, sondern etwas tut, bewirkt, auslöst. Dazu greift sie zu einer starken Analogie: Sie vergleicht das Sprechen der Pornografie mit dem Sprechen des Staates. Der Staat spreche durch Gesetze, die zwar bloß aus Worten bestünden, aber, sobald sie gesprochen würden, gälten und deren Befolgung verlangten. Gemäß MacKinnon tun Gesetze etwas, indem sie uns eine Realität aufzwingen, die wir nicht ignorieren können. Wir könnten sie befolgen oder nicht befolgen, aber im letzteren Fall müssten wir Verfolgung und Bestrafung befürchten. Das Gesetz werde gestützt und durchgesetzt durch staatliche Macht: »[L]aw is backed by power, so its words are seen as acts. But so is pornography: the power of men over women, expressed through unequal sex, sanctioned both through and prior to state power.« (Ebd., S. 40)

Pornografie tut laut MacKinnon etwas, indem sie ihre Realität Frauen aufzwinge, deren Handlungsspielraum eingrenze. Pornografie sei eine Handlung, die Schaden anrichte, und stehe deshalb nicht unter dem Schutz der durch die Verfassung garantierten Rede- und Meinungsfreiheit. "The social coding of sexuality as intimate and pleasurable also contributes to the distinctive sting and intrusiveness of harassment that is sexual.« (Ebd., S. 60) MacKinnon arbeitet hier eine Besonderheit der sexuellen Belästigung im Vergleich zu Angriffen aus rassistischer oder antireligiöser Motivation heraus: den Effekt der Vereinzelung. In einem sozialen Setting, das Sexualität im intimsten Bereich einer Person lokalisiere, schaffe ein Angriff auf die eigene Sexualität keine Gemeinsamkeit mit anderen Opfern von Übergriffen. MacKinnon trifft damit einen wunden Punkt der bürgerlichen Konzeption von Se- 
xualität. Wenn Sex, wie Foucault herausgearbeitet hat, in der bürgerlichen Moderne weniger eine soziale Interaktion als vielmehr eine intime Wahrheit über ein Subjekt darstellt, ist dieses Subjekt damit auch allein, da diese Wahrheit einzigartig ist.

Der Kern von MacKinnons Argumentation ist folgender: Opfer von Redefreiheit können diese nicht zu ihren Gunsten nutzen und einsetzen; wenn Redefreiheit als Wert über allem steht, ergibt sich die paradoxe Situation, dass Redefreiheit effektiv bestimmte Leute zum Schweigen bringt. Zur Auflösung dieses Paradoxons schlägt sie eine Relativierung der Redefreiheit gegenüber dem Grundsatz der Gleichheit vor: "In this new model, principle will be defined in terms of specific experiences, the particularity of history, substantively rather than abstractly. It will notice who is being hurt and never forget who they are.« (Ebd., S. 77) Ganz wie Dworkin ist sie der Meinung, dass Pornografie Ungleichheit sexuell auflade und damit entscheidend zur Persistenz dieser Ungleichheit gegenüber Frauen beitrage:

In pornography, there it is, in one place, all of the abuses that women had to struggle so long even to begin to articulate, all the unspeakable abuse: the rape, the battery, the sexual harassment, the prostitution, and the sexual abuse of children. Only in the pornography it is called something else: sex, sex, sex, sex, and sex, respectively. (MacKinnon 1995, S. 58f.)

Diese Aufladung von Gewalt gegen Frauen mit Sexualität habe großen Einfluss darauf, wie die Gesellschaft generell Gewalt gegen Frauen bewerte. Indem Pornografie eine soziale Realität konstruiere, in der Gewalt sexy sei, werde sowohl das durch Gewalt wie auch das durch Pornografie verursachte Leid unsichtbar: "If we live in a world that pornography creates through the power of men in a male-dominated situation, the issue is not what the harm of pornography is, but how that harm is to become visible. (Ebd., S. 61) Traditionell drehte sich die Debatte um die Zensur von Pornografie um den Grad der Obszönität einer Darstellung. MacKinnon dagegen findet, dass Pornografie und Obszönität zwei verschiedene Kategorien seien, die sich grundsätzlich im Ausmaß des Schadens, den sie verursachten, unterschieden: „Obscenity, in this light, is a moral idea, an idea about judgements of good and bad. Pornography, by contrast, is a political practice, a practice of power and powerlessness.« (Ebd.) Diese Unterscheidung haben wir in der Einleitung bei Carse als jene zwischen Anstößigkeits- und Schadensrestriktionismus kennengelernt. Sie macht MacKinnons Position noch einmal sehr klar. Ob jemand eine Darstellung obszön oder anstößig findet, ist für MacKinnon ein persönliches mo- 
ralisches Urteil. Ihre Kritik an der Pornografie richtet sich an eine politische Praxis, welche die Herrschaft von Männern über Frauen sichert. Deshalb stört es MacKinnon, dass nur gegen Obszönität, aber nicht Pornografie rechtlich vorgegangen werden kann.

MacKinnons Diagnose, dass die Redefreiheit bestimmte Leute zum Schweigen bringe, scheint mir berechtigt. Das Problem an MacKinnons Vorschlägen zur Behebung dieses Missstandes ist, dass sie Tür und Tor öffnen für Einschränkungen der Redefreiheit. Wer entscheidet, wer verletzt ist respektive wessen Anspruch auf Gleichheit verletzt worden ist? Mac-Kinnon überträgt dem Staat hier viel Entscheidungs- und Definitionsmacht. Denn »the particularity of history« kann potenziell von jedem Individuum und jeder Gruppe ins Feld geführt werden, der oder die sich an irgendeiner spezifischen Form der Ungleichheit stört. In einer Welt der Ungleichheiten soll also am Ende der Staat entscheiden, wessen Recht auf Gleichheit durchgesetzt wird. Es fragt sich, ob der Staat sich effektiv für bisher benachteiligte Rassen- und Geschlechtsidentitäten einsetzen wird, sobald das Primat der Redefreiheit fällt.

Zusammenfassend lässt sich festhalten, dass MacKinnons Argumentation zwar auf Dworkins Thesen basiert, den Fokus aber auf Sprache und Recht verschiebt. Dworkin geht es um die Freiheit und die sexuelle Selbstbestimmung der Frauen, die ihnen durch Pornografie verwehrt werde; denn in Pornografie werde ein männliches Sexualdispositiv verbreitet, das letztendlich Gewalt an Frauen legitimiere. Hier knüpft MacKinnon an: Diese Verbreitung eines frauenverachtenden Sexualdispositivs sei keine Meinungsäußerung mehr, die von der Verfassung geschützt werde, sondern eine Handlung, die Leid verursache. Für MacKinnon ist es nicht akzeptabel, dass Pornografie von der in der US-Verfassung garantierten Rede- und Meinungsfreiheit geschützt sein solle, die Opfer des durch Pornografie verbreiteten Sexualdispositivs aber ihr Leid nicht artikulieren könnten; denn in einer von Pornografie durchdrungenen Welt würden die Erfahrungen der Opfer umgedeutet oder nicht gehört. MacKinnon schließt daraus, dass der absolute Schutz der Meinungsfreiheit für Pornografie nicht gelten darf und dass stattdessen ein Prinzip, das den Anspruch auf Gleichheit schützt, in die Verfassung aufgenommen werden soll. Damit verengt MacKinnon das von Dworkin breiter diagnostizierte Problem der mangelnden Freiheit und sexuellen Selbstbestimmung der Frauen auf zwei rechtliche Forderungen: den Anspruch auf Gleichheit und die Aufhebung des Schutzes der Meinungsfreiheit für Pornografie. Sie setzt auf das 
Recht und auf staatliche Organe, um mehr Freiheit und sexuelle Selbstbestimmung für Frauen zu erreichen.

\subsubsection{Verortungen und Bezugnahmen}

Julia Long haben wir im Kapitel 3.2 als kritische feministische Stimme zur Pornografisierung kennengelernt. Ihr Werk ist hier von Interesse, weil sie sich selbst innerhalb einer Tradition der feministischen Pornografiekritik positioniert sowie die Argumente dieser Tradition wiederaufnimmt und neu reflektiert. So macht sie transparent, was bei anderen Exponentinnen der zeitgenössischen Pornografiekritik oft unausgesprochen mitschwingt. Um an die Wurzeln der feministischen Pornografiedebatte zu gelangen, bezieht sie sich direkt auf Bronstein:

In her history of US anti-porn feminism, Carolyn Bronstein identifies three factors that motivated women to identify sexually violent media as a major cause of female oppression: the failure of the sexual revolution to deliver sexual liberation for women; new knowledge about the extent and prevalence of male sexual violence, generated within consciousness-raising groups; and the radical feminist critique of heterosexuality. (Long 2012, S. 19)

Long ergänzt Bronsteins historischen Überblick zur Frauenbewegung in den USA mit einer Darstellung zur Situation in Großbritannien. Hier sieht sie die Pornografiedebatte von evangelikalen Kräfte dominiert, die im Rahmen eines Kampfes gegen den angeblichen moralischen Zerfall des Landes auch Pornografie ins Visier genommen hätten. Ihnen gegenüber hätten linksliberale Kräfte gestanden, die als zentrale Werte die Meinungsfreiheit und das Recht des Individuums auf Privatsphäre verteidigt hätten. So sei laut Long kein Raum für eine linksliberale Kritik der Pornografie geblieben; diese habe sich erst allmählich Ende der 1970er-Jahre gebildet. Inspiriert von Dworkins Schriften sei jedoch Anfang der 1980er-Jahre ein reger feministischer Aktivismus gegen Pornografie entstanden, den Long im Vergleich zum Aktivismus in den USA als radikaler einstuft. Als militanteste dieser aktivistischen Gruppierungen nennt sie die Bewegung Angry Women, die sogar Brandanschläge auf Sexshops und Sexkinos verübte.

Aus dieser historischen Auslegeordnung folgert Julia Long, dass in der Pornografiedebatte vier verschiedene Grundhaltungen aufeinandertreffen (vgl. ebd., S. 6off.): 
a) Aus konservativer Sicht muss Sexualität kontrolliert werden, sie findet idealerweise innerhalb der Ehe und zum Zweck der Fortpflanzung statt. Die in der Pornografie stattfindende öffentliche Zurschaustellung von Sexualität gefährdet Kinder und verstößt gegen die guten Sitten.

b) Aus liberaler Sicht gehört Sexualität zur autonomen Privatsphäre des Individuums, in die sich der Staat nicht einzumischen hat. Aus linker Sicht sind in der Pornografie repräsentierte Ungleichheiten ein Spiegel der Ungleichheiten in der kapitalistischen Gesellschaft, weshalb diese und nicht die Pornografie bekämpft werden sollten.

c) Aus postmoderner und queertheoretischer Sicht ist Sexualität Gegenstand von Normierung und Regulierung durch gesellschaftliche Institutionen. Pornografie ist aus dieser Sicht wertvoll als Möglichkeit zum spielerischen Ausdruck verschiedener sexueller Identitäten und Praktiken.

d) Aus radikalfeministischer Sicht ist Sexualität das Produkt einer Gesellschaft, die von einer strukturellen Ungleichheit zwischen Mann und Frau geprägt ist. Pornografie ist ein Instrument der Unterdrückung von Frauen durch Männer.

Long selber sieht sich als Vertreterin der vierten, also der radikalfeministischen Grundhaltung. Die übrigen drei Sichtweisen lehnt sie ab. Mit der konservativen Grundhaltung setzt sie sich nicht weiter auseinander, dafür mit der linksliberalen und der queertheoretischen Haltung. Ein erster Ansatzpunkt für Longs Kritik bildet die sogenannte sexpositive Haltung, die sowohl Vertreter der liberalen wie auch der queerfeministischen Grundhaltung auszeichnet.

The fundamental assumption of »sex positivity« is the right to sexual pleasure - which is seen as inherently good - and to the exploration and expression of sexual desire, with little concern for any questioning or critique of these desires. Sex positivity thus diverged from established practices of consciousness raising, which had sought not to take personal experience at face value, but to scrutinise it in the light of understandings of patriarchy. (Ebd., S. 31)

Gemäß Long liege dem sexpositiven Feminismus eine unkritische Bejahung von sexuellem Begehren und sexueller Selbstverwirklichung zugrunde. Sie fordert, dass selbstkritisch hinterfragt werden müsse, inwieweit auch persönliche sexuelle Erfahrungen und Wünsche durch die patriarchale Gesellschaft 
geprägt worden seien. Long beruft sich explizit auf den radikalen Feminismus, der Pornografie weniger über die Ästhetik als über die Etymologie definiert habe:»For radical feminists, the etymology of the word »pornography« is a useful reminder that pornography as a concept does not originate in notions of individual expression or erotic fantasy, but in relation to representations produced within specific, material conditions of inequality between women and men.«(Ebd., S. 57) Entsprechend habe feministische Pornografiekritik in der Regel eine als hegemonial wahrgenommene Form der Pornografie im Fokus. Long betrachtet die Heteronormativitätskritik der queerfeministischen Grundhaltung allerdings als Ablenkung vom Thema der Unterdrückung von Frauen durch Männer: »Given its preoccupation with the stransgressive< practices of sexual minorities, queer theory left little space to address questions of the structural oppression of women and the role of pornography in maintaining and perpetuating male domination.«(Ebd., S. 48) Pornografie als von sexuellen Minderheiten selbst gewählter Ausdruck der Sexualität kann für die feministische Pornografiekritik, wie Long sie versteht, kein zentrales Anliegen sein. Long stellt hier eine Opposition her von in Anführungsstrichen gesetzten transgressiven Praktiken sexueller Minderheiten auf der einen Seite und der strukturellen Unterdrückung der Frauen im Patriarchat auf der anderen Seite. Die angeblich transgressiven Praktiken sexueller Minderheiten sind für Long kein Mittel gegen patriarchale Unterdrückung, deshalb kann sie der queerfeministischen Pornografie nichts abgewinnen. Long nennt mehrere Gründe für ihre Skepsis gegenüber queerfeministischer Pornografie: Der Anteil queerfeministischer Pornografie am Total der produzierten Pornografie sei verschwindend klein. Es gebe zudem politisch wichtigere Ziele als das Produzieren alternativer Pornografie. Wenn schon, solle feministische Pornografie der Gewalt gegen Frauen in Pornos etwas entgegensetzen. Dies ist gemäß Long in queerfeministischen Pornos kein Thema, Gewalt und Herrschaftsverhältnisse würden in queeren Pornos sogar häufig erotisiert. Aus diesem Grund spricht Long ihnen das Prädikat feministisch ab.

Eine grundlegende Differenz des liberalen zum radikalen Feminismus zeigt sich in der Frage, ob Pornografie die Unterdrückung von Frauen in der realen Welt bloß spiegelt oder ob sie ein Instrument ist, diese Unterdrückung aufrechtzuerhalten. Für Long und den radikalen Feminismus ist die Antwort klar: Wenn Pornografie die Unterdrückung von Frauen erotisiert und naturalisiert, wird sie selber zum Instrument dieser Unterdrückung. Auf der Produktionsebene werde Frauen real Gewalt zugefügt; ob diese Frauen der Gewaltzufügung zugestimmt hätten, spiele für den Fakt der Gewaltaus- 
übung keine Rolle. Auf der Rezeptionsebene führten Pornos zu gewalttätigem Verhalten gegen Frauen - dies hätten Studien bewiesen. Auf der Repräsentationsebene schließlich sei Pornografie eine Form kultureller Gewalt, indem sie eine Kultur der Gewalt gegen Frauen nähre und aufrechterhalte.

Long wendet sich gegen eine unkritische Verwendung von Begriffen wie freie Wahl, Zustimmung oder Autonomie im Zusammenhang mit Pornodarstellerinnen. Diese Begriffe blendeten die Rahmenbedingungen der Herstellung von Pornografie aus. Long kritisiert auch individuelle Beschreibungen von Empowerment im Rahmen von Pornografie. Dies depolitisiere den ursprünglich für ermächtigende Handlungen einer ganzen unterdrückten Gruppe verwendeten Begriff. Empowerment für die Darstellerinnen von Pornografie gebe es nur in zwei Formen: als finanzielle Entschädigung und als anerkennender männlicher Blick:

The first of these is likely to constitute a significant benefit for the individual woman, particularly if she is economically disadvantaged and unable to secure a decent income by other means. The second relies on the woman being heavily invested in the approving male gaze for her sense of identity and self-worth; an internalisation of her objectified status under patriarchy. (Ebd., S. 99)

Finanziell profitiere die Pornoindustrie aber in ungleich größerem Ausmaß als die dargestellten Frauen; und die Aufwertung durch den männlichen Blick sei ein bloßes Gefühl, das durch den Entzug dieses Blickes jederzeit wieder zunichtegemacht werden könne. An der strukturellen Unterdrückung der Frau ändere sich durch solches Empowerment nichts. »Any attention to women's ragency< with regard to porn or >pornified practices needs to be informed by the recognition of women's lack of power as a class, and the fact that it is men, not women, who dictate the conditions within which any such agency is exercised." (Ebd., S. 102) Dieses Zitat unterstreicht einmal mehr Longs Sicht der Frauen als einer unterdrückten Klasse.

Long verweist als Argument für die Zensur von Pornografie auf die normalisierenden Effekte einer Gesetzgebung: Indem etwas zum Gesetz werde, verändere es, was in einer Kultur als normal betrachtet werde. »In the absence of any effective regulation or means of challenge to the industry, it has been profit-motivated porn producers and distributors - rather than feminist activists and feminist politicians - that have had a relatively free rein in shaping the norms of mainstream culture.« (Ebd., S. 44) 
An ihrer Darstellung der Pornografiedebatte fällt auf, dass Long die Position des radikalen Feminismus in Abgrenzung von den drei obengenannten Grundhaltungen konstruiert, ohne transparent zu machen, was den radikalen Feminismus mit diesen verbindet. Dieser hat jedoch mit der linken oder auch der queertheoretischen Grundhaltung mehr gemeinsam, als Long zugibt. Die These von der sozialen Konstruktion sexueller Identitäten und Praktiken ist grundlegend für eine queertheoretische Grundhaltung. Den Schwerpunkt auf materielle Formen der Unterdrückung zwischen sozialen Gruppen teilt der radikale Feminismus mit einer linken Grundhaltung. Long unterschlägt diese Gemeinsamkeiten vermutlich, weil ihr zwei Abgrenzungen wichtig sind: Sie unterstellt der linksliberalen Grundhaltung die Orientierung an einem autonomen Subjekt, das eigentlich ein männliches Subjekt sei; an der postmodernen, queertheoretischen Grundhaltung kritisiert sie die Abkehr von einer Theoretisierung der Unterdrückung von Frauen durch Männer.

Meiner Meinung nach ist Longs erste Abgrenzung - die Kritik an der liberalen Subjektkonzeption - ein wichtiges Element der postmodernen, queertheoretischen Grundhaltung. Die zweite Abgrenzung spielt in der innerfeministischen Auseinandersetzung eine große Rolle. Aus queertheoretischer Sicht ließe sich einwenden, dass diese nicht die Unterdrückung von Frauen durch Männer ausblenden will; ihr Ziel ist es vielmehr, auf andere Formen von Unterdrückung und Mehrfachdiskriminierungen aufmerksam zu machen, die bei einer ausschließlichen Fokussierung von Geschlechterungleichheit unter den Tisch fallen.

Dreh- und Angelpunkt von Longs Analyse ist die Unterdrückung der Frauen. Diese wird wie bei Dworkin so umfassend gesetzt, dass es schwierig scheint, im Rahmen von Longs Analyse einen Hebel zur Veränderung dieses Dominanzverhältnisses zu finden. Long stimmt mit Dworkin darin überein, dass Pornografie ein Instrument der Männer zur Unterdrückung der Frauen ist. Ein Überwinden dieser strukturellen Unterdrückung wird wie bei Dworkin angemahnt, aber es gibt keine Anleitung dazu.

Entsprechend stört sich Long auch am Vorkommen von Gewalt in queerfeministischer Pornografie. Die Darstellung von Gewalt in Pornografie ist ein zentraler Punkt, der die feministische Bewegung spaltet. Die Streitfrage ist hier, ob die Erotisierung von Herrschaftsverhältnissen und Gewalt unvereinbar mit einer feministischen Haltung ist. Indem Long diese Frage mit Ja beantwortet, geht sie von einem Konzept von Sexualität aus, das grundsätzlich Herrschaft und Gewalt als der Sexualität immer bloß äußerlich annimmt. 
Dies ist legitim, widerspricht aber Longs Behauptung, sie habe ein konstruktivistisches Konzept von Sexualität.

Longs bemüht sich, queere Pornografie rhetorisch $\mathrm{zu}$ marginalisieren, denn das für ihre Argumentation Gefährliche an alternativen Pornografien ist, dass diese die pauschale Kritik an Pornografie und auch deren Definition erschweren. Aus Longs Sicht wird transgressiven Elementen der Pornografie von queerfeministischer Seite zu viel Beachtung geschenkt.

Interessant ist ihr Hinweis auf das Fortbestehen der weiblichen Abhängigkeit vom männlichen Blick und wie diese aktuelle Formen der Pornografisierung prägt. Ebenfalls wichtig finde ich ihr Hinterfragen der unkritischen Bejahung von sexuellem Begehren und sexueller Selbstverwirklichung, die sie als Basis des sexpositiven Feminismus identifiziert. Finden sich diese Motive auch bei anderen Exponenten der zeitgenössischen Pornografiekritik?

Der Medienwissenschaftler Robert Jensen will ebenfalls zurück zum Ursprung der Anti-Porno-Bewegung. Er kritisiert die Pornografiedebatte seit Dworkin. Sie sei auf Abwege geraten und habe sich verzettelt. So torpedieren gemäß Jensen definitorische Streitigkeiten die Einigkeit im Kampf gegen Pornografie. Er selbst schlägt zwei pragmatische Definitionen vor. Die erste scheint ihm eine breit akzeptierte kulturelle Definition zu sein: »Pornography is the material sold in pornography shops for the purpose of producing sexual arousal for mostly male consumers. (Dines/Jensen/Russo 1998, S. 3) Die zweite entstammt der kritischen feministischen Analyse: »[P]ornography is a specific kind of sexual material that mediates and helps maintain the sexual subordination of women.« (Ebd.) Jensen versucht gemeinsam mit Gail Dines anhand dieser Definitionen eine inhaltliche Analyse der MainstreamPornografie zu leisten. Sie analysieren eine Auswahl an pornografischem Material aus einem Sexshop auf die Frage hin, ob es die Unterdrückung der Frau propagiert.

Pornografisch im Sinne von die Unterordnung der Frau propagierend ist Material laut Dworkin, wenn es vier Elemente aufweist: Hierarchie, Objektivierung, Unterwerfung und Gewalt. Nach ausführlicher Analyse und Beschreibung des von ihnen untersuchten Materials stellen Jensen und Dines fest: "Our analysis of the videos and novels shows that the four elements of pornography that Dworkin has outlined (hierarchy, objectification, submission, and violence) are central to the representation of sexuality in pornography. We found that, as the feminist critique of pornography asserts, at the core of contemporary pornography is contempt for women.«(Ebd., S. 99) Wie schon MacKinnon wehrt sich Jensen gegen die Reduktion der Diskussion um 
Pornografie von einer politischen auf eine moralische und damit letztlich auf eine Geschmacksfrage. Anstößigkeit von beziehungsweise Ekel vor Pornografie stehe in einer pluralistischen Gesellschaft nicht zur Debatte, sondern der Beitrag der Pornografie zu einem System zur Unterdrückung von Frauen; Anstößigkeit von Pornos basiere auf subjektiven Urteilen, aber der Kampf gegen Unterdrückung dürfe auch vor pornografischen Erzeugnissen nicht Halt machen.

Als Irrweg taxiert Jensen hingegen die von MacKinnon angestoßene Debatte um den Ersten Verfassungszusatz der Verfassung der USA, der die Meinungs- und Pressefreiheit garantiert. Jensen hält diese Debatte zwar für wichtig, aber für zu eng gefasst; der Umgang mit Pornografie sei in erster Linie eine politische und gesellschaftliche Frage. Für ebenso unproduktiv hält Jensen den Streit um eine allfällige Kausalbeziehung zwischen Pornografie und sexueller Gewalt: Mit den Instrumenten der Sozialwissenschaft werde nie bewiesen werden, dass es eine solche Kausalbeziehung gebe; trotzdem sei eine Diskussion über die Bedeutung der Pornografie und deren Rolle in unserer Kultur möglich und notwendig.

Meines Erachtens sind die von Jensen vorgeschlagenen PornografieDefinitionen mit Schwierigkeiten behaftet. Seine erste Definition ist tautologisch, denn sie heißt, zugespitzt formuliert: Pornos sind das, was in einem Laden verkauft wird, der Pornos verkauft. Die zweite Definition stellt die mediale Verbreitung der sexuellen Unterordnung der Frau ins Zentrum der Definition. Die Unterscheidung dieser zwei Definitionen von Pornografie dient meiner Meinung nach eher einem methodischen Trick: Sie schafft erst die Versuchsanlage, dass Jensen und Dines aus der großen Menge an Material, das gemeinhin als pornografisch bezeichnet wird, eine zufällige Auswahl herausgreifen, um diese darauf hin zu untersuchen, ob das Material im zweiten Sinn von Frauen herabsetzend pornografisch ist. In Tat und Wahrheit fallen jedoch beide Definitionen zusammen, die Versuchsanordnung ergibt das gewünschte Resultat. Daraus folgen allerdings Begriffsverwirrungen. Schwule Pornografie, die in einem Sexshop verkauft wird, würde beispielsweise nur unter die erste Definition fallen, da in ihr ja gar keine Frauen vorkommen. Unter die zweite Definition würde sie nur fallen, wenn zuträfe, was Dworkin behauptet, dass nämlich auch schwule Pornografie Frauen unterdrückt, indem sie schwule Männer dazu anregt, ihre sexuelle Überlegenheit über Frauen zu genießen. Doch dazu macht Jensen keine Aussage, schwule Pornografie bildet wie bei anderen Exponenten der zeitgenössischen Pornografiekritik eine Leerstelle in seiner Argumentation. 
Jensens Definition von Pornografie ist demnach sehr von Dworkin geprägt. Umso interessanter finde ich deshalb, dass er sich von den die bisherige Debatte dominierenden Streitpunkten, wie der von der US-amerikanischen Verfassung garantierten Meinungsfreiheit und der bisher umstrittenen Kausalität zwischen Pornokonsum und sexueller Gewalt, distanziert. Beides sind zentrale Punkte in den Schriften MacKinnons.

Die Geschlechterforscherin Ann Russo, die sich mit den Einwänden des liberalen Feminismus gegen die Anti-Pornografie-Bewegung auseinandersetzt, wehrt sich gegen den Vorwurf, die Bewegung wolle jegliches sexuell explizite Material zensurieren und verbannen, es gehe ihr vielmehr darum, die finanziell übermächtige Pornoindustrie und ihren Beitrag zu sozialer Ungleichheit und sexueller Gewalt zu bekämpfen. »The imaginative feminist vision is a society free of inequality and violence, not a society free of sexual desire and expression.« (Dines/Jensen/Russo 1998, S. 12) Wie Jensen distanziert sie sich von einer Komplizenschaft mit rechtskonservativen Kämpfern gegen Obszönität. Dworkins und MacKinnons juristischer Kampf gegen Pornografie habe nur betroffenen Frauen eine Möglichkeit geben wollen, sich gegen die diskriminierenden Folgen von Pornografie rechtlich zur Wehr zu setzen. »Rather than focusing on pornography as offensive images or speech, the ordinance targeted the harmful practices involved in pornography's production, consumption, and distribution and defined these as forms of sex discrimination.« (Ebd., S. 13) Auch Russo wendet sich also ab vom primären Kampfplatz der Anti-Porno-Bewegung der letzten Jahre, wo um das Zensurieren expliziter Bilder und Texte gestritten wird. Stattdessen fordert sie die Eliminierung konkreter Weisen, wie Frauen unter Produktion, Konsum und Verbreitung von Pornografie leiden. Russo nimmt im Streit, der sich unter Feministinnen am Thema Pornografie entzündet hat, eine Front wahr: Auf der einen Seite befinden sich liberale Feministinnen, die sich für individuelle Freiheit im Wählen der sexuellen Identität und Aktivität starkmachen; auf der anderen Seite stehen pornografiekritische Aktivistinnen wie sie selbst, die Pornografie als Teil eines Systems sozialer Strukturen und Praktiken attackieren, das Ungleichheiten und Gewalt im Leben von Frauen zementiert. Sie fordert: »The sexual restrictions and punishments placed on women that often operate simultaneously with the coercion and violence must be equally addressed and challenged in order to create the conditions for social justice and freedom." (Ebd., S. 35) Mit der Orientierung an der sexuellen Selbstbestimmung der Frau knüpft Russo an einer zentralen Forderung Dworkins an. Ihr Anliegen hier hat eine autobiografische Komponente, denn Russo hat am eigenen Leib 
sowohl sexuelle Gewalt erlebt als auch Stigmatisierung wegen ihrer sexuellen Identität erfahren. Ihr politischer Kampf gegen beide Phänomene positioniert sie damit zwischen den Fronten der Sex Wars: Den liberalen Feministinnen fehle das Bewusstsein für die Realität der Effekte einer Kultur, die von Gewalt gegen Frauen durchdrungen sei; die Anti-Pornografie-Bewegung dagegen ignoriere die Komplexität weiblichen Begehrens und sexueller Identität: »Women's lives are complex; they are not simple cut-outs to fit ideological boxes.«(Ebd., S. 153)

Im Gegensatz zu Russo weist Kat Banyard wie Julia Long den sogenannten third-wave feminism entschieden zurück. Sie hinterfragt dessen Kernbegriffe choice und agency: "But the question must always be: what impact does the practice have on gender relations as a whole? Does it help end the subordination of women - or does it further perpetuate it? « (Banyard 2010, S. 206) Banyard führt hiermit eine Art Lackmustest für aus Sicht der Geschlechtergerechtigkeit umstrittene Praktiken ein. Die einzelne Praktik wird in Bezug zur als allgemein gesetzten Unterdrückung der Frau gesetzt und damit universalisiert. Auf dieser Basis ruft sie zu einer neuen Graswurzelbewegung von feministischem Aktivismus auf. Choice und agency von Frauen sind von Banyard also nur im Dienst der Geschlechtergerechtigkeit erwünscht.

Auch Gail Dines nimmt in einem Beitrag zum Playboy-Magazin und zum Mainstreaming von Pornografie Bezug auf die Sex Wars. Sie beschuldigt die Gegenseite der übermäßigen Fokussierung auf den sogenannten Text der Pornografie außerhalb deren Produktionsbedingungen: »The slide toward celebration of the text in scholarly works on pornography posits pornography as a mode of representation rather than as a global capitalist industry that trades in female bodies.«(Dines/Jensen/Russo 1998, S. 63) Doch diese Polarisierung täuscht darüber hinweg, dass auch Dines Annahmen darüber macht, was Pornografie repräsentiert. Ihr Vergleich der Marketingstrategien der Magazine Playboy und Hustler kommt zwar wirtschaftssoziologisch daher, schließt aber andere methodologische Zugänge implizit mit ein. Dines liest die familienzentrierte Gesellschaftsstruktur der 1950er-Jahre und die strikten Rollen, die diese Männern und Frauen zuweist, wie einen symbolischen Text: Dem von den rigiden Moralvorstellungen und dem Zwang zur Verbesserung seines wirtschaftlichen Status eingeengten Mann der 5oer-Jahre präsentiere der Playboy das Rollenangebot des Playboys, der seine Unabhängigkeit genieße und sich materielle und sexuelle Wünsche erfüllen könne. Dines beschreibt detailliert, wie der Playboy Waren und Konsum sexualisiere und ein Männerbild kreiere, dem der Käufer nicht entspreche, aber gern entsprechen möch- 
te. Was ihr jedoch entgeht, ist der eskapistische Charakter des Playboy: Das Magazin bietet dem Käufer eine Flucht aus der Enge der Rolle des verantwortungsvollen Ehemannes und nützlichen Mitglieds der Gesellschaft.

Noch deutlicher lässt sich dieser eskapistische Charakter aus Dines' Analyse der Maketingstrategie des Männermagazins Hustler herauslesen. Es biete dem mittelständischen Leser die Möglichkeit, einen Blick in die Welt der Arbeiterklasse zu werfen, wo es rauher zu- und hergehe und der Mann weniger belastet von gesellschaftlichen Konventionen und moralischen Zwängen sei: "For the duration of the reading and masturbation, the reader is slumming in the world of the 'white trash , an observer to the workings of a social class that is not his.« (Ebd., S. 56) Der Wunsch des Lesers nach Eskapismus wird hier einfach in eine andere Richtung gelenkt; hinzu kommt das für Pornografie typische Element des Sexualisierens der Grenze und deren Überschreitung. Dieses Sexualisieren einer Grenze bestärkt diese auch: Nach dem sexuell enthemmenden Überschreiten der Grenze in eine andere soziale Klasse kann der Leser beruhigt wieder sein Leben innerhalb der Parameter seiner eigenen Klasse aufnehmen. Dies erklärt, weshalb der Erfolg von Magazinen wie Playboy und Hustler keine sexuelle Revolution eingeleitet hat, sondern sich gut in die Welt der bürgerlichen Mittelklasse integrieren ließ. Doch eine Theorie der Transgression, des Überschreitens von Grenzen findet sich bei Dines nicht, sie belässt es bei einer Interpretation dessen, was am Erfolg von Produkten wie Playboy und Hustler zeit- und klassenspezifisch ist.

Wie schon Long nehmen Dines, Banyard, Russo und Jensen ausdrücklich Bezug auf die Geschichte der Anti-Pornografie-Bewegung und verorten sich darin. Rhetorisch lässt sich mindestens bei Jensen, Russo und Dines eine Bewegung weg vom juristischen Streit um das Zensieren pornografischer Inhalte hin zum ursprünglichen Kampf gegen frauenfeindliche gesellschaftliche Praktiken feststellen. Inwieweit sie und andere zeitgenössische PornoKritikerinnen die zentralen Thesen von Dworkin und MacKinnon teilen, werden wir im Folgenden untersuchen.

\subsubsection{Parallelen in der Argumentation}

Wie wir gesehen haben, nimmt Robert Jensen bereits in seiner Definition von Pornografie auf Dworkin Bezug: Pornografie sei das Material, das die sexuelle Unterordnung von Frauen propagiere. In einem programmatischerweise Dworkin gewidmeten Band benennt er als Grundthese einer feministischen Pornografiekritik, »that the sexual ideology of patriarchy eroticizes 
domination and submission and that pornography is one of the key sites in which these values are mediated and normalized in contemporary culture (Dines/Jensen/Russo 1998, S. 2). Indem er in der Pornografie einen Königsweg der Vermittlung patriarchaler Ideologie sieht, verknüpft er, ganz nach Dworkin, Pornografiekritik mit Patriarchatskritik.

Auch Kat Banyard beschäftigt sich mit Pornografie unter der Prämisse der persistierenden Ungleichheit zwischen Männern und Frauen in der Gesellschaft. Einen starken Treiber für die Persistenz dieser Ungleichheit lokalisiert sie in der Sexindustrie, die sie unter den Aspekten Prostitution, Pornografie, Lap-Dancing und Sexualisierung des Mainstreams beleuchtet. In der Pornografie und der Sexualisierung des Mainstreams sieht sie zwei verschiedene Formen, wie die Sexindustrie auf die Gesellschaft Einfluss nimmt; Pornografie an sich trägt in ihren Augen bereits zur Ungleichheit zwischen den Geschlechtern bei. Ihre grundsätzliche Kritik an der Sexindustrie formuliert Banyard so: »For all the multitude of ways that the product is packaged, delivered, and consumed, the sex-industry boils down to a very simple product concept: a person (usually a man) can access a sexual interaction with a person (usually a woman) who doesn't want it with him.«(Banyard 2010, S. 141) Dieses Produktonzept habe mindestens zwei beunruhigende Konsequenzen: Erstens könne ungewollter Sex für Frauen schwerwiegende physische und psychische Folgen haben; zweitens gewöhnten sich Jungen und Männer daran, Sex mit Frauen zu begehren, die keinen Sex mit ihnen haben wollten. Pornografie verführe Männer dazu, Frauen ungewollten Sex aufzuzwingen, was diese wiederum in die Situation versetze, ständig auf der Hut vor sexuellen Übergriffen sein zu müssen, in eine Situation der Unfreiheit. Sexuelle Gewalt als Mittel patriarchaler Kontrolle: Genau dagegen wehrten sich die Frauen am Ursprung der Anti-Porno-Bewegung, wie wir bei Carolyn Bronstein gesehen haben.

Gail Dines behauptet, Pornografie propagiere Frauenhass, indem sie mit gewalttätigen Praktiken durchsetzt sei, die sich gegen Frauen richteten: »In porno the man makes hate to the woman, as each sex act is designed to deliver the maximum amount of degradation. (Dines 2010, S. XXIV) Dines spart allerdings auch nicht mit Gesellschaftskritik: Männern werde Empathie generell abtrainiert, diese gelte als unmännlich - dies prädestiniere sie für den Pornokonsum. Entsprechend sei die Differenz der in der Pornografie dargestellten Frauen zu realen Frauen gewollt: Bei den in Pornos präsentierten Frauen sollte ein Mann möglichst nicht an seine eigene Mutter, Schwester oder Tochter erinnert werden, sonst gerate er in Gefahr, zu viel Empathie für diese Frauen zu entwickeln, was den sexuellen Reiz der Bilder zerstören könn- 
te. Dies ist für Dines ein weiterer Beleg dafür, dass Pornografie nicht harmlose sexuelle Fantasien verkauft, sondern ein gestaltetes Konsumgut einer kalkulierenden Industrie ist. Der Kampf gegen die Tendenz zur Warenförmigkeit menschlichen Begehrens müsse in einen Kampf für wirtschaftliche, politische und rechtliche Gleichstellung münden: »This is why we need to build a vibrant movement that fights for a world where women have power in and over their lives - because in a just society, there is no room for porn.« (Ebd., S. 165) Dines wendet sich gegen die Haltung, pornografische Bilder seien ein Spiel mit sexuellen Fantasien, offen für vielfältige Interpretationen und ohne Einfluss auf die reale Welt: "So now we are in a somewhat strange place where people who argue that mainstream corporate media have the power to shape, mold, influence, manipulate, and seduce viewers simultaneously deny that porn has an effect on their consumers.« (Ebd., S. 184f.) Wenn zum Beispiel rechte Medienpropaganda die Menschen beeinflussen könne, müsse dies auch für Pornografie gelten. Da Geschlechterrollen gesellschaftlich konstruiert seien, könnten Frauen den sie umgebenden hypersexualisierten Frauenbildern wenig entgegensetzen.

Besonders extrem fällt laut Dines der der Pornografie inhärente Frauenhass in der Darstellung von Women of Colour auf. Diese würden in Pornos über die bloße Frauenfeindlichkeit hinaus auch noch auf rassistische Weise gedemütigt, sie würden buchstäblich als Dreck tituliert und behandelt. Dadurch, dass Männer zu rassistischen Stereotypen masturbierten, würden diese aktualisiert und erotisiert. »This is a powerful way to deliver racist ideology, as it not only makes visible the supposed sexual debauchery of the targeted group, but also sexualizes the racism in ways that make the actual racism invisible in the mind of most consumers and nonconsumers alike.« (Ebd., S. 140)

Die Sexualisierung und Objektivierung von Frauen thematisiert auch Susan Douglas in ihrer Untersuchung zum Männermagazin Maxim. Douglas stellt Folgendes fest:

But in its aggressive reclamation of an allegedly immutable beer- and libido-driven masculinity, and its view that women fall into two categories, »hotties « and worthless, Maxim resuscitates the mantras feminists skewered nearly forty years ago: that women's only value comes from their sex appeal, that women are rarely fully fledged people but things to be used by men for their sexual pleasure, and that there is only one narrow standard for sexiness, the size-zero D-cup starlet. (Douglas 2010, S. 167) 
Douglas unterstellt der Männerzeitschrift in etwa, was die Feministinnen der Pornografie schon in den 1970er-Jahren vorgeworfen hätten: Frauen würden auf ihr Äußeres reduziert, wobei die Standards zur Bewertung dieses Äußeren rigide und eindimensional seien, generell würden Frauen als Gebrauchsgegenstände und nicht als vollwertige Menschen behandelt. Das Maxim-Männerbild ist laut Douglas offenbar ähnlich reduktionistisch.

Dworkins These der Pornografie als Instrument der Unterdrückung von Frauen durch Männer wird also nicht nur von Long vertreten. Jensen und Douglas belegen diese These mit der Erotisierung und Normalisierung eines stereotypen, objektivierenden Frauenbildes, die sie der Pornografie zuschreiben. Banyard findet bereits das Produktekonzept der Pornografie beunruhigend, das Jungen und Männer daran gewöhne, sich Sex mit Frauen zu wünschen, die keinen Sex mit ihnen haben wollten. Sie schreibt Pornografie eine Mitschuld zu an der eingeschränkten Bewegungsfreiheit von Frauen, da sie sich vor sexuellen Übergriffen fürchten müssten. Noch einen Schritt weiter geht Dines, indem sie im Einklang mit Dworkin behauptet, Pornografie vermittle Frauenhass und Rassismus; wie Dworkin kritisiert sie, dass die Gesellschaft jungen Männern generell, aber auch mithilfe von Pornografie Empathie abtrainiere.

Als Nächstes möchte ich die Vorstellungen von Sexualität in der Argumentation der zeitgenössischen Pornografiekritik untersuchen. Wie ich bereits festgestellt habe, reproduziert Dworkin herrschende Geschlechterstereotype, indem sie einen Gegensatz von naturhafter, sinnlicher weiblicher Sexualität und aggressiver, erobernder männlicher Sexualität konstruiert. Diese Binarität prägt meiner Meinung nach auch das Sexualitätskonzept der zeitgenössischen Pornografiekritik. Ein Beispiel ist die Journalistin Ariel Levy, die darauf hinweist, dass das aufklärerische Potenzial der Pornografie begrenzt sei, da diese nicht transportiere, wie sich Sex anfühle:

You can see any act imaginable if you spend enough time on the Internet, but no matter how much porn you watch you will end up with a limited knowledge of your own sexuality because you still won't know how these things feel. That will depend on who you do them with, what kind of mood you're in when you do, whether you feel safe or scared (or scared in a good way) when you go about it, and so on. (Levy 2005, S. 185f.)

Einer solipsistischen Variante der Sexualität, wo ein Individuum anhand der sexuellen Fantasien der Pornografie sein eigenes Begehren erforscht, erteilt Levy hier eine Absage. Sie favorisiert die Erfahrungen, die bei einer sexuellen 
Interaktion mit einer realen Person gemacht werden, und betont die Wichtigkeit des Fühlens bei diesen Interaktionen gegenüber dem technischen Knowhow. Long scheint dies ähnlich zu sehen, formuliert sie ihr Konzept einer feministischen Sexualität doch folgendermaßen: »A feminist sexuality is not one that is separate from life and human connection, but is part of it. It is not based on a hierarchical relationship that reduces another to an object, in order that the subject can act out their solipsistic sexual fantasies or desires on her.« (Long 2012, S. 215) Dieses Konzept von Sexualität schließt jegliche Objektivierung des Partners oder der Partnerin aus und plädiert für eine nicht hierarchisch geprägte Sexualität, die ein Teil des lebendigen Austauschs zwischen Menschen sei.

Dines wiederum fordert über den individuellen Widerstand gegen Pornografie hinaus eine Bewegung, welche die Gesellschaft über die schädlichen Auswirkungen der Pornografie aufkläre. Eine solche Bewegung dürfe sich aber nicht nur darüber definieren, was sie bekämpfe, sondern müsse eine alternative Vision von Sexualität anbieten, um die Menschen hinter sich zu vereinen: »We need to offer an alternative way of being, a way to envisage a sexuality that is based on equality, dignity, and respect. Part of this inevitably means organizing against the commodification of human needs and desires." (Dines 2010, S. 164) Eine solche alternative Vision von Sexualität solle sich vom formelhaften Sex der Pornos befreien und individuelles Begehren authentisch ausdrücken.

Myrthe Hilkens stellt an die Medien die Forderung, sie sollten dem, was sie Pimp-Kultur nennt, keine Bühne bieten. Ihr geht es grundsätzlich um die Umkehrung einer der Forderungen der 68er-Generation: Sex solle mit Liebe wieder etwas zu tun haben dürfen. Denn: »Freiheit scheint sich auf dem Gebiet der Sexualität in Gleichgültigkeit verwandelt zu haben.« (Hilkens 2010, S. 198) Gleichgültigkeit sei in einem Gebiet, wo es um Körper, Begehren und den intimen Austausch mit anderen gehe, nicht wünschenswert. Es sei Zeit für eine neue sexuelle Revolution.

Natasha Walter benennt gleich selbst, was von der klassischen Pornografiekritik übersehen worden sei: Auch Frauen genössen es, Pornos zu schauen. Doch die in Pornos präsentierte Ungleichheit der Geschlechter bleibt für Walter störend:

This means that men are still encouraged, through most pornographic materials, to see women as objects, and women are still encouraged much of the time to concentrate on their sexual allure rather than their imagination 
or pleasure. No wonder we have seen the rise of the idea that erotic experience will necessarily involve, for women, a performance in which they will be judged visually. (Walter 2010, S. 108)

Dieser Fokus auf Performance bringt zum Ausdruck, wie Pornografie laut Walter eine entmenschlichte Version von Sexualität präsentiere: eine von Emotionen isolierte Sexualität mit auswechselbaren Performern, die körperliche Reaktionen stets veräußerliche, statt auf den Austausch von Innerlichkeit zu setzen. Es sei nötig, die Wirtschaft und die Medien für die Inhalte, die sie verbreiteten und mit denen sie Geld verdienten, stärker in die Verantwortung zu nehmen. Allgemein propagiert Walter, Sexualität wieder mehr als intimen Austausch zu betrachten.

Auch Naomi Wolf vermisst eine authentische Bildsprache über Sexualität: »Wenn es ein vollständiges Spektrum einer authentischen erotischen Bildsprache gäbe, die wirkliche Frauen und Männer darstellte, eine Bildsprache, deren Kontext erotisches Vertrauen signalisieren würde, könnte die Pornographie des Schönheitskults vermutlich niemandem Schaden zufügen.«(Wolf 1991, S. 187) Jedoch hätten sowohl der Staat als auch die Wirtschaft ein Interesse daran, dass heterosexuelle Liebe durch die Ungleichheit, welche die Pornografie in die Sexualität des Liebespaars hineintrage, unterminiert werde. Der Staat brauche den Mann als Soldaten, der nicht zu sehr an Frau und Familie hänge und auch im Feind nicht den Familienvater und Ehemann erkenne. Hier nimmt Wolf Dworkins Argumentation auf, dass die Gesellschaft Männern Empathie abtrainiert. Die Wirtschaft ihrerseits stimuliere bei den Konsumenten sexuelle Unzufriedenheit und das Gefühl körperlichen Ungenügens, um Produkte dagegen verkaufen zu können. Wolf befasst sich ausführlich mit der sogenannt weichen Pornographie à la Playboy, die sie »Schönheitspornografie« nennt. Diese verbreite einen Schönheitsmythos, dem sich jede reale Frau unterlegen fühlen müsse. Interessanterweise sieht sie die vom Schönheitsmythos befreite weibliche Sexualität folgendermaßen:

Am anderen Ende, am weiblichen, ist sexuelles Begehren nicht etwas, das abgetrennt von allem anderen existiert, sondern etwas, das alles Lebendige durchdringt, nicht auf die Genitalien beschränkt ist, sondern den ganzen Körper überflutet. Es ist persönlich, auf Berührung und Sensibilisierung angelegt, es ist eine Kraft, die sich zwei Menschen teilen. (Ebd., S. 250) 
Diese als weiblich beschriebene Vorstellung von Sexualität verwendet Wolf in ihrer gesamten Argumentation als Gegenbild zur repetitiven, anonymisierenden, entmenschlichenden Sexualität in der Pornografie.

Es zeigt sich, dass dieses von Dworkin entlehnte Bild einer harmonischen, weiblichen Sexualität sich verbreitet in der zeitgenössischen Pornographisierungskritik findet. Die Wichtigkeit der emotionalen Aspekte wird gegenüber einer technisch-instrumentellen Sexualität betont. Ein lebendiger Austausch statt einer hierarchisch geprägten, objektivierenden Sexualität wird gefordert. Sexualität solle kein formelhafter Plastiksex sein, sondern ein authentischer Ausdruck individuellen Begehrens und wieder enger mit Liebe verkoppelt werden.

Die von mir in Kapitel 2 als für die herrschende Konzeption von Sexualität zentral herausgearbeiteten Normen der Zweigeschlechtlichkeit und Intimität werden hier von der Kritik an der Pornografisierung ungebrochen reproduziert. Der Pornografie wird hier keinerlei transgressives Potenzial attestiert; sie erscheint im Gegenteil als Hindernis für eine Änderung der Verhältnisse hin zu einem authentischeren, weiblicheren Ausdruck sexuellen Begehrens. Dies offenbart ein nach Zappe liberales oder humanistisches Verständnis von Transgression, das die Befreiung von einem gesellschaftlich geprägten falschen Bewusstsein zugunsten einer authentischen Subjektivität zum Ziel hat.

\subsubsection{Parallelen in Methodik und Rhetorik}

Bisher haben wir Themen und Motive herausgearbeitet, welche die zeitgenössische Kritik an der Pornografisierung mit der Anti-Porno-Bewegung verbindet. Ich möchte nun einige Parallelen in der Methodik, Argumentationsweise und Rhetorik herausgreifen.

Ein erster Befund lautet: Der ausschließliche Fokus auf heterosexuelle Mainstream-Pornografie kontrastiert oft mit dem zum Teil sehr umfassenden Anspruch der Analysen. Beispielsweise macht sich Jensen die Analyse und Kritik der Herstellung, des Inhalts und des Konsums von Pornografie im sozialen, wirtschaftlichen und politischen Kontext zum erklärten Ziel. So umfassend sein Ziel auch ist, macht Jensen dennoch eine Einschränkung: Schwule und lesbische Pornografie werde nicht behandelt. Eine Kritik dieses pornografischen Materials sei zwar auch wertvoll, aber nicht Gegenstand seiner Analyse. (Dines/Jensen/Russo 1998, S. 7) Dies macht deutlich, auf welche Weise hier eine Aktualisierung von Dworkins Werk versucht wird. Jensens Rhetorik unterstreicht, was sein Text inhaltlich fordert, eine Rückbesinnung auf 
Dworkins ursprüngliches Anliegen: Pornografiekritik als Kritik einer herrschenden Ideologie. Charakteristisch für diese rhetorische Strategie ist der ohne Begründung vorgenommene Ausschluss schwuler und lesbischer Pornos aus der Diskussion. Um das Risiko nicht einzugehen, dass der Einbezug von nicht heterosexueller Pornografie in die Analyse $\mathrm{zu}$ anderen als den gewünschten Resultaten führen könnte, wird sie rhetorisch ausgeschloßen. So entsteht der irritierende Eindruck, dass die vorgelegten Analysen zwar auch auf schwule und lesbische Pornografie anwendbar seien, Hetero-Pornografie jedoch das wichtigere Problem sei. Der Anspruch auf eine umfassende Analyse wird so de facto aufgegeben.

Auffälligerweise verweist auch Dines analog zu Dworkin kaum auf schwule Pornografie. Eine Ausnahme stellt ihre Diskussion rassistischer Stereotype in Pornos dar, wo sie feststellt, in der Mainstream-Pornografie würden asiatische Männer analog zu asiatischen Frauen feminisiert: »It seems that the hyperfeminisation of Asian women in pop culture and porn leaks down to Asian men, whereby the group as a whole becomes feminized as the sexual object of white masculinity.«(Dines 2010, S. 131) Ich teile Dines' Einschätzung, dass asiatische Männer in Pornos oft feminisiert werden und so gewissermaßen in einem rassistischen Stereotyp - der Wahrnehmung von Asiaten generell als feminin - Geschlechtergrenzen überschreiten. Es irritiert jedoch, dass Dines die schwule Pornografie nur dann zum Thema macht, wenn das Vorkommen von Effeminierung ein nahtloses Einfügen in ihre Argumentation der Frauenfeindlichkeit von Pornografie ermöglicht.

Kat Banyard nähert sich dem Thema Pornografie in vier Fragen: »Exactly what are men masturbating to? Who are the women in the images? What effect does pornography have on viewers? And does pornography represent an attack on gender equality? « (Banyard 2010, S. 153) Zur Beantwortung der ersten Frage führt sie selbst eine Internetrecherche durch: Sie googelt das Wort porn und klickt sich durch die ersten zehn Ergebnisse. Sie gelangt auf Websites, deren Inhalte mit frauenfeindlichen Slogans beworben oder beschrieben werden. Sie gibt an, sich effektiv nur einen Film angesehen zu haben, in dem einer Frau Oralsex aufgezwungen wird, bis sie erbrechen muss, und dieselbe Frau anschließend beim Geschlechtsverkehr gezeigt wird, während sie weint. Danach fühlt sich Banyard außerstande, ihre Recherche fortzuführen, und stützt sich für den weiteren Verlauf ihrer Argumentation auf eine Studie, welche die Inhalte der meistverkauften Pornovideos analysiert hat. Ihr Fazit: 90 Prozent der analysierten Szenen hätten verbale oder körperliche Aggression enthalten, von diesen wiederum rund 90 Prozent körperliche Aggression; 
ein Großteil der Szenen habe sexuelle Akte enthalten, die Frauen laut Umfragen nicht gerne ausübten, wie zum Beispiel Analsex; zudem seien rassistische Stereotype in Pornofilmen sehr verbreitet. Ihre zweite Frage beantwortet Banyard, indem sie Schicksale von Frauen zitiert, welche die Arbeit für die Pornoindustrie als erweiterte Form der Prostitution erfahren haben und dabei auch Opfer sexueller Gewalt geworden sind. Zur Beantwortung ihrer vierten Frage zieht sie als Experten Robert Jensen heran, mit dessen Thesen wir uns bereits beschäftigt haben: Er bestätigt Banyards Vermutung, dass Pornografie die männliche Dominanz über Frauen erotisiere. Die Frage nach der Wirkung der Pornografie auf die Zuschauer beantwortet sie mit dem Verweis auf einen vom britischen Justizministerium in Auftrag gegebenen Bericht, der den Zusammenhang von Pornografiekonsum und aggressivem Verhalten gegenüber Frauen bestätigt. Banyard gibt zu, dass das Gegenteil sie überrascht hätte: »Men masturbating to pornography are experiencing one of the most physiologically powerful sensations there is to images of women engaging in unwanted and abusive sex acts.« (Ebd., S. 162)

Mich interessiert hier die Struktur von Banyards Argumentation, die sich stark auf Aussagen von Betroffenen abstützt. Dieser Strategie begegnet man in der pornografiekritischen Literatur öfters. Ohne die Aussagen der Befragten inhaltlich in Frage stellen zu wollen, möchte ich hier auf einige Besonderheiten dieser Argumentation hinweisen. Als rhetorische Strategie hat sie generell den Vorteil, dass sie eine Authentizität verspricht, die nicht hinterfragbar ist. Ich halte diese Strategie für ein Erbe der Frauenbewegung, deren Credo es ist, nicht aus der Distanz über Frauen zu reden, sondern diese selbst zu Wort kommen zu lassen. Dieser Gestus hat in feministischen Texten eine besondere Bedeutung, weil eine der zentralen Forderungen des Feminismus ist, Frauen mit ihren Erfahrungen selbst zu Wort kommen zu lassen, statt dass Männer an ihrer Stelle sprechen und entscheiden. Die Gefahr besteht allerdings, dass in diesem Gestus dann die Erfahrung einzelner Frauen stellvertretend für die Erfahrungen aller Frauen steht, also eine versteckte Universalisierung stattfindet. In der Argumentation des Textes wird die berichtete Erfahrung dann zum Expertenwissen, das von der Verfasserin als unhintergehbarer Beweis für die Richtigkeit ihrer These angeführt werden kann.

Eine weitere Auffälligkeit in der pornografiekritischen Rhetorik ist der Verweis auf eigene Erfahrungen im Rahmen der Recherche. Auch hier finden wir den Gestus wieder, authentische Erfahrungen in die Argumentation hereinzunehmen. Indem sich Banyard selbst dem Eindruck pornografischer Inhalte aussetzt, erhöht sie die Glaubwürdigkeit ihres Sprechens über diese 
Inhalte. Diese Strategie hat eine gewisse Berechtigung aufgrund der Inhalte, um die es geht. Erstens richtet sich die von Banyard untersuchte Pornografie nicht gezielt an ein weibliches Publikum, Banyard dringt mit ihrer Untersuchung also in einen Raum ein, der eigentlich als exklusiv den Männern vorbehalten gedacht ist. Zweitens beruht eine ihrer Thesen auf dem physiologischen Affizierungsgrad der Pornografie, den Banyard selbst erfahren wollte, um ihn belegen zu können.

Natasha Walters Gestus ist es, das Schweigen über die schädlichen Auswirkungen von Pornos zu brechen. Dazu zitiert sie Statistiken über die Verbreitung von Pornografie und lässt beispielsweise Pornosüchtige und deren Angehörige erzählen.

Bei Myrthe Hilkens sticht hervor, dass sie in ihrem Buch mit eingeschobenen Erlebnisberichten in direkter Rede arbeitet. In diesen berichten verschiedenste Leute über ihren Umgang mit Pornos oder Sexualität. Hilkens' Argumentation durchzieht ein Grundton der Besorgnis. Beim Lesen entsteht so der Eindruck: Der negative Einfluss von Pornografie auf die Gesellschaft lässt sich zwar wissenschaftlich nicht beweisen, aber angesichts all der angeführten Beispiele muss es ihn einfach geben.

An Gail Dines' Rhetorik fällt auf, dass die Autorin analog zur klassischen feministischen Pornografiekritik das Beispiel eines Sexualstraftäters anführt, das die These belegen soll, die Pornokultur mache Frauen zu Opfern sexueller Übergriffe. Eine weitere Parallele ist, dass Dines viele direkte Zitate von Pornowebsites in den Text einfließen lässt, die den Leser oder die Leserin emotionalisieren sollen.

Auch Robert Jensen präsentiert ausgewählte Lebensgeschichten von Frauen und Männern, die über ihre Erfahrungen mit Pornografie und Gewalt berichten. Die präsentierten Erzählungen von Frauen handeln allesamt von Vergewaltigungen, bei denen die Vergewaltiger behaupteten, von Pornos zu ihren Taten inspiriert zu sein. Die Frauen, die diese Erfahrungen berichten, sind also alle Opfer sexueller Gewalt geworden, sei es im häuslichen Bereich, sei es bei ihrer Arbeit als Prostituierte. Jensen ergänzt diese Erzählungen mit Interviews, die er mit Männern geführt hat. Elf Interviews führte er mit Pornokonsumenten, die sich freiwillig gemeldet hatten, dreizehn Interviews führte er mit verurteilten Sexualstraftätern. Von der ersten Gruppe beschrieb nur einer einen Hang zu sexueller Gewalt - er hatte selbst als Kind sexuelle Gewalt erlebt; in der zweiten Gruppe sahen immerhin elf von dreizehn Männer einen Zusammenhang zwischen ihrem Pornokonsum und ihren Gewalttaten. Zuletzt beschreibt Jensen noch seine eigenen Erfahrungen mit Pornografie. 
Pornos hätten ihn sexuell aufgeklärt, doch seine Vorstellungskraft auch in standardisierte Bahnen gelenkt, sie hätten ihn ermutigt, Frauen als Objekte wahrzunehmen und Gewalt erotisch zu finden. Als besonders wichtig erscheint ihm retrospektiv das Thema Kontrolle: „For me, retreating to a pornographic world allowed me to regain a sense of control over female sexuality that I had lost in real life. (Dines/Jensen/Russo 1998, S. 145) Unter der Überschrift A Footnote beschließt Jensen diesen autobiografischen Exkurs mit dem Hinweis auf sein kürzliches Coming-out und stellt fest: »My use of heterosexual pornography was one way in which I, with the help of a heterosexist culture, made myself heterosexual.« (Ebd., S. 146) Jensen gelingt es zwar aufzuzeigen, dass bei sexuellen Gewaltakten Pornografie häufig eine Art Ideenlieferantin zu sein scheint oder einen Denkrahmen liefert, in welchem der Täter die gegen Frauen ausgeübte sexuelle Gewalt sinnvoll einordnen und als legitim empfinden kann. Da es jedoch unmöglich ist $\mathrm{zu}$ beweisen, dass die beschriebenen Gewalttaten nicht stattgefunden hätten, wenn die Täter keine Pornografie konsumiert hätten, wird nicht klar, worauf Jensens Analyse hier abzielt.

Am nützlichsten scheint es mir, aus seiner Analyse herauszugreifen, dass Sexualität sich zwar erst in einem Raum entfaltet, wo Wissen über Sexualität verfügbar ist, dass dieser Raum jedoch auch von Machtverhältnissen beherrscht ist. Sexualität muss verstehbar sein, und sie spielt sich in einem Raum ab, wo gewisse Dinge erlaubt sind und andere verboten. Wenn wir besser zu verstehen versuchen, wie Pornografie diese Grenzen zwischen erlaubt und verboten, verstehbar und nicht verstehbar überschreitet, umspielt und so auch wieder absichert, können wir vielleicht Phänomene wie die durch Pornos abgesicherte Heterosexualität des späteren Homosexuellen Jensen oder die Übergriffe, die sexuelle Gewaltakte an Frauen darstellen, besser einordnen. Das Thema Kontrolle, das Jensen anspricht, ist für den transgressiven Charakter der Pornografie zentral. Wie bereits dargelegt, ermöglicht Pornografie die Lust am Überschreiten der Grenzen der eigenen Sexualität - ohne die Angst, die dieses Überschreiten im realen Leben mit sich bringen würde.

Weshalb habe ich hier die angesichts wissenschaftlicher Standards methodisch fragwürdigen Strategien von Pornografiekritikerinnen und -kritikern aufgelistet? Andrea Dworkin schrieb, wie Jenefsky und Russo in ihrer Studie darlegen, keine analytischen, sondern aufrüttelnde, rhetorisch geschickt gebaute Texte, die Partei für die Opfer von Sexismus nahmen, um damit politische Ziele zu erreichen. Die von mir aufgeführten Beispiele zeigen meiner Meinung nach, dass Dworkins rhetorisches und methodisches 
Erbe weiter nachwirkt. Ich finde es bemerkenswert, dass in der Pornografiedebatte Emotionalisierung und Einseitigkeit in der Auswahl von Beispielen und Interviewpartnern offenbar gang und gäbe sind. Und ich frage mich, ob dieses Phänomen etwas mit dem transgressiven Charakter der Pornografie zu tun hat. Denn die Bearbeitung der Pornografie in einer immerhin mehr oder weniger wissenschaftlichen Debatte scheint die entsprechenden Verfasserinnen und Verfasser zum Verlassen wissenschaftlicher Standards zu zwingen und zum Überschreiten der für solche Texte geltenden Normen.

\subsection{Fazit}

Ziel des Kapitels 3 war es, die aktuelle Kritik an der Pornografisierung in einer Tradition der feministischen Kritik an der Pornografie selbst zu verorten. Dabei wurde deutlich, dass in der aktuellen Pornografisierungskritik bestimmte Themen und eine bestimmte Art und Weise der Argumentation wiederauftauchen, die bereits in den Anfängen der Anti-Pornografie-Bewegung vorhanden waren.

Der Begriff Pornografisierung umschreibt zwei Tendenzen: erstens die zunehmende Verbreitung von Pornografie selbst, zweitens das Einfließen pornografischer Inhalte in Medien und Popkultur. Mit Julia Long lässt sich Pornografisierung als Prozess der Inkorporierung pornografischer Bilder und Handlungsweisen beschreiben. Über mehrere Stationen entwickelt sich ein pornografischer Blick, der auf sich und andere angewandt wird. Dieser Blick objektiviert und wertet, er fordert zur Selbstoptimierung auf. Damit ist Pornografisierung ein Teilaspekt des Neoliberalismus, der über Leistung und Konsum Ermächtigung und sexuelle Befreiung verspricht.

In meiner Analyse ging ich mit der geäußerten Kritik an der Pornografisierung einig. Misstrauisch machte mich allerdings die mehrfach vorgefundene Annahme, dass vor allem Frauen und Jugendliche Opfer dieses pornografischen Blicks werden. Deshalb wollte ich die feministische Kritik an der Pornografisierung in den größeren Kontext der feministischen Pornografiekritik setzen. Dazu befasste ich mich mit den Thesen von Andrea Dworkin und Catharine MacKinnon, den zwei Exponentinnen der AntiPorno-Bewegung, auf die auch in der aktuellen Pornographisierungskritik am häufigsten Bezug genommen wird. Gestützt auf die Aufarbeitung von Carolyn Bronstein, stellte ich fest, dass Dworkin und MacKinnon den Fokus der Anti-Porno-Bewegung entscheidend verschoben: Aus einem Kampf gegen 
reale sexuelle Gewalt an Frauen, die Frauen in einem Status der auch sexuellen Unfreiheit festhält, wurde ein Kampf gegen eine sexuelle Bilderwelt und eine allgemein gewaltförmige Sexualität, vor der Frauen geschützt werden müssen.

Als Stärken von Dworkins Analyse ergaben sich für mich die konsequente Orientierung am Recht der Frauen auf sexuelle Autonomie und die daraus folgende Kritik an der Objektivierung von Frauen durch Pornografie, die Gewalt an Frauen sexualisiert und legitimiert. Als Dworkins Schwächen taxierte ich ihr Ausschließen anderer Sichtweisen außer der Opferperspektive, ihre fehlende Vision einer nicht sexistischen Sexualität und nicht zuletzt ihr Ignorieren der transgressiven Aspekte von Pornografie.

MacKinnon treibt die schon bei Dworkin zu beobachtende Verschiebung des Fokus auf Sprache und Recht auf die Spitze. Sie sieht das Verbreiten von frauenverachtenden Bildern nicht mehr als durch die Meinungsfreiheit geschützte Äußerung, sondern als direkt Leid verursachende Handlung an. Pornografie bringe Frauen zum Schweigen, indem deren Erfahrungen als Opfer umgedeutet oder nicht gehört würden. Damit verengt MacKinnon das Problem der Gewalt an Frauen weiter auf die rechtliche Forderung der Aufhebung des Schutzes der Meinungsfreiheit für Pornografie. Das Recht und die staatlichen Organe sollen letztlich Freiheit und sexuelle Selbstbestimmung für Frauen garantieren.

Carolyn Bronstein kritisiert diese von MacKinnon und Dworkin vorgenommene Festschreibung von Frauen auf den Opferstatus, die weit entfernt sei vom frühen Ziel der Anti-Porno-Bewegung, den Frauen ihre Macht und Handlungsfähigkeit bewusst $\mathrm{zu}$ machen. Meiner Ansicht nach unterscheidet sich allerdings Dworkins Haltung darin, dass sie mit ihrer Rhetorik der Empörung über sexuelle Gewalt noch näher am Ursprung der Anti-PornoBewegung ist als MacKinnon. Deswegen erstaunt es nicht, dass die zeitgenössische Pornografiekritik sich wieder eher an Dworkin als an MacKinnon orientiert.

So etwa Julia Long, die sich explizit in der Tradition des radikalen Feminismus positioniert, den sie in Opposition zur linksliberalen Grundhaltung auf der einen Seite wie auch zur postmodernen, queertheoretischen Grundhaltung auf der anderen Seite definiert. Charakteristisch für Longs Orientierung an Dworkins Pornografiekritik ist ihre Ablehnung von Transgression im Bereich der Sexualität, die wiederum mit einer rhetorischen Marginalisierung von alternativer Pornografie einhergeht. Wie zu den Zeiten der Sex Wars ist die Erotisierung von Herrschaftsverhältnissen und Gewalt ein 
zentraler Streitpunkt. Auch Gail Dines, Kat Banyard, Ann Russo und Robert Jensen nehmen ausdrücklich Bezug auf die Geschichte der Anti-PornografieBewegung und verorten sich darin. Mindestens Jensen, Russo und Dines distanzieren sich vom juristischen Streit um die Zensur pornografischer Inhalte und fordern generell zum Kampf auf gegen frauenfeindliche gesellschaftliche Praktiken. Dworkins Grundthese von Pornografie als Instrument der Unterdrückung von Frauen durch Männer stößt jedoch in der aktuellen Pornografiekritik auf breite Zustimmung. Jensen und Susan Douglas belegen diese These mit der Erotisierung und Normalisierung eines stereotypen, objektivierenden Frauenbildes, die sie der Pornografie zuschreiben. Banyard findet das Produktkonzept der Pornografie beunruhigend, das Jungen und Männer daran gewöhne, sich Sex mit Frauen zu wünschen, die keinen Sex mit ihnen haben wollten; sie nimmt damit ein Motiv der Frauenbefreiungsbewegung wieder auf, das Pornografie ablehnt, weil sie mitschuldig sei an einer Situation, wo Frauen in ihrer Bewegungsfreiheit eingeschränkt seien, da sie sich vor sexuellen Übergriffen fürchten müssten. Noch einen Schritt weiter geht Dines, indem sie im Einklang mit Dworkin behauptet, Pornografie vermittle Frauenhass und Rassismus; wie Dworkin kritisiert sie, dass die Gesellschaft jungen Männern generell, aber auch durch Pornografie Empathie abtrainiert.

Dworkins Reproduktion herrschender Geschlechterstereotype, indem sie einen Gegensatz zwischen naturhafter weiblicher und erobernder männlicher Sexualität konstruiert, prägt das Sexualitätskonzept der zeitgenössischen Pornografiekritik. So fungiert zum Beispiel bei Naomi Wolf ein als weiblich definiertes sexuelles Begehren durchwegs als Gegenbild zur repetitiven, anonymisierenden Sexualität der Pornografie.

Cindy Jenefsky und Ann Russo nehmen Dworkins Schriften vor dem Vorwurf der Unwissenschaftlichkeit in Schutz, da es sich nicht um analytische, sondern um politisch agitative Texte mit literarischem Anspruch handle. Dworkins rhetorisches Erbe scheint in der zeitgenössischen Pornografiekritik weiterzuwirken. Emotionalisierung sowie Einseitigkeit in der Auswahl von Beispielen und Interviewpartnern sind häufig. Unbeabsichtigt scheint sich hier der abgelehnte transgressive Charakter der Pornografie wieder einzuschleichen, indem das Argumentieren gegen Pornografie die Grenzen des analytischen Sprechens deutlich macht und die Grenze zu politischem, wenn nicht gar polemischem Sprechen überschreitet.

In welchem Licht erscheinen damit die Argumente der zeitgenössischen Pornografiekritik zur Tendenz der Pornografisierung? Hier gibt insbesondere der objektivierende Blick der Pornografie Anlass zur Sorge um die Jugendli- 
chen. Der Effekt der Objektivierung ist seit Dworkin ein zentraler Topos in der feministischen Pornografiekritik. Ihre These von Pornografie als Mittel der Unterdrückung der Frauen durch Männer hängt stark von dieser Beschreibung des pornografischen Blicks als objektivierend ab. Auch die Selbstobjektivierung der Frau hat Dworkin bereits kritisiert; sie sieht dieses Verhalten als das patriarchale System stützend, Selbstobjektivierung als Empowerment hat sie nicht im Blick. Einige Exponentinnen und Exponenten der zeitgenössischen Pornografiekritik wie Robert Jensen, Julia Long oder Susan Douglas halten an diesem Urteil fest. Paula-Irene Villa oder Julia Jäckel hingegen können in der Strategie, sich selbst zum Objekt des pornografischen Blicks zu machen, auch ermächtigende Aspekte feststellen. Das ist neu, wie auch das Phänomen, vor allem die Jugendlichen als schutzlos gegenüber den Bildern der Pornografie zu konstruieren. Dies stand bei der feministischen AntiPorno-Bewegung früher nicht im Fokus, es ging eher um den Kampf um die eigene Freiheit und sexuelle Selbstbestimmung. Swen Lewandowski hält diese Sorge um die Jugendlichen deshalb für eine Voraussetzung für die Furcht vor der Pornografisierung.

Allgemein scheint es Dworkin und MacKinnon gelungen zu sein, das Vokabular der sexuellen Selbstbestimmung aus der Anti-Porno-Bewegung hinauszudrängen. Auch in der zeitgenössischen Pornografiekritik kommt der Begriff kaum vor, wenn doch, wird er dem Sexpositivismus der queerfeministischen Bewegung zugeschrieben und damit disqualifiziert. So sieht Julia Long in diesem bloß ein Ablenkungsmanöver von der realen Ungleichheit und Gewalt zwischen Mann und Frau. Allgemein lässt sich konstatieren, dass die aktuelle Pornografisierungskritik versucht, den Diskurs über Pornografie wieder in einen Diskurs über Machtstrukturen, ökonomische Prozesse und Klassenfragen einzubetten. Vor diesem Hintergrund formulierte schon Andrea Dworkin ihre Pornografiekritik, der Diskurs verengte sich jedoch unter dem Einfluss von Catharine MacKinnon immer mehr auf einen bloß rechtlichen Diskurs.

Als positiv werte ich, dass eine neue Generation eine feministische Pornografiekritik formuliert, welche die veränderten kulturellen und ökonomischen Rahmenbedingungen einbezieht. Doch sie schleppt als Ballast aus Sex-Wars-Zeiten eine scharfe, emotionalisierende Rhetorik und eine Abwertung queerfeministischer Errungenschaften mit sich. In Kapitel 4 möchte ich deshalb eine andere Form feministischer Pornografiekritik diskutieren: die alternativen Pornografien. Diese wollen den normierenden 
Bildern der Mainstream-Pornografie eigene entgegensetzen. Inwieweit ist diese Strategie an den transgressiven Charakter der Pornografie geknüpft? 



\section{Transgression in alternativen Pornografien}

\section{1 Überblick}

In diesem Kapitel möchte ich einen Blick auf exemplarische Konzepte alternativer Pornografien werfen. Pornografie von und für Frauen, SchwulenPornografie oder Transmänner-Pornografie bereiten den Weg für das aktuelle Phänomen der Post-Pornografie. Diese Konzepte möchte ich unter dem Blickwinkel untersuchen, inwieweit sie auf den transgressiven Charakter der Pornografie rekurrieren und inwieweit sie, analog zur Mainstream-Pornografie, ebenfalls Ausdruck von Normierungen sind.

Doch was unterscheidet alternative Pornografien von MainstreamPornografie? Die Politikwissenschaftlerin Doris Allhutter schreibt:

Was als Mainstream und was als alternative Repräsentation von Sexualität bezeichnet werden kann, ist natürlich weder eindeutig definierbar, noch gibt es eine objektive Interpretation oder eine klare Trennlinie. Nach meinem Verständnis drückt Mainstream-Pornografie ein Phantasma aus, das auf einer Sichtweise von Sexualität beruht, die das geschlechtlich Imaginäre beinahe ausschließlich heterosexuell und/oder dichotom-hierarchisiert besetzt. [...] Als alternative Pornografie verstehe ich in Abgrenzung zum Mainstream Repräsentationen von Sexualität, die sexuelle und geschlechtliche Identität uneinheitlicher und mehrdeutiger darstellen und entgegen klassischer Cenrekonventionen pornografische Stereotype durchbrechen, die also pornografische Genrekonventionen konterkarieren oder auf einer MetaEbene thematisieren. (Allhutter 2009, S. 33f.)

Allhutters Unterscheidung finde ich einleuchtend, aber auch anspruchsvoll. Für meine Zwecke werde ich alternative Pornografien allgemeiner definieren: Ich verstehe unter Mainstream-Pornografie kommerzielle, in erster Linie für ein heterosexuelles männliches Publikum produzierte Pornografie; alter- 
nativ wären dann alle in einem oder mehreren Punkten von dieser Definition abweichenden Pornografien. In der detaillierten Analyse wird sich zeigen, inwiefern diese auf den ersten Blick alternativen Pornografien auch eine Alternative im Sinne der Definition Allhutters darstellen. Und natürlich interessiert mich im Speziellen, welchen Gebrauch alternative Pornografien für das von Allhutter erwähnte Durchbrechen von Genrekonventionen vom transgressiven Charakter der Pornografie machen.

\subsection{Strategien alternativer Pornografien}

\subsubsection{Eine weiblichere Pornografie}

Pornografie von und für Frauen hat ihre Wurzeln in der Spaltung der Frauenbewegung an der Pornografiefrage, den sogenannten Sex Wars. Carolyn Bronsteins Sicht auf diese Spaltung haben wir im Kapitel 3.3.2 kennengelernt. Die Fokussierung auf Männergewalt auf Kosten der Forderung nach sexueller Freiheit für Frauen stand laut Bronstein am Ursprung der Sex Wars. Lynne Segal teilt diese Einschätzung. Ihrer Meinung nach beginnen zwei sich widersprechende Argumente den feministischen Diskurs ab Mitte der 1970er-Jahre zu dominieren:

The first, exemplified by Susan Brownmiller in her influential book Against Our Will, was to deny that rape was sexually motivated, and analyse it purely in terms of violence, as the timeless and global method by which men had sought and managed to keep women subordinate throughout time and place. The second, existing in implicit but cosy contradiction, was to analyse all of male sexuality in terms of a continuum of violence: to proclaim, as had Susan Griffin in 1971, that the basic elements of rape are involved in all heterosexual relationships. (Segal 1992a, S. 3)

Der Widerspruch liegt darin, dass das eine Argument behauptet, Vergewaltigung habe mit Sexualität nichts zu tun, sondern sei ein bloßes Machtinstrument der Männer, während das andere Argument behauptet, die männliche Sexualität an sich sei gewaltförmig, heterosexueller Geschlechtsverkehr beinhalte per se Elemente von Vergewaltigung. Das erste Argument führt Vergewaltigung auf Gewalt zurück und trennt sie von Sexualität, das zweite Argument führt zumindest die dominierende heterosexuelle Praktik auf Gewalt zurück. Beide Argumente zusammen können nicht wahr sein, denn entweder 
lässt sich Sexualität von Gewalt trennen oder Sexualität ist Gewalt. Um nun Pornografie ins Zentrum der Debatten um Männergewalt zu rücken, sind laut Segal zwei weitere Schritte nötig gewesen:

The first was to insist that sexuality was the primary, the overriding, source of men's oppression of women, rather than the existing sexual division of labour, organization of the state or diverse ideological structures. The second was to cite pornography as the cause of men's sexual practices, now identified within a continuum of male violence: »Pornography is the theory, and rape the practice.«(Ebd.)

Wenn die Unterdrückung der Frauen ihren Ursprung vor allem in der Sexualität hat und Pornografie die Ursache der sexuellen Praxis der Männer ist, wird der Kampf gegen Pornografie zum primären Schauplatz des Kampfes zur Befreiung der Frauen. Dabei geht männliche Sexualität vollständig in einem gewaltförmigen Ausdruck des Willens der Männer zur Unterwerfung der Frauen auf. So kritisiert zum Beispiel auch die Rechtssoziologin Mariana Valverde MacKinnons reduktionistische Sicht auf Sexualität, die unabhängig vom Kontext als Frauen unterdrückend dargestellt werde: »The eventual result is a construction of sexuality as uniformly oppressive, a picture of relentless male violence drawn with the twin brushes of feminist functionalism (all phenomena are explained as serving a purpose for >patriarchy< in general) and philosophical pessimism. Resistance, subversion, and pleasure are written out of the account. (Valverde 1995, S. 181) Daraus resultiere eine Sicht der Frau als Opfer, das mit rechtlichen Mitteln vor dem Ärgsten geschützt werden müsse. Gegen eine solche Verkürzung wehrten sich die sogenannten sexpositiven Feministinnen und versuchten alternative Visionen von Sexualität zu entwickeln, die nicht einfach Machtverhältnisse reproduzieren.

Auch die Juristin Nadine Strossen stört die Unmündigkeit, in die eine Gesetzgebung nach Dworkins und MacKinnons Vorschlägen Frauen führen würde. Wenn ein Gesetz festhalte, dass eine Frau unter keinen Umständen freiwillig an pornografischen Aufnahmen mitgewirkt haben könne, auch wenn sie dies behaupte, dann bringe diese Gesetzgebung Frauen in eine Position der Unmündigkeit: »Procensorship feminists conclude that - at least in the realm of sexuality and sexual expression - women can never make free, voluntary, consensual choices, and that, rather, women are always coerced in this context, whether they realize it or not. (Strossen 1996, S. 180f.) Solche Gesetze behandelten Frauen wie Kinder und verliehen ihnen so einen Status, den Feministinnen über Jahrhunderte loszuwerden versucht hätten. Strossen ver- 
teidigt die Freiheit von Frauen, aus einer rationalen ökonomischen Wahl in der Sexindustrie zu arbeiten, wo die Verdienstmöglichkeiten oft besser seien als in anderen niedrig qualifizierten Jobs. Ein Verbot pornografischer Erzeugnisse werde die Sexarbeit in den Untergrund verlagern und gefährlicher statt sicherer machen.

Konstruktive Ansätze zur Reduktion von Diskriminierung und Gewalt gegenüber Frauen sieht Strossen in der konsequenten Bekämpfung von sexueller Diskriminierung und sexueller Gewalt an den Orten ihrer Entstehung: in der Familie, in der Schule, am Arbeitsplatz, im Sport, im Militär. Diese Bekämpfung erfordere freies Reden über Sexualität, also genau das, was durch die Zensuranstrengungen der Pornografiegegner gefährdet scheine: »Just as suppressing sexual speech plays an essential role in maintaining the political, social, and economic status quo, conversely, protecting sexual speech plays an essential role in challenging the status quo. (Ebd., S. 178)

Bezüglich der Redefreiheit sagen Pornografiekritikerinnen wie MacKinnon, das Perfide an der Pornografie sei, dass sie eine Situation schaffe, in der Frauen, wenn sie Nein sagten, eigentlich Ja meinten. Das pornografische Subjekt sei damit des Rechts beraubt, seine Äußerung das bedeuten zu lassen, was sie bedeuten solle; damit verliere es ein Recht, welches das Subjektsein wesentlich ausmache. Auf diese Weise objektiviere Pornografie.

Mit Butler lässt sich einwenden: Äußerungen sind, sofern sie performativ sind, gerade dadurch gekennzeichnet, dass sie misslingen können. Insofern können wir uns ohnehin nie darauf verlassen, dass unser Nein immer Nein bedeutet. Noch problematischer ist MacKinnons Forderung, dass eine höhere Instanz sicherstellen soll, dass eine Äußerung bedeutet, was sie bedeuten soll. Mit welchem Recht? Dies ist eine unverhältnismäßige Einschränkung dessen, was Äußerungen bedeuten können, eine Einschränkung, zu der wir niemandem das Recht geben sollten: »Wenn man die Aufgabe, über hate speech zu urteilen, an den Staat übergibt, übergibt man ihm die Aufgabe der Fehlaneignung.« (Butler 2006, S. 160f.) Solche staatliche Einschränkungen und Regulierungen des Sprechens könnten sich in einem anderen Fall genau gegen das Sprechen derjenigen richten, die sich im Fall der Pornografie Schutz davon versprächen.

Pornographie, als kulturelles Reservoir eines sexuell überdeterminierten visuellen Feldes, zirkuliert gerade ohne unseren Konsens, aber deswegen nicht schon unbedingt gegen ihn. Darauf zu beharren, dass der Sexualität in jedem Fall ein Konsens vorausgeht, zeigt die Rückkehr zu einem vor- 
freudianischen Begriff eines liberalen Individualismus an, in dem Konsens konstitutiv für das Person-Sein ist. (Ebd., S. 151)

Dass der Sexualität nicht in jedem Fall ein Konsens vorausgeht, ist eine wichtige Beobachtung. In der Forderung an Sexualität, nur konsensuell stattzufinden, steckt implizit die Annahme, dass Sexualität schon da ist, bevor über sie ein Konsens hergestellt wird. Sexualität zeichnet sich gerade dadurch aus, dass sie sich der bewussten Steuerung teilweise entzieht. »Allgemeiner gefasst, die Zirkulation von Pornographie lässt sich nicht effektiv kontrollieren, und selbst wenn solche Kontrolle doch möglich wäre, würde der Kontrollmechanismus einfach in die pornographische Thematik integriert werden - ein nur um so pikanterer Plot, der das Gesetz und seine Überschreitung fokussiert.« (Ebd., S. 152) Dieser unkontrollierbare Rest stellt natürlich ein Risiko dar, er ist aber auch eine Chance. Denn dieser unkontrollierbare Rest ermöglicht erst das Misslingen der Pornografie. Wir sind der Pornografie nicht in einer Weise ausgeliefert, dass sie zwingend bei jedem Betrachter Erregung auslöst. Was den einen antörnt, kann den anderen abstoßen oder kaltlassen. Der Grund dafür ist weniger in einer bewussten Entscheidung, sondern im Unbewussten $\mathrm{zu}$ suchen.

Butler macht sich für die Fantasie stark, welche die Beschränkungen des Realen und Normierten überschreitet. Sie weist darauf hin, dass das Zensieren der Fantasie in Form kultureller Produkte zwangsläufig den sozialen Tod von Personen in Kauf nehme. Denn Fantasie artikuliert, was real nicht oder noch nicht lebbar ist, was aber vielleicht gerne gelebt würde oder einmal gelebt werden wird.

Die Zensur pornografischer Erzeugnisse bedeutet aus dieser Perspektive einen gewaltförmigen Versuch, das aktuell Reale und Mögliche abzusichern gegen zurzeit noch verworfene Weisen, Sexualität zu leben. Es ist dies ein wirklich gefährlicher Aspekt der Zensur. Denn er setzt Personen, die derzeit nicht akzeptierte Formen der Sexualität leben, dem sozialen Tod aus, da ihre Leben nicht verstehbar sind und bewusst außerhalb der Grenzen der Verstehbarkeit gehalten werden.

Die feministische Rechts- und Politikwissenschaftlerin Drucilla Cornell wehrt sich gegen MacKinnons Behauptung, Pornografie spreche nicht zum Verstand des Mannes, sondern zu dessen Penis: „Das Phantasma des Schwanzes, der den Mann kontrolliert, ist unmittelbar mit der pornographischen Welt verbunden. MacKinnons Sicht der Männlichkeit spiegelt ebendie pornographische Welt wider, vor der es ihr schaudert.« (Cornell 1995, S. 72) Um 
MacKinnons mechanistischem Modell des Pornografiekonsums etwas entgegenzusetzen, beharrt Cornell darauf, dass Pornografie etwas mit der Sphäre des Imaginären zu tun habe. Unter der Sphäre des Imaginären versteht Cornell Folgendes: »The imaginary domain is the moral and psychic space we as sexuate beings need in order to freely play with the sexual persona through which we shape our sexual identity, whether as man or woman, straight, gay, lesbian or transgender.« (Cornell 2004, S. 151) Laut Cornell sind Männer und Frauen im Alltag in ein enges Korsett von Geschlechterrollen geschnürt, das durch die Sphäre des Imaginären teilweise gestützt werde, das mithilfe der Sphäre des Imaginären aber auch gelockert werden könne. Um die Versuchung der Pornografie zu erklären, nimmt Cornell Lacans Theorie der phallischen Mutter auf. Die phallische Mutter ist in der Mutter-Kind-Dyade die allmächtige Mutter, von der das Kind sich lösen muss, um eine eigenständige Identität zu gewinnen. Diese Loslösung gelingt durch die teilweise Identifikation mit dem Vater, dessen Phallus das Einzige ist, durch den die phallische Mutter regiert werden kann. Die narzisstische Wunde, die das Verlassenwerden von der Mutter dem Kind zugefügt hat, kann mithilfe des väterlichen Phallus der Mutter zugefügt werden. Cornell behauptet nun, dass Mainstream-Pornografie eine imaginäre Szenerie bereitstelle, in der diese Kontrolle der phallischen Mutter durch den Phallus des Vaters wieder und wieder durchgespielt werden könne. Diese Möglichkeit zur Rache an der phallischen Mutter mache den Reiz der Mainstream-Pornografie aus, da sie einen Raum biete, um das von Verlassenheit und Sehnsucht nach der Mutter geplagte Selbst des Pornografienutzers durch die Identifikation mit dem Vater wieder zu stabilisieren. Der Grund für die herabwürdigende Darstellung von Frauen in der Mainstream-Pornografie wäre dann, dass diese Frauen stellvertretend für die phallische Mutter bestraft werden:

In the place of a rich and diversified account of the actual power of women as sexed beings, whose sexuality is defined and lived by them, we have a phantasmatic figure who threatens and lurks and who must be controlled. The excitement and the sexual arousal in pornography is inseparable from the fantasy of transcendence in which one has finally separated himself absolutely from that bodily Other upon which one was once utterly dependent. (Cornell 2004, S. 156)

Dies entspricht Lewandowskis Sicht auf Pornografie als Selbstverständigungsdiskurs über heterosexuelle Männlichkeit. Cornell beschreibt die Versuchung der Pornografie als Transgression. Pornografie ermögliche es 
dem Betrachter, die Abhängigkeit vom begehrten Andern zu überschreiten und sich in einem imaginären Akt der Autonomie aus dieser Abhängigkeit zu befreien. Dieser Befreiungsschlag sei das effektiv sexuell Anregende an den zum Teil Frauen herabwürdigenden Szenarien der Mainstream-Pornografie. Es sei jedoch ein Fehler, diesen Befreiungsschlag als Ausbruch aus der Dynamik der heterosexuellen Dyade zu verstehen: »The psychoanalytic account of pornography argues that pornography speaks not to the penis but to the unconscious, and is an expression of the fantasy underpinnings of so-called heterosexuality.« (Ebd., S. 159) Die Pornografie spreche also eher unbewusste Wünsche, Ängste oder auch Frustrationen an, die in der heterosexuellen Zweierbeziehung bereits angelegt seien; sie schaffe eine Fantasiewelt, wo diese unbewussten Emotionen und Begierden in einem sicheren Rahmen ausagiert werden könnten.

Die heterosexuelle Mainstream-Pornographie bietet keine befreiende, aufbrechende Sicht der Sexualität, weil sie auf die Darstellung starrer Ceschlechterrollen angewiesen ist. Es ist möglich, sich mit entgegengesetzten Geschlechterrollen, wie sie im pornographischen Szenario gezeigt werden, zu identifizieren; trotzdem sind diese Positionen selbst durch starre Ceschlechtsrollen etabliert. (Cornell 1995, S. 84)

Entsprechend sei Mainstream-Pornografie weniger von geheimen sexuellen Wünschen der Männer bestimmt, sondern präsentiere vielmehr ein Phantasma, ein Szenario, in welchem sich Männer von ihrer Kastrationsangst zu lösen versuchten: »Pornographie ist nicht, was Männer wollen, sondern Ersatz für den Mangel und die Spaltung der Männer, die die ihnen auferlegte Struktur männlicher Identität besetzen. Nicht männliche Macht, sondern der Mangel an Sicherheit darüber, wer sie eigentlich sind, kommt in Pornographie zur Darstellung.«(Ebd., S. 121)

Am Beispiel der Post-Pornografie-Pionierin Annie Sprinkle präsentiert Cornell eine Alternative zu der vom Phantasma der phallischen Mutter verfolgten männlichen Sexualität der Mainstream-Pornografie. Sie sieht in der Pornografie Raum für ein neues weibliches Imaginäres, das Frauen hilft, aus den starren Rollenzuweisungen der heterosexuellen Dyade auszubrechen.

Die feministische Aktivistin Ellen Willis weist darauf hin, dass in Pornos von der Gesellschaft verdrängte Triebe wiederauferstehen: "About the only generalization one can make is that pornography is the return of the repressed, of feelings and fantasies driven underground by a culture that atomizes sexuality, defining love as a noble affair of the heart and mind, 
lust as a base animal urge centered in unmentionable organs. (Willis 1995, S. 171) Damit nimmt Willis Freuds Gedanken zur Triebunterdrückung auf. Laut Freud erzeugen die rigiden Kulturanforderungen eine geheime Kultur sexueller Fantasien und Praktiken, wie sie etwa Marcus in seinen Untersuchungen zur Kultur der Viktorianer beschrieben hat. Darauf aufbauend beschreibt Willis die Ambivalenz der Pornografie folgendermaßen: »Insofar as pornography glorifies male supremacy and sexual alienation, it is deeply reactionary. But in rejecting sexual repression and hypocrisy - which have inflicted even more damage on women than on men - it expresses a radical impulse.« (Ebd., S. 173) Durch die Bekämpfung der Pornografie aufgrund der männlichen Überlegenheit, die diese transportiere, laufe die Anti-PornoBewegung Gefahr, die für Frauen befreienden Aspekte der Pornografie zu übersehen. In der Abgrenzung zur gewaltförmigen männlichen Sexualität der Pornografie finde sich die Anti-Porno-Bewegung dann bei einem Konzept von Sexualität wieder, das von einer Geschlechterdichotomie geprägt sei, die sie eigentlich habe überwinden wollen: »This goody-goody concept of eroticism is not feminist but feminine. It is precisely sex as an aggressive, unladylike activity, an expression of violent and unpretty emotion, an exercise of erotic power, and a specifically genital experience that has been taboo for women." (Ebd.) Damit spricht Willis an, was wir bei der Analyse von Dworkins Schriften festgestellt haben: Weibliche Sexualität wird in der Anti-Porno-Bewegung negativ zur gewaltförmigen, dominanten männlichen Sexualität gedacht und verbleibt so in der Aktiv/passiv-Binarität der Norm der Zweigeschlechtlichkeit.

Wie Gail Dines legt die Medienwissenschaftlerin Laura Kipnis eine Analyse des Porno-Magazins Hustler aus Klassenperspektive vor (vgl. Kipnis 1993, S. 219-242). Dines zufolge bietet Hustler dem mittelständischen Leser die Möglichkeit, sich für die Zeit der Lektüre im Sumpf der rauen sexuellen Sitten der Arbeiterklasse zu suhlen, und schafft so Gelegenheit zur sexuellen Überschreitung der Klassengrenzen. Kipnis richtet in ihrer Analyse den Fokus darauf, wie Inhalt und Ästhetik des Hustlers durch die Übertretung bürgerlicher Grenzziehungen des guten Geschmacks und der Moral, aber auch der Akzeptabilität von Körperformen und sexuellen Praktiken eine Kritik an ebendiesen bürgerlichen Grenzziehungen darstellen. Aus dieser Perspektive müssten sich die anti-pornografischen Feministinnen die Frage gefallen lassen, ob ihre Kritik nicht auch ein Ausdruck von klassendefiniertem Unbehagen gegenüber der Arbeiterklasse seien, symbolisiert durch verfemte Körperteile und -öffnungen. 
So in mapping social topography against bodily topography, it becomes apparent how the unsettling effects of grossness and erupting bodies condense all the unsettling effects (to those in power) of a class hierarchy tenuously held in place through symbolic (and less symbolic) policing of the threats posed by bodies, by lower classes, by angry mobs. (Ebd., S. 225)

Kipnis gibt zu, dass auch bei ihr das Lesen des Hustlers Ekel hervorruft. Im Gegensatz zu Feministinnen wie Dworkin möchte sie aber einer Naturalisierung dieses Ekels und dessen Mobilisierung für den konstruierten Gegensatz der natürlichen weiblichen Sexualität gegenüber der gewalttätigen männlichen Sexualität widerstehen und stattdessen die historischen, klassenspezifischen und psychologischen Wurzeln dieses Affekts aufspüren. "So perhaps it becomes a bit more difficult to see feminist disgust in isolation, and disgust at pornography as strictly a gender issue, for any gesture of disgust is not without a history and not without a class character. (Ebd., S. 226) Kipnis vermutet, dass der Widerstand gewisser Feministinnen gegen Pornografie damit zu tun habe, dass diese auf die Konstruiertheit, Klassenbasiertheit und Historizität der weiblichen Sexualität und Subjektivität hinweise. Denn nicht alle Frauen fühlten sich von Pornografie abgestoßen oder in ihrer Weiblichkeit beleidigt. "The differences between female spectators as to how this address or misaddress is perceived appears to be bound up with the degree to which a certain version of female sexuality is hypostatized as natural, versus a sense of mobility of sexuality (at least at the level of fantasy). «(Ebd., S. 231)

Als exemplarische Vertreterin eines sexpositiven Zugangs zu Pornografie gilt die feministische Autorin Cathy Winks, die zehn Jahre im ältesten frauenfreundlichen Sexshop der USA arbeitete. Ihre Devise lautet: »The only way to improve the quality of what's out there is not to produce less porn, but to produce better porn.« (Winks 1998, S. 11) In ihrem Vorwort zum Good Vibrations Guide to Adult Videos nennt sie vier Gründe, weshalb es - auch für Frauen gut ist, Pornos zu konsumieren: erstens, um sich mit seiner eigenen Sexualität und der Sexualität von anderen wohler zu fühlen; zweitens zur Inspiration; drittens zur Erweiterung des Repertoires an erotischen Fantasien; und viertens, um unterhalten und erregt werden. Sie spricht damit wichtige Punkte an: Sexualität ist kulturell mit Tabus und Scham behaftet. Dies macht es für viele Menschen schwierig, sich beim Sex wohlzufühlen. Da können Pornos Orientierung und Sicherheit vermitteln. Indem sie aufklären und inspirieren, können sie zudem Partnerschaften zu mehr Langlebigkeit verhelfen. Das vierte Argument unterstreicht die Fiktionalität von Pornofilmen: Sie sind wie 
andere Filme eine Form von Unterhaltung, und die Imagination spielt eine wichtige Rolle für die Stimulierung des Begehrens.

Doch inwiefern entsprechen nun an Frauen gerichtete Pornos Winks' Forderungen nach besseren Pornos? Und versprechen diese Pornos tatsächlich ein Mehr an sexueller Freiheit für Frauen? Valverde artikuliert Skepsis gegenüber einer naiven Form von feministischem Sexpositivismus und beharrt darauf, dass ein Konzept der sexuellen Freiheit nicht ahistorisch sein dürfe und soziale Kontexte einbeziehen müsse:

When feminists speak about gaining autonomy and self-determination for our sexual choices, what is usually meant is autonomy from male authority, tradition, and similar constraints; what is not meant is absolute autonomy, even if such a thing were possible. We seek to be free not as self-sufficient egos wandering in a void (an intrinsically bourgeois image of utopia) but as active participants in communities that are establishing a counterdiscourse on sexual ethics. (Valverde 1995, S. 188)

Um diese Herausforderung zu verdeutlichen, möchte ich eine Studie der Anthropologin Michelle Carnes hinzuziehen. Sie analysiert darin Filme von drei verschiedenen Regisseurinnen: Nina Hartley, Carole Queen und Tristan Taormino. Gemeinsam ist den Filmen, dass sie an Frauen gerichtete Instruktionsvideos zu Analsex sind. Die Tatsache, dass Frauen Instruktionsfilme zu Analsex machen, sieht Carnes als Statement für ein aufklärerisches Potenzial der Pornografie. Zudem grenzten sie sich damit von Regisseurinnen wie Candida Royalle ab, die auf die Darstellung von Analsex verzichte, da dieser für Frauen nicht lustvoll sei: »Because the anus is neither unique to men nor unique to women (but shared by all), the eroticization of the anus creates a new playground for women partnered with men. The penetrated male anus - a pleasure associated with gay male sexuality - becomes incorporated in a straight< sexual diet.« (Carnes 2007, S. 158) Damit sieht sie diese Filme als transgressiv in Bezug auf Geschlechternormen und heteronormative Sexualpraktiken an. Doch neben der Demystifizierung tabuisierter analer Sexpraktiken sei in den Filmen eine Remystifizierung am Werk, zum Beispiel würden Exkremente in den Instruktionsfilmen auf der visuellen Ebene nicht thematisiert, Analsex erscheine durchgängig als sauber, es gebe keine diesbezüglichen Pannen. Zudem fällt Carnes auf, dass in den Videos zwar heterosexuelle und lesbische Paare, aber keine schwulen Paare beim Analsex gezeigt werden:»Maleon-male sex is not included as something that women of any sexual iden- 
tity would enjoy, nor as something a man partnered with a woman would be interested in seeing as part of their anal sex education.« (Ebd., S. 159)

Interessant ist, dass lesbische Szenen in der von Frauen für Frauen produzierten Pornografie ebenso wie in der an heterosexuelle Männer gerichteten Pornografie einen selbstverständlichen Platz haben. Damit laufen diese Filme Gefahr, ein weiteres Stereotyp der Mainstream-Pornografie zu reproduzieren. Denn wie die Kulturanthropologin Jenny Kangasvuo analysiert hat, stellt weibliche Bisexualität in der Pornografie keine sexuelle Identität dar. In ihrer Studie zur Bisexualität in Porno-Magazinen kommt sie zum Schluss, dass diese vor allem dazu dient, eine Frau als unersättlich und hypersexualisiert darzustellen. »The bisexual woman is an updated version of the ideal woman of porn: active, open and ready to fulfil all possible fantasies. (Kangasvuo 2007, S. 143) Bisexualität breche die heterosexuelle Hegemonie in den Porno-Magazinen nicht auf, sondern erhöhe die Attraktivität der Frau um ein reizvolles Extra. Dies scheine auch aus den Selbstbeschreibungen der in den Magazinen abgedruckten Frauen durch:

Both amateur models and porn stars seem eager to confirm their lack of inhibitions with the label of bisexuality. In all interviews, bisexuality is depicted as a positive trait, something that makes a porn career or activity in fetish circles appear natural. While all women in porn are presented as inherently interested in each other, naming oneself bisexual is a way to prove one's upto-date attitude. (Ebd., S. 144)

Das Konzept der Bisexualität sichere die heterosexuelle Hegemonie sogar gegen Homosexualität ab, indem sie die Existenz einer lesbischen Frau ohne Bedürfnis nach Sex mit Männern negiere. Die Sexualität der Frau erscheine als fluid und verfestige sich nicht zu einer lesbischen oder bisexuellen Identität im gebräuchlichen Sinne identitätsstiftender Kategorien. "Since all women in porn are ready to have sex with other women, bisexuality loses its commonsensical meaning. The concepts used to discuss female desire and sexuality are emptied in the process. (Ebd., S. 146) Kangasvuo sieht in der Darstellung der Bisexualität in Porno-Magazinen einen weiteren Beweis für die Auslöschung realen weiblichen Begehrens, realer weiblicher Sexualität. Die Verflüssigung sexueller Identitäten in der Pornografie erscheine hier nicht als etwas Transgressives, sondern als Stütze der heterosexuellen Hegemonie. Dies treffe auch auf das Verhandeln männlicher Bisexualität in denselben Magazinen zu: 
While sex and desire between women is constantly present in heteroporn, sex and desire between men is depicted as either ridiculous or problematic. The term bisexuality can refer to all women but bisexual men are presented as either the troubled souls of counselling columns or pathetic clowns who fail in their attempts to prove that they are not gay. (Ebd., S. 148)

Während in Pornos weibliches Begehren als offen dargestellt werde und sich potenziell auf alles richten könne, scheine männliches Begehren immer durch das Objekt des Begehrens definiert werden zu müssen. Schwules Begehren ist offenbar das Nichtdarstellbare sowohl der an Männer wie an Frauen gerichteten Hetero-Pornografie. Deshalb möchte ich als Nächstes die SchwulenPornografie in Bezug auf ihre Möglichkeiten zur Transgression näher betrachten.

\subsubsection{Die identitätsstiftende Funktion schwuler Pornografie}

Pornografie scheint in der Gay Community eine andere Rolle $\mathrm{zu}$ spielen, als es bei Heterosexuellen der Fall ist. Die größere Sichtbarkeit etwa in schwulen Bars und Buchläden lässt eine größere Akzeptanz und ein geringeres Tabuisieren der Pornografie vermuten. Die enge Verbundenheit der Gay Community mit Pornografie wurzelt in der Stigmatisierung der Homosexualität. Wir haben mit Butler schwule Gruppenidentität bereits als Ergebnis von performativ ausagierten, ursprünglich ausgrenzenden Zuschreibungen kennengelernt. Bourdieu beschreibt dieses Stigma folgendermaßen:

Die Homosexuellen, die mit einem Stigma behaftet sind, das im Unterschied zur Hautfarbe oder zur Weiblichkeit verborgen gehalten (oder ostentativ herausgestellt) werden kann, sind die Opfer einer besonderen Form von symbolischer Herrschaft. Sie ist dadurch gekennzeichnet, dass sie sich durch kollektive Kategorisierungsakte aufzwingt, die die Existenz von negativ bewerteten, signifikanten Unterschieden und damit von stigmatisierten sozialen Gruppen, Kategorien, zur Folge haben. Wie bei bestimmten Formen des Rassismus nimmt sie in diesem Fall die Form einer Bestreitung des Rechts auf eine sichtbare öffentliche Existenz an. (Bourdieu 2005, S. 201f.)

Die Existenz der gesellschaftlichen Kategorie der Homosexuellen verdankt sich einem Akt der symbolischen Herrschaft, einem Stigma. Die Verweigerung des Rechts auf eine sichtbare öffentliche Existenz führte dazu, dass Ho- 
mosexuelle sich lange Zeit nur im Verborgenen treffen konnten. Laut Bourdieu ist ein Effekt der symbolischen Gewalt des Stigmas, dass die stigmatisierte Person die herrschenden Wahrnehmungskategorien übernimmt und auf sich selbst anwendet: »Was dann unweigerlich dazu führt, dass er die sexuelle Erfahrung, die ihn vom Standpunkt der herrschenden Kategorien aus definiert, schamvoll erlebt und hin- und herschwankt zwischen der Furcht, wahrgenommen, enttarnt zu werden, und dem Wunsch, von anderen Homosexuellen erkannt zu werden. (Ebd., S. 202f.) So erklärt sich, dass sich bei Schwulen eine Subkultur herausbildete, die bestimmte ästhetische Codes entwickelte. Diese Heterosexuellen im Allgemeinen unbekannten Codes erfüllten einerseits den Zweck der leichteren Erkennbarkeit der Schwulen untereinander - sie ließen sich bis zur Signalisierung bevorzugter sexueller Praktiken ausdifferenzieren -, andererseits den Zweck des Community Building: Gemeinsame Codes schweißen eine Szene, deren Mitglieder sich im Alltag nicht zueinander bekennen dürfen, zusammen. Beiden Zwecken ist gemeinsam, dass sie als Nebenprodukt eine schwule Identität hervorzubringen halfen, die sich stark über ästhetische Merkmale definiert. Welche Rolle spielt nun schwule Pornografie in der Hervorbringung dieser Identität?

Pornografie bietet dem Begehren, das die sexuellen Normen der Gesellschaft überschreitet, eine Plattform. Wenn Mainstream-Pornos zeigen, was sich Hetero-Männer heimlich wünschen, zeigen schwule Pornos natürlich eine ganze Palette idealisierter Männlichkeiten und, ebenfalls wichtig, detaillierte schwule Sexualpraktiken. Dies ist deshalb keine Banalität, weil Wissen über schwule Sexpraktiken in der Öffentlichkeit kaum zirkuliert, außer als Diffamierung. Nun könnte man sagen, hier bestehe keine große Differenz zur heterosexuellen Pornografie, die ebenfalls idealisierte Frauenbilder zeigt plus Praktiken, über die in der Gesellschaft ebenfalls nicht offen gesprochen wird. Der Unterschied liegt darin, dass für heterosexuelle Männer Pornografie sozusagen die schmutzige Seite der Sexualität repräsentiert, sie leben im Alltag eine durch bestimmte Normen sanktionierte Form der Sexualität und überschreiten deren Grenzen im Geheimen durch Pornografie. Da für Schwule der gesamte Bereich ihrer Sexualität von der symbolischen Herrschaft zur Unsichtbarkeit verurteilt wurde, war es möglich, ein ungebrochenes Verhältnis zur entsprechenden Pornografie zu entwickeln. Zum Ursprung der Stigmatisierung der Homosexuellen meint Bourdieu:

Es ist die Besonderheit dieser symbolischen Herrschaftsbeziehung, dass sie nicht mit den wahrnehmbaren Geschlechtsmerkmalen, sondern mit der Se- 
xualpraxis zusammenhängt. Die herrschende Definition der legitimen Form dieser Praxis als einem Verhältnis der Herrschaft des männlichen Prinzips (aktiv, penetrierend) über das weibliche Prinzip (passiv, penetriert) impliziert das Tabu der in die homosexuelle Beziehung eingezeichneten Feminisierung als Sakrileg am Männlichen, d.h. am herrschenden Prinzip. (Ebd., S. 203)

Bourdieus Befund ist, dass gerade die sexuellen Praktiken der Schwulen mit dem für die männliche Herrschaft unannehmbaren Einnehmen der sexuell passiven Rolle durch einen Mann der Grund für die kollektive Stigmatisierung sind. Daraus folgt, dass die Zelebrierung ebendieser Praktiken in der Pornografie geradezu konstitutiv für die Herausbildung einer schwulen Identität sein musste. Schwule Pornos stellen demnach eine Heterotopie dar, sie sind wie bestimmte Saunas, Parks oder Darkrooms eine Parallelwelt, wo alle Männer für sexuelle Praktiken verfügbar sind, die in der Gesellschaft tabuisiert werden, eine Fantasiewelt, wo schwules Begehren keinen gesellschaftlichen Einschränkungen unterliegt. Damit vermitteln Pornos eine virtuelle Heimat für schwule Identität. Wie wir bei Laqueur gesehen haben, kann die Masturbationspraxis einen Weg für marginalisierte Gruppen darstellen, sich mit ihrer abgewerteten Sexualität zu versöhnen und ein positives Selbstbild zu entwickeln.

Die Wichtigkeit der Pornografie für die Herausbildung einer schwulen Identität beschreibt der Literaturwissenschaftler Michael Warner folgendermaßen:

In order for the porn to exist, not only did some of its producers have to have gay sex, they and many others had to acknowledge that they were having it. What is traded in pornographic commerce is not just speech, privately consumed; it is publicly certifiable recognition. This is part of the meaning of every piece of porn, and what is difficult to communicate in the dominant culture is that the publicity of porn has profoundly different meanings for nonnormative sex practices. When it comes to resources of recognition, queers do not begin on a level playing field. (Warner 1999, S. 184f.)

Pornos stellen für Schwule eine materialisierte Form der Anerkennung ihrer sexuellen Praktiken und damit ihrer sexuellen Identität dar. Damit leisten Pornos eine Vermittlungsarbeit, die permanent die Grenze zwischen als asexuell konstruierten Staatsbürgern und sexuellen Subjekten überschreitet. Sie vermittelt zwischen einer gesellschaftlich konstruierten Aufspaltung je- 
des einzelnen Menschen in einen sexlosen Staatsbürger für die Öffentlichkeit und in ein sexuelles Subjekt für den privaten Raum. Sie unterhöhlt so eine kollektive Amnesie: »These twin fantasies, of dead citizens and sexual subjects, require massive and complementary amnesias. Citizens must routinely forget everything they know about sex. And sexual subjects must routinely forget everything they know about public culture.« (Ebd., S. 184)

Warner beklagt in The Trouble with Normal eine Desexualisierung der Schwulenbewegung infolge des Kampfes um bürgerliche Rechte und gesellschaftliche Anerkennung. Betrachten wir diesen Prozess noch etwas genauer. Denn er scheint ja konträr zu dem parallel stattfindenden Prozess der Pornografisierung zu verlaufen. Wie hängen die beiden Prozesse zusammen? Schwule sind aus dem Blickwinkel der heteronormativen bürgerlichen Gesellschaft das personifizierte Sexuelle, Nichtbürgerliche. Zur Erlangung bürgerlicher Rechte hat die Schwulenbewegung diese explizite Gleichsetzung von Schwulsein und Sexualität gekappt und Schwule als seriöse Staatsbürger präsentiert, sodass ihnen diese Rechte nicht mehr verwehrt werden konnten. Doch die bisher in der Figur des Schwulen verkörperte und ausgegrenzte Sexualität sucht nun die bürgerliche Gesellschaft als Gespenst der Sexualisierung heim.

Schwule Pornografie zeichnet sich dadurch aus, dass sie sehr eng mit einem Emanzipationsprojekt verknüpft worden ist. Wie andere Emanzipationsdiskurse auch will die Homosexuellenbewegung, gestützt auf ein liberales Menschenbild, gegen bestehende Ungleichheiten ankämpfen. Horkheimer und Adorno zeigen auf, wie solche Emanzipationsdiskurse totalitär werden. Wie sieht dies im Falle des schwulen Emanzipationsdiskurses aus? Die Homosexuellenbewegung fordert gleiche Rechte und Schutz vor Diskriminierung für Homosexuelle auf dem Hintergrund der liberalen Prämisse, dass alle Menschen gleichwertig sind, ungeachtet ihrer sexuellen Präferenzen. Diesem Diskurs um Rechte und Antidiskriminierung ist eine solche liberale Anthropologie sicher dienstbar, sie riskiert allerdings die Verwischung von Unterschieden innerhalb der Homosexuellenbewegung: »Bezahlt wird die Identität von allem mit allem damit, dass nichts zugleich mit sich selber identisch sein darf. Aufklärung zersetzt das Unrecht der alten Ungleichheit, das unvermittelte Herrentum, verewigt es aber zugleich in der universalen Vermittlung, dem Beziehen jeglichen Seienden auf jegliches." (Horkheimer/Adorno 1969, S. 18) Horkheimer und Adorno kritisieren an Emanzipationsdiskursen eine Gleichmacherei, welche die je eigene Identität des befreiten Subjekts aufhebt. »Den Menschen wurde ihr Selbst als ein je eigenes, von allen anderen 
verschiedenes geschenkt, damit es desto sicherer zum gleichen werde. Weil es aber nie ganz aufging, hat auch über die liberalistische Periode hin Aufklärung stets mit dem sozialen Zwang sympathisiert.« (Ebd., S. 19)

Über sozialen Zwang und Konsum findet eine Normierung der Subjekte statt, welche die Homosexuellen gesamtgesellschaftlich als negativ erfahren. Ihr Befreiungsdiskurs in Form der Homosexuellenbewegung hat jedoch unter den Homosexuellen zur selben Gleichmacherei geführt, die gesamtgesellschaftlich kritisiert wird. Diese Gleichmacherei funktioniert einerseits über sozialen Druck, indem bestimmten Idealen entsprochen werden muss, um akzeptiert zu werden. Andererseits funktioniert sie über Konsum, indem auf dem Markt der Identitäten auch die schwule Identität im Angebot ist, in Form von Statussymbolen, Kleidung, Lifestyle und Fitnessabo zu erwerben.

Eines der Anliegen der Queer Theory ist deshalb der Widerstand gegen Kategorisierungen und Klassifikationen. Horkheimer/Adorno schreiben dazu: "Klassifikation ist Bedingung von Erkenntnis, nicht sie selbst, und Erkenntnis löst die Klassifikation wiederum auf.« (Ebd., S. 231) Darin ist treffend ein bereits angesprochenes Dilemma der Homosexuellenbewegung artikuliert. Um im Kampf gegen Diskriminierung überhaupt sichtbar zu werden, müssen Homosexuelle ihre Gemeinsamkeit zur Klasse zusammenschließen. Diese Klassifikation führt dank der gesellschaftlichen Sichtbarkeit nach langem Kampf eventuell zum Abbau von Diskriminierungen. Auf der Strecke bleiben dabei aber individuelle Besonderheiten der betroffenen Subjekte. »Was vielen Einzelnen gemeinsam ist, oder was im Einzelnen immer wiederkehrt, braucht noch lange nicht stabiler, ewiger, tiefer zu sein als das Besondere.« (Ebd.)

Durch verschiedene Faktoren bedingt, lässt sich im Bereich der SchwulenPornos eine gewisse Parallelität zum Kampf der Schwulenbewegung um gesellschaftliche Akzeptanz erkennen. Während in den Schwulen-Pornos der 1960er-Jahre noch ein eher zufälliges Durcheinander von Looks, Körpern und Praktiken herrschte, setzte in den 8oern eine Normierungswelle ein. Die hat mit dem Aufkommen der VHS-Kassetten zu tun, die aus einem szeneinternen Untergrundphänomen eine Massenware machte, die sich jedermann diskret nach Hause bestellen konnte. Interessanterweise geschah dies zeitlich parallel zum vermehrten An-die-Öffentlichkeit-Treten der Schwulen und der Schwulenbewegung. Das Aufkommen von Aids war hier ein wichtiges Bindeglied. Auf der politischen Ebene haben die Aidspanik und die sie begleitende Stigmatisierung der Schwulen zu einem Strategiewechsel innerhalb der Schwulenbewegung geführt. Um die im wörtlichen Sinne tödliche Stigmati- 
sierung zu bekämpfen, mussten die Schwulen ihre Anliegen vermehrt an die breite Öffentlichkeit tragen, ihr Privatleben öffentlich machen. Dieser Gang an die Öffentlichkeit hatte eine gewisse Normalisierung, aber auch Normierung dessen zur Folge, was als schwule Identität lebbar war, da ein gewisser Teil der schwulen Subkultur diesen Gang an die Öffentlichkeit nicht mitmachen konnte oder wollte. Kulturell hatte die Aidspanik bei den Schwulen einen verstärkten Schönheits-, Körper- und Fitnesskult zur Folge, da man bestrebt war, gegenüber der tödlichen Bedrohung durch Aids das gesunde und unversehrte Aussehen des Körpers zu betonen; sexuell hatte die Aidspanik einen Aufschwung der Masturbation zur Folge, da die Frage nach safen sexuellen Praktiken längere Zeit ungeklärt war. Entsprechend stieg auch die Bedeutung der Pornografie für Schwule nochmals an.

Der All-American Boy, der mit seiner jugendlichen, properen Fitness die Schwulen-Pornografie der 8oer-Jahre dominiert hatte, machte in den 9oerJahren wieder einer größeren Vielfalt an Pornodarstellern und ausgeübten Praktiken Platz. Insbesondere das Aufkommen des Internets machte es nochmals leichter, auf den individuellen Geschmack zugeschnittene Pornografie zu finden. Doch allein durch die Erweiterung der Palette an Identitätsangeboten nahm der Normierungsdruck auf die Schwulen nicht automatisch ab. Parallel hatte die Schwulenbewegung in Sachen gesellschaftliche Anerkennung erste große Erfolge zu verzeichnen, die den Normierungsdruck, der auf den Schwulen lastete, wieder ein wenig lockert. Ein von der Schwulenbewegung vermitteltes sozusagen offizielles Bild von schwuler Identität und schwulen Beziehungen bestand zwar fort, doch daneben gab es mehr Spielraum für Diversität. Mit der Entwicklung von Medikamenten, die eine HIV-Infektion zu etwas machten, was sich managen lässt, und dem Erlangen eines rechtlichen Status für homosexuelle Beziehungen kam es dann in den Nullerjahren des 21. Jahrhunderts in der Schwulen-Pornografie zum Tabubruch: Erstmals seit Mitte der 8oer wurden wieder schwule Pornos produziert, in denen die Darsteller keine Kondome verwenden. Heute macht die sogenannte BarebackPornografie einen großen Teil des Markts für schwule Pornografie aus. Im Sinne des transgressiven Charakters der Pornografie erstaunt dieser Erfolg nach Jahren der Safer-Sex-Propaganda nicht.

Empowerment ist also ein wichtiger Faktor in der Schwulen-Pornografie. Einerseits macht schwule Pornografie sexuelle Akte, die in der Gesellschaft lange Zeit stigmatisiert waren und als verworfen galten, sichtbar und präsentiert diese als lustvoll. Der Zelebrierung solcher Akte kann ein bestärkender 
Effekt auf Männer mit einem Wunsch nach diesen Akten kaum abgesprochen werden.

Gleichzeitig hat die Hypermännlichkeit und Hypersexualität der Schwulen-Pornos die Ästhetik der Schwulenszene derart stark geprägt, dass ein abschreckender Effekt auf Schwule, die diesen ästhetischen Standards nicht entsprechen, ebenfalls sehr wahrscheinlich ist. Der Medienwissenschaftler Sharif Mowlabocus bejaht zwar grundsätzlich das politische Potenzial der schwulen Pornografie, einer verworfenen Minderheit ein positives Selbstbild zu vermitteln. Die Auswirkungen der realen schwulen Mainstream-Pornografie auf das schwule Durchschnittsleben stimmen ihn weniger optimistisch. Dies zeigt er am Beispiel des Datingportals Gaydar. Auf Gaydar erstellen Schwule analog zu anderen Datingsites Profile von sich selbst. Dazu müssen sie sich anhand vorgegebener Kategorien selber beschreiben und einstufen, die aus der schwulen Mainstream-Pornografie entlehnt sind. Dabei geht es sowohl um äußerliche Merkmale wie auch um sexuelle Vorlieben, Praktiken und Fetische. Diesen Prozess beschreibt Mowlabocus so:

In authoring a profile, which then becomes his online persona, the gay man subjects himself to a discursive machinery that fragments, analyses, codifies and evaluates him. This surveillance apparatus is a knowledge machine and its aim is to identify the male subject through a specifically erotic knowledge established within the arena of commercial gay male pornography. (Mowlabocus 2007, S. 70)

Wer sich nicht den Kategorisierungen der Pornowelt unterwerfen möchte, kann sich zwar sehr wohl bei Gaydar anmelden, er bleibt jedoch für die Suchfunktionen und Ratings des Portals weitgehend unauffindbar, seine Sichtbarkeit ist deutlich eingeschränkt. Subjektivitäten außerhalb des MainstreamPornos wie zum Beispiel körperlich Behinderte oder Übergewichtige, die ja vielleicht besonders froh um den Service eines Datingportals wären, werden bereits durch die Vorgaben des Portals zur Selbstbeschreibung unsichtbar gemacht. Daraus zieht Mowlabocus den ernüchternden Schluss:

Gay-porn is securing the perimeters of gay identity, forming ever more impenetrable boundaries and validating a set of identifications and practices at the expense of all others. If the potential of homosexual pornographies is to queer reality, then the reality of gay-porn serves to condense homosexual- 
ity into a single overarching identity; one that does little to challenge hegemonic norms or to liberate sexuality. (Ebd., S. 71)

Im Überschreiten der heterosexuellen Matrix kann schwule Pornografie offenbar schwule Identität bestärken. Damit geht jedoch das Problem einher, dass in diesem identitätsbestärkenden Effekt das eigentlich Transgressive der schwulen Pornografie wieder verlorengeht: Im Überschreiten der Grenzen der sexuellen Identität werden neue Grenzen gezogen. Damit hat schwule Pornografie ebenso normierende Auswirkungen wie heterosexuelle MainstreamPornografie. Wie lässt sich der transgressive Charakter der Pornografie anders nutzen? Mit Camp schauen wir uns im Folgenden eine mögliche Strategie dazu an.

\subsubsection{Camp als politisch-ästhetische Strategie}

Der Kulturwissenschaftler Nathan Scott Epley analysiert einen bereits unter dem Stichwort Porn-Chic angesprochenen Aspekt der Pornografisierung: die Beliebtheit nostalgischer Darstellungen von Pin-up-Girls auf Plakaten und Alltagsgegenständen bei einem jungen, urbanen Publikum. Dieses Publikum hält meist eine ironische Distanz zu den Darstellungen, da es um den Sexismus der Darstellungen weiß, sich jedoch eben aufgrund dieses Wissens in ihrer Wertschätzung der Darstellungen von Sexismus frei glaubt: »Hipster consumers appreciate these lowbrow, mass-produced and unavoidably sexist remnants of 1940s' and 1950s' culture despite, and even, because, they know better. «(Epley 2007, S. 46) Eine solche ironisch-affirmative Haltung zu Kitsch, Konsum und Massenkultur nennt Epley mit Bezug auf Susan Sontag Camp. Eine solche Haltung läuft ihm zufolge jedoch immer Gefahr, sich apolitisch und unkritisch konsumbejahend auszuwirken und letztlich $\mathrm{zu}$ Zynismus zu führen. Epley schlägt stattdessen vor, den Retro-Chic der Pin-ups als eine Form von Drag im Butler'schen Sinne wahrzunehmen: »In their excessive idealization of femininity, pin-ups display women in drag as girls - or, rather, the impossible dream girls of industrial popular culture. The secret is in the mix, the pastiche of familiar conventions of female beauty - classic pin-up iconography - combined with elements taboo to dominant ideologies of gender and sexuality.« (Ebd., S. 56f.) Neben Drag ist Camp ein oft zitiertes Beispiel für queere Strategien zur Transformation der Gesellschaft. Im Folgenden möchte ich versuchen, den kritischen Gehalt von Camp und seine Brauchbarkeit für alternative Pornografie herauszuarbeiten. 
Der Filmwissenschaftler Matthew Tinkcom (2002) sieht Camp als eine Möglichkeit der kritischen Antwort auf die Erfahrungen der Moderne: Damit unterstellt er dem Phänomen Camp eine politische Wirksamkeit. Dies ist deshalb ein bemerkenswertes Vorhaben, weil Camp von marxistischer Seite die gegenteiligen Attribute zugeschrieben werden. Durch seine Nähe zum Kitsch sei Camp eine rein ästhetische Angelegenheit, seine spielerische Art könne keine ernsthafte Kritik artikulieren und sein affirmativer Gehalt mache ihn letztlich zum Verteidiger des Status quo. Analoge Vorwürfe werden von marxistischer Seite der Strategie Drag entgegengebracht.

Was unterscheidet denn Camp von Kitsch? Kitsch ist vermutlich das Endprodukt der Kulturindustrie als Massenbetrug, wie sie Horkheimer und Adorno in Dialektik der Aufklärung verstehen. Im Kitsch ist Kunst zur konventionalisierten, marketingtauglichen Ware geronnen. Dem kitschigen Produkt entspricht eine kitschige Haltung auf der Rezeptionsseite. Statt als Einzelner von authentischer Kunst ergriffen zu sein, kauft der Kitschkonsument sich ein Gefühl und die Zugehörigkeit zu einer Gruppe, die dasselbe fühlt. Ein Beispiel: Nach dem tödlichen Unfall von Lady Diana nahm der Sänger Elton John eine Neuversion seines ursprünglich anlässlich des Todes von Marilyn Monroe geschriebenen Songs Candle in the Wind auf. Sie wurde innert Kürze zur weltweit meistverkauften Single aller Zeiten. Der Kauf dieser Single war für sehr viele Menschen ein Weg, ihre Trauer über den Tod von Lady Diana auszudrücken und sich darin mit anderen Menschen verbunden zu fühlen eine Trauer über den Tod einer Person, die die meisten nur über die Medien kannten. Diese medial erzeugte Trauer wurde durch den Kauf eines Produkts verarbeitet, das in diesem speziellen Fall sogar noch die Kopie eines früheren zu ähnlichem Zweck produzierten Songs war. Das ist Kitsch, legitimiert durch den wohltätigen Zweck, für den die Einnahmen aus dem Verkauf der Single verwendet wurden.

Was ist dagegen Camp? Camp ist laut Tinkcom der Name für ein Produkt queerer Arbeit. Queere Arbeit sei Arbeit, die von Individuen verrichtet werde, die sich selbst als queer bezeichnen oder von anderen so bezeichnet worden seien. Für unsere Frage nach alternativen Pornografie-Konzepten ist dies deshalb interessant, weil Tinkcom beschreibt, wie sich eine queere Identität in Arbeitserzeugnissen ausdrückt. Seine Grundfrage ist: Kann ein queeres Individuum den Erzeugnissen seiner Arbeit einen queeren Stempel aufdrücken und wenn ja, auf welche Weise geschieht das?

Tinkcoms These ist: Es gibt klar als solche erkennbare queere Arbeitserzeugnisse. Den Nachweis dafür versucht er zu erbringen in einer Analyse der 
Werke, der Arbeitsweise und der Arbeitsbedingungen von vier queeren Regisseuren: Vincente Minnelli, Andy Warhol, Kenneth Anger und John Waters. Jedoch geht es Tinkcom nicht bloß um eine spezifisch schwule Filmästhetik. Er möchte den Begriff Camp aus einem rein ästhetischen Diskurs herauslösen und ihn im Rahmen einer Theorie der Arbeit und der kulturellen Produktion reformulieren. Dabei bedient er sich bei Marx. Camp ist laut Tinkcom nicht bloß ein Spiel mit kulturellen Interpretationen von Geschlechterdifferenz. Nach Marx liege es ganz grundsätzlich im System des Kapitalismus, künstlich Differenzen zu erzeugen, um den Konsum anzukurbeln. Die Ästhetik der Filme von Minnelli, Warhol, Anger und Warhol sei deshalb Camp, weil sie die Künstlichkeit dieser Differenzen sichtbar mache und so den Warencharakter des Films unterstreiche. Dies geschehe inhaltlich durch parodistische Übertreibung von Differenz und formal durch ästhetische Exzesse. Was heißt das in Bezug auf die einzelnen Regisseure, und wie steht es um die politische Wirksamkeit solcher Strategien?

Vincente Minnelli habe seine Filme, so Tinkcom, in einer Situation gedreht, die es dem Regisseur schwergemacht habe, eine eigene Handschrift in die Filme einzubringen. Im Hollywood der 1940er- und 1950er-Jahre seien die Regisseure einem rigiden Studiosystem unterworfen gewesen, in dem die produzierenden Studios vom Drehbuch bis zum Casting einem Regisseur im Prinzip den Film diktierten. Den Schauspielern sei aufgrund der Vermarktung der Filme über das Starsystem mehr Aufmerksamkeit geschenkt worden, die Regisseure hingegen seien als Angestellte gesehen worden, die einen Auftrag auszuführen hatten. Erschwerend sei die staatliche Zensur ins Gewicht gefallen, welche auf der Narrations- und auf der Darstellungsebene den Spielraum für Regisseure sehr eng gemacht habe.

Minnellis Leistung sieht Tinkcom nun darin, dass er unter solchen Bedingungen dennoch in seinen Filmen eine gewisse Ambiguität der Geschlechterrollen kenntlich machen konnte. Dies sei Minnelli in Musicals wie Zigfield Follies oder The Pirate gelungen. Das Musical sei bei Minnelli eine Kunstform zur Umgehung von Zensur; dafür biete sich das Musical an, weil darin die von der Zensur besonders kritisch beobachtete Narration durch Musicalnummern unterbrochen werde. In diesen Musicalnummern werde ein Exzess der Darstellung möglich, der auf Narrationsebene nicht toleriert werden würde. Musik, Songtexte, Choreografie, Kostüme und Ausstattung: All das liege nicht im primären Fokus der Zensur. Bei Minnelli beschwörten die Songs und die exzessive Mise en Scène - Minnelli war ursprünglich Schaufensterdekorateur und Bühnenbildner - eine Welt der sexuellen Möglichkeiten herauf, die au- 
Berhalb der Musicalnummern in der streng auf heterosexuelle Romanze getrimmten Storyline keinen Platz habe. Camp liege in Minnellis Filmen in dieser Spannung zwischen dem exzessiven Surrealismus der Musicalnummern und dem Mainstream-Realismus des Erzählungsstrangs.

Minnelli und sein Team entwickelten so Camp als subversive Strategie gegen die Normierungsmacht der Politik und des Kapitals. Da Camp sich den Kontrollmechanismen dieser Mächte entzieht, liest Tinkcom Camp auch als Signal einer Krise des Kapitals. Minnellis experimentellste Filme in Richtung Camp seien denn auch finanzielle Flops gewesen, erst mit deutlich konventionelleren Filmen wie An American in Paris oder Gigi habe er wieder das ganz große Publikum erreicht.

"Warhol's movies are about the critical, camp act of watching movies." (Tinkcom 2002, S. 80) Mit diesem Schlüsselsatz zu Andy Warhol deutet Tinkcom eine Akzentverschiebung an. In Minnellis Filmen manövriert ein Team von versteckt sexuell ambivalenten Filmschaffenden über einen Exzess in der Mise en Scène versteckte Botschaften sexueller Ambivalenz an der Zensur vorbei zu ebenfalls versteckt sexuell ambivalenten Zuschauern. Camp ist darin eine Maskerade, die eine Krise der Heteronormativität im kapitalistischen Hollywood-Starsystem gleichzeitig verdeckt und zugleich enthüllt. Warhols Filme entstehen laut Tinkcom nun genau aus dem Blickwinkel des sexuell ambivalenten Zuschauers, der einerseits vom Glamour des Starsystems magisch angezogen werde, andererseits kritisch auf die damit verbundene Heteronormativität reagiere. Die Thematisierung von Glamour sei für queere Filmemacher deshalb so attraktiv, weil Glamour den Filmstar für einen Moment aus der heteronormativen Narration herausreiße in eine überzeitliche, mythische Ebene. Die Verehrung von schwulen Fans für weibliche Stars gründe darin, dass diese den Aufstieg aus einer sozial benachteiligten, über ihr Geschlecht definierten Rolle zu einem außerhalb alltäglicher, heteronormativer Zwänge stehenden Mythos geschafft hätten. Dieser Aufstieg bleibe dem Durchschnittsschwulen von der Straße, der dauernd über seine Sexualität definiert werde, versagt.

Indem nun Warhol Alltagsgegenstände, Alltagshandlungen und beliebige Freunde und Gäste aus seiner Warhol-Factory ins Zentrum seiner Filme rückt, leisten diese Filme laut Tinkcom eine Reflexion über Glamour - darüber, wie Glamour erzeugt wird und welche Arbeit dahintersteckt. Sie seien deshalb sowohl als Tribut wie als Kritik an Hollywoods Starsystem lesbar. Camp bezeichne in Warhols Filmen die Spannung zwischen dem Feiern des Startums und dessen gleichzeitiger Dekonstruktion durch das Transparentmachen sei- 
ner Produktionsmechanismen. In Warhols Filmen arbeiteten ständig Leute daran, Stars zu werden, und scheiterten. Camp ist die Feier dieses Scheiterns.

In Kenneth Angers Filmen wird laut Tinkcom Camp als Mittel eingesetzt, um die Zusammenhänge zwischen Männlichkeit, Objektfetischismus und Faschismus aufzuzeigen, und John Waters erzeuge in seinen Trash-Filmen Camp durch die Verlegung des Hollywood-Melodrams in eine Sphäre der Kleinbürgerlichkeit, wo ein hysterischer Kampf gegen Schmutz, Verbrechen und Perversion gekämpft und verloren werde.

Was ist nun aber die politische Wichtigkeit von Tinkcoms Theoretisierung von Camp? Welche Hilfestellung bietet Camp für alternative PornografieKonzepte? Diese Fragen lassen sich über einen Vergleich beantworten. Obwohl Tinkcom in seinem Buch die Werke von vier schwulen Filmemachern untersucht, heißt dies nicht, dass alle Filme von schwulen Filmemachern notwendigerweise Camp sind. Noch viel weniger sind Filme, die Homosexualität thematisieren, notwendigerweise Camp. Viele der in den letzten zwanzig Jahren unter dem Label Schwulenfilm realisierten Filme - seien es die AidsDramen der späten 8oer- oder die Coming-out-Komödien der 9oer-Jahre haben höchstens am Rande mit Camp zu tun; ihr Hauptanliegen ist es, Sympathie für eine sexuelle Minderheit zu wecken. So wichtig diese Filme für das Selbstverständnis der Homosexuellen und deren bessere Anerkennung in der Gesellschaft sind und waren, ihre Narration ordnet sich einem heteronormativen Muster unter. Ihr Ziel ist eher die Versöhnung mit der bestehenden Ordnung als die Transformation derselben. Das gilt auch für schwule Pornografie. So wichtig sie für das schwule Selbstverständnis ist, ordnet sie sich oft dem heteronormativen Muster der Mainstream-Pornografie unter.

Tinkcom macht klar, dass das Ziel von Camp im Film nur das Enthüllen von Heteronormativität und deren Funktionieren in Abhängigkeit vom Kapital sein kann. Camp reflektiert, wie in einem kapitalistischen Gesellschaftssystem Wert erzeugt und entlang heterosexuell geprägter Leitlinien distribuiert wird. Diese Reflexion ist für alternative Pornografie interessant, wenn sie auf einer grundlegenden Ebene Gerechtigkeitsfragen und Identitätsfragen unter den Bedingungen einer heteronormativ strukturierten Gesellschaft thematisieren will. Camp zeigt auf, wie Heteronormativität über die Verleihung von Wert stabilisiert und an Erzeugnisse der kapitalistischen Warenwelt gebunden wird. Zusätzlich gibt Camp ein Beispiel dafür ab, wie sich dieser Heteronormativität des Kapitals etwas entgegensetzen lässt. Beides sind wichtige Lektionen für eine alternative Pornografie mit Ambitionen zu politischer Veränderung. Die Post-Pornografie wird diese Lektionen aufnehmen, verbin- 
det sie aber mit queeren Körper- und Identitätskonzepten. Schauen wir uns deshalb als Nächstes Transgender-Körper in der Pornografie an.

\subsubsection{Transgender-Körper in der Pornografie}

Bereits bei Butler haben wir Transmenschen als Akteure der Verflüssigung von binären Geschlechtsidentitäten kennengelernt. Auch der Queertheoretiker Tim Stüttgen sieht in der Materialisation von Transgender-Körpern und der performativen Herstellung von Männlichkeit oder Weiblichkeit im Rahmen von Drag einen Paradigmenwechsel in den Machtverhältnissen zwischen den Geschlechtern. Pornografie könne hier eine entscheidende Rolle spielen: "It seems to be the case today that post-porn is for the most part reactualized through the strategies of drag and prosthetics, genderfucking, and transgender experience.«(Stüttgen 2009, S. 16) Dass Pornografie eine Rolle in Emanzipationsbewegungen spielen kann, haben wir am Beispiel der schwulen Pornografie analysiert. In einem weiteren Bereich der alternativen Pornografie drücken sich Transmänner aus. Transmänner sind Personen mit einer männlichen Geschlechtsidentität, die jedoch mit einem biologisch weiblichen Körper zur Welt gekommen sind. Die Körper der Transmänner können sich durch Einnahme von Hormonen oder operativen Eingriff, aber auch durch Muskeltraining, Haarschnitt, Kleidung auf ganz verschiedenen Stadien auf dem Weg zu einem Männerkörper befinden, ohne dass dieser als Endpunkt notwendigerweise angestrebt wird.

Erstaunlicherweise waren Transmänner in der Geschichte der Pornografie bisher kaum präsent - im Gegensatz zu Transfrauen, die eine konstante Rolle in der pornografischen Imagination spielen. Auch der der Pornografie benachbarte Bereich der Prostitution ist traditionell ein Arbeitsfeld für Transfrauen. Während der Körper von Transfrauen also in der kollektiven sexuellen Fantasie seinen Platz hat, scheint es einen solchen Platz für Transmänner noch nicht zu geben.

Wieso machen Transmänner Pornografie? Meine Vermutung ist, dass im Zuge der heutigen Aufweichung der starren Geschlechterbinaritäten Transmänner ihren Körper nicht mehr als defizient sehen, sondern vermehrt sein lustvolles Potenzial einsetzen und erfahren wollen. Es geht also darum, die eigene Körperlichkeit in ein sexuell stimulierendes Szenario einzubetten. Aber wer soll hier sexuell stimuliert werden? Wenn wir an Michael Warners Erklärung der Existenzberechtigung von schwuler Pornografie zurückdenken, müssten es in erster Linie andere Transmänner sein, deren Körper bisher in 
pornografischen Szenarien fehlten und entsprechend in einer öffentlichen sexuellen Imagination nicht vorhanden waren. Es sind wohl aber auch weitere aufgeschlossene Pornografiekonsumenten egal welcher sexuellen Identität und Orientierung. Da sich Fantasien nicht streng an Kategorien halten, bieten Pornos mit Transmännern neue Bilder, also neues Wissen über Körper und Lust an.

Lässt sich also aus Pornos mit Transmännern ein utopisches Ideal der Pornografie herauslesen? Wie bei der schwulen Pornografie bestünde dieses einmal darin, dass Menschen anderen Menschen freiwillig ihr Wissen über Lust zur Verfügung stellen. Die Empfänger dieses Wissens gewinnen ein positives Körperbild und mehr Kenntnisse über dessen lustvolles Potenzial. Pornografie motiviert sie im doppelten Sinne zu einer erotischen Selbsterfahrung: erstens ganz direkt über Selbstbefriedigung beim Konsumieren des pornografischen Materials, wo an körperlichen Reaktionen unmittelbar ablesbar ist, was erregt und was nicht; zweitens speichern sich diese Erfahrungen und das Nachdenken darüber als neues Wissen über sich selbst und Sexualität ab.

Doch erotische Darstellungen transsexueller Körper bringen auch landläufige Vorstellungen von Körperlichkeit und Alter durcheinander. Darauf weist der Performance-Künstler Tobaron Waxman in einem Interview hin:

One of the realities of transmasculine embodiment is that the individual finds himself ambiguously aged as well, and can look like a so-called "youth « until he is years into his transition. This evokes complex power dynamics of implied age difference between the people in the video. The resulting image is ambiguously legal, as transgender and gender deviance embodied call into question whether or not someone who looks like a minor has a legal right to be sexualized on camera. (Waxman 2009, S. 337)

Die Verwirrung, die transsexuelle Körper auf die Porno-Leinwand bringen, beschränkt sich also nicht nur auf Geschlechter, deren Rollen und Sexpraktiken, sie schlägt sich als Diskontinuität auch auf das Alter der Performer nieder, das der Betrachter nicht mehr mit ihren Körpern in Übereinstimmung bringen kann. Damit konfrontiert Transmänner-Pornografie den Betrachter gleich mehrfach mit Tabus.

Waxman berichtet über den Dreh eines pornografischen Kurzfilms, der mitten in einer gespielten Vergewaltigungsszene unterbrochen werden musste, worauf die drei Darsteller sich in einer Art Nachsorge oder Anschlussprogramm liebevoll umeinander kümmerten. Da Waxman die Kamera auch 
während des Unterbruchs laufen ließ, entsteht mitten im Porno ein Bruch, der eine nicht inszenierte Art der Sexualität sehen lässt.

The result is that the viewer simultaneously remembers and forgets that one is watching a tape from a safe distance. This is all complicated by the fact that the players are non-actors, which creates a kind of realism, and that they are all transsexual men, in different states of transition. This means that they to varying degrees appear male, androgynous, and youthful. The viewer is put in a position of questioning their role in violence and consent, as well as their part in determining the gender identity of the players. (Ebd., S. 338)

Waxman betont allerdings neben dem kritischen oder verstörenden Potenzial der Post-Pornografie auch ihr Potenzial für Schönheit und Ermutigung: »JJ Bitch, the Bottom in the scene, said that watching the uncut footage immediately following the shoot was the first time he ever felt beautiful.« (Ebd., S. 338f.) Die Analyse pornografischer Äußerungen sexuell marginalisierter Subjekte lässt also Folgendes erkennen: Ohne greifbare Bilder der kollektiven sexuellen Imagination ist es schwierig, den eigenen Körper als sexuell und damit potenziell lustvoll wahrzunehmen. Das Produzieren solcher Bilder kann also als eine Form von Sexaktivismus verstanden werden, da sie zu einer positiven Körperwahrnehmung und einem positiven Selbstbild motivieren. Diese Bilder produzieren neues Wissen über Körper und ihre Lüste. Sie verwirren aber auch nachhaltig festgefügte Vorstellungen über Körperbilder, Geschlecht, sexuelle Orientierung und Alter.

Bevor ich diese Überlegungen zu Transgender-Körpern in der Pornografie in den theoretischen Rahmen der Post-Pornografie einbette, möchte ich noch auf einen oft übersehenen Punkt hinweisen. Weiter oben habe ich erwähnt, dass im Gegensatz zu Transmännern die Körper von Transfrauen schon lange einen festen Platz in der Pornografie haben. Ein Grund dafür ist sicher, dass in der Mainstream-Pornografie der nackte männliche Körper ein Problem für den meist männlichen, heterosexuellen Zuschauer darstellt und Weiblichkeit, auch wenn es Transweiblichkeit ist, einfacher in die erotische Fantasie integrierbar ist. Jedoch ist für mich die kontinuierliche Existenz von Transfrauen in der Pornografie ein Beleg dafür, dass auch Mainstream-Pornografie dem Zuschauer ein transgressives Erlebnis ermöglicht. Denn in der Darstellung des Transfrauenkörpers als begehrenswert werden die Grenzen der unseren Alltag strukturierenden heterosexuellen Matrix erotisch aufgeladen und überschritten. Nur wird im Alltag die Existenz nicht binären Begehrens margina- 
lisiert. Dagegen wehrt sich die Post-Pornografie, die sich explizit als politisch und subversiv versteht.

\subsection{Post-Pornografie}

\subsubsection{Ein subversives Potenzial}

In den letzten Jahren ist an verschiedenen Filmfestivals und Tagungen wie dem Pornfilmfestival Berlin oder den Porny Days in Zürich, aber auch in Publikationen die Forderung nach einer Pornografie mit einem subversiven Potenzial lautgeworden, das gegen die stereotypen Darstellungen von Sexualität in der Mainstream-Pornografie in Stellung gebracht werden könnte. Unter diesem subversiven Potenzial wird in der Regel der Versuch verstanden, die in der Queer Theory als instabil und angreifbar wahrgenommenen Geschlechternormen und sexuellen Rollenzuschreibungen auch in der Pornografie ins Wanken zu bringen - es wird ein queerer Porno angedacht.

Die Geschlechterforscherin Bettina Wilke bezieht sich direkt auf Judith Butlers für die Queer Theory konstitutive Theorie von Geschlechtsidentität als Performativität, wenn sie auf den performativen Charakter der Pornografie setzt, der wie die Drag-Performances bei Butler Möglichkeiten zur Resignifizierung von Geschlecht und Sexualität offenlässt. Sie schreibt:

Der Mainstream-Porno könnte durchaus genutzt werden, andere sexuelle Praktiken als die hegemonialen sichtbar zu machen, und da der Porno an sich performativen Charakter trägt, läge in ihm auch das Potenzial, durch Resignifizierung die heteronormative Ordnung zu queeren. Cerade die als verdoppelte Schauspieler entlarvten Darsteller des Mainstream-Pornos, die die Inszenierung der Inszenierung von Ceschlecht und Sexualität betreiben, könnten durch eine Umdeutung der einen Inszenierung - der des Pornofilms - auch die andere Inszenierung - die der gesellschaftlichen Ceschlechterverhältnisse - sichtbar machen. (Wilke 2004, S. 174)

Wilke beobachtet, dass in der Pornografie eine doppelte Inszenierung von Sexualität stattfindet. Sexualität werde im Porno filmisch in Szene gesetzt, darüber hinaus würden aber Geschlechterrollen und eine idealtypische Form der Sexualität inszeniert. Dieser doppelte Inszenierungscharakter der Pornografie macht es laut Wilke möglich, subversiv einzugreifen und so die Insze- 
niertheit der Sexualität im Porno selbst kenntlich machen. Ein Porno, der dies täte, wäre dann ein queerer Porno.

Der Begriff des queeren Pornos schleppt allerdings als Ballast die definitorische Unschärfe des Begriffs queer mit sich. Einerseits fungiert queer als Sammelbegriff für sexuelle Minderheiten, andererseits soll damit auch eine kritische und teilweise subversive Haltung gegenüber der herrschenden Geschlechterordnung signalisiert werden. Auf dieselbe Weise unklar ist deshalb, ob mit dem Begriff des queeren Pornos einfach Pornos von oder aus der Sicht von in der Mainstream-Pornografie nicht vertretenen sexuellen Minderheiten gemeint sein sollen oder ob damit auch eine kritische beziehungsweise subversive Haltung dieser Pornos angesprochen werden soll.

Als Label für eine kritische oder gar subversive Pornografie scheint mir deshalb der Begriff Post-Pornografie besser geeignet. Subversive Strategien sind ein wichtiger Bestandteil dessen, was Post-Pornografie ausmacht. Um zu einer Definition der Post-Pornografie zu gelangen, möchte ich deshalb zuerst klären, wo verschiedene Autoren subversives Potenzial in der Pornografie vermuten. Anschließend möchte ich die Definition des Queertheoretikers Paul B. Preciado von Post-Pornografie in Beziehung setzen zu dem von ihm entwickelten und postulierten Konzept der Kontra-Sexualität. Am Fallbeispiel des Herrenmagazins Playboy zeigt Preciado auf, wie Pornografie im Kapitalismus in ein ganzes Set architektonischer, ökonomischer und technologischer Strategien eingebettet ist. Es folgt eine Abgrenzung der Post-Pornografie von einigen anderen zum Mainstream alternativen Pornografien. Abschließend versuche ich dann alle an die Post-Pornografie gestellten Ansprüche in drei Kernelementen zu bündeln. Im Hintergrund steht für mich dabei immer die Leitfrage nach den transgressiven Aspekten der Pornografie und deren Einsatz in der Post-Pornografie.

Worin also besteht das in der Pornografie vermutete subversive Potenzial? Hier ein Vorschlag des Komparatistikers Martin Büsser:

Der reine Porno kennt hingegen keine Vor- und Nachgeschichte, zeigt wenig Interesse an Charakteren oder Individuen - genaue diese Eigenschaft, die immer wieder als sein Mangel bezeichnet wird, als seine filmische Minderwertigkeit, könnte vor dem Hintergrund queerer Diskurse aber auch seine Chance sein: Porno muss - genauer gesagt: müsste - seine Akteure nicht festlegen und hat oder hätte damit die Möglichkeit zum freien sexuellen Experiment, das keiner gesellschaftlichen oder biographischen Begründung bedarf. Dieser mögliche Freiraum von Porno als Überwindung der klassi- 
schen Erzählung und des Zwangs zur Begründbarkeit von Lust könnte subversives Potential haben und somit weit über die bisherige, Normen stabilisierende Funktion von Porno hinausgehen. (Büsser 2008, S. 85)

Büsser macht hier aus einer scheinbaren Schwäche der Pornografie eine Stärke: das Fehlen einer Einbettung der sexuellen Handlungen in eine glaubhafte Story oder deren mangelnde Anbindung an glaubhafte Charaktere. Im Vergleich zu anderen filmischen Genres schneidet in diesen Aspekten die Pornografie oft schlecht ab. Büsser dreht nun diesen Nachteil in einen Vorteil um: Gerade weil von der Pornografie keine Einordnung der sexuellen Akte in einen sinnstiftenden Zusammenhang erwartet wird, steckt in ihr die Möglichkeit zu sexuellem Experimentieren jenseits von gesellschaftlichen oder biografischen Logiken. Gesellschaftliche und biografische Zwänge stecken ja der eigenen Möglichkeit zu sexuellem Experimentieren Grenzen, da einem Individuum an jeweils einem bestimmten Punkt in seiner Biografie immer nur eine begrenzte Anzahl Formen von Sexualität persönlich möglich und sozial erlaubt sind.

Als Beispiel greift Büsser den Zwang zur Begründbarkeit der Lust heraus. Dieser Zwang sei einerseits ein gesellschaftlicher, da die Lust auf einen bestimmten Sexualpartner oder einen bestimmten sexuellen Akt, sobald sie öffentlich werde, einem Begründungszwang unterliege. Die Gesellschaft verlange vom Individuum eine Begründung für seine spezifische Lust auf etwas, denn sie möchte Individuen nach ihren Lüsten klassifizieren. Durch die Lust auf einen Sexualpartner oder eine Praktik lasse sich das Individuum einordnen und bewerten. Keine Begründung für eine bestimmte Lust zu haben, sei in dieser Logik nicht vorgesehen, dem Individuum würden in diesem Fall von der Gesellschaft einfach bestimmte Motivationen oder Triebe unterstellt. Es gebe also kein Entkommen vor dem gesellschaftlichen Begründungszwang.

Doch auch für die persönliche Biografie herrsche ein gewisser Begründungszwang der Lust, da eine Lust, die nicht begründet werden könne, das Selbstbild eines Individuums ins Wanken bringe, die sinnhafte Erzählung einer Person über sich selbst störe. Pornografie eröffnet laut Büsser nun die Möglichkeit der Freiheit der Lust von einem solchen Begründungszwang: Die Akteure in Pornos müssen sich nicht rechtfertigen für ihre Lust. Es sei geradezu ein Markenzeichen der Pornografie, dass in ihr jeder beliebige Anlass für die Akteure ein Anlass zu Lust sein könne, es machten hier beispielsweise weder Situation noch Aussehen der Körper einen Unterschied. Darin liegt für Büsser das subversive, normensprengende Potenzial des Pornos. 
Der Mainstream-Porno allerdings zeichnet sich vor allem durch einen stereotypen Look der Körper und starre Geschlechterrollen aus. Genau darin ortet auch die Kunsttheoretikerin Kerstin Stakemeier das Reaktionäre am Mainstream-Porno:

Er wiederholt die gewalttätige Herrschaft der Ceschlechter über die Subjekte, indem er abermals Frauen und Männer nicht als gesellschaftliche Rollenkonstruktion, sondern als biologisch unterschiedene Spezies präsentiert. Sein Begehren richtet sich auf eben diese Rollenbilder und ihre Erfüllung, nicht auf das Verhältnis der Körper. Dieses Verhältnis der Körper im geilen, im progressiven Porno zu bestimmen, würde eben auf eine Praxis abzielen, die die gesellschaftlichen Figuren des Begehrens nicht in Marktsegmenten voneinander abspaltet, sondern aneinander reflektiert. (Stakemeier 2008, S. 90)

Wie Stakemeier beobachtet, wird im Mainstream-Porno Lust nicht über ein bestimmtes Verhalten der Körper zueinander hergestellt, sondern über das Erfüllen gesellschaftlicher Rollenvorstellungen. Das Reaktionäre am Mainstream-Porno wäre demnach die als lustvoll präsentierte Wiederherstellung eines traditionellen, patriarchalen Geschlechterverhältnisses. Ein subversiver Porno würde dagegen die Art und Weise, wie Begehren gesellschaftlich repräsentiert wird, thematisieren und versuchen, Körper jenseits von Marktlogiken zueinander in neue Verhältnisse des Begehrens zu bringen.

Solchen neuen Verhältnissen zwischen Körpern ist auch die Regisseurin und Autorin Barbara Eder auf der Spur. Sie sieht in der Darstellung von Sexualität in Independentproduktionen wie zum Beispiel sogenannten RapeRevenge-Filmen den transgressiven Aspekt sexueller Bilder angedeutet: » $\mathrm{Zu}$ sehen sind darin männliche, weibliche, transgender und andere Körper, die einander Lust bereiten, sich berühren und zeitweilig auch ineinander eindringen. Sie wissen um das gewalttätige Potential, das im Sexuellen schlummert, schaffen es aber dennoch, Bilder von Lust und Begehren glaubwürdig zu transportieren.« (Eder 2008, S. 100) Ein subversiver Porno müsste nach Eder das gewalttätige Potenzial der Sexualität also nicht negieren. Sie erwähnt einen Porno, in dem ein heterosexueller Mann durch eine Lesbe und eine bisexuelle Frau verführt und anschließend mit einem Dildo penetriert wird. Hier wird die Gewaltausübung, die im Akt der Penetration steckt und von Feministinnen kritisiert wurde, auf lustvolle Weise thematisiert und dazu benutzt, herrschende Geschlechterrollen und sexuelle Kategorisierungen durcheinanderzubringen. Das gewalttätige Potenzial der Sexualität ließe sich 
in der Post-Pornografie also gegen normative Vorstellungen von Geschlecht und Sexualität mobilisieren.

Tim Stüttgen begrüßt das destabilisierende kritische Potenzial der PostPornografie. Er macht darauf aufmerksam, dass eine solche Pornografie auch produktiv sei, sie produziere neue sexuelle Subjekte.

Acts such as drag, cruising or dildo sex should not be limited to the uncovering of the constructedness of heterosexual gender positions, but as affective articulations of the body that possess their own spatialities and temporalities and enable alternative forms of social practice and the production of subjectivity - and thus alternative forms of sexual identity and subjectivity. (Stüttgen 2009, S. 15)

Transgression im Sinne der Post-Pornografie sei nicht auf Kritik an der hegemonialen Geschlechterordnung beschränkt, sondern bestehe auch im Kreieren neuer sexueller Identitäten; die in ihr über Körperpraktiken vermittelten Affekte eröffneten neue Räume und Zeitlichkeiten alternativer sexueller Subjekte. »In general, one can say that a post-porn image emancipates itself from the binary logic of hetero-power and makes potentials available for other forms of representation critical affirmation, forms which make new subjectivities and power relations within the practice of sexuality conceivable and debatable.« (Ebd., S. 18) Laut Stüttgen positioniert sich das post-pornografische Bild im Idealfall an der Schnittstelle von Theorie und Praxis: Es verkompliziere beides, verdeutliche die geschlechtertypischen und ökonomischen Hintergründe seiner eigenen Herstellung und stelle diese zur Debatte.

Zusammenfassend wird also von diversen Autoren ein subversives Potenzial im Porno vermutet. Dieses wurzelt im Umstand, dass Lust im Porno frei ist vom Begründungszwang, dem sie im Alltag unterworfen ist. Dieser Umstand eröffnet der Sexualität im Porno theoretisch die Möglichkeit, gegen herkömmliche Narrationslogiken und Rollenmodelle eingesetzt zu werden. Dadurch entstehen neue Formen sexueller Identität. Das Gewaltpotenzial der Sexualität sowie deren Verstrickung in Machttechnologien können so produktiv gegen Normierung gewendet werden.

Mit dem Rückgriff auf das Gewaltpotenzial der Sexualität und auf die Freiheit der Lust von Begründungszwängen werden zwei zentrale transgressive Aspekte der Pornografie aufgenommen und in den Dienst einer Subversion von hegemonialen Geschlechternormen und der Kreierung von neuen Formen sexueller Subjektivität gestellt. Wie das Konzept der Post-Pornografie 
bei Paul B. Preciado auf einer bestimmten Vorstellung dissidenter Sexualität aufbaut, möchte ich im Folgenden aufzeigen.

\subsubsection{Kontra-Sexualität}

Für den Begriff Post-Pornografie schlägt Paul B. Preciado folgende Definition vor:

The notion of post-pornography, drawing from Annie Sprinkle's »post-porn modernist « performances, will be a map concept used to describe different strategies of critique and intervention in pornographic representation arising out of the feminist, queer, transgender, intersexed and anti-colonial movements. Post-pornography names multiple and heterogenous critiques to these three pornographic regimes and their segregated disciplinary spaces for production of pleasure and subjectivity (the museum, the city and the pornographic room) and to the modern biopolitical techniques of spacialization of pleasure. (Preciado 2009, S. 30)

Preciado versteht unter Post-Pornografie also ein Bündel von Strategien, um in pornografische Repräsentationen kritisch intervenieren zu können. Dabei ist es ihm wichtig, auch die räumlichen Gegebenheiten, unter denen diese Repräsentationen stattfinden, in den Blick zu nehmen. Seine These ist, dass in einer Gesellschaft Lust jeweils nicht einfach allen überall zur Verfügung stehe, sondern auf bestimmte Räume verteilt und für bestimmte Personengruppen reserviert werde. In seinem Aufsatz zur Architektur des Porno macht Preciado drei Räume aus, in denen traditionellerweise Pornografie konsumiert werde: das Museum, die Stadt und der Stag Room. Der Begriff Stag Room ließe sich auf Deutsch etwa mit Raum für Herrenabende oder Junggesellenpartys übersetzen.

Mit dem Regime des Museums nimmt Preciado Bezug auf Walter Kendricks Untersuchungen zu geheimen Museen, in denen Autoritäten erotische Darstellungen einer männlichen Elite zugänglich machen, aber vor Frauen, Kindern und den niederen Klassen verbergen wollten (vgl. Kendrick 1987). Das Regime der Stadt bezeichne die Bestrebungen städtischer Autoritäten, das Zirkulieren von Texten und Bildern über Sexualität zu regulieren. Mithilfe hygienischer Argumente sei über die Regulierung von Pornografie Einfluss auf weibliche Sexualität und männliche Lust genommen worden. Im Stag Room hingegen seien die ersten pornografischen Fotografien und Filme im Rahmen von Bordellen oder Herrenclubs konsumiert worden. Der 
Blick der weißen Männer, die im Stag Room zusammenkamen, definiere den Inhalt der Filme und Fotos erst als Pornografie. Der Stag Room als exklusiver Ort der männlichen Schaulust schaffe jedoch bereits bei der Entstehung der Kategorie der pornografischen Filme oder Fotos eine kompromittierende Nähe zwischen den Betrachtern, lasse die Grenzen zwischen Homo- und Heterosexualität verschwimmen. Er schaffe so sowohl Objekte als auch Subjekte der Pornografie. Und genau dies ist Preciados These, nämlich dass die drei Räume Museum, City und Stag Room entscheidend an der Definition dessen beteiligt sind, was als Pornografie gilt und was nicht: »Pornography, itself an architectonic exercise, is neither a private image nor a public representation, but the act of framing that constructs the limits not only between public and private, but also between bodies who enjoy visual experience and bodies who are not allowed to be sexually aroused in public.« (Preciado 2009, S. 28) Da Räume ab- und ausgrenzen, Publikum ein- oder ausschließen, kreiere Architektur letztlich Pornografie als etwas, was verborgen und exklusiv sei, sie verschaffe einem ausgewählten Kreis von Personen Zugang zu Lust. Post-Pornografie soll laut Preciado eine Kritik daran formulieren, wie ein biopolitisches Regime versuche, Lust auf diese Räume $\mathrm{zu}$ verteilen und zugleich $\mathrm{zu}$ beschränken. "[T]he notion of post-pornography suggests an epistemological and political break, another way of knowing and producing pleasure through vision and body-machine assemblage, but also a new sexual definition of the public space, new ways of inhabiting the city, and counter-biopolitical forms of embodiments." (Ebd., S. 30) Die Kritik der Post-Pornografie solle also sowohl epistemologisch als auch politisch sein, sie solle sowohl ein neues Verständnis für Technologien und Körper fördern als auch Widerstand gegen Biopolitik und Regulierungen des öffentlichen Raumes markieren.

Inspiriert von Preciado entstand im Jahr 2002 in Barcelona das Kollektiv GirlsWhoLikePorno, das in Workshops und Performances an einer alternativen Vision von Pornografie arbeitete. Ihre Absichten erklärten die GirlsWhoLikePorno, analog zu Preciado, in einem Manifest:

We vindicate the pleasure of generating and consuming pornography - and even more so if it's pornography which we've made ourselves, pornography constructed by its actors and actresses, pornography that does not negate any body type or any practice that emerges from consensus, that visualizes the delicious reality in which HIV-positive people continue living and fucking, that generates new visual references which inspire some and make oth- 
ers melt, pornography which empowers us, surpassing juvenile titters and easy jokes or insults, pornography which dares to speak about sex and our sexualities from a position of power which we have not traditionally had. (Llopis 2009, S. 281)

In diesem Auszug aus ihrem Manifest springen einige Punkte ins Auge, die bisher unter dem Stichwort Post-Pornografie noch nicht erwähnt worden sind. Zum Beispiel soll auch HIV-positiven Menschen eine lustvolle sexuelle Realität zugestanden und visualisiert werden. Kein Körpertyp und keine Praxis, die auf Konsens beruht, soll negiert werden. Visuelle Tabus sollen gebrochen und neue, inspirierende Bilder gefunden werden. Allgemein wird ein Do-it-yourself-Approach zu Pornografie postuliert. Die GirlsWhoLikePorno sehen in der Pornografie explizit eine Gelegenheit zur Selbstermächtigung. Zudem fällt eine Distanzierung von der Idee eines weiblichen Pornos auf: "GirlsWhoLikePorno do not believe in femininity, nor in pornography for women, as this label is used to talk about pornography full of femininity, i.e. romantic music and soft shags, loving, affectionate, and heterosexual.« (Ebd.) Tatsächlich hat Preciado bereits in Artikel 13 seiner Grundsätze der kontrasexuellen Gesellschaft eine neue Form der Pornografie gefordert, die sich stark abhebt von klassischen Vorstellungen einer weiblichen, sprich sanfteren, emotionaleren Pornografie: "Die kontrasexuelle Gesellschaft beschließt die Abschaffung der Prostitution und der Pornographie als Praktiken, mit denen im heterozentristischen Repräsentationsregime und mit der im Körper erzeugten Lust Maskulinität und Femininität konstruiert und legitimiert werden. Die Kontra-Sexualität will eine Kontra-Produktion von Lust und Wissen im Rahmen eines Systems kontrasexueller Kontra-Ökonomie entwickeln.« (Preciado 2003, S. 31)

Preciado fordert keine weiblichere Pornografie, weil er Pornografie als eine Praxis ansieht, die im Rahmen einer hegemonialen Heterosexualität erst Männlichkeit und Weiblichkeit erzeugt. Entsprechend definiert er die queere Praxis der Kontra-Sexualität folgendermaßen: »Kontra-Sexualität untersucht die technologischen Transformationen der sexualisierten und vergeschlechtlichten Körper. Die Hypothese einer sozialen oder psychologischen Konstruktion der Geschlechter wird nicht zurückgenommen, aber als Mechanismen, Strategien oder Gebrauchsweisen in einem größeren technologischen Zusammenhang neu verortet.« (Ebd., S. 13) Da Kontra-Sexualität die Konstruktion von Geschlecht auch unter technologischen Gesichtspunkten untersuchen will, gerät Pornografie in ihren Fokus. Kontra-Sexualität soll je- 
doch nicht bloßes Analyseinstrument sein, sondern produktive Praxis gegen herrschende Sexualnormen: »Der Name Kontra-Sexualität leitet sich indirekt von Foucault ab, für den die wirksamste Form des Widerstands gegen die disziplinierende Produktion der Sexualität nicht der Kampf gegen das Verbot ist (eine anti-repressive Befreiungsbewegung), sondern die KontraProduktivität. «(Ebd., S. 11) Preciado meint damit, dass Verbote als neue Quellen von Lust produktiv genutzt werden können. Als Beispiel führt er an, wie die Repression gegen Masturbation zur Herausbildung einer Idee des Sex und des Orgasmus beitrug. Dieselben repressiven Praktiken sieht er im Dienste der Kontrolle von Schmerz und Lust im subkulturellen S/M-Kontext wieder aufkommen (vgl. ebd., S. 77). In einer weiteren Analyse entlarvt er in der medizinischen Behandlung von Intersexuellen eine heimliche Norm des Penis: »Femininität beziehungsweise feminine Geschlechtsbestimmung stellt sich seit den 5oer Jahren immer als eine Möglichkeit für alle Körper dar, gleich ob sie genetisch als männlich oder als weiblich bestimmt werden, während die Zuschreibung auf das männliche Geschlecht denjenigen Körpern vorbehalten bleibt, die XY- oder XX-Chromosome mit normal aussehendem Penis verbinden.«(Ebd., S. 106)

Der Penis stellt für Preciado das heimliche homosoziale Zentrum der heteronormativen Gesellschaft dar. Diese zentrale Stellung des Penis ist allerdings durch den Dildo bedroht, deswegen nimmt der Dildo bei Preciado als bevorzugte Waffe der Kontra-Sexualität eine wichtige Position ein: »Die Asymmetrie in der sozialen Geschlechtskonstruktion findet sich in den medizinischen Konstruktionstechnologien und der Geschlechtsumwandlung wieder. Daher könnte man sagen, dass der Penis außerhalb aller Artefakte steht, dass er Natur ist. Und genau in dieses Reich der Natürlichkeit des Penis tritt der Dildo als Unterbrechung, als `lebendiges Gespenst «.« (Ebd., S. 107)

Preciados Bezugnahme auf umcodierte Praktiken der Repression im S/MKontext und die dekonstruktive Funktion des Dildos geben bereits Hinweise darauf, was im Rahmen einer Post-Pornografie an kontrasexuellen Praktiken denkbar wäre. Bemerkenswert an Preciados queerer Vision der KontraSexualität ist meiner Meinung nach sein Fokus auf Ökonomie, Technik und Architektur. Er weist nach, inwiefern das, was wir für das Intimste und Persönlichste halten, unsere Sexualität, zutiefst von ökonomischen, technologischen und architektonischen Strategien durchdrungen ist. Sie lässt sich gar nicht außerhalb dieser Strategien denken, sondern ist letztlich deren Produkt. Und in dieser strategischen Produktion unserer Sexualität spielt Porno- 
grafie eine bedeutende Rolle. Wie Pornografie ganz konkret zur Implementierung eines hegemonialen sexuellen Lebensstils eingesetzt werden kann, zeigt Preciado am Beispiel des Herrenmagazins Playboy auf.

\subsubsection{Die Pornotopie}

In der Einleitung zum Werk Pornotopia verkündet Preciado programmatisch: »Für den Philosophen der Gegenwart ist der >Playboy< heute das, was für Marx im 19. Jahrhundert die Dampfmaschine war: ein Modell der ökonomischen und kulturellen Produktion, das es erlaubt, den Übergang vom Industriekapitalismus zum pharmakopornographischen Kapitalismus zu denken.« (Preciado 2012, S. 9) Er verortet die Entstehung des Playboy in der USamerikanischen Gesellschaft der Nachkriegsjahre, die er als »eine Zeit der Erweiterung und Konsolidierung eines Ensembles geschlechtlicher und sexueller Normierungen« (Ebd., S. 28) charakterisiert. Der Playboy habe seine Mission darin gesehen, den heterosexuellen Mann aus dem Gefängnis des Vorstadt-Familienidylls zu befreien:

Die heterosexuelle weiße Familie ist nicht nur eine mächtige ökonomische Produktions- und Konsumeinheit, sie ist vor allem die Matrix des amerikanisch-nationalistischen Imaginären. Vor diesem Hintergrund muss der »Playboy« seinen Kampf um die Herauslösung des Mannes aus der vorstädtischen Reproduktionszelle unbedingt mit einem vehementen Plädoyer für Heterosexualität und Konsum verbinden, um jeden Verdacht auf die »antiamerikanischen Laster« der Homosexualität und des Kommunismus zu zerstreuen. (Ebd.)

Die vom Playboy propagierte Gegenwelt zur kleinbürgerlichen Vorstadtidylle sei das urbane Junggesellen-Penthouse. Preciado zieht von diesem eine Verbindungslinie zum bereits beschriebenen Stag Room, da die Frauen, die im Playboy dieses Penthouse bevölkern, bloße Objekte der Schaulust seien, während die sie betrachtenden Männer nur die Subjekte dieser Lust seien. Die reich bebilderten Reportagen über Junggesellen-Penthouses sieht Preciado als den Beginn einer Enthäuslichung des bürgerlichen Innenraums: »Die Erfindung der Pornotopie ist mit anderen Worten die Produktion einer Häuslichkeit, die von technischen Dispositiven der Überwachung und der audiovisuellen Reproduktion orchestriert und choreographiert wurde.« (Ebd., S. 56) Am Ende dieses Prozesses stehe ein Innenraum, der nicht mehr durch Privatheit charakterisiert sei, sondern den Darsteller und Zuschauer bevölker- 
ten. Hugh Hefners Playboy-Villa seien das Paradebeispiel für Innenräume, die gleichzeitig Räume der wirtschaftlichen wie der sexuellen Produktion seien, gleichzeitig Büro und Bordell: »Die Villa und ihre medialen Erweiterungen funktionierten im wahrsten Sinne des Wortes wie eine audiovisuelle Industrie: Der >Playboy hatte eine einzigartige Pornotopie geschaffen, nämlich das erste Multimedia-Bordell der Geschichte.« (Ebd.)

Steven Marcus kreierte den Neologismus Pornotopia für die utopischen Welten der Pornografie, wo alles Auslöser für Sex sein kann. Preciado setzt diesen Begriff in einen ökonomischen und politischen Kontext. Er versteht unter einer Pornotopie einen Ort, der mehrere an sich inkompatible Räume in sich vereinigt und dadurch die gängigen Normen in Bezug auf Geschlecht und Sexualität außer Kraft setzt. Sades Pornotopien etwa stünden am Anfang einer Erotisierung von Disziplinar- und Überwachungstechniken; sie enthüllten »die libidinöse Ökonomie, die in der institutionellen Internierungsarchitektur, in den Gefängnissen, den Kliniken und den Fabriken, am Werk war: Kontrolle und körperliche Beschränkung, Unterwerfung, Exhibitionismus und Voyeurismus waren in Wirklichkeit die dem Disziplinarregime eigenen Techniken der sexuellen Subjektivation.«(Ebd., S. 92) Die sich in der Architektur manifestierenden Herrschafts- und Überwachungstechniken einer kapitalistischen Gesellschaft wirkten sich also auf die Sexualität der Subjekte aus, die sich in dieser Architektur aufhielten. Dadurch, dass Hefner Innenräume transparent für die Öffentlichkeit mache, sei es ihm möglich, die männlichen Privilegien des Blicks, die im öffentlichen Raum gälten, auf die häusliche Sphäre zu übertragen. So gelinge es Hefners Pornotopie der Playboy-Villa, die beiden Räume, in denen Männer bisher vor allem Sexualität gelebt hätten, nämlich das familiäre Heim und das Bordell, miteinander kurzzuschließen und daraus etwas Neues zu machen:

Als Ersatz für beides (aber auch als Hybridisierung von beidem) dachte sich Hefner die perfekte sexuelle Heterotopie aus: eine unnachahmliche Falte des öffentlichen Raums im Innenraum, ein Multimediabordell, ein öffentliches Haus und eine neue Form des Cenießens ohne direkten Sex: eine Art von virtueller Lust, hervorgebracht durch die Verbindung des Körpers mit einem Komplex von Informationstechnologien. (Ebd., S. 102)

Preciado zufolge hat der Playboy auch im Zeitalter der weltweit produzierund konsumierbaren Internet-Pornografie, in dem sich sein Monopol nicht aufrechterhalten ließ, sein Vermächtnis hinterlassen. So lebe etwa die der allgemeinen Krise der Männlichkeit entgegengesetzte mythische Männlichkeit 
des Playboys in Reality-TV-Formaten wie Jersey Shore oder in Musikvideos fort: »Der Whirlpool mit einem (schwarzen oder weißen) Hiphopper, umringt von halbnackten Mädchen, die zum Lapdance Schlange stehen, ist ein Mutant der Pornotopie. Der Kitsch ist nicht ganz derselbe, doch die sexuelle Ordnung, die er zum Ausdruck bringt, garantiert das Überleben der Playboy-Werte.« (Preciado 2012, S. 142) Darüber hinaus werde in weiteren Reality-TV-Formaten wie Big Brother oder Ich bin ein Star, holt mich hier raus! die in der Playboy-Villa vorzelebrierte Lust an der Einsperrung und Überwachung weitergeführt.

Der Kulturkritiker Georg Seesslen sieht in den Massenmedien sogar einen Krieg der Bilder im Gang, in dem Nacktheit als Währung oder Waffe eingesetzt werde: »In der post-demokratischen, post-fordistischen und post-bürgerlichen Gesellschaft, in der wir leben, und für die wir nur wenig Erklärungsmodelle haben, ist die komplizierte Dialektik zwischen dem Bekleideten und dem Nackten medialisiert; der Krieg zwischen dem sexuellen Körper und der gesellschaftlichen Macht ist in einen Krieg der Bilder gespiegelt: Das Medium produziert ein neues Proletariat der öffentlichen Entblößungen.« (Seesslen 2008, S. 19)

An der Polarität Verhüllung/Nacktheit werden laut Seesslen Klassen-, Rassen- und Religionskonflikte verhandelt: »Die Bildermaschinen produzieren die neueste Variante des nackten Wilden. Genauer gesagt, ein doppeltes Bild davon: Die nackte Wilde ist gespalten in die barbusige Frau im Park und in die Kopftuchträgerin. Der nackte Wilde ist gespalten ins Pimp-HiphopUnterhosenmodel-Boygroup-Soap-Opera-Sexobjekt und in den Terroristen. Beide sind zugleich Bilder der Rebellion und der Unterwerfung. Der sexuelle Kolonialismus wendet sich (auch) nach innen.« (Ebd.) Die Post-Pornografie stellt sich solchen biopolitischen Kontrollsystemen in den Weg.

Dies konstatiert auch die Kulturwissenschaftlerin Katja Diefenbach. Sie sieht Post-Pornografie als nicht utopische Bewegung in Richtung einer anderen Ökonomie der Körper und der Lüste: »From this post-pornographic perspective the body is desexualized and intensified at the same time. On the one hand, post-porn detaches itself from practices centered around the reproductive organs and the primacy of the orgasm; on the other hand, it invents new ways of using various parts of the body for having sex." (Diefenbach 2009, S. 77) Foucault entlarvt laut Diefenbach das Freiheitsversprechen des Dispositivs der Sexualität als Geständniszwang im Dienst biopolitischer Strategien. Sie bezieht sich direkt auf eine Stelle im ersten Band von Sexualität und Wahrheit, wo Foucault schreibt: 
Und träumen müssen wir davon, dass man vielleicht eines Tages, in einer anderen Ökonomie der Körper und der Lüste, nicht mehr recht verstehen wird, wie es den Hinterhältigkeiten der Sexualität und der ihr Dispositiv stützenden Macht gelingen konnte, uns dieser kargen Alleinherrschaft des Sexes zu unterwerfen; wie es ihnen gelingen konnte, uns an die endlose Aufgabe zu binden, sein Geheimnis zu zwingen und diesem Schatten die wahrsten Geständnisse abzuringen. Ironie dieses Dispositivs: Es macht uns glauben, dass es darin um unsere »Befreiung« geht. (Foucault 1977, S. 189)

Die Post-Pornografie soll laut Diefenbach also den Körper in dem Sinne desexualisieren, dass sie ihn ablöst vom herrschenden Dispositiv der Sexualität mit dessen Fokus auf die Genitalien und den Orgasmus. Indem die PostPornografie jedoch bisher nicht im Zentrum stehende Körperregionen in ihre Sexualpraktiken einbeziehe und mit erotischer Bedeutung auflade, würden der Körper und seine erotischen Möglichkeiten neu und intensiver wahrgenommen. Die Post-Pornografie stelle den Fetischismus in Frage, der im Rahmen eines herrschenden Dispositivs bestimmte Dinge mit Wert auflade und andere nicht. Die Akteurinnen und Akteure der Post-Pornografie machten selbst zum Fetisch, worauf sie gerade Lust hätten, lenkten den fetischisierenden Blick ab auf neue Zonen und scheuten sich auch nicht davor, sich selbst vorübergehend zum Ding, zur Ware zu machen und dies zu genießen. Bezugnehmend auf den Philosophen Gilles Deleuze und den Psychoanalytiker Félix Guattari schreibt Diefenbach:

These concepts of thisness and nonsubjective micropolitics could be nice tools for a theory of post-pornographic politics that deals with an economy of pleasure withdrawn from the axis of fucking subjects and fucked objects. To avoid being transformed into a denaturalized version of sexual liberation, a call for a mere combination of body parts, sex toys, drugs and hormones, or a metapolitical universal porn practice that is assumed to dissolve the heterosexual regime, post-porn politics must become aware of the fact that politics is nothing but another name for militant connectionism. (Diefenbach 2009, S. 84)

Dem Einsickern von sexualisierten Bildern in die Mainstream-Unterhaltungskultur via Reality-TV stellt sich die Post-Pornografie mit einer Strategie der Desexualisierung entgegen. Wobei Desexualisierung hier nicht Verzicht auf Sex meint, sondern ein Ablösen des Sex von den Praktiken, Körperteilen und Rollenverteilungen in den sexuellen Inszenierungen der Mainstream- 
Pornografie. Wir finden hier ein Echo von Marcuses Forderungen nach einer Resexualisierung des Körpers im Kampf gegen das Leistungsprinzip. Doch wie ordnet sich Post-Pornografie im Verhältnis $\mathrm{zu}$ anderen alternativen Pornografien ein?

\subsubsection{Alternative Körper, Gonzo und Post-Pornografie}

Der Theoretiker Julien Servois versucht eine Einordnung der Post-Pornografie im weiten Feld der Alternativen zur Mainstream-Pornografie. Den grundsätzlichen Trend hin zum alternativen Porno mit im Mainstream-Porno nicht repräsentierten Körpern sieht Servois kritisch:»Les productions de Vivid-Alt reflètent cette ambiguïté: elles prétendent rendre visibles des corps alternatifs, des modes d'existence marginaux dans une optique volontiers contestataire, mais elles apparaissent en fait comme des gonzos >ciblés` où les exigences du marketing se trahissent à chaque image."(Servois 2009, S. 99) Die Darstellung alternativer Körper erschließe einfach neue Zielgruppen durch die Pornoindustrie. Die mit dieser Darstellung verbundene Behauptung, statt der Hochglanzsexualität des Mainstream-Pornos würden reale Körper und Sexualitäten gezeigt, rücke den alternativen Porno in die Nähe des Gonzo-Genres. Als Gonzo klassifiziere sich ein Porno laut Servois durch die Erfüllung von mindestens einem der drei folgenden Kriterien: »1) l'absence de scénario (l'absence de mise en intrigue, la disparition du récit, les acteurs qui interagissent avec la caméra), 2) le peu de soin accordé à la mise en scène, aux cadrages, à l'éclairage (bref, le coté bas de gamme du produit), 3) la spécialisation fétichiste et l'escalade dans les pratiques dites extrêmes« (Ebd., S. 78f.). Während Gonzo für seine mangelnde Narration und Produktionstechnik sowie für seine exzessive Fokussierung auf spezielle Fetische und Praktiken geschmäht werde, liege seine Qualität im Spiel mit einer ewigen Ambiguität des Kinos. Dieses erhebe seit jeher den Anspruch, Realität abzubilden, produziere dabei jedoch fortwährend Fiktion. So spiele Gonzo mit dem Anspruch des Pornos, reale Sexualität abzubilden, während er den Sex stets inszeniere: "De même, le projet pornographique de stout montrer $<$, bien qu'il repose sur la croyance en un réel qui se laisse capturer tel quel par la caméra, produit son propre référent. Le mythe du degré zéro de la représentation repose sur l'invisibilisation du procédé par lequel le représenté est construit.« (Ebd., S. 88f. ) Indem Gonzo einerseits vorgeblich zum realen, ungeschminkten Sex vordringe, andererseits seine eigenen Produktionsbedingungen ständig sichtbar mache, 
bespiele er laut Servois lustvoll die Grenzen zwischen sexueller Fantasie und Realität.

Das Sichtbarmachen der eigenen Produktionsbedingungen verbindet die Gonzo-Pornografie mit der Post-Pornografie. Servois leitet den Impuls zur Post-Pornografie von den Konzepten Monique Wittigs und Michel Foucaults $a b$, welche sexuelle Lust vom Geschlecht und von geschlechtlich vorstrukturierten Rollen und Praktiken ablösen wollten: Die feministische Theoretikerin Wittig versuche dies über die Figur der Lesbe, die sich aus der Mann/FrauDichotomie herauslöse und diese angreife; Foucault über die Befreiung der Lust von ihrer Zentrierung auf die Genitalien, wie sie in S/M-Praktiken stattfinde. „Ce qui rapproche Foucault de Wittig, c'est bien cette croyance en la nécessité de créer des champs de plaisirs et de nouvelles cartographies érotiques 'hors-sexes: c'est-à-dire post-génitaux et surtout déliés du binarisme sexuel en tant que ce dernier est un rapport de pouvoir producteur d'identités fixes.«(Ebd., S. 113) Die Post-Pornografie versuche nun diese neuen Karten der Erotik außerhalb der heterosexuellen Matrix zu zeichnen. Preciado nutze laut Servois die Pornografie in einer Weise, wie Judith Butler Drag-Performances beschreibe, nämlich als subversive Entlarvung der Geschlechterrollen als kontingent:

Sur cette base théorique, il est donc possible de mettre en place une pratique de subversion interne: utiliser les caractères structurels de la perfomativité de genre pour le performer à contre-courant (hacker le code). C'est cette forme subversive de performance qui selon Preciado rend possible une postpornographie. (Ebd., S. 118)

Angesichts der heteronormativen Pornografie böten sich laut Servois der Post-Pornografie zwei Wege: die Utopie oder die Dekonstruktion - also entweder die Darstellung eines utopischen Ortes, der die heteronormative Sexualität schlicht negiere, oder das Sichtbarmachen der heteronormativen Codes zum Zweck der Umprogrammierung sexueller Skripts.

Als Beispiele für den zweiten Weg zieht Servois die post-pornografischen Performances der Künstlerin Annie Sprinkle heran. In einer marxistisch inspirierten Dekonstruktionsarbeit mache Sprinkle die Produktionsbedingungen des Pornos zum Thema und untersuche so die sozioökonomischen Grundlagen des Fetischs. Dabei bleibe sie jedoch nicht stehen, sondern bezeuge, indem sie sich die fetischisierten Codes aneigne, die von Preciado proklamierte Genussfähigkeit des Körpers im Rollenspiel. 
Denn laut Servois ist allein das Genießen an der Post-Pornografie revolutionär, nicht die Körper, nicht die Praktiken. Pornografie wirke dadurch, dass die Genussfähigkeit des Körpers in ihr zur Darstellung komme: »La jouissance n'est pas un moyen pour rendre visible des individualités dont l'existence est niée mais c'est la présence de corps venant fissurer l'évidence du visible qui rend possible la manifestation cinématographique de la jouissance." (Ebd., S. 138) Dieses revolutionäre Potenzial des Pornos durch die Darstellung der Genussfähigkeit des Körpers sei vor allem in den oft utopischen S/M-Szenarios der Post-Pornografie realisiert. Die S/M-Performance bewege sich in vorher ausgehandelten Grenzen, spiele jedoch mit der Gefahr, diese zu überschreiten, und stelle damit die Grenzen zwischen Realität und Fiktion in Frage. Die S/M-Filme der Post-Porn-Performerin Maria Beatty präsentieren laut Servois diese Transgressivität des S/M: „En ce sens, avec la subversion parodique et le militantisme de la jouissance, cette dépsychologisation du fétichisme, fluidifiant les frontières entre ce qui est sexuel et ce qui ne l'est pas, forme la troisième voie, le troisième pôle d'investigation de la post-pornographie.« (Ebd., S. 148)

Wie Diefenbach sieht also auch Servois, ausgehend von Preciados Theorie der Kontra-Sexualität, in einem nicht psychologischen und marxistisch-dekonstruktiven Verständnis des Fetischs ein zentrales Element der Post-Pornografie. Ebenso zentral sind für Servois die Subversion der heteronormativen Codes der Pornografie und die utopische Zurschaustellung der Genussfähigkeit des Körpers. Wie verhalten sich nun diese drei Punkte zu meiner in der Einleitung aufgestellten These von der Transgressivität der Pornografie?

\subsection{Fazit}

Ausgangspunkt dieses Kapitels waren zwei sich widersprechende Argumente im feministischen Diskurs, die zur Spaltung der Frauenbewegung führten: Das eine Argument trennte Vergewaltigung von Sexualität und führte sie zurück auf patriarchale Gewalt, das andere Argument setzte männliche Sexualität mit Gewalt gleich. In Letzterem geht männliche Sexualität ganz in Gewalt auf, Pornografie im Propagieren sexueller Gewalt. Aus dieser Logik heraus kollaborieren Frauen, die Pornografie genießen, mit einem System patriarchaler Unterdrückung. 
Diese reduktionistische Sicht, die männliche Sexualität auf Gewalt reduziert und Frauen auf die Opferrolle festschreibt, ließ Stimmen des Widerstands lautwerden, die den Wert der Redefreiheit gegenüber der Gefahr der Zensur von sexuellen Äußerungen in Bildung und Kunst betonen. Judith Butler stellt den impliziten Bezug zum transgressiven Charakter der Sexualität her, indem sie in der Zensur von Pornografie einen gewaltförmigen Versuch sieht, gesellschaftlich verworfene Weisen von Sexualität zu unterdrücken. Drucilla Cornell erachtet, wie Swen Lewandowski, Pornografie als Selbstverständigungsdiskurs über heterosexuelle Männlichkeit; sie fordert alternative Pornografien, die Raum für neue Imaginationen von Weiblichkeit schaffen.

In diesem Sinne nennt auch Cathy Winks vier Gründe für den Pornokonsum von Frauen: Pornos unterhalten, sie erregen, sie inspirieren, und sie erweitern die Kenntnisse zur eigenen Sexualität und zu der von andern. Damit spricht sie bereits transgressive Aspekte der Pornografie an, die von der Anti-Pornografie-Bewegung ignoriert werden. Die Frage ist nun, ob speziell für Frauen produzierte Pornografie diese transgressiven Aspekte realisieren und die frauenfeindlichen und gewaltförmigen Inhalte der MainstreamPornos vermeiden können.

Mit Michelle Carnes wurde klar, dass solche Filme doppelgesichtig sind: Sie überschreiten Geschlechternormen und die Grenzen heteronormativer Sexualpraktiken, doch daneben remystifizieren sie auch bestimmte Praktiken und blenden potenziell beunruhigende Aspekte aus. Damit bleiben sie den beiden für die herrschende Geschlechterordnung essenziellen Normen Zweigeschlechtlichkeit und Intimität weitgehend treu.

Entsprechend dringlich wurde eine Analyse schwuler Pornografie, die über eine lange Tradition eng mit der Schwulenbefreiungsbewegung verbunden ist und zumindest vordergründig mit den Normen der herrschenden Geschlechterordnung bricht. Ihre politische Anziehungskraft besteht darin, verworfene sexuelle Akte als lustvoll zu präsentieren. Dies hat einen bestärkenden Effekt auf Schwule als gesellschaftlich stigmatisierte Minderheit. Schwule Pornografie ist hierin allerdings so weit gegangen, dass sie eine spezifisch schwule Ästhetik der Hypermännlichkeit und Hypersexualität hervorgebracht hat, die für Schwule, die deren Kriterien nicht entsprechen, problematisch ist. Im Überschreiten der Grenzen der heterosexuellen Matrix wurden offenbar neue Grenzen gezogen, die ebenso normierende Auswirkungen haben wie die Mainstream-Pornografie. 
Bei Matthew Tinkcom fand sich jedoch eine andere ästhetische Strategie, die spezifisch von schwulen Künstlern eingesetzt wird: Camp. Die Ästhetik des Camp macht sichtbar, wie stark Heteronormativität für ihr Funktionieren von Kapital abhängig ist. Wenn alternative Pornografien nicht nur an einer Versöhnung von sexuellen Minderheiten mit der herrschenden Ordnung interessiert sind, sondern Letztere verändern wollen, wäre Camp hierzu ein wichtiges Element.

Mit der Transmänner-Pornografie griff ich ein Beispiel einer noch stärker stigmatisierten Minderheit heraus. Hier wird umso deutlicher, dass der Einsatz queerer Körper in der Pornografie eine Form von Sexaktivismus sein kann: Die queeren Körper helfen, den eigenen, nicht ins System der Zweigeschlechtlichkeit passenden Körper als lustvoll wahrzunehmen; zudem bringen sie feste Vorstellungen über Körper, Geschlecht, sexuelle Orientierung und Alter durcheinander.

Entsprechend erkennen diverse Autoren in der Pornografie ein subversives Potenzial. Denn im Gegensatz zum Alltag ist die Existenz von Lust in der Pornografie nicht begründungspflichtig. Sexuelles Begehren kann in der Pornografie gegen die Regulierungen gewendet werden, denen Sexualität sonst unterworfen ist. Dies produziert neue Formen sexueller Identität. Die Hoffnung ist, dass sich trangressive Aspekte der Pornografie im Kampf gegen hegemoniale Geschlechternormen politisch nutzbar machen lassen.

In Preciados queerem Konzept der Kontra-Sexualität habe ich einige Faktoren ausgemacht, die im Rahmen der Post-Pornografie wirksam sein könnten. Ökonomische, technologische und architektonische Faktoren sind strategisch entscheidend an der Produktion der herrschenden Vorstellung von Sexualität beteiligt. In der Post-Pornografie lassen sich Parameter verändern, sodass andere Formen von Sexualität denkbar werden.

Konkret heißt das zum Beispiel bei Diefenbach, dass die Post-Pornografie die Möglichkeit hat, den Körper zu desexualisieren, ihn außerhalb einer genital- und orgasmusfixierten Sexualität einzusetzen. Dies vervielfacht die erotischen Möglichkeiten des Körpers. Zudem macht die Post-Pornografie so sichtbar, wie im Rahmen eines herrschenden Sexualdispositivs bestimmte Körperteile, Sexualpraktiken und Accessoires mit Wert aufgeladen sind und andere nicht.

Damit sind zwei Untersuchungsgegenstände der Post-Pornografie benannt: Dekonstruktion und Subversion. Servois stellt diesen beiden noch die Utopie hinzu. Unter diesen drei Stichworten möchte ich nochmals zu- 
sammenfassen, wie die Post-Pornografie den transgressiven Charakter der Pornografie politisch nutzbar macht.

Dekonstruktion meint in der Post-Pornografie das Desexualisieren des Körpers, das Dezentrieren der Lust und das Dekonstruieren des Fetischs aber auch das Mobilisieren des gewalttätigen Potenzials der Sexualität gegen Geschlechternormen und kategorisierte Sexualität sowie das Nutzen von Technologien, um die Grenzen zwischen öffentlich und privat, Körper und Maschine zu durchbrechen.

Subversion beschreibt die Art und Weise, wie Post-Pornografie die Hintergründe der Produktion von Pornos transparent macht und zur Debatte stellt. Damit thematisiert sie die herrschenden gesellschaftlichen Repräsentationen des Begehrens. Indem Post-Pornografie verfemte Körper und Praktiken lustvoll sichtbar macht, kritisiert sie das Regime, welches Lust auf bestimmte Räume und Körper verteilt und andere davon ausschließt.

Als Utopie begreift Servois das freie sexuelle Experimentieren jenseits von gesellschaftlichen oder biografischen Begründungen. Dieses schafft neue Verhältnisse zwischen Körpern jenseits von Marktlogiken, es kreiert neue sexuelle Subjekte. Aber auch in der Selbstermächtigung der Porno-Akteure oder in der Zurschaustellung der Genussfähigkeit des Körpers sind utopische Momente auszumachen.

Wo taucht in diesen drei Punkten nun der transgressive Charakter der Pornografie auf? Im Punkt Utopie ist das Transgressive das Ausbrechen aus der individuellen sexuellen Situiertheit, die Überschreitung dessen, was individuell sexuell möglich oder geboten scheint. Transgressives Potenzial beweist die Post-Pornografie hier auch in der Zurschaustellung der Genussfähigkeit des Körpers, die gesellschaftliche Normen sprengt und in ihrer Grenzenlosigkeit Ängste auslöst und den Wunsch nach Kontrolle provoziert.

Im Punkt Dekonstruktion ist das gewalttätige Potenzial der Sexualität transgressiv, das beispielsweise in S/M-Szenarien genutzt werden kann, um Begehren von Zuschreibungen abzukoppeln und neu zu verorten. Aber auch gängige Fetische und Zentren der Lust zu verschieben, heißt, sexuelle Normen zu überschreiten.

Im Punkt Subversion ist die Sachlage weniger eindeutig. Gemäss Butler muss Heteronormativität in wiederholter performativer Praxis immer wieder neu hergestellt werden, was Gelegenheiten zu Parodie, Subversion und Intervention bietet. Bei Bataille haben wir gesehen, dass gerade das Aufstellen von Regeln im Bereich der Sexualität eine Lust kreiert, diese Regeln zu überschreiten, den Regelverstoß erotisiert. Das Transparentmachen der Pro- 
duktionsbedingungen von Pornografie sehe ich eher als transgressiv im Sinne eines Tabubruchs bezogen auf die Mainstream-Pornografie, die eine solche Transparenz vermeidet. 


\section{Schlussteil}

\subsection{Résumé}

Im Folgenden resümiere ich die im Lauf der vorliegenden Untersuchung gewonnenen Erkenntnisse und präsentiere einen Ausblick auf transgressive Aspekte der Pornografisierung. Das Résumé soll noch einmal die Verbindungslinien zwischen den in Kapitel 2 skizzierten theoretischen Grundlagen und der Diskussion der beiden konkreten Phänomene in den Kapiteln 3 und 4 deutlich machen.

Porne graphein - über Huren schreiben - von dieser Urbedeutung des Begriffs hat diese Untersuchung den Anfang genommen. Bereits in dieser Urbedeutung steckt, dass über etwas gesellschaftlich Randständiges - die Huren - geschrieben, ein Diskurs produziert wird. Es geht bei der Pornografie also um eine Diskursproduktion an den Rändern des gesellschaftlich Akzeptablen. Man spricht in der Pornografie von etwas, von dem eigentlich nicht gesprochen werden darf. Diese schillernde Ambivalenz der Pornografie, das lustvolle Aussprechen von etwas Verbotenem, verweist auf ihre Positionierung an der Grenze des herrschenden Diskurses. Um der Pornografie zu begegnen, müssen wir uns an diese Grenze bewegen, müssen sie sichtbar machen. Sichtbar wird die Grenze des Diskurses aber erst in einer Geste der Überschreitung, der Transgression. Mit diesem Vorverständnis habe ich die Untersuchung begonnen: Pornografie markiert die Grenze des gesellschaftlich akzeptablen Diskurses über Sexualität. Transgression ist der Akt, in dem die Normen dieses Diskurses übertreten werden.

Wenn wir von einem gesellschaftlich akzeptablen Diskurs über Sexualität sprechen, legen wir bereits zugrunde, dass Sexualität nicht gänzlich außerhalb eines gesellschaftlichen Diskurses stattfindet. Mit Foucault gehe ich davon aus, dass sexuelle Beziehungen Gegenstand gesellschaftlicher Regulierung sind. Das geschieht allerdings historisch nicht immer auf dieselbe Wei- 
se. Foucault zufolge wird seit der Antike sexuelles Begehren zunehmend als Gefahr für das Individuum, aber auch für das soziale Gefüge wahrgenommen. Es zeigt sich deshalb in der bürgerlichen Moderne ein zunehmender Wille zur Regulierung von Körpern und Reproduktion.

Ich habe vor allem zwei Aspekte hervorgehoben, die in der bürgerlichen Moderne Sexualität normativ regulieren: Zweigeschlechtlichkeit und Intimität. Die Übertragung des antiken Freundschaftsmodells auf die Ehe trägt die Binarität von Aktivität und Passivität in die eheliche Sexualität hinein und überträgt sie damit auf die Geschlechterrollen. Weiblichkeit wird dann über die Reduktion auf einen Objektstatus hergestellt. Indem die Ehe aber exklusiver Ort für Intimbeziehungen und Sexualität wird, fallen soziale Dimensionen der Sexualität weg. Dagegen wird die eheliche Sexualität mit dem narzisstischen Anspruch auf Authentisierung und Validierung der Selbstdarstellung belastet.

Damit ist der Zusammenhang zwischen Sexualität und Normen hergestellt und wichtige Normen, die die Sexualität in der bürgerlichen Moderne prägen, sind identifiziert. Meine Anschlussfrage lautete: Ist das Subjekt an diese Normen komplett gebunden, oder wie kann die Möglichkeit der Übertretung dieser Normen theoretisch gefasst werden?

Laut Bataille ist es genuin menschlich, der eigenen Sexualität Grenzen zu setzen. Doch damit wird der ausgegrenzte Bereich erotisch aufgeladen, dies verführt zur Transgression. Transgression hat dadurch auch eine politische Komponente, indem das gesellschaftlich Abgewertete reizvoller erscheint als das Akzeptierte. Akte der Transgression heben also die Hierarchie zwischen Binaritäten auf. Dass dies nicht zwingend in einen Umsturz der Hierarchien münden muss, haben wir mit Zappes Differenzierung zwischen dem modern-humanistischen Konzept und dem postmodernen Konzept der Transgression gesehen. Im postmodernen Konzept entsteht auf der Normgrenze ein hybrider Raum: das Zwischen, wo für einen Augenblick neue Identitäten und Erfahrungen möglich werden.

Das Verhältnis von Sexualität und Transgression lässt sich auch psychoanalytisch herleiten. Freud beispielsweise hält Beschränkungen im Ausleben des Sexualtriebs zwar für zivilisatorisch unumgänglich. Er weist aber darauf hin, dass zu starke Beschränkungen, wie sie die herrschende Sexualmoral einfordere, auf die Dauer Transgressionen in Gestalt von Neurosen hervorbringe. Auch Marcuse sieht in einer Lockerung der Kulturanforderungen im Bereich der Sexualität das Rezept zur Befreiung des Individuums von entfremdeter Arbeit, Monogamie und Patriarchat. 
Mir ist hier wichtig, dass Freud und Marcuse sich bloß für eine Lockerung der Kulturanforderung aussprechen und nicht eine vollständige Befreiung des Sexualtriebs im Sinne Reichs (vgl. Reich 1971 oder Reich 1972) postulieren. Gefordert wird also nicht ein revolutionärer Akt der Überwindung aller Beschränkungen der Sexualität, was in Zappes Einteilung dem liberalen oder humanistischen Konzept der Transgression entsprechen würde. Wie in Zappes postmodernem Konzept sehen Freud und Marcuse Transgression als etwas, was im Zusammenhang mit beschränkter Sexualität unweigerlich stattfindet, aber im Falle gelockerter Kulturanforderungen deutlich weniger neurotische oder gewaltförmige Nebenwirkungen hätte.

Einen weiteren wichtigen Punkt stellt eine Gemeinsamkeit von Freud und Foucault dar: Beide Theoretiker konzipieren Sexualität letztlich als den Ort, wo das bürgerliche Subjektverständnis in eine Krise gerät. Die Tendenz des sexuellen Begehrens, das vermeintlich autonome bürgerliche Subjekt über seine selbst auferlegten Grenzen hinauszuführen, löst dieses Subjektverständnis auf.

Mit Butler habe ich gezeigt, wie das sexuelle Begehren des bürgerlichen Subjekts mit dem biologischen Geschlecht, der Geschlechtsidentität und der sexuellen Praxis zu einem regulativen Ideal der Heteronormativität verkoppelt wird. Bricht eines dieser Elemente weg, droht das Subjekt für die Gesellschaft unlesbar zu werden und damit die soziale Anerkennung zu verlieren. Das Subjekt ist also durch sein sexuelles Begehren extrem verwundbar und deshalb gezwungen, in wiederholten performativen Akten dem regulativen Ideal der Heteronormativität nachzuleben. Durch Aussetzen oder Abändern dieser Akte entstehen Spielräume für Transgression.

Der Wandel von einer Konzeption, die Sexualität vor allem in sozialen Interaktionen verortet, hin zu einer Konzeption, die in der Sexualität eine individuelle Wahrheit über das Subjekt sucht, hat schwerwiegende Konsequenzen. Die Regulierung der Sexualität geschieht nicht mehr über die Sanktionierung bestimmter sozialer Beziehungen, sondern über die Einübung gesellschaftlicher Normen mittels Selbsttechnologien. Dass das so eingehegte sexuelle Begehren eine Tendenz zum Übertreten dieser Normen aufweist, bezeichne ich als transgressiven Charakter der Sexualität. Dieser transgressive Charakter evoziert Fantasien, die letztlich in der Pornografie einen Ausdruck finden.

Um das Spannungsverhältnis zwischen Transgression und Normierung, in dem sich die Pornografie befindet, sichtbar zu machen, habe ich als Erstes eine historische Perspektive eingenommen. Ausgangspunkt war die Fest- 
stellung, dass das Konsumieren von Pornografie in der Regel von einer sexuellen Handlung begleitet ist, nämlich der Masturbation. Bei Laqueur wurde deutlich, wie erst mit der Entstehung einer bürgerlichen Subjektkonzeption Masturbation ein Problem wird. Masturbation wird meist im Geheimen ausgeübt, ist von unkontrollierten Fantasien begleitet und kann zu Exzessen führen. Diese drei Aspekte stehen der Konzeption des autonomen, rationalen Bürgers, der nichts zu verbergen hat, diametral entgegen. Die Gesellschaft des 18. Jahrhunderts reagiert darauf mit einer Pathologisierung der Masturbation, die bis ins 20. Jahrhundert hinein anhält. Anhand von Marcus' Forschungen zeigte ich auf, wie die Pornografie des 18. Jahrhunderts die gesellschaftlichen Beschränkungen jener Zeit einerseits spiegelt und andererseits sprengt. Letztlich bietet Pornografie eine Bühne für sexuelle Allmachtsfantasien, die ebenfalls die Elemente des Geheimen, der Fantasie und des Exzesses beinhalten, die für die bürgerliche Gesellschaft des 18. Jahrhunderts bereits an der Masturbation so problematisch waren.

Bis heute sorgen die Schriften des Marquis de Sade für Kontroversen. Seine pornografischen Allmachtsfantasien treiben die Objektivierung der Frau auf die Spitze. Im Vergleich verschiedener Interpretationen von Sades Texten wollte ich der ungebrochenen Provokation dieser Texte auf die Spur kommen. Horkheimer und Adorno erkennen in den organisierten Transgressionen bei Sade nur die Exzesse eines totalitär gewordenen bürgerlichen Subjekts. De Beauvoir betont dagegen den utopischen Charakter dieser Schriften stärker, in denen sich bürgerliche Subjekte durch transgressive Akte von der Bestimmtheit durch die Natur befreien wollen. Auch Bataille macht diesen utopischen Charakter deutlich, da nur im Imaginären ein begehrtes Objekt passiv genug ist, um dem Begehren keine Schranken entgegenzusetzen. Entsprechend stellt laut Sontag Pornografie eine wichtige Möglichkeit bereit, sich zu überschreiten. Pornografie vermittelt uns aus dieser Perspektive wichtige Informationen über die menschliche Existenz, seine Begierden und seine Beschränktheiten; damit stellt sie die Normen in Frage, die definieren, was ein Subjekt ist.

Nun handelt es sich bei Sades Schriften um schriftliche Pornografie. Lässt sich auch pornografischen Bildern oder Filmen ein transgressiver Charakter attestieren? Ich habe hier gegen Flasspöhler argumentiert, für die Pornofilme eine Utopie der Regression präsentieren, wo der transgressive Charakter der Sexualität ungefährdet genossen und damit gebannt werden kann. Flasspöhler unterscheidet zwischen schriftlicher und filmischer Pornografie, wobei sie nur der schriftlichen einen transgressiven Charakter zugesteht. Dieses 
Urteil baut auf einem Verständnis von Transgression auf, das ich mit Zappe als modern-humanistisches bezeichnen würde. In diesem Verständnis ist nur das Überschreiten der eigenen sexuellen Beschränkungen in einen als unbeschränkt angenommenen Raum der Fantasie wahrhaft transgressiv. In einem postmodernen Verständnis öffnet Transgression auf der Normgrenze einen Zwischenraum, wo gesellschaftliche Zensurregeln gleichzeitig aufgehoben sind und in Kraft bleiben. Mit Lewandowski argumentiere ich, dass die transgressive Kraft des sexuellen Begehrens, um aushaltbar zu sein, immer maskiert ist, sowohl im Traum wie auch in der Pornografie. Damit ist der Unterschied zwischen schriftlichen und bildlichen Darstellungen von Pornografie nur ein gradueller.

Zusammengefasst besteht der transgressive Charakter der Pornografie also darin, dass sie dem bürgerlichen Subjekt der Moderne die Möglichkeit bietet, sich zu überschreiten. Sie präsentiert dem Subjekt eine Utopie, wo sein Begehren auf keinen Widerstand stößt. Gesellschaftliche Normen spiegeln sich auf zweierlei Weise in der Pornografie: einerseits in den Inhalten, die von gesellschaftlich nicht akzeptablem Begehren erzählen, andererseits in der Maskerade, die den transgressiven Inhalten deren Bedrohlichkeit nehmen. Verkürzt lässt sich also sagen: Transgressiv an der Pornografie sind die Inhalte, sie beziehen sich auf Normen, indem sie die Normgrenze markieren und Utopien jenseits derselben aufzeigen. Normiert dagegen ist die Maskierung der Inhalte, die Form, die die Inhalte annehmen; sie spiegelt Normen unseres gesellschaftlichen Alltags direkt. Diese zwei Modi der Pornografie, sich auf Normen zu beziehen, sind wichtig für das Verständnis der beiden Phänomene, die ich in den Kapiteln 3 und 4 behandelt habe: die Pornografisierung und die alternativen Pornografien.

Als Erstes wandte ich mich der Pornografisierungsdebatte zu. Obwohl betreffend die genaue Definition von Pornografisierung Verwirrung besteht, lautet der Grundtenor der Debatte, dass es eine gesellschaftliche Tendenz gibt, die der Begriff benennt: Diese Tendenz ist die Normalisierung von Pornografie. Dieser Prozess der Normalisierung besteht aus zwei Aspekten: Einerseits ist damit die erleichterte Verfügbarkeit der Pornografie gemeint, andererseits das Einfließen von pornografischen Inhalten in die Massenkultur. Pornografisierung lässt sich als Prozess der Inkorporation pornografischer Inhalte verstehen. Inkorporiert werden mit den Inhalten auch die mit ihnen verbundenen Normen. Aus diesem Umstand erwächst der Pornografisierung in feministischen Kreisen Kritik: Jugendliche würden durch sie einen porno- 
grafischen Blick auf sich und andere entwickeln, sie verspreche Ermächtigung durch Selbstobjektivierung.

Diese feministische Kritik an der Pornografisierung möchte ich in Bezug setzen zu dem, was wir über den Zusammenhang von Sexualität und Normen erkannt haben. Wenn Körper und Begehren Gegenstand einer Regulierung sind, die über das Einüben von Selbsttechnologien funktioniert, dann lässt sich Pornografisierung als Teil davon erkennen. $\mathrm{Zu}$ verstehen, wie wichtig die Objektivierung von Frauen als Bedingung zur Aufrechterhaltung der männlichen Herrschaft ist, lässt die Verbreitung des pornografischen Blicks auf sich und andere in einem kritischen Licht erscheinen. Darin ist die mit dieser Verbreitung einhergehende Selbstobjektivierung Teil eines ganzen Bündels von Anrufungen der herrschenden neoliberalen Wirtschaftsordnung. Beispiele sind hier Forderungen nach mehr Eigenverantwortung, Selbstoptimierung, Leistungsbereitschaft. Diese Forderungen schüren gleichzeitig Ängste um Körper, Jugendlichkeit und Gesundheit, die sich ebenfalls in der Pornografisierungsdebatte niederschlagen.

Ich teile die im Rahmen der feministischen Kritik formulierte Analyse der mit Pornografisierung verbundenen Selbstobjektivierung als Teil der neoliberalen Wirtschaftsordnung. Ich unterstelle allerdings gewissen Exponentinnen oder Exponenten dieser Kritik eine idealisierte Konzeption des sexuellen Subjekts. Diese lässt sich aus der Geschichte der feministischen Pornografiekritik herleiten. Gestützt auf die Aufarbeitung von Bronstein stellte ich fest, dass Dworkin und MacKinnon den Fokus der Anti-Porno-Bewegung entscheidend verschoben: Aus einem Kampf gegen reale sexuelle Gewalt an Frauen wurde ein Kampf gegen eine sexuelle Bilderwelt. Das Recht und die staatlichen Organe sollen den Frauen letztlich Freiheit und sexuelle Selbstbestimmung garantieren. Damit werden Frauen auf den Opferstatus ohne eigene Handlungsmacht festgelegt.

Exponentinnen und Exponenten der zeitgenössischen feministischen Pornografisierungskritik wie Long, Dines, Banyard, Russo oder Jensen verorten sich in der Tradition der Anti-Porno-Bewegung und nehmen direkt Bezug auf Dworkin und MacKinnon. Charakteristisch ist ihnen die Ablehnung von Transgression im Bereich der Sexualität, die einhergeht mit einer rhetorischen Marginalisierung alternativer Pornografien. Die Erotisierung von Herrschaftsverhältnissen und Gewalt ist ihr zentraler Kritikpunkt an der Pornografie. Sie teilen Dworkins Grundthese, dass Pornografie ein Instrument der Unterdrückung von Frauen durch Männer ist. Als Belege dienen ihnen das durch die Pornografie verbreitete objektivierende Frauenbild und 
die Erotisierung von Gewalt gegen Frauen, die zu einer Desensibilisierung von Männern gegenüber weiblichem Leiden führe.

Damit reproduziert jedoch die Pornografisierungskritik das die gesamte Anti-Pornografie-Bewegung durchziehende Gegensatzpaar von naturhafter weiblicher und erobernder männlicher Sexualität. Zweigeschlechtlichkeit und Intimität bleiben unkritisierte Normen; die die herrschende Geschlechterordnung bestimmende Aktiv/passiv-Binarität wird fortgeschrieben statt aufgebrochen. Der den Frauen zugewiesene Opferstatus steht einer Theoretisierung von sexueller Selbstbestimmung im Wege. Diese wird als queerfeministische Selbstverwirklichung und Ablenkung von der Ungleichheit zwischen Mann und Frau disqualifiziert. Positiv zu werten ist jedoch, dass die zeitgenössische Kritik an der Pornografisierung die Debatte wieder öffnet. Durch die Abkehr von einem rein rechtlichen Streit um Zensur und Meinungsfreiheit werden wirtschaftliche Macht- und Klassenverhältnisse vermehrt in die Analyse einbezogen. Leider verstellt zuweilen eine politisch agitative Rhetorik den Blick auf die Stärken der feministischen Analysen. Ich halte auch dies letztlich für eine Folge des diskursiven Grenzcharakters der Pornografie. Dieser erschwert das Debattieren dieser Fragen innerhalb eines sachlich-rationalen gesellschaftlichen Diskurses. So verweist die Rhetorik der Pornografisierungskritik unfreiwillig auf den transgressiven Charakter der Pornografie, der inhaltlich ignoriert oder abgelehnt wird.

Mit Villa habe ich darauf hingewiesen, dass die Strategie, sich selbst zum Objekt des pornografischen Blickes zu machen, auch ermächtigend sein kann. Auf dieser Überzeugung gründen die alternativen Pornografien, die ich in Kapitel 4 näher betrachtet habe. Sie wollen den normierenden Bildern der Mainstream-Pornografie eigene entgegensetzen. Diesem Anspruch werden sie jedoch in unterschiedlichem Maß gerecht.

Der speziell an Frauen gerichteten Pornografie gelingt es, Frauenfeindlichkeit und Gewaltförmigkeit der Mainstream-Pornos zu vermeiden. Damit beweisen sie, dass Pornos im Gegensatz zu den Behauptungen der Anti-Porno-Bewegung für Frauen durchaus erregend und inspirierend sein können. Sie bestätigen in diesem Sinne auch die transgressive Kraft der Pornografie. Unangetastet bleiben jedoch die für die herrschende Geschlechterordnung zentralen Normen der Intimität und der Zweigeschlechtlichkeit.

Weiter geht hier die Schwulen-Pornografie. Mit Normen wie Intimität und Zweigeschlechtlichkeit wird gebrochen, von der Gesellschaft verworfene sexuelle Akte werden als lustvoll präsentiert. Wie die Geschichte der Schwulenbewegung beweist, hatten und haben diese Pornos einen bestärkenden 
Effekt auf eine wegen ihrer Sexualität gesellschaftlich marginalisierte Gruppe. Sie setzen aber auch neue Schönheits-, Körper- und Männlichkeitsideale durch, die wiederum eine Reproduktion der Normen sind, welche schwule Sexualität unterdrücken. Mit Camp stellte ich deshalb eine Strategie vor, welche die Ideale der Zweigeschlechtlichkeit übersteigert und ironisiert. Camp macht zudem die Abhängigkeit der Heteronormativität von einer kapitalistischen Wirtschaftsordnung sichtbar.

Auch Transmänner-Pornografie wirkt ermächtigend. An ihr lässt sich eine weitere Facette von gegen Normen gerichteter Pornografie herausarbeiten. Wenn ein Körper nicht mehr klar einem von zwei Geschlechtern zugeordnet werden kann, geraten fixe Vorstellungen von Körpern, Geschlecht, sexueller Orientierung und Alter durcheinander. Die Post-Pornografie bündelt all diese transgressiven Strategien. Sie arbeitet dekonstruktiv, subversiv und utopisch: Ihre dekonstruktive Arbeit besteht darin, den Körper aus einer genital- und orgasmusfixierten Sexualität zu lösen; subversiv ist sie, weil sie Lust an Orten findet und sichtbar macht, denen sie in der herrschenden Geschlechterordnung nicht zugestanden wird; utopisch wird sie in der Erforschung neuer Möglichkeiten zur Erweiterung der Genussfähigkeit der Körper und in der Kreation neuer sexueller Subjekte. In den folgenden drei Kapiteln möchte ich nun in einer Art Ausblick nochmals diese Strategien der Dekonstruktion, Subversion und Utopie zusammendenken mit der Pornografisierung. Inwiefern ist diese durch technologische und ökonomische Faktoren geprägte Normalisierung von Pornografie transgressiv?

\subsection{Transgressive Aspekte der Pornografisierung}

Der Blick auf die beiden in dieser Arbeit behandelten Phänomene offenbart Gemeinsames und Trennendes. Die feministische Pornografisierungskritik stellt zwar das Normierende an der Pornografie ins Zentrum, indem sie die Objektivierung von und die Gewalt gegen Frauen thematisiert, aber sowohl in der Frage der Gewalt als auch in der Besorgnis über die Ausbreitung der Pornografie in die Alltagskultur drückt sich in ihr eine Skepsis gegenüber dem transgressiven Charakter der Pornografie aus. Damit ist sie mindestens ebenso sehr eine Reaktion auf die transgressiven wie auf die normierenden Elemente der Pornografie. Alternative Pornografien, insbesondere die PostPornografie, versuchen den transgressiven Charakter der Pornografie für gesellschaftliche Veränderungen nutzbar zu machen. Letztlich eint beide Bewe- 
gungen die Kritik an hegemonialen Sexualitäts-, Geschlechter-, Schönheitsund Körpernormen. Es trennt sie, dass sie Transgression einerseits als Chance, anderseits als Gefahr wahrnehmen.

In dieser Untersuchung ging es mir in erster Linie darum, die Existenz des transgressiven Charakters der Pornografie sichtbar zu machen. Bei der Pornografisierungskritik wurde deutlich, dass sie diesen transgressiven Charakter in der Tradition der feministischen Anti-Porno-Bewegung entweder ignoriert oder bekämpft; bei den alternativen Pornografien dagegen wird dieser transgressive Charakter von sexuellen Minderheiten für politische Zwecke instrumentalisiert.

In Form eines Ausblicks möchte ich nun in einem ersten Schritt den von der Pornografisierungskritik vernachlässigten Zusammenhang von Pornografisierung und Transgression noch einmal weiterdenken. In einem zweiten Schritt möchte ich an einigen Beispielen aufzeigen, wie Pornografie Angebote für irreguläre Identifizierungen macht. Abschließen werde ich mit einigen Gedanken dazu, wie eine neue Ethik der Lüste in Bezug auf Pornografie aussehen könnte.

Kehren wir also zuerst zur Pornografisierung zurück. Überraschend argumentiert Marcus, dass die heutige legale Verbreitung von Pornografie eher ein Zeichen für deren abnehmenden gesellschaftlichen Einfluss sei als umgekehrt; Pornografie scheine für die Normen der heutigen Gesellschaft keine ernsthafte Bedrohung mehr darzustellen: „Die freizügige Veröffentlichung und Verbreitung pornographischer Schriften scheinen mir nicht notwendigerweise Indizien für den moralischen Verfall oder den Niedergang der Gesellschaft zu sein. Sie deuten vielmehr darauf hin, dass die Pornographie ihre Macht verloren hat.« (Marcus 1979, S. 241)

Auch Preciado hat ja darauf hingewiesen, dass Pornografie immer durch die Räume mit definiert wird, in denen sie stattfindet. Pornografie ist, seit es sie gibt, gebunden an bestimmte Räume, zu denen nicht alle Zugang haben. Eine ubiquitäre Pornografie wäre keine mehr. Stehen wir demnach vor dem Ende der Pornografie?

Ich bin mit Lewandowski der Meinung, dass wir eher in eine Phase der Entgrenzung der Pornografie eingetreten sind. Ihm zufolge haben wir das Post-Pornografische Zeitalter schon hinter uns, wobei er den Begriff anders verwendet als Sprinkle und Preciado. In Lewandowskis Definition zeichnet sich das Post-Pornografische Zeitalter durch eine national unterschiedliche gesellschaftliche Einhegung des Konflikts von Pornografie und Gesellschaft aus. Er geht also davon aus, dass sich Pornografie und Gesellschaft definiti- 
onsgemäß in einem Konflikt befinden, was sich auf den transgressiven Charakter der Pornografie zurückführen lässt. Im Post-Pornografischen Zeitalter sei temporär der Versuch gelungen, die Pornografie innerhalb bestimmten Grenzen gewähren zu lassen, sie aber aus dem öffentlichen Raum zurückzudrängen. Der Neoliberalismus nun habe diesen fragilen Waffenstillstand aufgekündigt, indem er eine möglichst schrankenlose freie Marktwirtschaft fordert. Einerseits baut der Neoliberalismus nationalstaatliche Grenzen und nationale Regelungen $\mathrm{ab}$, andererseits macht er auch vor der Schwelle zum Privaten nicht halt, sucht auch in bisher privaten Räumen einen Markt herzustellen.

Auch Sennett hat den Wegfall einer sozialen Dimension der Sexualität diagnostiziert. Welche Folgen hat dies für die Pornografie? Die fortschreitende Ausdifferenzierung des Pornografieangebots in Bezug auf Szenarien, Fetische, Techniken und sonstige Präferenzen führt dazu, dass die Pornografie immer breitere Zielgruppen erschließt, deren Wünsche sie dann immer spezifischer bedient. Zwar ist diese Diversifizierung ökonomisch betrachtet nichts Außergewöhnliches, aber damit sie funktioniert, muss eine Nachfrage nach dieser verbreiterten Angebotspalette da sein. Die Existenz dieser Nachfrage läge dann darin begründet, dass die breite Produktpalette der Pornografie dem Subjekt Gelegenheiten zur Authentisierung der eigenen Persönlichkeit bietet. Über das Erfüllen sehr spezifischer sexueller Wünsche bestätigt sie es in seiner Einzigartigkeit.

Die Erotik der sozialen Beziehungen ist demgegenüber in der Pornografie in den Hintergrund gerutscht, strukturiert sie aber weiterhin mit. Die unstandesgemäße Liebe als klassisches Thema der Literatur des 18. und 19. Jahrhunderts hat sich in Blockbustern wie Pretty Woman oder in Telenovelas erhalten; in der Pornografie unterfüttert sie Szenarios wie das sexuelle Aufeinandertreffen von Chef und Sekretärin, Hausfrau und Handwerker, Lehrer und Schüler etc. In diesen Szenarien bearbeitet die Pornografie weiterhin soziale Tabus und Klassenunterschiede. Zwar folgt diese Bearbeitung oft den tatsächlichen Machtverhältnissen in den sozialen Beziehungen, es finden sich jedoch auch Plots, in denen diese Verhältnisse auf den Kopf gestellt werden, die also die Rebellion gegen die sozialen Normen erotisieren. Die Pornografie widerspiegelt hier eine gewisse Unberechenbarkeit des Begehrens, das in einer sozialen Situation in verschiedene Richtungen ausschlagen kann. Durch die Dynamik der sexuellen Handlungen kann zudem plötzlich jemand die Szene dominieren, der von der sozialen Codierung her eigentlich in einer untergeordneten Position ist. 
Mainstream-Pornografie begegnet dieser Bedrohung der Machtverhältnisse, indem in der Regel in diesen Szenarios die Frauen dominiert werden, unabhängig von ihrer sozialen Codierung. Das Patriarchat und damit die universelle sexuelle Verfügbarkeit der Frau für den Mann wird so als über den sonstigen sozialen Herrschaftsverhältnissen stehend dargestellt. Die Dominierung der Frau in pornografischen Szenarios ist in der Lesart der feministischen Pornografiekritik eine Reaktion auf die Bedrohung des sozialen Status des Mannes durch die Frau. Die Pornografisierung erscheint aus diesem Blickwinkel als strategisches Manöver des Patriarchats, das die offizielle Geschlechtergleichheit zu torpedieren versucht, oder als direkter Beweis dafür, dass diese Gleichheit gar nicht existiert. Weshalb bedient sich der Markt sexistischer Gemeinplätze, um seine Waren zu verkaufen? Eine Antwort könnte lauten, dass der der Pornografisierung inhärente Sexismus ein kultureller Gemeinplatz ist, auf den zurückgegriffen wird. Auf das Mittel der nackten Haut als Aufmerksamkeitsgenerator setzt ja ebenfalls politischer Aktivismus - auch feministischer - mit Erfolg. Zudem hat in einer Weiterführung von Foucault die Wirtschaft ein Interesse an nach Geschlechterrollen sortierten Konsumentengruppen. Wie Butler herausgearbeitet hat, werden diese Rollenmodelle insbesondere durch die Kopplung an sexuelles Begehren hergestellt und aktiviert. Über die Pornografisierung der Gesellschaft versucht der Markt, seine nach Geschlechtern differenzierte Warenpalette weiterhin unter die Leute $\mathrm{zu}$ bringen. Er stellt die Zielgruppe für ihre Produkte über die Pornografisierung selber her. Foucault und Butler weisen jedoch darauf hin, dass solche Strategien auch fehlschlagen können. Potenzielle Konsumentinnen und Konsumenten können abgestoßen, abgeschreckt oder entmutigt werden. Statt in feste Identitätskonstitutionen und entsprechende Kaufentscheide zu münden, kann das durch die Pornografisierung ausgelöste Begehren auch überschießen in eine hybride Konstruktion von Identität.

Der Neoliberalismus hat den transgressiven Charakter der Pornografie also neu entfesselt. Es fragt sich, ob er diese Kräfte auch kontrollieren kann. Auf den ersten Blick scheint es so, da, wie die Kritik an der Pornografisierung belegt, der Einfluss der Pornografie auf Selbstbild und sexuelle Beziehungen tendenziell zu gesteigertem Konsumverhalten führt. Dennoch gibt es auch unvorhergesehene, durch den regulatorischen Abbau im Neoliberalismus ausgelöste Effekte, die diesen eher bedrohen. Dazu gehört die Kritik an der Pornografisierung selbst. Diese wird ja nicht nur von feministischer, sondern auch von religiös-konservativer Seite geäußert und hat zum Teil bereits zu neuen Regulierungen geführt. Ein weiterer Effekt wären ebendie im regu- 
lierungsarmen Klima entstandenen alternativen Pornografien. Sie gestalten sich zumindest nicht zur Gänze marktförmig, sondern stellen teilweise eine Form der Kritik an der herrschenden neoliberalen Gesellschaftsordnung dar. Es besteht allerdings die Gefahr, dass gerade die Versuche, Pornografie erneut zu regulieren und deren transgressive Aspekte einzudämmen, zu einem Verlust an individueller Freiheit und an Möglichkeiten sexueller Selbstverwirklichung führen.

Als bedrohlich wird die Pornografisierung immer wieder für die Paarbeziehung angenommen. Laut Luhmann ist die Ablehnung der Sexualität außerhalb der Intimbeziehung als obszön für diese konstitutiv. Wie bewährt sich diese These in Zeiten der Pornografisierung mit Social Media und Cybersex? Ich vermute, dass die Differenz zwischen persönlichen und unpersönlichen Beziehungen konstitutiv für den Liebescode bleibt, dass sie jedoch durch die neuen Möglichkeiten und Zwänge der virtuellen Selbstdarstellung belastet und schwieriger zu fassen geworden ist. Die immer noch vornehmlich in der Intimbeziehung gesuchte Validierung der Selbstdarstellung wird zunehmend von einem größeren Kreis virtueller Freundschaften eingefordert. Dies entlastet zwar die Intimbeziehung, erschwert aber das Ziehen der Grenze zwischen persönlichen und unpersönlichen Beziehungen, denn in welche Kategorie gehört jemand, der zu einem von mir auf Facebook hochgeladenen Porträt den »Gefällt mir«-Knopf drückt? Analog ließe sich der Erfolg von Amateurporno-Plattformen im Internet damit erklären, dass durch das Ausstellen der eigenen sexuellen Aktivität eine Validierung dieser Aktivität eingeholt werden kann. Dieser überbordende Narzissmus muss Intimbeziehungen, die diesem nicht ausreichend rückbestätigen können, was er von ihnen erwartet, auf die Probe stellen. Ein zusätzlicher Blickwinkel auf die Amateurpornos im Internet ergibt sich durch Eva Illouz, die zur Präsentation des Selbst im Internet schreibt:

Durch die Präsentation in einem Photo finden sich die Individuen buchstäblich in der Position von Leuten wieder, die für die Schönheitsindustrie als Models oder Schauspieler arbeiten, das heißt, sie finden sich in einer Position wieder, a) die ihnen ein Höchstmaß an Bewusstsein für ihre physische Erscheinung abverlangt; b) in der ihr Körper die Hauptquelle sozialer und ökonomischer Werte ist; c) wo sie über ihren Körper in Konkurrenz zu anderen treten; d) wo ihr Körper und ihre Erscheinung insgesamt öffentlich ausgestellt werden. (Illouz 2007, S. 123) 
Illouz bezieht sich an dieser Stelle auf die Selbstdarstellung, die Partnersuchenden auf den entsprechenden Plattformen abverlangt wird, und macht darauf aufmerksam, wie Subjekte ironischerweise sehr schnell auf ihren Körper mit all seinen Defiziten zurückgeworfen werden, sobald sie sich im auf den ersten Blick so unkörperlichen World Wide Web irgendwie präsentieren wollen. Dieselbe Unterwerfung unter der Pornografie entlehnten Körpernormen hatte Mowlabocus in seiner Analyse schwuler Datingsites festgestellt. Die Selbstpräsentation auf den Amateurporno-Plattformen lässt sich demnach verstehen als eine Form, dieses Zurückgeworfensein auf den Körper im Netz zu thematisieren. Die Mainstream-Pornos machen dem Subjekt mehr oder weniger schmerzlich bewusst, dass sein Körper in dieser Hochglanzwelt nichts verloren hat. Die Selbstpräsentation auf den Amateurporno-Plattformen wäre dann eine Trotzreaktion, die der Welt die von der Mainstream-Pornografie verfemten Körper vor Augen führen will. Doch diese Selbstpräsentation ist hochambivalent: Auf der einen Seite bedeutet die Vielfalt dieser Körper tatsächlich eine queere Attacke auf die normierten Körper der Mainstream-Pornografie; auf der anderen Seite kommen diese Körper natürlich den Forderungen des Mediums nach, sie sind ausgestellt, buhlen um Aufmerksamkeit, sind Ratings ausgesetzt.

An Illouz' Beobachtungen finde ich interessant, dass sie zeigen, wie im World Wide Web eine neue Form des Leistungsprinzips den Narzissmus überlagert. Der Zwang zur Selbstvalidierung scheint die Allmachtsfantasie des Narzissmus zu begrenzen. Ohnehin kann Empowerment durch Pornografie individuell sehr verschieden funktionieren. Wie Gill ausführt, ist es gut möglich, mit bestärkenden Botschaften bombardiert zu werden und sich dennoch eingeschüchtert und schlecht zu fühlen. Dieser Mechanismus lässt sich auch bei den Reaktionen von Männern auf heterosexuelle MainstreamPornos ablesen. Gerade männliche Jugendliche scheinen sich durch Pornos oft eingeschüchtert zu fühlen, sie sind verunsichert in Bezug auf ihren Körper und ihre sexuellen Fähigkeiten. Zudem schaffen Pornos Unklarheit über die sexuellen Bedürfnisse und Wünsche von Frauen. Im Folgenden möchte ich jedoch auf einen selten beachteten Aspekt der Pornografie eingehen: ihr Potenzial zu irregulären Identifizierungen. Dafür möchte ich nun einige Beispiele anführen. 


\subsection{Irreguläre Identifizierungen}

Für die Zwecke dieser Untersuchung sind wir bisher implizit davon ausgegangen, dass heterosexuelle Männer Heteropornografie, schwule Männer Schwulen-Pornografie, Frauen für Frauen produzierte Pornografie konsumieren und so weiter. An Beispielen möchte ich hier aufzeigen, wie Pornografie Identifikationsangebote macht, die von verschiedenen Zielgruppen genutzt werden können, sodass sie letztlich zur Transgression einlädt. Methodisch erweitere ich hier den Blick und wende die Diskursanalyse auf Internetpornografie und empirische Befragungen an.

Heterosexualität ist in der Schwulen-Pornografie präsent als Bestandteil des Settings: Der Reiz von im Schwulen-Porno häufigen Settings wie Militärkaserne, Gefängnis, Baustelle oder Autowerkstatt besteht zu einem großen Teil in deren heteronormativ geprägtem Kontext. Räume, in denen Homosexualität unerwünscht oder gar gefährlich ist, werden in der SchwulenPornografie symbolisch zurückerobert. Zudem kommen heterosexuell codierte Männer als Objekte der Verführung vor, zum Beispiel werden Ehemänner oder Klassenkameraden zu sexuellen Handlungen überredet.

Im Internet sind hier neue Formen zu beobachten. Da gibt es die Fantasie des Broke Straight Boy, der sich auf Sex vor der Kamera einlässt, weil er das Geld braucht. Es gibt die Fantasie der Falle, wo Heteromänner auf verschiedenen Wegen in eine Situation hineingetrickst werden, wo sie dann Sex mit Männern haben. Eine Extremform davon ist die Rachefantasie Straight Hell, wo Heteromänner entführt und zu demütigenden Sexpraktiken gezwungen werden. Auch die Fantasie des Initiationsritus im Studentenheim setzt schwulen Sex als Form der Demütigung ein.

Nun stellt sich die Frage, was diese neuen Formen heterosexueller Präsenz in der Schwulen-Pornografie inhaltlich leisten. Ich behaupte, dass sich in ihnen einerseits ein ambivalentes neues schwules Selbstbewusstsein artikuliert und dass sie andererseits ein Angebot für heterosexuelle Männer darstellen, das diesen erlaubt, schwule Fantasien zuzulassen.

Beginnen wir mit dem ersten Punkt. Der Broke Straight Boy, der Heterojunge in Geldnot, ist eine Fantasie ökonomischer Macht. Darin äußert sich ein neues schwules Selbstbewusstsein, das Macht und gesellschaftlichen Status über Wirtschaftsleistung erlangt hat und jetzt die Früchte davon ernten will. Hier steckt bereits eine Rachefantasie für erlittene Demütigungen als sexuelle Minderheit drin, die in der Fantasie der Website Straight Hell explizit wird. Diese Fantasie stellt eine Extremform dar, auch deshalb, weil sie in der 
Regel darauf verzichtet, dem Zuschauer eine Konversion des Heteromannes glaubhaft zu machen. Genau eine solche Konversion - der Heteromann lehnt die schwulen Sexpraktiken erst ab, nur um danach doch an ihnen Gefallen zu finden - ist die Basisannahme hinter den Verführungsfantasien. Straight Hell verzichtet auf diese Annahme zugunsten einer reinen Rachefantasie: Sie verkehrt die paradigmatische Konstellation, die jeder Schwule in seiner Jugend erlebt, nämlich von lauter Heterojungs umgeben zu sein, ins Gegenteil. Entsprechend wird hier auch nicht die effektive Nichtverfügbarkeit von Heteromännern für Schwule erotisiert, sondern Macht- und Gewaltausübung, die Möglichkeit, es einem Vertreter der sexuellen Mehrheit einmal heimzuzahlen. Doch der Fokus von Straight Hell auf Racheinstinkte und der gezielte Einsatz schwuler Sexualpraktiken zur Demütigung von Heteromännern scheint manche schwule User abzustoßen. Die Site wird im Netz für ihre aggressiven, teils hasserfüllten Bilder und Filme kritisiert: Wenn das Element der Konversion wegfalle, wirkten die Pornos abtörnend. Meine Vermutung ist deshalb, dass diese Art von Pornografie eigentlich heterosexuelle User ansprechen soll.

In der Hetero-Pornografie gibt es eine lange Tradition von masochistischen Fantasien, in denen sich Männer von Frauen demütigen lassen. Ein wichtiger Aspekt dieser Demütigungsfantasien besteht in der Verweiblichung des Mannes, er muss etwa Frauenkleider anziehen. Ein bekanntes literarisches Beispiel für diese Fantasie wäre Leopold von Sacher-Masochs Novelle Venus im Pelz (Sacher-Masoch, 2013). In der heutigen Ausdifferenzierung dieser Fantasie im Internet gibt es eine Vielzahl von Websites für solche Verweiblichungsfantasien, sie reichen vom Zwang zum Crossdressing bis zum Penetriertwerden durch Frauen mit Umschnalldildos. Eine spezielle Fantasie unter diesen Rollentauschfantasien, die ja gesellschaftliche Machtverhältnisse in ihr Gegenteil verkehren, ist das als CFNM (Clothed Female, Naked Male) kategorisierte Szenario, in dem Männer von einer Gruppe Frauen, welche die ganze Zeit bekleidet bleiben, dazu gezwungen werden, sich auszuziehen. In einem Teil dieser Szenarios kommt es vor, dass mehrere Männer sich einer solchen Musterung unterziehen müssen und anschließend zu sexuellen Handlungen miteinander gezwungen werden, als ultimative Demütigung und Verweiblichung. An dieser Stelle ist der Schritt zur Straight-Hell-Fantasie klein, man braucht nur die Frauen durch Schwule auszutauschen. Die Platzierung der schwulen Sexpraktiken in einem S/M-Kontext erleichtert es heterosexuellen Männern, die Grenzen ihrer sexuellen Identität zu überschreiten und schwule Fantasien zuzulassen. 
Etwas komplizierter stellt sich der Fall dar beim Initiationsszenario im Studentenheim in der Schwulen-Pornografie. Zugrunde liegt dieser Fantasie einmal der auch schon in der Vor-Internet-Pornografie vorhandene Kick von schwulem Sex in einem heteronormativen Kontext. Hinzu kommt jedoch wieder der Faktor Demütigung, der sich auf schwule und heterosexuelle Pornokonsumenten verschieden auswirkt: Bei Schwulen kann das dargestellte Szenario Erinnerungen an Demütigungen auslösen, die sie aufgrund ihrer sexuellen Identität während der Schulzeit erlebt haben. Das Porno-Szenario erotisiert diese unangenehmen Erlebnisse und gibt dem Betrachter die Kontrolle über das Ereignete zurück. Das Szenario kann bei Schwulen aber auch Erinnerungen wecken an schwules Begehren, das im Schulkontext nicht ausgelebt werden konnte. Und hier können sich wiederum auch Heteromänner einklinken mit ihren Erinnerungen an sexuell aufgeladene Situationen unter Männern in der Schulzeit, wo es eventuell sogar zu sexuellen Handlungen kam, die aber in der Zwischenzeit aus der sexuellen Identität hinausgedrängt wurden. Gerade die Kombination aus Mutprobe, Zwang und Demütigung in der Studentenheim-Fantasie erleichtert Heteromännern den Einstieg in das schwule Szenario.

Dass das Studentenheim-Szenario sowohl für schwule als auch für heterosexuelle User für Pornografie zentrale Erinnerungen weckt, belegt eine Umfrage von David Loftus. Er hat fast 150 Männer zu Pornografie befragt: Männer aus verschiedenen Ländern, mit oder ohne religiösen Hintergrund, Hetero-, Bi- und Homosexuelle. Natürlich ist eine Studie mit 150 Teilnehmern nicht repräsentativ, zumal sich die meisten von ihnen selbst für das Projekt angemeldet hatten. Loftus' Anspruch ist denn auch bescheidener: Er möchte einfach Stimmen der effektiven Konsumenten in die Debatte einbringen. Viele dieser Männer wurden schon in relativ früher Jugend mit Pornografie konfrontiert, mit zehn, elf Jahren (vgl. Loftus 2002, S. 2). Sie stolperten sozusagen darüber, ein Pornoheft lag beispielsweise versteckt in einer Schublade der Eltern oder wurde von Klassenkameraden in Umlauf gebracht. Dies belegt die frühe Wichtigkeit der homosozialen Komponente des Konsums von Pornografie, viele Männer sahen in ihrer Jugend gemeinsam mit anderen Jungen pornografische Bilder. Loftus liest jedoch diesen Umstand nicht als Bestätigung für die These eines Teils der feministischen Pornografiekritik, dass sich in der Pornografie Männer gegen Frauen verbünden. Denn einige von Loftus' Männer wiesen auch darauf hin, dass sie sich in diesen Situationen unwohl gefühlt hätten, unter sozialem Druck, die Bilder zu mögen oder zu kommentieren, oder dass es ihnen peinlich war, in einer Gruppe sichtbar erregt zu 
sein. In einer speziellen Situation befanden sich die schwulen Befragten, da für sie Pornografie zwar eine Chance bot, nackte Männer zu sehen, sie dieses Interesse jedoch kaschieren mussten, indem sie Interesse für die Frauen vorspielten (vgl. ebd., S. 12f.). Mit schwuler Pornografie kamen sie erst später in Kontakt, dafür spielte diese dann eine umso wichtigere Rolle. Da die schwulen Befragten gegen das Stigma ankämpfen mussten, schwuler Sex sei widernatürlich und ekelerregend, und sich diesen teilweise gar nicht konkret vorstellen konnten, da sonst keine Informationen dazu verfügbar waren, erlebten sie die pornografischen Bilder als wichtige Hilfe dabei, ihre sexuelle Orientierung zu verstehen und $\mathrm{zu}$ akzeptieren.

Laut David Loftus empfinden heterosexuelle Männer die in der HeteroPornografie gezeigten männlichen Darsteller in der Regel als hässlich und abstoßend. Sie dienten nicht als Identifikationsfiguren, es stelle sich den Konsumenten gar die Frage, wie so attraktive Frauen mit so hässlichen Männern Sex haben könnten (vgl. ebd., S. 62). Was lässt sich diesen Aussagen entnehmen? Im Gegensatz zu Schwulen, die sich in der Regel beim Betrachten ihrer Pornos nicht durch die Präsenz von Frauen verwirren lassen müssen, haben es Heteromänner in ihrer Pornografie zwangsläufig meistens mit Männern zu tun. Sie müssen also mit der Präsenz eines Körpers, der nicht primär ihr Begehren erregt, klarkommen. Die befragten Konsumenten scheinen den Eindruck vermeiden zu wollen, sie würden die Präsenz männlicher Körper in den Pornos allzu stark zur Kenntnis nehmen, denn das würde heißen, sie interessierten sich dafür. In der Bewertung der männlichen Akteure als hässlich und abstoßend kommt dieselbe Verwerfung schwulen Begehrens zum Ausdruck. Der Einsatz unattraktiver Männer in Hetero-Pornos minimiert das Risiko, dass der Betrachter sich mit uneingestandenem schwulen Begehren konfrontieren muss. Außerdem hebt es sein Selbstvertrauen, wenn er im Vergleich mit dem Aussehen der Akteure gut abschneidet - Loftus' Befragungen haben auch ergeben, dass Schwule der Vergleich mit den Akteuren in Schwulen-Pornos eher verunsichert.

Erstaunlicherweise betonten in Loftus' Umfrage jedoch viele heterosexuelle Pornokonsumenten, dass sie sich mit den Frauen in den Filmen und auf den Bildern identifizieren, dass sie sich vorzustellen versuchen, was die Frauen beim Akt gerade empfinden. Die Tatsache, dass offenbar viele Pornokonsumenten sich in die weiblichen Akteure hineinzuversetzen versuchen bis $\mathrm{zu}$ einem Punkt, an dem sie sich fragen, wie solche Frauen mit so unattraktiven Männern Sex haben können, unterminiert das in den genannten Aussagen vorgeschobene Desinteresse an den männlichen Akteuren. Dies leuchtet auch 
aus einer Logik des Blicks ein, denn beim Betrachten der Pornografie bleibt der Blick ja nicht wie angeheftet bei der weiblichen Darstellerin, sondern er wandert zwischen ihr und dem männlichen Darsteller hin und her.

Dass die befragten Männer zwischen realer Person und dargestellter Rolle unterscheiden, zeigt sich bei einem besonders umstrittenen Aspekt der Mainstream-Pornografie: Sexszenen zwischen zwei Frauen, sogenannten lesbischen Szenen. Im Gegensatz zu gewissen feministischen Befürchtungen, Pornos würden hier ein falsches Bild von Lesben und lesbischer Sexualität propagieren, stehen die Aussagen vieler Männer, ihnen sei klar, dass die dargestellten Frauen keine Lesben seien und der dargestellte Sex nicht wirklich lesbischer Sex sei. Gewünscht wird das möglichst authentische Ausagieren einer künstlich kreierten Situation. Diese künstlich kreierte Situation lautet folgendermaßen: Nach heterosexuellen Standards attraktive Frauen experimentieren sexuell, überschreiten Grenzen aus purer Lust am Sex. Die befragten Männer sind folglich nicht wirklich an Lesben interessiert, sondern die gleichgeschlechtliche Liebe interessiert als Transgression - Männer agieren auf diesem Umweg Anziehung wie Ekel vor Gleichgeschlechtlichem aus. Loftus betont, dass gerade diese Szenen männliche Kompetenz im Rollentausch und im Umgehen mit Fiktion bezeugen: "That so many men said they envied women, and wished they could know what it was like to be a woman enjoying sex, flies in the face of the notion that male viewers get off on the domination, degradation, and pain of women.« (Ebd., S. 60) Die Szenen werden aus mehreren Gründen geschätzt: Es kommen keine Männer drin vor, sie ermöglichen den Männern die Identifikation mit einer Frau, und die gezeigte Sexualität darf weich und sanft sein. Angeblich wird gezeigt, was Frauen sexuell mögen, und solche Szenen helfen den Männern, in der Fantasie das Tabu des gleichgeschlechtlichen Sex zu brechen.

In mehrerer Hinsicht einen Spezialfall stellen Bi-Pornos dar. Das Zielpublikum von Bi-Pornos müssten definitionsgemäß Bisexuelle sein. Wenn wir davon ausgehen, dass Hetero-Pornos vor allem heterosexuelle Männer und weniger heterosexuelle Frauen ansprechen, dann richteten sich Bi-Pornos primär an bisexuelle Männer. Nun könnten ja bisexuelle Männer einfach nach Belieben einmal Hetero-Pornos, ein andermal Schwulen-Pornos konsumieren, was also ist die Funktion der Bi-Pornos? Im Internet werden unter dem Titel Bi-Pornos interessanterweise fast ausschließlich Konstellationen angeboten, die gleich- und gegengeschlechtliche Sexualität kombinieren. Bisexualität findet also in Pornos vor allem als Gruppensex statt. Dies erstaunt, da vermutlich die meisten Bisexuellen ihre Sexualität hauptsächlich 
in Zweierkonstellationen leben und Gruppensex nicht ausgesprochen häufiger praktizieren Schwule oder Heterosexuelle. Nun lässt sich argumentieren, dass Bisexualität bildlich schwierig anders als in einer Gruppenkonstellation darzustellen ist. Das Identifikationsangebot scheint allerdings nicht der ausschließliche Grund für die Existenz von Bi-Pornos zu sein. Meine Vermutung ist, dass Bi-Pornos hauptsächlich eine Einladung zur Grenzüberschreitung in einem sicheren Rahmen darstellen, und zwar sowohl für schwule als auch für heterosexuelle Pornokonsumenten. Das paradigmatische MannMann-Frau-Trio bietet dem schwulen Betrachter die Möglichkeit, den Reiz der Präsenz eines nackten weiblichen Körpers auf sich zu testen, während sexuelle Handlungen der beiden Männer miteinander Vertrautheit herstellen. Umgekehrt kann der heterosexuelle Betrachter bei dieser Konstellation schwule Fantasien im sicheren Rahmen der weiblichen Präsenz erleben. Dass diese Absicherung schwuler Fantasien durch weibliche Präsenz Tradition hat, hat bereits Henry Jenkins in einem Aufsatz zu gleichgeschlechtlichem Begehren in Penthouse-Leserbriefen untersucht (vgl. Jenkins 2006).

Zusammenfassend lässt sich also sagen, dass während des Betrachtens von Pornografie sowohl bei hetero- als auch bei homosexuellen Zuschauern ein ständiger Wechsel zwischen der Einnahme verschiedener Rollen im Gange ist. Der Reiz der Pornografie scheint unter anderem in ebendiesem Changieren zwischen aktiv und passiv, männlich und weiblich, dominant und unterwürfig et cetera zu bestehen. Da beim heterosexuellen User jedoch eine unterschwellige homosexuelle Panik bei diesem Changieren mitschwingt, wird diese Lust am Rollentausch in der Regel verdrängt. Wer seine homosexuelle Panik hingegen so weit im Griff hat, dass ihn auch Szenarien, in denen Männer explizit passiv, verweiblicht, unterwürfig in Szene gesetzt werden, erregen, gehört zum Zielpublikum für die oben erwähnten Formate der Schwulen-Pornografie.

Die Verfügbarkeit dieser Nischenformate auch für Männer, die in einem Sexshop nie ein Schwulenmagazin gekauft hätten, ist letztlich ein Ergebnis der Pornografisierung. Was heißt dies für die Zukunft der Sexualität und der Pornografie?

\subsection{Für eine neue Ethik der Lüste}

In The Invention of Heterosexuality stellt Jonathan Ned Katz einige Vermutungen über die zukünftige Struktur von Sexualität an (Katz 1996, S. 167ff.). Er 
prophezeit eine Aufhebung der Unterscheidung hetero-/homosexuell. Diese Aufhebung sei weniger eine Folge der theoretischen Debatten um sexuelle Kategorien, sondern mehr das Resultat wirtschaftlicher und politischer Tendenzen. Die permanente Aufforderung zur Lustmaximierung, die die Wirtschaft an die Konsumenten richte, bleibe nicht ohne Folgen auf deren Sexualverhalten; Lustmaximierung im Bereich der Sexualität bedeute aber unweigerlich einen Ausbruch aus dem engen Korsett der monogamen heterosexuellen Zweierbeziehung und eine Annäherung an homosexuelle Lebensformen: Die Gleichstellung dieser Lebensformen habe ein Verschwinden von ehemals wichtigen Unterscheidungsmerkmalen von homo- und heterosexuellen Lebensformen zur Folge.

Katz hält das Begriffspaar homosexuell/heterosexuell für unrettbar verknüpft mit einer spezifischen historischen Herrschaftssituation: »It makes as much sense, then, to look for the cause of heterosexual or homosexual feeling in biology as it does to look for the physiological determinants of the slave's mentality or the master's.« (Ebd., S. 189) Ebenso wie die Abschaffung der Sklaverei zur Unbrauchbarkeit des Begriffspaars Herr/Sklave geführt habe, werde auch das Begriffspaar homosexuell/heterosexuell künftig obsolet. Über die nach dieser Aufhebung sich ergebende Strukturierung von Sexualität will Katz keine detaillierten Spekulationen anstellen. Er weist bloß darauf hin, dass auch die zukünftige Strukturierung von Sexualität weitgehend durch ökonomische und politische Faktoren bestimmt sein werde: »The social organization of erotic interaction is not fixed, the political economy of pleasure has changed over time - and it can change again. We can struggle together to make relationships and a social world more welcoming to erotic diversity and carnal joy.« (Ebd., S. 190) Die Verwirklichung eines neuen Systems der Lüste ist also auch vom Individuum abhängig, das im Rahmen seiner erotischen und politischen Möglichkeiten die Rahmenbedingungen des Systems mitbestimmt.

Robert Jensen möchte deshalb die politische Debatte um Pornografie wieder auf eine ethische Ebene verlagern. Er sieht die Produktion, den Konsum und die Verbreitung von Pornos mit Schmerz verbunden. Dieser Schmerz entstehe etwa, wenn eine Frau sich nicht aus freiem Willen, sondern aus Verzweiflung über ihre finanzielle Lage dafür entscheide, Pornos zu drehen - oder wenn eine Frau nicht freiwillig pornografische Szenen in ihr Sexleben integriere, sondern weil sie dazu gezwungen werde. Jensen appelliert an Männer, die Pornos konsumieren, diese Formen von Schmerz zu bedenken und ihren Konsum so zu hinterfragen: »What would it be like if we struggled 
to empathize and connected it to political and social analysis, if we all reconsidered such entertainment in light of the costs, of the pain? (Dines/Jensen/Russo 1998, S. 162 )

Wie lässt sich Jensens Vorschlag, das Thema Schmerz in ethische Überlegungen zu Pornografie einzubeziehen, theoretisch fassen? Eine Möglichkeit bietet Judith Butler in Gefährdetes Leben. Sie argumentiert dort, dass Akte der Gewalt und die Opfer, die sie hinterlassen, in einer Art und Weise gerahmt sein müssen, dass sie verstehbar und betrauerbar werden. Fänden Gewaltakte außerhalb dieses Rahmens der Verstehbarkeit statt, würden die Opfer der Gewalt nicht als solche wahrgenommen und ihr Leid könne nicht betrauert werden. Butler postuliert Verletzbarkeit als Grundbedingung menschlicher Existenz. Wenn jemandes Verletzungen nicht wahrgenommen würden, jemandes Verletzbarkeit nicht anerkannt werde, werde diesem jemand ein Stück Menschlichkeit abgesprochen. "Die Dehumanisierung entsteht vielmehr an den Grenzen des diskursiven Lebens, an Grenzen, die durch Verbot und Verwerfung errichtet werden. Hier ist weniger ein dehumanisierender Diskurs am Werk als eine Verweigerung des Diskurses, welche die Dehumanisierung zur Folge hat.« (Butler 2005, S. 53f.) Hier lässt sich Butlers These mit Jensens Forderung nach Wahrnehmung und Anerkennung des durch Pornografie verursachten Schmerzes verknüpfen. Da Pornografie sich an einer solchen Grenze des diskursiven Lebens abspielt, einer Grenze, die durch Verbot und Verwerfung errichtet worden ist, drohen die Verletzungen, die durch Pornografie entstehen, nicht wahrgenommen und nicht anerkannt zu werden. Wer in einem pornografischen Film mitspielt, hat eine Grenze des Diskursiven betreten, über diese Person und ihre Handlungen kann nicht mehr gesprochen werden. Wenn ihr nun beim Pornodreh eine Verletzung widerfahren ist, wird diese weder wahrgenommen noch anerkannt, die Person erscheint dehumanisiert. Oder wenn eine Person von ihrem Partner zur Teilnahme an sexuellen Praktiken genötigt wird, die dieser vorher in Pornos gesehen hat, kann diese Person die während des Aktes erlebten Verletzungen nicht kommunizieren, ihre Verwandlung vom Sexualpartner zum Sexualobjekt geht mit einer Dehumanisierung einher, für die sie keine Sprache hat. Ethische Überlegungen zur Pornografie müssten folglich bei der Frage ansetzen, wie sich das Phänomen Pornografie diskursiv neu rahmen lässt, sodass durch Pornografie erzeugte Verletzungen wahrgenommen, anerkannt und betrauert werden können. 



\section{Dank}

Ein erster Dank gilt Prof. em. Dr. Georg Kohler (Universität Zürich) und Prof. em. Dr. Andrea Maihofer (Universität Basel) für das Betreuen dieser Arbeit. Sie haben mich immer wieder ermutigt, in diesem kontroversen Forschungsfeld weiterzuforschen, und mir mit ihren fachlichen Inputs sehr geholfen.

Ich danke dem gesamten Graduiertenkolleg »Geschlechterverhältnisse Normalisierung und Transformation« des Zentrum Gender Studies der Universität Basel für unzählige bereichernde Diskussionen. Insbesondere PD Dr. Katrin Meyer, mein designierter "Coach « aus der Trägerschaft, hat mehrfach bei entscheidenden Weichenstellungen diese Arbeit in die richtige Richtung gelenkt und Denkblockaden aus dem Weg geräumt.

Großer Dank gebührt Maria Dätwyler und Karin Hostettler für das detaillierte Diskutieren und Kommentieren von Teilen dieser Arbeit, ihre Unterstützung und Expertise waren extrem wichtig.

Sehr dankbar bin ich Daniela Oertle sowie Mirjam und Jonas Schocher für das aufmerksame Gegenlesen von Teilen dieser Arbeit. Ich danke auch Daniel Schnurrenberger und Benjamin Dutoit von Die Orthografen $\mathrm{GmbH}$ für das gewissenhafte Lektorat der Publikation.

Ganz viele Menschen haben im Laufe der Jahre entweder diese Arbeit durch kritische Fragen und Feedback vorangebracht oder mich schlicht motiviert und angespornt. Hier die wichtigsten in alphabetischer Reihenfolge: Pascal Bartlomé, Tobias Baumgartner, Nathalie Büsser, Christina Caprez, Sonia Cirillo, Pierfrancesco Fois, Martin Gerber, Dorothee Guggenheimer, Tina Hofmann, Marietta Jemmi, Erich Lang, Yv E. Nay, Davide Pellandini, Ramon Schocher, Cornelia Staub sowie Ruth und Bernhard Tschaggelar.

Ich danke meinen Eltern Carina und Christian Schocher, die mich in meinem Wissensdurst und meiner Begeisterung für die Philosophie immer bestärkt haben. Von ihrem offenen, interessierten Zugang zu Film und Literatur, 
aber auch gesellschaftspolitischen Fragen profitiere ich heute noch. Ohne sie gäbe es dieses Buch nicht.

$\mathrm{Zu}$ guter Letzt danke ich meinem Mann Markus Tschaggelar und meinen beiden Kindern Seraphine und Jonathan Aaron Guggenheimer. Dank ihnen ergibt alles Sinn.

Zürich, im September 2020, Nathan Schocher 


\section{Literaturverzeichnis}

Ahmed, S., Happy Objects, in: Gregg, M./Seigworth, G. J. (Hg.), The Affect Theory Reader, Durham 2010, 29-51

Allhutter, D., Dispositive digitaler Pornografie, Frankfurt a.M. 2009

American Psychological Association (APA), Report of the APA Task Force on the Sexualization of Girls, Washington 2007

Attwood, F., Sexed up: theorizing the sexualization of culture, in: Sexualities 9 (1), 2006, 77-94

Banyard, K., The Equality Illusion, London 2010

Bataille, G., Lhistoire de l'érotisme; Le surréalisme au jour le jour; Conférences 1951- 1953; La souveraineté; Annexes (Oeuvres complètes 8), Paris 1976

Bataille, G., L'érotisme; Le procès de Gilles de Rais; Les larmes d'Eros (Oeuvres complètes 10), Paris 1987

Beauvoir, S. de, Soll man de Sade verbrennen? Drei Essays zur Moral des Existentialismus, München 1964

Benhabib, S. et al., Der Streit um Differenz. Feminismus und Postmoderne in der Gegenwart, Frankfurt a.M. 1993

Bourdieu, P., Die männliche Herrschaft, Frankfurt a.M. 2005

Boyle, K., Introduction: Everyday Pornography, in: Boyle, K. (Hg.), Everyday Pornography, Abingdon 2010, 1-13

Bronstein, C., Battling pornography: the American feminist anti-pornography movement, 1976-1986, New York 2011

Büsser, M. , For your pleasure. Fragmente einer Porno-Komparatistik, in: testcard: Beiträge zur Popgeschichte 17, 2008, 78-85

Butler, J., Das Unbehagen der Geschlechter, Frankfurt a.M. 1991

Butler, J., Körper von Gewicht, Frankfurt a.M. 1997

Butler, J., Psyche der Macht. Das Subjekt der Unterwerfung, Frankfurt a.M. 2001 
Butler, J., Gefährdetes Leben, Frankfurt a.M. 2005

Butler, J., Hass spricht. Zur Politik des Performativen, Frankfurt a.M. 2006

Butler, J., Die Macht der Geschlechternormen, Frankfurt a.M. 2009

Butler, J., Raster des Krieges, Frankfurt a.M. 2010

Carnes, M., Bend over Boyfriend: Anal Sex Instructional Videos for Women, in: Paasonen, S./Nikunen, K./Saarenmaa, L. (Hg.), Pornified, Oxford 2007, 151-160

Carse, A. L., Pornographie und Bürgerrechte, in: Balzer, P./Rippe, K. P. (Hg.), Philosophie und Sex, München 2000, 167-210

Collins, H., Collins English Dictionary, Glasgow 2014

Cornell, D., Die Versuchung der Pornographie, Berlin 1995

Cornell, D., Pornography's Temptation, in: Freiburger FrauenStudien 15: Entfesselung des Imaginären? Zur neuen Debatte um Pornografie, 2004, 149164

Cowie, E., Pornography and fantasy. Psychoanalytic perspectives, in: Segal, L./McIntosh, M. (Hg.), Sex exposed: sexuality and the pornography debate, New Brunswick 1992, 132-152

Danto, A., Die Verklärung des Gewöhnlichen. Eine Philosophie der Kunst, Frankfurt a.M. 1999

Derrida, J., Die différance, in: Engelmann, P. (Hg.), Postmoderne und Dekonstruktion. Texte französischer Philosophen der Gegenwart, Stuttgart 1990, 76-113

Diefenbach, K., Fizzle Out in White. Postporn Politics and the Deconstruction of Fetishism, in: Stüttgen, T. (Hg.), Post/Porn/Politics. Symposium/Reader, Berlin 2009, 72-87

Dines, G., Pornland: How porn has hijacked our sexuality, Boston 2010

Dines, G./Jensen, R./Russo, A., Pornography. The Production and Consumption of Inequality, New York 1998

Dines, G. et al., Arresting images: anti-pornography slide shows, activism and the academy, in: Boyle, K. (Hg.), Everyday Pornography, Abingdon 2010, 17-33

Douglas, S. J., The Rise of Enlightened Sexism, New York 2010

Dudenredaktion, >-isieren $<$ auf Duden online, o.J.a, Website; aufgerufen am 20.8.2017 (URL: www.duden.de/node/809957/revisions/1615515/view)

Dudenredaktion, >Pornographie auf Duden online, o.J.b, Website; aufgerufen am 14.8.2017 (URL: www.duden.de/node/679895/revisions/1379233/view)

Dudenredaktion, >Transgression ‘ auf Duden online, o.J.c, Website; aufgerufen am 15.8.2017 (URL: www.duden.de/node/761283/revisions/1241620/ view) 
Dworkin, A., Pornographie. Männer beherrschen Frauen, Frankfurt a.M. 1990 Dworkin, A., Geschlechtsverkehr, Hamburg 1993

Eder, B., From Hard-Core to Post-Porn. Sex, Gender und der kalte Blick aufs nackte Fleisch, in: testcard: Beiträge zur Popgeschichte 17, 2008, 96-100

Epley, N. S., Pin-Ups, Retro-Chic and the Consumption of Irony, in: Paasonen, S./Nikunen, K./Saarenmaa, L. (Hg.), Pornification, Oxford 2007, 45-57

Flasspöhler, S., Der Wille zur Lust. Pornographie und das moderne Subjekt, Frankfurt a.M. 2007

Foucault, M., Die Ordnung der Dinge, Frankfurt a.M. 1971

Foucault, M., Überwachen und Strafen. Die Geburt des Gefängnisses, Frankfurt a.M. 1976

Foucault, M., Der Wille zum Wissen. Sexualität und Wahrheit. Band 1, Frankfurt a.M. 1977

Foucault, M., Der Gebrauch der Lüste. Sexualität und Wahrheit. Band 2, Frankfurt a.M. 1986a

Foucault, M., Die Sorge um sich. Sexualität und Wahrheit. Band 3, Frankfurt a.M. 1986 b

Foucault, M., Schriften in vier Bänden. Dits et Ecrits. Band 1, 1954-1969, Frankfurt a.M. 2001

Foucault, M., Schriften in vier Bänden. Dits et Ecrits. Band 3, 1976-1979, Frankfurt a.M. 2003

Freud, S., Drei Abhandlungen zur Sexualtheorie, Frankfurt a.M. 1991

Freud, S., Das Unbehagen in der Kultur. Und andere kulturtheoretische Schriften, Frankfurt a.M. 2009

Fukuyama, F., Das Ende der Geschichte: Wo stehen wir? München 1992

Gill, R., Media, Empowerment and the >Sexualisation of Culture Debates, in:

Sex Roles 66, 2012, 736-745

Hall, S. et al., Policing the Crisis: Mugging, the State and Law and Order, Basingstoke 1978

Harrap, C., The Chambers Dictionary, London 2014

Hegel, G. W. F., Phänomenologie des Geistes, Frankfurt a.M. 1970

Hilkens, M., McSex. Die Pornofizierung unserer Gesellschaft, Berlin 2010

Horkheimer, M./Adorno, T. W., Dialektik der Aufklärung, Frankfurt a.M. 1969

Hunt, L., Die Erfindung der Pornographie. Obszönität und die Ursprünge der Moderne, Frankfurt a.M. 1996

Illouz, E., Gefühle in Zeiten des Kapitalismus, Frankfurt a.M. 2007 
Jäckel, J., »Popstars mit Penis«? Selbst-Pornografisierung in Musikclips als Female Agency, in: Schuegraf, M./Tillmann, A. (Hg.), Pornografisierung von Gesellschaft, Konstanz 2012, 125-134

Jenefsky, C./Russo, A., Without Apology. Andrea Dworkin's Art and Politics, Boulder 1998

Jenkins, H., He's in the Closet but He's Not Gay: Male-Male Desire in Penthouse Letters, in: Lehman, P. (Hg.), Pornography: Film and Culture, New Brunswick 2006, 133-153

Jenks, C., Transgression, London 2003

Kangasvuo, J., Insatiable Sluts and Almost Gay Guys: Bisexuality in Porn Magazines, in: Paasonen, S./Nikunen, K./Saarenmaa, L. (Hg.), Pornification, Oxford 2007, 139-149

Katz, J., The Invention of Heterosexuality, New York 1996

Kendrick, W., The Secret Museum, Pornography in Modern Culture, Berkeley 1987

Kierkegaard, S., Die Wiederholung. Die Krise und eine Krise im Leben einer Schauspielerin, Hamburg 1991

Kipnis, L., Ecstasy unlimited: on sex, capital, gender, and aesthetics, Minneapolis 1993

Laqueur, T. W., Solitary Sex. A Cultural History of Masturbation, New York 2003

Levy, A., Female chauvinist pigs: women and the rise of raunch culture, New York 2005

Lewandowski, S., Die Pornographie der Gesellschaft, Bielefeld 2012

Llopis, M., GirlsWhoLikePorno, in: Stüttgen, T. (Hg.), Post/Porn/Politics. Symposium/Reader, Berlin 2009, 258-281

Loftus, D., Watching Sex. How Men Really Respond to Pornography, New York 2002

Long, J., Anti-porn: the resurgence of anti-pornography feminism, London 2012

Luhmann, N., Liebe als Passion. Zur Codierung von Intimität, Frankfurt a.M. 1982

MacKinnon, C. A., Only Words, London 1994

MacKinnon, C. A., Francis Biddle's Sister: Pornography, Civil Rights, and Speech, in: Dwyer, S. (Hg.), The problem of pornography, Belmont 1995, 53-66

Marcus, S., Umkehrung der Moral. Sexualität und Pornographie im viktorianischen England, Frankfurt a.M. 1979 
Marcuse, H., Schriften: Band 5. Triebstruktur und Gesellschaft, Frankfurt a.M. 1979

McNair, B., Mediated sex: pornography and postmodern culture, New York 1996

Mowlabocus, S., Gay Men and the Pornification of Everyday Life, in: Paasonen, S./Nikunen, K./Saarenmaa, L. (Hg.), Pornification, Oxford 2007, 61-71

Paasonen, S., Repetition and hyperbole: the gendered choreographies of heteroporn, in: Boyle, K. (Hg.), Everyday Pornography, Abingdon 2010, 63-76

Paasonen, S./Nikunen, K./Saarenmaa, L., Pornification and the Education of

Desire, in: Paasonen, S./Nikunen, K./Saarenmaa, L. (Hg.), Pornification, Oxford 2007, 1-20

Preciado, B., Kontrasexuelles Manifest, Berlin 2003

Preciado, B., Pornotopia. Architektur, Sexualität und Multimedia im >Playboy<, Berlin 2012

Preciado, B., The Architecture of Porn. Museum Walls, Urban Detritus and Stag Rooms for porn-prosthetic Eyes, in: Stüttgen, T. (Hg.), Post/Porn/Politics. Symposium/Reader, Berlin 2009, 22-39

Reich, W., Die Massenpsychologie des Faschismus, Köln 1971

Reich, W., Der Einbruch der sexuellen Zwangsmoral, Köln 1972

Sacher-Masoch, L. von, Venus im Pelz, Frankfurt a.M. 2013

Sargeant, J., Deathtripping: The Cinema of Transgression, London 1995

Seesslen, G., Die nackten Wilden des Kapitals. 10 Ungebote von Sexualität und Marktwirtschaft, in: testcard: Beiträge zur Popgeschichte 17, 2008, 14-19

Segal, L., Introduction, in: Segal, L./McIntosh, M. (Hg.), Sex exposed: sexuality and the pornography debate, New Brunswick 1992a, 1-11

Segal, L., Sweet sorrows, painful pleasures: Pornography and the perils of heterosexual desire, in: Segal, L./McIntosh, M. (Hg.), Sex exposed: sexuality and the pornography debate, New Brunswick 1992b, 65-91

Sennett, R., Verfall und Ende des öffentlichen Lebens. Die Tyrannei der Intimität, Berlin 1983

Servois, J., Le cinéma pornographique, Paris 2009

Smith, C., Pornographication: A discourse for all seasons, in: International Journal of Media and Cultural Politics 6 (1), 2010, 103-108

Sontag, S., Kunst und Antikunst. 24 literarische Analysen, Frankfurt a.M. 1982

Stakemeier, K., Come. Möglichkeiten eines geilen Pornos, in: testcard: Beiträge zur Popgeschichte 17, 2008, 86-90 
Strossen, N., Defending Pornography: Free Speech, Sex, and the Fight for Women's Rights, New York 1996

Stüttgen, T., Before Orgasm. Fifteen Fragments on a Cartography of Post/Pornographic Politics, in: Stüttgen, T. (Hg.), Post/Porn/Politics. Symposium/Reader, Berlin 2009, 8-21

Tinkcom, M., Working Like a Homosexual: Camp, Capital, Cinema, Durham 2002

Valverde, M., Beyond Gender Dangers and Private Pleasures: Theory and Ethics in the Sex Debates, in: Dwyer, S. (Hg.), The problem of pornography, Belmont 1995, 177-191

Villa, P.-I., Pornofeminismus? Soziologische Überlegungen, in: Schuegraf, M./Tillmann, A. (Hg.), Pornografisierung von Gesellschaft, Konstanz 2012, 51-66

Walter, N., Living Dolls. The Return of Sexism, London 2010

Warner, M., The Trouble with Normal: Sex, Politics and the Ethics of Queer Life, New York 1999

Waxman, T., The First Time He Thought He Was Beautiful: A Transmasculine Pornographic Sublime, in: Stüttgen, T. (Hg.), Post/Porn/Politics. Symposium/Reader, Berlin 2009, 332-353

Wikipedia, >Transgression ‘ auf Wikipedia, Die freie Enzyklopädie, 2015, Website; aufgerufen am 7.6.2016 (URL: https://de.wikipedia.org/w/index.php? title=Transgression\&oldid=138784971)

Wilke, B., Die Inszenierung der Inszenierung. Beitrag zu einer neuen Sicht auf Pornografie, in: Freiburger FrauenStudien 15: Entfesselung des Imaginären? Zur neuen Debatte um Pornografie, 2004, 165-180

Willemsen, R., Über das Obszöne, in: Vinken, B. (Hg.), Die nackte Wahrheit: zur Pornographie und zur Rolle des Obszönen in der Gegenwart, München 1997, 129-149

Willis, E., Feminism, Moralism, and Pornography, in: Dwyer, S. (Hg.), The problem of pornography, Belmont 1995, 170-176

Winks, C., The Good Vibrations Guide: Adult Videos, San Francisco 1998

Wolf, N., Der Mythos Schönheit, Reinbek bei Hamburg 1991

Zappe, F., Das Zwischen schreiben. Transgression und avantgardistisches Erbe bei Kathy Acker, Bielefeld 2013

Žižek, S., Lacan. Eine Einführung, Frankfurt a.M. 2008 


\section{Philosophie}

Die konvivialistische Internationale

Das zweite konvivialistische Manifest

Für eine post-neoliberale Welt

Das zweite

konvivialistische

Manifiost

Für eine

post-neoliberale Welt

[transcript $]$

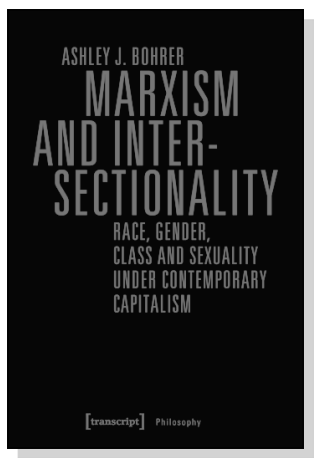

Ashley J. Bohrer

Marxism and Intersectionality

Race, Gender, Class and Sexuality

under Contemporary Capitalism

2019, 280 p., pb.

29,99€ (DE), 978-3-8376-4160-8

E-Book:

PDF: $26,99 €$ (DE), ISBN 978-3-8394-4160-2

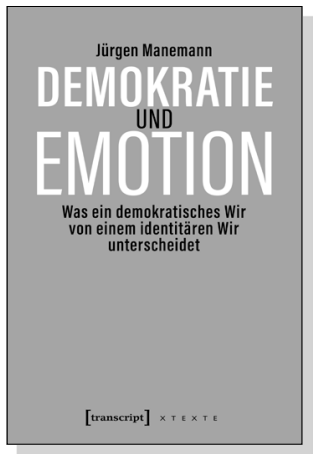

Jürgen Manemann

\section{Demokratie und Emotion}

Was ein demokratisches Wir

von einem identitären Wir unterscheidet

2019, 126 S., kart.

$17,99 €(D E), 978-3-8376-4979-6$

E-Book:

PDF: 15,99 € (DE), ISBN 978-3-8394-4979-0 


\section{Philosophie}

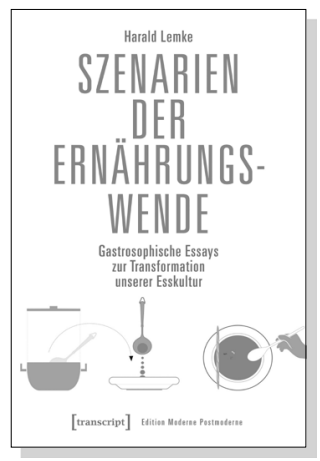

Harald Lemke

Szenarien der Ernährungswende

Gastrosophische Essays

zur Transformation unserer Esskultur

2018, 396 S., kart.

29,99€ (DE), 978-3-8376-4483-8

E-Book:

PDF: $26,99 €$ (DE), ISBN 978-3-8394-4483-2

EPUB: $26,99 €(D E)$, ISBN 978-3-7328-4483-8

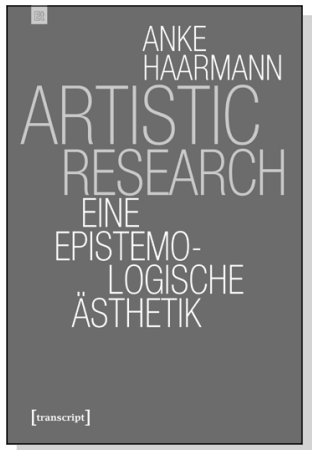

Anke Haarmann

\section{Artistic Research}

Eine epistemologische Ästhetik

2019, 318 S., kart.

$34,99 €(D E), 978-3-8376-4636-8$

E-Book: 34,99 € (DE), ISBN 978-3-8394-4636-2

EPUB: $34,99 €$ (DE), ISBN 978-3-7328-4636-8

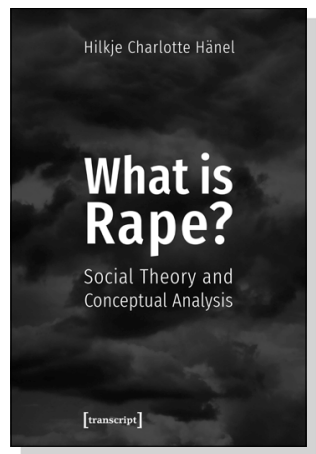

Hilkje Charlotte Hänel

\section{What is Rape?}

Social Theory and Conceptual Analysis

2018, 282 p., hardcover

99,99€ (DE), 978-3-8376-4434-0

E-Book: 99,99€ (DE), ISBN 978-3-8394-4434-4 